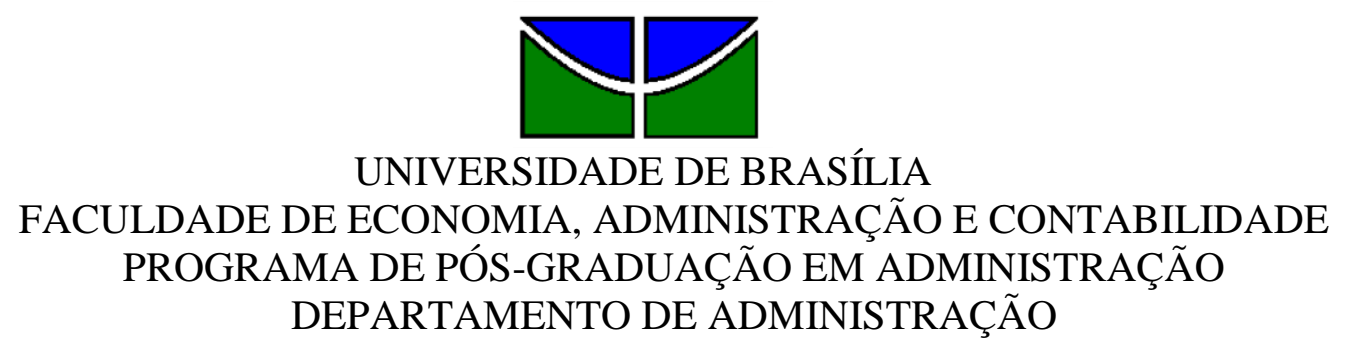

PABLO FERNANDO PESSOA DE FREITAS

Relações entre Competências Gerenciais de Líderes de Grupos de Pesquisa e Resultados Alcançados 
PABLO FERNANDO PESSOA DE FREITAS

\section{Relações entre Competências Gerenciais de Líderes de Grupos de Pesquisa e Resultados Alcançados}

Dissertação apresentada ao Programa de PósGraduação em Administração da Universidade de Brasília (PPGA/UnB) como requisito parcial à obtenção do título de Mestre em Administração. Área de Concentração: Estudos Organizacionais e Gestão de Pessoas

Orientadora: Prof ${ }^{\mathrm{a}}$. Dr ${ }^{\mathrm{a}}$. Catarina Cecília Odelius

Brasília

2016 


\section{Freitas, Pablo Fernando Pessoa de.}

Relações entre competências gerenciais de líderes de grupos de pesquisa e resultados alcançados / Pablo Fernando Pessoa de Freitas. - Brasília, 2016.

209 p.: il.

Dissertação (Mestrado em Administração) - Universidade de Brasília, Faculdade de Economia, Administração e Contabilidade, Programa de Pósgraduação em Administração, 2015.

Orientadora: Profa. Dra. Catarina Cecília Odelius

Área de Concentração: Estudos Organizacionais e Gestão de Pessoas

1.Grupos de Pesquisa; 2. Competências Gerenciais; 3. Resultados; 4. Desenvolvimento de Escalas 


\section{Relações entre competências gerenciais de líderes de grupos de pesquisa e resultados alcançados}

Dissertação apresentada ao Programa de Pós-Graduação em Administração da Faculdade de Economia, Administração e Contabilidade da Universidade de Brasília, como requisito parcial para obtenção do título de Mestre em Administração, analisada pela Comissão Julgadora composta pelos membros:

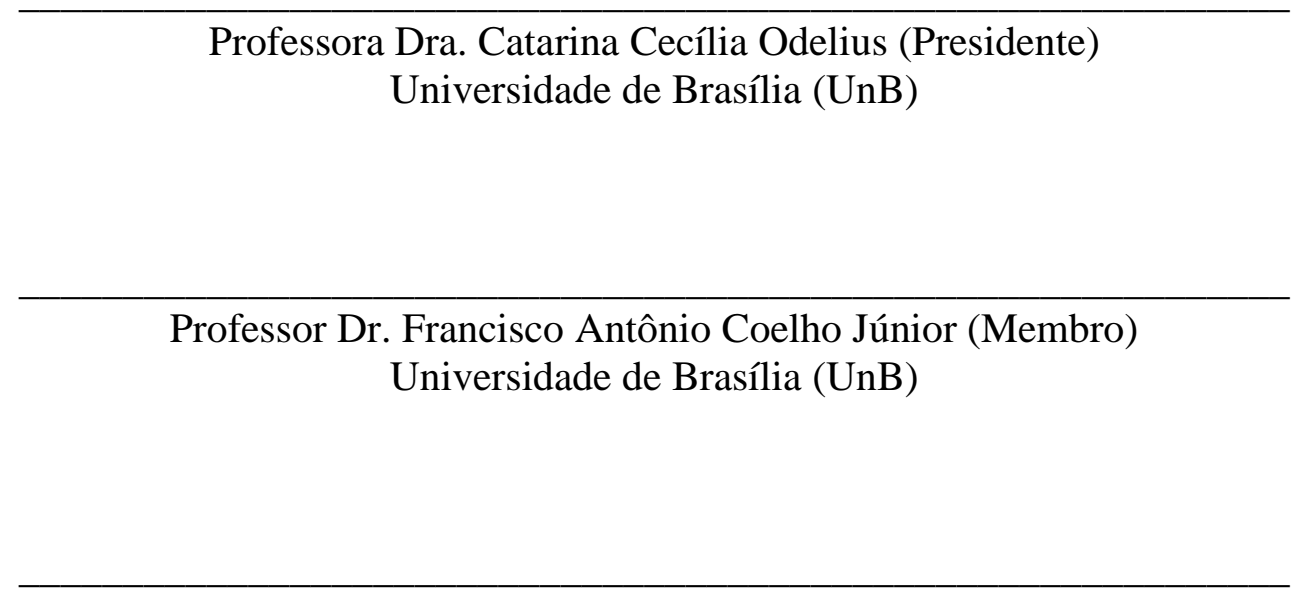

Professora Dra. Dra. Denise Del Prá Netto Machado (Membro) Universidade do Sul de Santa Catarina - UNISUL

Aprovada em: 29 de fevereiro de 2016.

Local de defesa: Sala 06/37 - Prédio da FACE - Universidade de Brasília - UnB. 
Dedico este trabalho aos líderes de grupos de pesquisa brasileiros. 


\section{AGRADECIMENTOS}

Agradeço a Fernando, companheiro de todas as horas, pela motivação, compreensão, paciência e abdicação, e por valorizar e aproveitar cada instante precioso do meu tempo escasso.

Aos meus familiares: a Nise e Fernando, meus pais, pelo amor a mim dedicado, pelos valores compartilhados e pelo constante incentivo aos estudos; a Virgínia, minha irmã, pelo exemplo de determinação e coragem e pela cumplicidade de sempre; a Lis e Luísa, minhas sobrinhas, pela alegria de seus sorrisos e pela doçura no olhar; e a Nino, meu cunhado, pelo apoio de sempre.

Aos meus amigos, por permanecerem do lado esquerdo do peito, mesmo quando o tempo e a distância diziam 'não'. Agradeço aos amigos de Pernambuco, de Teresina, do Rio e de Brasília, em especial, aos amigos do G6, da Miguxada, dos Carangas, do Souza Leão, do DH, de Candeias, de Toritama, do antigo CEFET-PE, da UFPE, da LASA, da Rapidão Cometa, do SEBRAE-PE, da Controladoria e da AGU.

Ao Charlie, pela companhia nas madrugadas em claro.

Ao STJ e a todos os amigos da CDEP, em especial, a Jeanne, Bárbara, Dayse, Fabíola, Ari e Marina, que ficaram na "retaguarda", proporcionando que eu realizasse este sonho; a Cláudia, Wal, Julierne, Renato e Fabi, que tanto me apoiaram nesta empreitada; e a Isa, Iraci, Camila, Juliana e Valter, que contribuíram no processo seletivo ou na finalização da Dissertação.

Aos amigos do APINOV, em especial, Pedro, Ronaldo, Fábio's, Rafael, Joelma e Paulo, por tantas 'cricrizagens', pelos estudos prévios, e por compartilharem comigo a riqueza de aprender em grupo.

À Professora Catarina Odelius, minha orientadora, por tantos debates, tantos ensinamentos, tantas sugestões de leitura, por estar sempre a postos (presencialmente, por telefone, $e$-mail e whatsapp) e, sobretudo, por ser um exemplo de dedicação, comprometimento, presteza e amor à profissão.

Aos professores do PPGA-UnB: Francisco Coelho Jr., Josivânia Farias, Pedro Meneses, Carlos Denner, Solange Alfinito, Pedro Albuquerque, Gardênia Abbad, Tomás de Aquino Guimarães e Pedro Resende, por contribuírem de modo ímpar para a construção do conhecimento relativo a este estudo. E também à Professora Denise Del Prá, que se dispôs a examinar este trabalho, na condição de avaliadora externa.

Aos colegas do PPGA-UnB, em especial, Igor, PC, David, Mari, Lear, Lana, Kesley, Rodrigo, Leo, George, Ken, Peng, Luiz, Cris, Ju, Jana, Walter, Nayra, Alan, Alex, Finazzi, Natasha, Sílvia, Cecília, Marilu, Shirley, por fazerem com que esta jornada fosse trilhada com leveza e cooperação, e a Mariane, que me auxiliou na seleção do Mestrado.

E enfim, a Deus, por me presentear com essas pessoas extraordinárias, por ter me dado ânimo a cada dia, mesmo diante das adversidades, e por perdoar os meus percalços, que não são poucos.

A todos vocês, agradeço, no terceiro nível de gratidão - segundo a definição de São Tomás de Aquino. Considero-me vinculado e comprometido a cada um de vocês! Fico obrigado no mais profundo nível do tratado da gratidão! E, com toda a sutileza e profundidade que essa expressão possa representar, peço que acolham o meu "Muito obrigado"! 
"Vês a glória do mundo? É glória vã. Nada tem de estável. Tudo passa."

Santa Teresa D’Ávila

"Você que está aí sentado, levante-se! Há um líder dentro de você. Governe-o, faça-o falar, faça-o falar, faça-o falar..." Chico Science - cantor e compositor pernambucano

"Preferi a sabedoria aos cetros e aos tronos, e, em comparação com ela, vi que não eram nada as riquezas.

Nem sequer a comparei às pedras preciosas, pois o ouro todo, diante dela, é um pouco de areia, e a prata, perante ela, será como lodo. Amei-a mais que a saúde e a beleza, $e$ antes a quis ter a ela que a luz, pois a sua claridade jamais acaba.". 


\title{
Relações entre competências gerenciais de líderes de grupos de pesquisa e resultados alcançados
}

\begin{abstract}
RESUMO
Líderes de grupos de pesquisa exercem competências gerenciais, que repercutem nos resultados alcançados. Com o objetivo de identificar as relações entre competências gerenciais de líderes e resultados de grupos de pesquisa brasileiros, este estudo recorreu a revisão bibliográfica, pesquisa documental, avaliação de juízes e pré-teste, para aprimorar versões preliminares de instrumentos não-validados sobre competências gerenciais e resultados no contexto grupos de pesquisa. Por meio de pesquisa de levantamento, foi aplicado um questionário eletrônico a uma amostra de 528 participantes de grupos de pesquisa, sendo 374 líderes. Com base em Análise Fatorial Exploratória pôde-se apresentar indícios de validade de duas escalas: Domínio de competências gerenciais em grupos de pesquisa (com 50 itens e 2 fatores); e Resultados alcançados por grupos de pesquisa (com 28 itens e 3 fatores). Mediante testes não-paramétricos, mostraram-se estatisticamente significativas as diferenças encontradas nas competências gerenciais ou nos resultados em grupos de pesquisa, com relação às variáveis sociodemográficas e funcionais (sexo, idade, experiência com pesquisa, tempo de vínculo do líder ao grupo, bolsa de produtividade do CNPq, realização de pós-doutorado pelo líder e grande área do conhecimento); e também com relação ao grau de domínio de competências gerenciais e ao nível de concordância com o alcance de resultados pelo grupo. Por fim, dentre os resultados decorrentes da análise de correlação, alguns merecem destaque: competências para a captação de recursos e de pessoas precisam ser fomentadas, uma vez que estão mais correlacionadas com a consecução de resultados do grupo do que os demais competências para gestão de pessoas e de resultados de pesquisa; as gestoras consideram dominar mais competências de gestão de pessoas e de resultados; a realização de pós-doutorado proporciona maior percepção de domínio para a captação de recursos e pessoas; os grupos com líderes mais experientes consideram alcançar resultados de maior visibilidade e repercussão externa; os líderes de grupos vinculados a instituições públicas de ensino e pesquisa consideram alcançar maiores resultados diretos de pesquisa, tais como a produção de conhecimento e o desenvolvimento de competências técnicas e sociais; os grupos das Ciências Agrárias e das Ciências Exatas e da Terra são os que consideram produzir mais resultados concretos de pesquisa, tais como protótipos, artefatos, patentes, livros, etc. Após as análises, conclui-se que as principais contribuições desta pesquisa foram (a) apresentar indícios de validade de duas escalas no contexto de grupos de pesquisa e (b) identificar relações entre os fatores de competências gerenciais e de resultados de grupos de pesquisa, bem como entre estes e algumas variáveis sociodemográficas/funcionais.
\end{abstract}

Palavras-chave: Grupos de Pesquisa. Competências Gerenciais. Resultados. Desenvolvimento de Escalas. 


\title{
Relations between managerial skills of leaders of research groups and results achieved.
}

\begin{abstract}
Leaders of research groups exert managerial skills, which affect the results achieved. In order to identify the relations between managerial skills of leaders and results of Brazilian research groups, this study referred to literature review, documentary research, evaluation of judges and pre-test, to improve preliminary versions of non-validated instruments about managerial skills and results in the context of research groups. By means of survey research, an electronic questionnaire was applied to a sample of 528 participants of research groups, 374 of them being leaders. Based on Exploratory Factor Analysis, it was possible to present evidences of validity of two scales: Mastery of managerial skills in research groups (with 50 items and 2 factors); and Results achieved by research groups (with 28 items and 3 factors). By the aid of the nonparametric tests, were statistically significant the differences found in managerial skills or in results of research groups, concerning sociodemographic and functional variables (sex, age, experience with research, leader's bonding time with the group, CNPq's productivity grant, postdoctoral accomplished by the leader and wide-ranging area of knowledge); and also concerning the level of mastery of managerial skills and the level of agreement with the achievement of results by the group. Lastly, among the results of the correlation analysis, some deserve to be highlighted: resource and people attraction competencies need to be fostered, once they are more correlated to achieving group results than to the other competencies related to people and research results management; female managers consider to master people and results competencies the most; earning a post-doctoral degree provides a better perception of mastery to attract resources and people; groups with more experient leaders consider to reach results of greater visibility and external repercussion; leaders of groups linked to public institutes of education and research consider to reach greater direct research results such as the production of knowledge and development of technical and social competencies; groups from Agricultural Sciences and Exact and Earth Sciences consider to product concrete research results the most such as prototypes, artifacts, patents, books, etc. After the analyses, it is concluded that the major contributions of this research are (a) presenting evidences of validity of two scales in the context of research groups and (b) identifying relations between the factors of managerial skills and of results of research groups, as well as between each another and some sociodemographic and functional variables.
\end{abstract}

Keywords: Research Groups; Managerial Skills; Results; Scale Development. 


\section{LISTA DE FIGURAS}

Figura 1 - Habilidades necessárias ao administrador propostas por KATZ (1955) ……………………..... 34

Figura 2 - As competências e papéis dos líderes no quadro de valores competitivos.................................... 38

Figura 3 - Competências apresentadas por chefias de uma instituição hospitalar ......................................... 42

Figura 4 - Competências de nutricionistas-gestores de Unidades de Alimentação e Nutrição Terceirizadas45

Figura 5 - Competências exigidas e reais de líderes da área de tecnologia de informação............................. 46

Figura 6 - Grau médio de percepção de competências gerenciais no comércio varejista .............................. 47

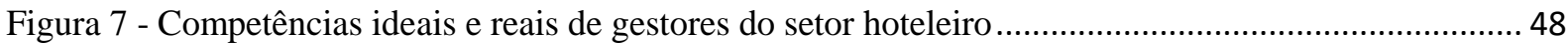

Figura 8 - Comparação entre o percentual de líderes homens e mulheres .................................................... 88

Figura 9 - Percentual de Doutores entre os Pesquisadores de Grupos de Pesquisa brasileiros ..................... 89

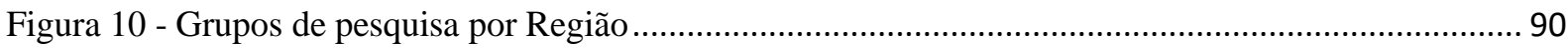

Figura 11 - Grupos de pesquisa por Grande Área do Conhecimento......................................................... 91

Figura 12 - Quantidade de Produções Técnicas ao longo dos anos ............................................................ 93

Figura 13 - Comparação entre artigos de circulação nacional e internacional................................................. 94

Figura 14 - Respondentes por tipo de atuação no grupo de pesquisa ...................................................... 101

Figura 15 - Comparação entre população e amostra quanto ao sexo dos respondentes............................... 109

Figura 16 - Comparação entre população e amostra quanto à localização dos grupos ................................ 109

Figura 17 - Comparação entre população e amostra quanto à Grande área do conhecimento...................... 111

Figura 18 - Fatores das Competências Gerenciais segundo o Scree plot................................................. 118

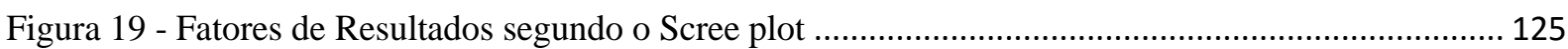

Figura 20 - Resultados Proximais de Pesquisa versus Tipo de Instituição ............................................... 137

Figura 21 - Resultados Tangíveis de Pesquisa versus Tipo de Instituição................................................. 138

Figura 22 - Resultados Proximais versus Tipo de Instituição (Amostra aleatória)....................................... 139

Figura 23 - Resultados Tangíveis versus Tipo de Instituição (Amostra aleatória) ...................................... 139

Figura 24 - Gestão de Pessoas e de Resultados de Pesquisa versus Sexo do Líder ....................................... 140

Figura 25 - Gestão de Pessoas e de Resultados versus Pós-doutorado ...................................................... 141

Figura 26 - Captação de Recursos e de Pessoas versus Pós-doutorado....................................................... 142

Figura 27 - Captação de Recursos e de Pessoas versus Bolsa de Produtividade CNPq .............................. 143

Figura 28 - Resultados Distais de Repercussão Externa versus Bolsa Produtividade CNPq...................... 144

Figura 29 -Resultados Proximais de Pesquisa versus Bolsa Produtividade CNPq ...................................... 144

Figura 30 - Resultados Tangíveis de Pesquisa versus Bolsa Produtividade CNPq.................................. 145

Figura 31 - Gestão de Pessoas e de Resultados de Pesquisa versus Tipo de bolsa CNPq .......................... 147

Figura 32 - Captação de Recursos e de Pessoas versus Tipo de bolsa CNPq ............................................ 147

Figura 33 - Gestão de Pessoas e de Resultados de Pesquisa versus Grande Área do Conhecimento .......... 149

Figura 34 - Captação de Recursos e de Pessoas versus Grande Área do Conhecimento ............................. 150

Figura 35 - Resultados Distais de Repercussão Externa versus Grande Área do Conhecimento ................ 151

Figura 36 - Resultados Tangíveis de Pesquisa versus Grande Área do Conhecimento ............................... 152

Figura 37 - Resultados Distais de Repercussão Externa versus Idade do líder........................................... 153

Figura 38 - Gráfico de Dispersão - Resultados Distais de Repercussão Externa versus Idade do líder..... 154

Figura 39 - Gestão de Pessoas e de Resultados de Pesquisa versus Tempo de Experiência com pesquisa 155

Figura 40 - Captação de Recursos e de Pessoas versus Tempo de Experiência com pesquisa .................... 156

Figura 41 - Resultados Proximais de Pesquisa versus Tempo de Experiência com pesquisa...................... 156

Figura 42 - Captação de Recursos e de Pessoas versus Tempo de participação no grupo atual ................... 158

Figura 43 - Correlações entre as cinco variáveis de competências gerenciais e resultados .......................... 164

Figura 44 - Resumo das correlações mais significativas entre Competências Gerenciais e Variáveis

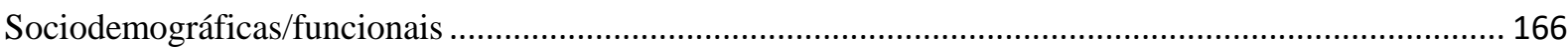

Figura 45 - Resumo das correlações mais significativas entre Resultados e Variáveis

Sociodemográficas/funcionais . 


\section{LISTA DE QUADROS}

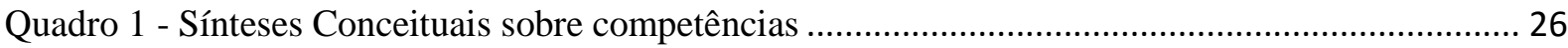

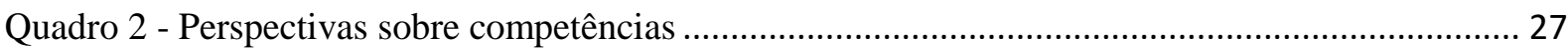

Quadro 3 - As 21 Competências Gerenciais de Boyatizis (1982) ........................................................... 34

Quadro 4 - Elementos constitutivos de definições para competências gerenciais .................................. 35

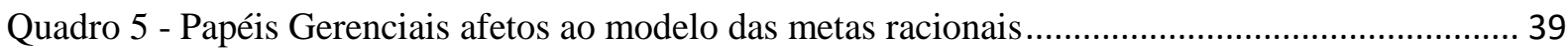

Quadro 6 - Papéis afetos ao modelo das relações humanas ................................................................. 39

Quadro 7 - Papéis Gerenciais afetos ao modelo dos processos internos ............................................... 40

Quadro 8 - Papéis Gerenciais afetos ao modelo dos sistemas abertos ............................................... 40

Quadro 9 - Contexto e Amostra de estudos empíricos que usaram o modelo de Quinn (1988) ........... 41

Quadro 10 - Semelhanças e Peculiaridades nas Competências Gerenciais de diferentes profissões .... 54

Quadro 11 - Matriz de Competências Gerenciais no estudo de Ferigotti e Fernandes (2014) .............. 58

Quadro 12 - Classificação das Competências Gerenciais segundo diferentes autores ...........................63

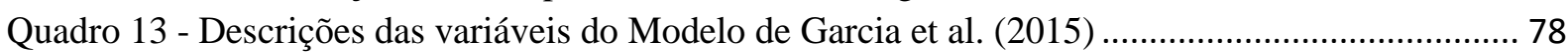

Quadro 14 - Estudos relativos a aspectos que influenciam resultados de grupos de pesquisa .............. 83

Quadro 15 - Relação entre os objetivos específicos e o método ....................................................... 104

Quadro 16 - Variáveis Sociodemográficas e funcionais ................................................................. 106

Quadro 17 - Competência gerencial com indicativo de exclusão ..................................................... 120

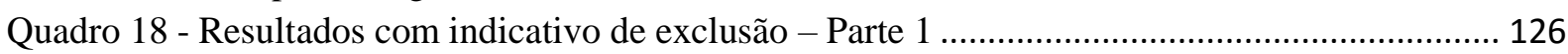

Quadro 19 - Resultados com indicativo de exclusão - Parte 2 ........................................................ 127 


\section{LISTA DE TABELAS}

Tabela 1 - Médias gerais de cada papel antes e depois das disciplinas gerenciais cursadas por estudantes de enfermagem

Tabela 2 - Competências gerenciais para a atuação dos gerentes de agência ......................................... 53

Tabela 3 - Esquema geral da pesquisa Brito e Leone (2012) .............................................................. 56

Tabela 4 - Faixa etária da população de Líderes de grupos de pesquisa .............................................. 87

Tabela 5 - Titulação máxima dos Pesquisadores............................................................................. 89

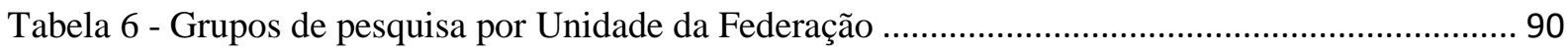

Tabela 7 - Grupos de pesquisa por número de Integrantes ................................................................. 92

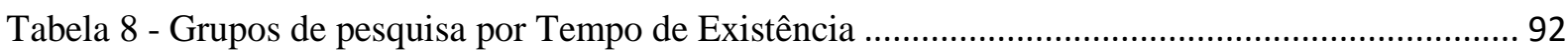

Tabela 9 - Detalhamento da coleta de dados ................................................................................ 100

Tabela 10 - Comparação entre População e Amostra quanto à Titulação Máxima dos pesquisadores108

Tabela 11 - População e amostra por Unidade da Federação............................................................. 110

Tabela 12 - Percentual de Líderes que consideram que o resultado é decorrente de uma ação individual e não do grupo.

Tabela 13 - Comparação dos Eigenvalues das Competências Gerenciais durante a Análise Paralela 119

Tabela 14 - Análise do Alfa de Cronbach para os fatores das Competências Gerenciais................... 121

Tabela 15 - Análise da variância explicada relativa aos fatores das Competências Gerenciais........... 121

Tabela 16 - Escala de Competências Gerenciais em grupos de pesquisa.......................................... 122

Tabela 17 - Definições para os fatores relativos a Competências Gerenciais .................................... 123

Tabela 18 - Comparação dos Eigenvalues dos Resultados durante a Análise Paralela........................ 126

Tabela 19 - Análise do Alfa de Cronbach para os fatores de Resultados alcançados por Grupos de

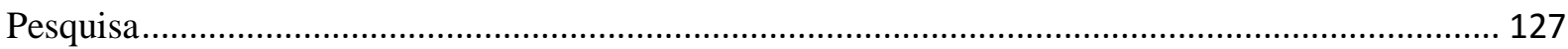

Tabela 20 - Análise da variância explicada relativa aos fatores de Resultados alcançados por grupos de

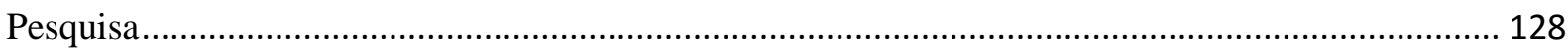

Tabela 21 - Escala de Resultados alcançados por grupos de pesquisa.............................................. 129

Tabela 22 - Definições adotadas para os fatores relativos a Resultados de Grupos de Pesquisa ........ 130

Tabela 23 - Diferenças nos Resultados a depender da suficiência ou insuficiência no domínio de

Competências para a Gestão de Pessoas e de Resultados de Pesquisa................................................. 134

Tabela 24 - Diferenças nos Resultados a depender da suficiência ou insuficiência no domínio de Competências para a Captação de Recursos e de Pessoas

Tabela 25 - Diferenças nas Competências Gerenciais a depender da concordância ou discordância

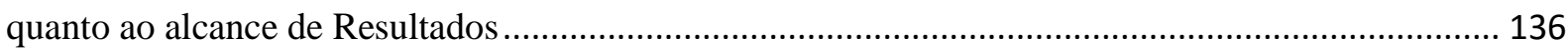

Tabela 26 - Valores das bolsas de produtividade CNPq e respectivos adicionais de bancada............ 146

Tabela 27 - Resumo dos Achados nos Testes não-paramétricos...................................................... 159

Tabela 28 - Correlações Kendall-Tau entre Competências Gerenciais e Resultados.......................... 161 


\section{SUMÁRIO}

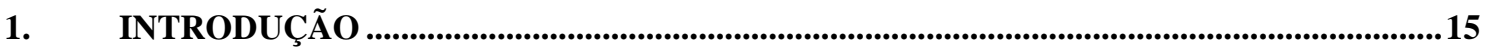

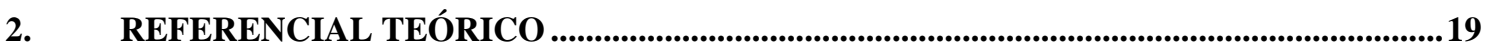

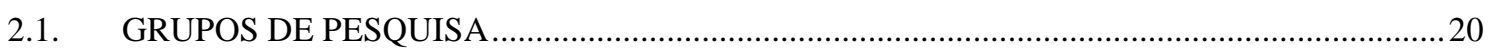

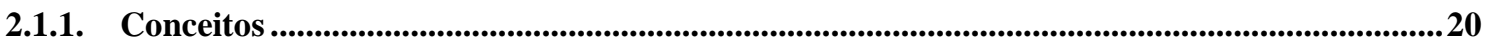

2.1.2. Atribuições ...........................................................................................................................................22

2.1.3. Desafios.................................................................................................................................................23

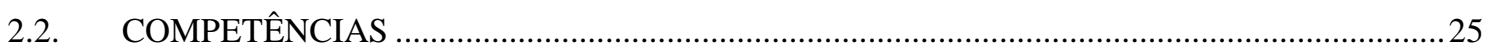

2.2.1. Competências para atuação em grupos de pesquisa ....................................................................28

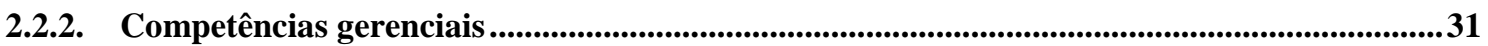

2.3. RESULTADOS EM GRUPOS DE PESQUISA E ASPECTOS QUE OS INFLUENCIAM .......65

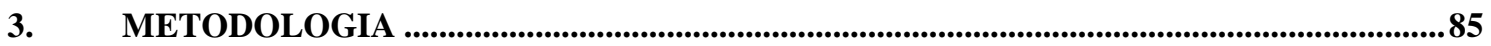

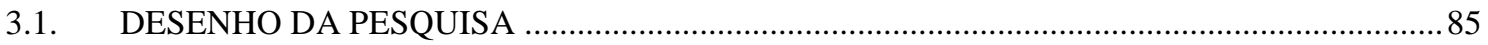

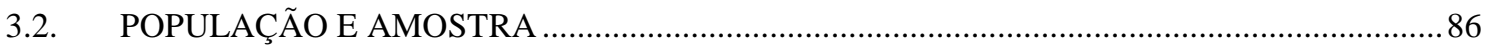

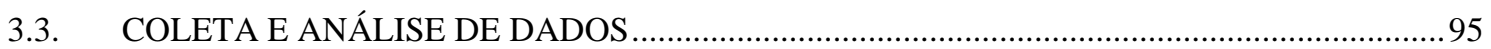

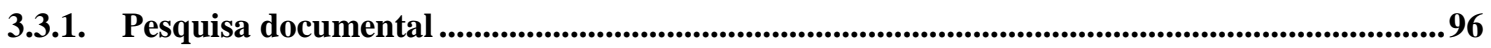

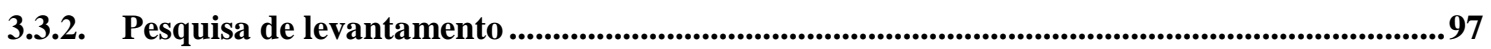

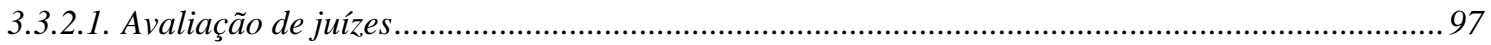

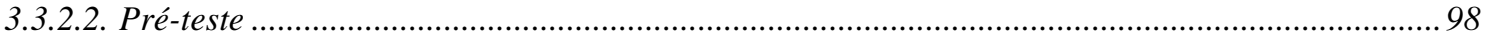

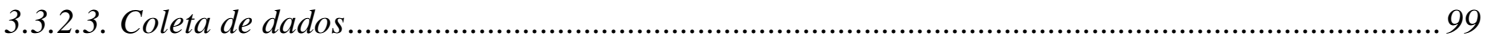

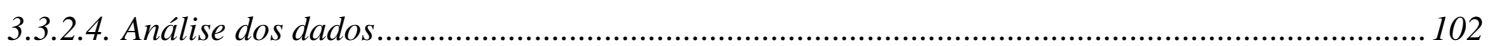

4. APRESENTAÇÃO E DISCUSSÃO DOS RESULTADOS ................................................105

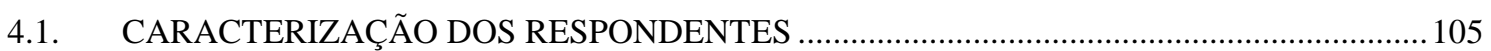

4.2. ANÁLISE EXPLORATÓRIA E TRATAMENTO INICIAL DOS DADOS ..............................112

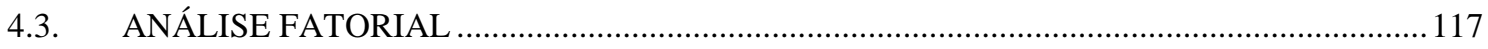

4.3.1. Escala de domínio de competências gerenciais em grupos de pesquisa ...................................117

4.3.2. Escala de resultados alcançados por grupos de pesquisa..............................................................124

4.4. TESTES NÃO-PARAMÉTRICOS U DE MANN-WHITNEY E H DE KRUSKALL-WALLIS132

4.4.1. Diferenças entre os graus de domínio de competências gerenciais ...........................................133

4.4.2. Diferenças entre a ocorrência ou não de resultados ......................................................................135

4.4.3. Diferenças entre os tipos de instituição de pesquisa ou ensino .....................................................136

4.4.4. Diferenças entre o sexo dos líderes de grupo de pesquisa ..............................................................140

4.4.5. Diferenças entre líderes com ou sem pós-doutorado ...................................................................141

4.4.6. Diferenças entre líderes com ou sem bolsa de produtividade do CNPq .................................143 
4.4.7. Diferenças quanto ao tipo de bolsa de produtividade do CNPq recebida .145

4.4.8. Diferenças entre as grandes áreas do conhecimento ..............................................................148

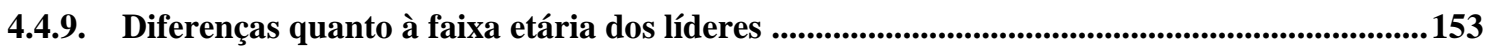

4.4.10. Diferenças quanto à experiência dos líderes com pesquisa acadêmica ...................................154

4.4.11. Diferenças quanto ao tempo de vínculo do líder com o grupo atual ......................................157

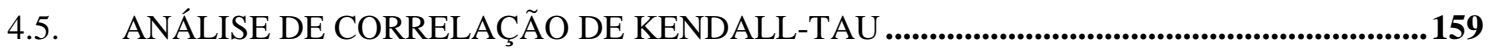

4.5.1. Correlações entre competências gerenciais e resultados .........................................................160

4.5.2. Correlações entre competências gerenciais e variáveis sociodemográficas/funcionais ........164

4.5.3. Correlações entre resultados e variáveis sociodemográficas e funcionais ...............................166

5. CONCLUSÃO

6. REFERÊNCIAS 175

APÊNDICE A - Iens: Domínio de competências gerenciais em grupos de pesquisa. 193

APÊNDICE B - Itens: Resultados de grupos de pesquisa 195

APÊNDICE C - Questionário aplicado - versão completa 196

ANEXO A - Instrumento preliminar: Competências relativas à Coordenação de Atividades de Pesquisa

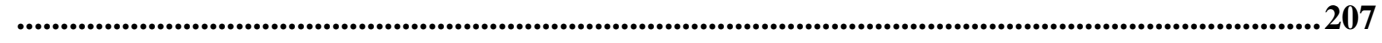

ANEXO B - Instrumento preliminar: Resultados alcançados por grupos de pesquisa.....................208

ANEXO C - Instrumento preliminar: Inserção em atividades do meio acadêmico............................209 


\section{INTRODUÇÃO}

Para que uma organização se perpetue, as competências gerenciais se revelam um pilar essencial no alcance de um patamar superior de desempenho, contribuindo para a geração e manutenção de diferenciais competitivos, de acordo com a visão institucional adotada pela organização (GARCIA, 1999). E essa necessidade de aprimorar o desempenho dos indivíduos também é experimentada por grupos de pesquisa, os quais estão cada vez mais orientados estrategicamente, o que exige que os seus líderes estejam atentos a uma eficiente gestão de recursos, constante busca de financiamentos, além de investimento em conexões com outras organizações, de forma a agregar valor à sua pesquisa, bem como a promover a aprendizagem a seus membros (HARVEY; PETTIGREW; FERLIE, 2002; BUENO, 2014; BERCHE et al., 2015).

O problema a ser enfrentado nesta pesquisa é a identificação de competências gerenciais de líderes de grupos de pesquisa, bem como a compreensão das relações existentes entre as referidas competências e resultados de grupos de pesquisa. A pergunta central que se quer investigar é "Quais são as relações entre as competências gerencias de líderes e resultados de grupos de pesquisa?".

Em relação à matriz teórica adotada, Moura e Bitencourt (2006) afirmam não haver considerável benefício em fazer opção por uma matriz teórica específica e explicam que o que diferencia as duas perspectivas mais relacionadas a competências gerenciais é que, enquanto a proposta racionalista busca justificar os resultados organizacionais a partir da descrição estática de competências gerenciais, a proposta interpretativista visa compreender a dinâmica que leva atributos gerenciais a ganharem destaque e, assim, passa a diagnosticar qual o repertório de competências gerenciais ideal para cada contexto em determinada organização. De qualquer forma, julga-se que esta pesquisa se aproxima mais da sociologia funcionalista, sobretudo pelo trajeto metodológico adotado (BURREL, 1996; MORGAN, 2005).

Vale destacar também que pressupostos voluntaristas e deterministas permeiam os estudos sobre competências gerenciais, e, da mesma forma, irão permear este trabalho, sendo a relação entre esses pressupostos um fator crucial para a compreensão do papel gerencial. $\mathrm{O}$ epicentro da administração estratégica reside na adaptação ao ambiente. Assim, o poder em relação à mudança precisa ser observado tanto em aspectos gerenciais, quanto em aspectos ambientais (ASTLEY; VAN DE VEN, 1983). A inovação organizacional pode ser vista, de um lado, como um reflexo de escolhas gerenciais entre alternativas possíveis (voluntarismo) e, de 
outro, como uma resposta obrigatória às intempéries (determinismo) (ALDRICH; PFEFFER, 1976; CHILD, 1972).

Estudos sobre competências gerenciais normalmente pressupõem ou voluntarismo ou determinismo, já que esses dois "vieses" são considerados mutuamente exclusivos em organizações complexas. Contudo, este estudo seguirá a recomendação de Astley e Van de Ven (1983) que orientam o pesquisador a, inicialmente, aceitar a possibilidade concomitante de ocorrência do determinismo e do voluntarismo e de seus efeitos, e somente numa segunda análise, buscar o diálogo e as interdependências reflexas das duas visões para a inovação organizacional (ASTLEY; VAN DE VEN, 1983).

Buscando responder à questão central mencionada, adota-se o seguinte objetivo geral: 'Identificar as relações entre competências gerenciais de líderes e resultados de grupos de pesquisa brasileiros'. Especificamente, espera-se atingir os seguintes objetivos:

a) identificar os comportamentos que demonstram o domínio de competências gerenciais em grupos de pesquisa;

b) apresentar indícios ou evidências de validade para uma escala de domínio de competências gerenciais em grupos de pesquisa;

c) identificar os aspectos que evidenciam resultados de grupos de pesquisa;

d) apresentar indícios ou evidências de validade para uma escala de aspectos que evidenciam resultados de grupos de pesquisa;

e) identificar eventuais diferenças ou semelhanças entre grupos com relação a competências gerenciais ou resultados em grupos de pesquisa, a depender de dados sociodemográficos e funcionais (tipo de instituição, unidade da federação e grande área do conhecimento a que o grupo se vincula; sexo, faixa etária, tempo de experiência, recebimento de bolsa de produtividade do $\mathrm{CNPq}$ e titulação/escolaridade do líder; entre outros); e

f) identificar relações existentes entre competências gerenciais e aspectos que evidenciam resultados de grupos de pesquisa brasileiros.

O interesse neste estudo surgiu mediante a participação no grupo de pesquisa 'Inovação e Aprendizagem em organizações', que tem como uma de suas linhas de pesquisa a 'a aprendizagem e o desenvolvimento de competências em organizações'. Esta pesquisa está inserida num contexto mais amplo de um projeto de pesquisa firmado em 1\%11/2012, certificado e financiado pelo $\mathrm{CNPq}$, e vinculado à Universidade de Brasília, cujo título é "Relações de Aprendizagem em Organizações, Competências, Redes Sociais e de 
Colaboração e Desempenho: uma análise em grupos de pesquisa" (Processo n 477496/20121). Partiu-se do uso de resultados anteriores em caráter de continuidade, visando à evolução da área e ao avanço científico.

Com relação à justificativa social, a contribuição científica decorrente desta pesquisa poderá representar um ganho social no sentido de indicar relações entre competências gerenciais e resultados de grupos de pesquisa, que são organizações de destaque na atual sociedade do conhecimento (FREITAS JR., 2003).

Ademais, evidências empíricas de relação entre competências gerenciais e resultados de grupos de pesquisa podem estimular o desenvolvimento dessas competências mediante um melhor preparo dos pesquisadores e futuros líderes de grupo, bem como incentivar o aprimoramento contínuo desses profissionais nas instituições de ensino a que estão vinculados, bem como junto a instituições de fomento (ODELIUS et al., 2011; BUENO, 2014).

Além disso, há que se apresentar como justificativa institucional a contribuição que o presente trabalho pode conferir à política brasileira de pesquisa científica, tecnológica e de inovação, uma vez que identificar as relações entre competências gerencias e resultados de grupos de pesquisa pode contribuir para que o Ministério de Ciência, Tecnologia e Inovação (MCTI) e o Conselho Nacional de Desenvolvimento Científico e Tecnológico (CNPq) formulem políticas específicas em relação a esses temas que contribuam ao cumprimento de sua função de promover o desenvolvimento econômico e social do Brasil, gerando benefícios a toda a sociedade.

Quanto à justificativa acadêmica, essa investigação científica é importante porque a relação entre competências e seus resultados não é devidamente articulada (SANTOS; CAETANO; JESUÍNO, 2008; BRANDÃO, BORGES-ANDRADE; GUIMARÃES, 2012). Investigações com maior acurácia são recomendadas para que se verifique como as práticas gerenciais, de fato, modificam resultados organizacionais (JESUS et al., 2014). Ademais, há um crescente interesse na adoção de "grupos de pesquisa" como locus investigativo (HOLLIS, 2001; ACEDO et al., 2006; MAUTHNER; DOUCET, 2008; MOURA et al., 2008, ERDMANN; LANZONI, 2008; SUTTON, 2010).

Outrossim, inúmeras são as lacunas identificadas por outros pesquisadores da área, sendo que o escopo do presente trabalho vislumbra contribuir, ainda que indiretamente, para as seguintes: a) estudo abrangendo competências e aspectos relacionados à gestão - visão estratégica; visão sistêmica; gestão de pessoas e de recursos (ODELIUS et al., 2011); b) instrumentos de coleta que indiquem os resultados de um grupo de pesquisa (VASQUEZ-RIZO, 
2010; BERCHE et al., 2015); c) análise de como competências podem intermediar as relações de entrega no trabalho (BRANDÃO; BORGES-ANDRADE, 2008); d) análise mais abrangente da gestão de formação e do desempenho de grupos de pesquisa (IZQUIERDO-ALONSO; MORENO-FERNÁNDEZ; IZQUIERDO-ARROYO, 2008); e) identificação da medida em que as competências profissionais expressas por pessoas e equipes de trabalho explicam a variância dos resultados organizacionais (BRANDÃO; BORGES-ANDRADE, 2008); f) estudo do impacto das competências sociais e gerenciais sobre o desempenho organizacional de diversos segmentos (LOPES et al., 2010; BÜNDCHEN; ROSSETTO; SILVA, 2011); g) pesquisas capazes de apurar se o domínio de competências está associado à produtividade, ao desempenho em grupos de pesquisa e a outras medidas do comportamento organizacional (FERNANDEZ; ODELIUS, 2013); e i) identificação de competências relevantes nos mais diversos segmentos profissionais, propósitos e contextos organizacionais (GUIMARÃES et al., 2001; BÜNDCHEN; ROSSETTO; SILVA, 2011).

Apresentados o contexto do tema, o problema de pesquisa, a questão central de pesquisa, o paradigma e matriz teórica predominante, os objetivos, as justificativas e as lacunas apontadas por outros pesquisadores, passa-se, então, às demais partes que compõem a presente dissertação, além deste capítulo introdutório. O segundo capítulo tratará do referencial teórico, que abrange estudos sobre grupos de pesquisa; competências; e resultados em grupos de pesquisa e aspectos que os influenciam. O terceiro capítulo é reservado à metodologia, explicitando informações sobre o desenho da pesquisa; população e amostra; e procedimentos de coleta e de análise dos dados. No quarto capítulo, os resultados serão apresentados e discutidos, enquanto que, o quinto capítulo, ficará reservado às considerações finais para a pesquisa, incluindo as recomendações, limitações e agenda para pesquisas futuras. E, por fim, no sexto capítulo, estão elencadas as referências a que se recorreu para a elaboração deste estudo. 


\section{REFERENCIAL TEÓRICO}

A base para a busca bibliográfica da literatura priorizou artigos publicados entre 2005 e 2015, disponibilizados nos Portais de Periódicos CAPES, Scielo, ProQuest, Web of Science e Google Acadêmico, assim como, a base de acesso livre do Spell - Scientific Periodicals Electronic Library, por ser um sistema de indexação, pesquisa e disponibilização gratuita, que concentra a produção científica da área de Administração.

Visando compreender os fundamentos teóricos que perpassam o problema de pesquisa, este tópico abrangerá três seções: Grupos de pesquisa; Competências; e Resultados em grupos de pesquisa e aspectos que os influenciam. Para compor esse quadro teórico, as palavras-chave utilizadas nas buscas parametrizadas foram: 1) para grupo de pesquisa: research group; e grupo de investigación; 2) para competências: skill, competence, competences, competencies, managerial skill, managerial skills, managerial competence, managerial competences, managerial competencies; e 3) para resultados: organizational result, organizational performance.

Sobre competências gerenciais, foram selecionados 46 artigos que elencavam competências gerenciais nos mais diversos loci de pesquisa, desde pequenas empresas a multinacionais, com os mais variados objetivos, mediante abordagens quantitativas e qualitativas, quais sejam: Félix (2005); Moura e Bitencourt (2006); Godoy e Forte (2007); Picchiai (2008); Santos, Caetano e Jesuíno (2008); Moraes e Corrêa (2008); Baráth (2009); Dias e Paiva (2009); Leite (2009); Jansen, Vera e Crossan (2009); Cardoso (2009); Brandão et al. (2010); Noro e Abbade (2010); Lopes et al. (2010); Dias e Paiva (2011); Teixeira, Silva e Lima (2011); Ésther (2011); Pelissari, Gonzalez e Vanelle (2011); Fleck e Pereira (2011); Mithas, Ramasubbu e Sambamurthy (2011); Bündchen, Rossetto e Silva (2011); Nóbrega et al. (2012); Brandão, Borges-Andrade e Guimarães (2012); Godoy e D'amelio (2012); Baisch et al. (2012); Galvão, Silva e Silva (2012); Brito e Leone (2012); Brito, Paiva e Leone (2012); Sousa e Valadão Jr. (2013); Paiva e Ferreira (2013); Barros et al. (2013); Paula et al. (2013); Paiva, Santos e Lacerda (2014); Ferigotti e Fernandes (2014); Almeida e Muniz Jr. (2014); Cardoso (2014); Irmão e Barbalho (2014); Mello e Melo (2014); Pinto et al. (2014); Regio et al. (2014); Santos e Honório (2014); Silva, Gil e Okabayashi (2014); Tosta e Dalmau (2014); Nascimento e Alves (2015); Peixoto e Souza (2015); e Seabra, Paiva e Luz (2015).

Já sobre grupos de pesquisa e resultados, foram selecionados 26 estudos, considerados de maior destaque para o referencial teórico, por abordarem os aspectos que influenciam resultados em grupos de pesquisa, ou possíveis indicadores que contribuiriam para auferir 
resultados em grupos de pesquisa, quais sejam: Hollis (2001); Harvey, Pettigrew e Ferlie (2002); Freitas Jr. et al. (2003); Morris e Goldstein (2007); Garviria-Velásquez; Mejía-Correa; Henao-Henao (2007); Mejía-Correa (2007); Restrepo e Villegas (2007); Mauthner e Doucet (2008); Mejía, Sánchez e Leza (2008); Weijden et al. (2008); Erdmann e Lanzoni (2008); Vincent (2009); Odelius e Sena (2009); Odelius et al. (2010); González-Alcaide, AleixandreBenavent e Granda-Orive (2010); Vasquez-Rizo (2010); Odelius et al. (2011); Erdmann et al. (2012); Mendes, Caliari e Santos (2014); Pinto e Dornelas (2014); Santana et al. (2014); Araujo et al. (2015); Ferraz e Dornelas (2015); Garcia et al. (2015); Henderson et al. (2015); e RamosVielba, Sánchez-Barrioluengo e Woolley (2015). A partir das referências comuns nesses textos, identificaram-se outras referências e obras seminais relativas ao tema.

No levantamento bibliográfico, as referências foram selecionadas de acordo com a adequação e relevância temática em relação ao objeto deste estudo. Na bibliografia referente a competências gerenciais, consideraram-se adequados os estudos que continham achados empíricos e que apresentaram alguma forma de mapeamento ou classificação de competências gerenciais em determinados contextos, possibilitando a identificação ou classificação das competências importantes para os gerentes, a relação entre variáveis sociodemográficas/funcionais e competências e a relação entre competências gerenciais e resultados organizacionais. Já na literatura concernente a grupos de pesquisa, foram selecionados os artigos que abordavam tanto competências aplicadas no contexto de pesquisa, quanto resultados de grupos e suas formas de classificação. Além disso, atentou-se para as referências comuns citadas nos artigos, de forma que estudos anteriores à delimitação temporária citada também fossem considerados.

\subsection{Grupos de Pesquisa}

Embora na visão Mejía, Sánchez e Leza (2008) a literatura relativa a grupos de pesquisa seja heterogênea e reduzida, foi possível identificar na busca bibliográfica os conceitos de grupos de pesquisa; atribuições dos grupos de pesquisa e desafios dos grupos de pesquisa, os quais estão organizados e apresentados em três seções, a seguir.

\subsubsection{Conceitos}

Trabalhar conjuntamente é uma prioridade para organizações modernas, uma vez que alcança resultados superiores aos decorrentes do trabalho individual, seja pela qualidade do trabalho, seja pelo estímulo à externalização de habilidades individuais, ou ainda porque 
confere maior flexibilidade ao trabalho, além de ampliar a capacidade de implantação de mudanças (JEZERSKYTË; ŽYDŽIŪNAITE, 2005).

Grupo é um aglomerado de pessoas atuando conjuntamente, de forma estruturada, e com um propósito compartilhado (STONER; FREEMAN, 1999; FERRAZ; DORNELAS, 2015). Organizações, por sua vez, podem ser definidas como um conjunto de grupos interrelacionados (MONTANA; CHARNOV, 1998; FERRAZ; DORNELAS, 2015). Na perspectiva sistêmica, quando se estuda uma organização, examina-se ao mesmo tempo as relações e o funcionamento de seus sistemas menores (KENDALL; KENDALL, 2005). Considerando esses conceitos, os grupos de pesquisa podem ora ser tratados como grupo - dada a sua vinculação sistêmica a instituições de maior vulto - ora como organizações - privilegiando o seu caráter autônomo e sua subdivisão interna (SIERRA-FLORES; RUSSEL-BARNARD, 2009).

Vários são os conceitos de grupo de pesquisa encontrados na literatura recorrida. Alguns destacam seus objetivos; outros, sua composição; e outros ainda, suas características.

Para denominar-se grupo de pesquisa, faz-se necessário que o grupo possua o objetivo comum de cooperar no processo de produção científica em suas respectivas áreas e linhas de pesquisa. E, além disso, precisa ser composto por líderes (professores em cargos de diferentes planos de carreira) que atribuem atividades, orientam e acompanham os trabalhos dos pesquisadores (estudantes de iniciação científica, graduandos em conclusão de curso, mestrandos, doutorandos e pós-doutorandos) e, eventualmente, pode contar com indivíduos de apoio técnico (ALVAREZ; VIDAL, 2001; ODELIUS et al., 2011; HENDERSON et al., 2015). Vale sublinhar uma característica inerente aos grupos de pesquisa: sua composição é, normalmente, constituída de indivíduos que se agrupam para realizar determinados projetos, podendo se desfazer ou se reagrupar ao final dele (MEJÍA-CORREA, 2007).

Os grupos de pesquisa são coalizões formais atreladas às instituições de pesquisas (como as Universidades) e registrados junto ao CNPq, cuja atribuição é investigar assuntos específicos inerentes a áreas de pesquisa de seus interesses (PINTO; DORNELAS, 2014). Podem ser considerados também como organismos propulsores para a formação de redes, tanto em âmbito interno às instituições a que se vinculam, quanto na promoção de cooperação entre distintas instituições de pesquisa (PEREIRA; ANDRADE, 2008; SANTANA et al., 2014).

Além disso, Grupos de pesquisa se inserem num contexto propício ao desenvolvimento de competências coletivas (habilidades interpessoais necessárias ao trabalho em equipe, atitudes favoráveis à solução colaborativa de problemas, respeito à diversidade humana), geralmente pouco estimuladas em situações formais e tradicionais de ensino-aprendizagem 
(PEREIRA; ANDRADE, 2008; ODELIUS et al., 2011; FERNANDEZ; ODELIUS, 2013; SANTANA et al., 2014).

Segundo a proposição do Instituto Colombiano para Desenvolvimento da Ciência e Tecnologia - Colciencias, grupo de pesquisa, em tradução livre, é o "conjunto de pessoas que se reúnem para realizar pesquisas em relação a um determinado tema, formular uma ou várias questões de interesse, traçar um plano estratégico de longo ou de médio prazo e, trabalhando nele, produzir resultados e conhecimentos relativos ao assunto" ${ }^{1 "}$ (CASTRO, 2008, p. 16).

Já para o CNPq, grupo de pesquisa é o conjunto de indivíduos organizados hierarquicamente em torno de uma ou, eventualmente, duas lideranças: cujo fundamento organizador dessa hierarquia é a experiência, o destaque e a liderança no terreno científico ou tecnológico; no qual existe envolvimento profissional e permanente com a atividade de pesquisa; cujo trabalho se organiza em torno de linhas comuns de pesquisa que subordinam-se ao grupo (e não ao contrário); e que, em algum grau, compartilha instalações e equipamentos; admitindo-se o grupo composto de apenas um pesquisador.

Adotar-se-á, no âmbito deste estudo, o último conceito apresentado - o do CNPq (2015) -, uma vez que se revela mais abrangente que os demais. Faz-se necessária, contudo, a ressalva de que esta pesquisa não compactuará com a concessão final constante do referido conceito, que prevê a possibilidade de um grupo de pesquisa ser formado por apenas um pesquisador. Essa aceitação inviabilizaria o conceito de grupo exposto no início desta seção.

\subsubsection{Atribuições}

Entre as atribuições de um grupo de pesquisa estão a produção de conhecimento e a formação de seus participantes seja em seus hábitos seja na forma de realizar pesquisa (GARVIRIA-VELÁSQUEZ; MEJÍA-CORREA; HENAO-HENAO, 2007; SUTTON, 2010; ODELIUS et al., 2011; FERNANDEZ; ODELIUS, 2013). Evidências disso constam do estudo realizado por Odelius et al. (2010), que tinha o propósito de descrever as atividades realizadas por membros de grupos de pesquisa de uma universidade federal brasileira, atuantes em diversas áreas de conhecimento, bem como, as competências necessárias para a atuação no grupo. Esses autores relataram que os principais benefícios gerados aos participantes são o desenvolvimento de: a) habilidades relacionadas à produção e disseminação de conhecimentos;

\footnotetext{
1 “conjunto de personas que se reúnen para realizar investigación en una temática dada, formulan uno o varíos problemas de su interés, trazan un plan estratégico de largo o mediano plazo para trabajar em él e producen unos resultados de conocimiento sobre el tema en cuestión"
} 
b) habilidades interpessoais necessárias ao trabalho em equipe; c) atitudes favoráveis à solução colaborativa de problemas; e d) respeito à diversidade humana.

A principal função detectada para os grupos pesquisados por Odelius et al. (2011) foi a facilitação da produção de conhecimentos, bem como a reunião de pesquisadores com interesses comuns. Segundo esses autores, também é função do grupo de pesquisa coletar, analisar e interpretar dados, bem como divulgar seus resultados à comunidade. Compete ainda aos grupos de pesquisa estimular novos estudos e novas metodologias, promovendo a aplicação prática de seus achados (MOURA et al., 2008; RIQUELME; LANGER, 2010).

Interessante notar ainda que muitos grupos de pesquisa conseguem construir uma visão global em torno dos fenômenos abarcados por suas linhas de pesquisa. Isso se deve ao fato de que os participantes, independentemente do seu nível instrucional, procuram contribuir de forma crítica, particular e colaborativa para cobrir toda a temática que envolve o escopo de pesquisa de seu grupo (VALENTIM, 2007).

Ao grupo de pesquisa atribui-se, por fim, a conexão entre o sistema de pesquisas e os anseios das instituições de fomento (PEREIRA; ANDRADE, 2008; SUTTON, 2010; SANTANA et al., 2014). Afinal, dos resultados de seus projetos pode-se desenvolver aplicações industriais, governamentais, ambientais e sociais (RIQUELME; LANGER, 2010; BACKES et al., 2012; MENDES; CALIARI; SANTOS, 2014; ARAUJO et al., 2015; GARCIA et al., 2015; RAMOS-VIELBA; SÁNCHEZ-BARRIOLUENGO; WOOLLEY, 2015). Além disso, há que se destacar o seu papel integrador do ensino, da pesquisa e da extensão (RIQUELME; LANGER, 2010; BACKES et al., 2012). São instituições tão importantes para as universidades que Tourinho (2006) e Mauthner e Doucet (2008) afirmam que a criação de grupos de pesquisas é extremamente estimulada por instituições de fomento, podendo, inclusive, advir de pressões políticas.

\subsubsection{Desafios}

É possível identificar uma série de aspectos que desafiam grupos de pesquisa e dificultam a aprendizagem no grupo. Há líderes que estão ora sobrecarregados ora ausentes ou distantes dos membros; desorganizados quanto aos processos de trabalho e cronogramas; inertes na proposição de discussões teóricas, desatentos às dificuldades dos membros, e que solicitam ou cobram desnecessariamente trabalhos sem relação com o projeto de pesquisa. A quantidade de participantes nos grupos é, geralmente, insuficiente; e há membros descompromissados e ausentes das reuniões presenciais, que alegam falta de tempo e 
dificuldades em conciliar agendas, além de se relacionarem sem integração, colaboração e companheirismo, o que contribui para a rotatividade. Falta também apoio institucional por parte das universidades, órgãos de fomento e governos, sobretudo, na manutenção de redes de pesquisas interinstitucionais e internacionais (ODELIUS; SENA, 2009; ODELIUS et al., 2010; ODELIUS et al., 2011).

Além desses aspectos, as experiências dos grupos de pesquisa confirmaram a tendência à multidisciplinaridade anunciada por Gladney et al. (2003), o que representou uma alteração no padrão de realização de pesquisa. Contudo, ainda se trata de uma interdisciplinaridade frágil (BACKES et al., 2012). Por um lado, as perspectivas apresentadas por variadas disciplinas a determinado fenômeno tende a elevar o mérito científico e a possibilidade de aplicação prática dos resultados (ERLEN, 1997); por outro, exige o envolvimento de múltiplos atores, o que requer tomadas de decisão compartilhadas.

Outro desafio relevante seria proporcionar que o espaço acadêmico mantenha sua essência quanto ao fomento ao debate de ideias e ao pensamento livre. Schwartzman (2008) propõe que a pluralidade de grupos de pesquisa seja uma das formas de se evitar o "esclerosamento do mundo acadêmico", de forma que não se construam monopólios em determinadas áreas do saber, nem tampouco que um grupo de pesquisa aja de forma impositiva com os demais.

Martin (2006) elenca os principais desafios dos grupos de pesquisa: crescer, manter a qualidade e, como se já não bastasse, acelerar a produção científica. Esse autor não vislumbra outra forma de combater esse desafio senão investindo na ação coletiva em detrimento da individual. O problema é que há que se atentar também para as estratégias que visam evitar o desvirtuamento temático em atuações coletivas. O estudo documental de Erdmann e Lanzoni (2008) sobre grupos de pesquisa na área de enfermagem, por exemplo, revela uma tendência à redução do número de linhas de pesquisa, evitando-se a dispersão de temas, com o objetivo de conferir mais homogeneidade e delimitação dos campos de interesse. Manter o foco sem enrijecer as relações decorrentes do fenômeno principal é outro desafio experimentado pelos grupos de pesquisa.

Mais um fator a ser combatido são características demeritórias atribuídas ao contexto de grupos de pesquisa. Estudo qualitativo colombiano sobre a confiança nas interações em grupos de pesquisa de uma universidade pública revelaram que muitos grupos convivem com um constante clima de desconfiança, além de haver evidências de canibalismo (uso desautorizado do trabalho de outrem), de arrogância intelectual (desprezo e desqualificação do 
trabalho dos colegas) e o oportunismo (atitude de apropriação do trabalho alheio sem esforço) (CARDONA; CALDEIRÓN, 2010).

Enfim, além desses desafios, os grupos de pesquisa costumam carecer de locais específicos de pesquisa, locais de trabalho individual e coletivo, bibliotecas e videotecas atualizadas, laboratórios, campos de experimentação, equipamentos, recursos materiais e financeiros, bolsas de iniciação científica entre outras necessidades infraestruturais (DEMO, 1996; ODELIUS; SENA, 2009; ODELIUS et al., 2011; BACKES et al., 2012). Ao estudarem sobre o contexto de universidades americanas, Mendes, Caliari e Santos (2014) e Lach e Schankerman (2008) reafirmam a importância desse suprimento infraestrutural para que os organismos de pesquisa mantenham ou incrementem seu potencial inovativo, uma vez que melhores condições de pesquisa ensejam melhorias nos resultados.

Esse desafio relacionado às condições infraestruturais de pesquisa é vivenciado em diferentes proporções no Brasil: os grupos de pesquisa que funcionam em regiões com elevados número de docentes doutores e com maior Produto Interno Bruto (PIB), normalmente, dispõem de infraestrutura minimamente adequada aos resultados pretendidos (BACKES et al., 2012; BUENO, 2014; CANEVER et al., 2014; VIEIRA; WELTER; MELLO-CARPES, 2014; FERRAZ; DORNELAS, 2015).

Encerrada a exposição sobre o conceito, as atribuições e os desafios de grupos de pesquisa, passa-se, na próxima seção, à exposição das contribuições sobre competências, sobretudo as gerenciais e as requeridas para a atuação em grupo de pesquisa. Vale também informar que outros conteúdos relativos a grupos de pesquisa serão apresentados tanto no tópico que tratará a respeito de competências quanto no de resultados, relacionando os estudos sobre competências em grupos de pesquisa, e resultados em grupos de pesquisa, respectivamente.

\subsection{Competências}

A expressão 'Competência' tem sido usada, numa concepção eminentemente jurídica, para denotar incumbência, responsabilidade para julgamento ou emissão de pareceres desde a Idade Média. Somente na década de 1970 o conceito migrou para a área de Psicologia Organizacional, notadamente, nas obras seminais Gilbert e McClelland, que se dedicaram ao estudo das competências individuais no contexto do trabalho. Vinte anos mais tarde, o fenômeno passou a ganhar relevo na área de Administração, incorporando-se aos estudos organizacionais na década de 1990 (BRANDÃO, 2007; MONTEZANO; SILVA; COELHO JR., 2015). 
O estudo de competências perpassa múltiplas abordagens. Há também ausência de consenso conceitual e epistemológico atinente ao tema. São esses os fatores que agravam o desafio em se avaliar ou mensurar competências (GARAVAN; MCGUIRE, 2001; BRANDÃO; BORGES-ANDRADE, 2008). Outrossim, essa dificuldade em se mensurar competências tende a aumentar, uma vez que se exige cada vez mais um maior nível de complexidade nas competências, independentemente do campo de ocupação (GODOY; ANTONELLO, 2009).

Complexo e multifacetado são adjetivos próprios do conceito de competências (BRANDÃO, 2007). Sendo que ora se refere a competências como um resultado (o que é feito) ora como um processo (como se faz) (ROWE, 1995; BERGENHENEGOUWEN; HORN; MOOIJMAN, 1997).

Mas a multiplicidade conceitual é ainda maior. Brito, Paiva e Leone (2012), mediante levantamento teórico, apresentaram a pluralidade na definição de competências, relacionando palavras-chave, sínteses conceituais, e seus principais autores, conforme Quadro 1.

\section{Quadro 1 - Sínteses Conceituais sobre competências}

\begin{tabular}{|c|l|l|}
\hline Palavra-chave & \multicolumn{1}{|c|}{ Síntese conceitual } & \multicolumn{1}{|c|}{ Principais Autores } \\
\hline Formação & $\begin{array}{l}\text { Desenvolvimento de } \\
\text { conceitos, habilidades e } \\
\text { atitudes }\end{array}$ & $\begin{array}{l}\text { Boyatizis (1982), Parry (1996), Boog (1991), Becker } \\
\text { (2001), Spencer e Spencer (1993), Magalhães et al. } \\
\text { (1997), Hipólito (2000), Dutra et al. (1998), Sandberg } \\
(1996)\end{array}$ \\
\hline Capacitação & Aptidão (potencial) & $\begin{array}{l}\text { Moscovicci (1994), Magalhães et al. (1997), Dutra et } \\
\text { al. (1998), Zarifian (2001) }\end{array}$ \\
\hline Ação & $\begin{array}{l}\text { Práticas de trabalho, } \\
\text { capacidade de mobilizar } \\
\text { recursos, fato esse que a } \\
\text { difere do conceito de } \\
\text { potencial }\end{array}$ & $\begin{array}{l}\text { Sparrow e Bognanno (1994), Durand (1998), Hase et } \\
\text { al. (1998), Cravino (2000), Ruas (1999), Moscovicci } \\
\text { (1994), Boterf (1997), Perrenoud (1998), Fleury e e }\end{array}$ \\
Fleury (2000), Davis (2000), Zarifian (2001)
\end{tabular}

Fonte: adaptado de Brito, Paiva e Leone (2012) 
Essa multiplicidade conceitual advém da literatura seminal e foi evidenciada, por exemplo, por Dutra (2004), Brandão (2007) e Carbone, Brandão e Leite (2009), conforme apresentado no Quadro 2.

Quadro 2 - Perspectivas sobre competências

\begin{tabular}{|l|l|l|}
\hline \multicolumn{1}{|c|}{ Perspectiva } & \multicolumn{1}{|c|}{ Conceitos de competências } & \multicolumn{1}{c|}{ Precursores } \\
\hline $\begin{array}{l}\text { Americana (ênfase } \\
\text { em atributos } \\
\text { pessoais) }\end{array}$ & $\begin{array}{l}\text { Conjunto de qualificações ou características subjacentes } \\
\text { à pessoa, e que permitem ao indivíduo, ocasionalmente, } \\
\text { realizar determinado trabalho e ter um desempenho } \\
\text { superior, ou lidar com uma dada situação. }\end{array}$ & $\begin{array}{l}\text { McClelland (1973) e } \\
\text { Boyatzis (1982) }\end{array}$ \\
\hline $\begin{array}{l}\text { Francesa (ênfase no } \\
\text { desempenho entregue } \\
\text { e no contexto) }\end{array}$ & $\begin{array}{l}\text { Conjunto de realizações produzidas por indivíduo em } \\
\text { determinado contexto de trabalho e não um conjunto de } \\
\text { atributos de uma pessoa. }\end{array}$ & $\begin{array}{l}\text { Zarifian (1999) e Le } \\
\text { Boterf (1999) }\end{array}$ \\
\hline $\begin{array}{l}\text { Integradora (ênfase } \\
\text { em atributos pessoais, } \\
\text { no desempenho } \\
\text { entregue e nonjunto de conhecimentos, habilidades e atitudes } \\
\text { contexto) }\end{array}$ & $\begin{array}{l}\text { Cocessários para exercer certa atividade, mas também o } \\
\text { desempenho da pessoa em um determinado contexto, em } \\
\text { termos de comportamentos adotados no trabalho e } \\
\text { realizações decorrentes. }\end{array}$ & Gonczi (1999) \\
\hline
\end{tabular}

Fonte: elaborado pelo autor com base na literatura

Outros conceitos corroboram a corrente americana. São exemplos as definiç̧ões de Parry (1996), para quem competência se refere a um conjunto de conhecimentos, habilidades e atitudes (elementos constitutivos da competência) que se relacionam e afetam a maior parte de um trabalho, um papel ou responsabilidade; e de Lima (2005) que visualiza competências como características pessoais (qualidades) vinculadas à capacidade ou atributos (cognitivos, psicomotores e afetivos) para resolver certos assuntos, que, combinados, formam distintas maneiras de realizar, com sucesso, as ações essenciais e características de uma determinada prática profissional.

Mais afinadas com a corrente francesa estão a concepção de Fleury e Fleury (2001), que compreendem a competência como uma ação responsável e reconhecida que mobiliza, integra, transfere conhecimentos, recursos e habilidades, que agreguem valor econômico à organização e valor social ao indivíduo, e a de Stuart e Lindsay (1997), que definem competência como uma declaração de valor, associada a uma cultura em particular e dentro de um determinado ambiente.

Outros conceitos dificultam a classificação em uma das três correntes, como é o caso do apresentado por Rowe (1995), que trouxe a definição de competência como habilidades relativas a um padrão de desempenho atingido ou como comportamentos pelos quais o desempenho é alcançado, a qual, sem fazer menção à integração entre as correntes, já trazia antes mesmo da obra de Gonczi (1999) - elementos tanto da corrente americana quanto da francesa. 
Sob a influência da corrente integradora estão os autores McMullan et al. (2003), que ora compreendem competências, de modo geral, como inerente ao indivíduo e vinculada a um patamar superior de desempenho seja no cumprimento de atividades específicas ou em determinado contexto (aproximando-se da corrente americana); ora as relacionam com ações ou comportamentos ou resultados que uma pessoa deve demonstrar com o seu desempenho (tangenciando a corrente francesa).

De qualquer forma, vale destacar, desde já, que a definição mais alinhada ao presente trabalho é a adotada pela corrente integradora. Acredita-se que não basta aos líderes de grupos de pesquisa deterem certo conjunto de atributos, se não o coloca em ação, de forma que o grupo eleve seu patamar de desempenho requerido pelo contexto.

Por fim, vale frisar que muitos autores consideram que a temática das competências convive com uma teoria fragmentada (BRANDÃO; BORGES-ANDRADE; 2008; GODOY; ANTONELLO, 2009); que a maioria dos estudos se limita a auferir isoladamente os elementos constitutivos da competência (conhecimentos, habilidades e atitudes) e não a sinergia entre eles (BRANDÃO, 2007).

\subsubsection{Competências para atuação em grupos de pesquisa}

A atuação em um grupo vai além do que o mero somatório das competências dos indivíduos que o integram, uma vez que a atuação grupal manifesta competências coletivas (ZARIFIAN, 1999; LOPES et al. 2010), as quais emergem de compartilhamentos, trocas e articulações entre os membros do grupo (LE BOTERF, 2000).

Há, portanto, na atuação em grupo, a coexistência de competências individuais (relativas a um espaço ocupacional específico) e competências comuns (decorrentes da complementaridade entre os espaços ocupacionais individuais) (LE BOTERF, 2000). Segundo Ruas (2005) as competências coletivas são inerentes à organização como um todo, ou também específicas de áreas, grupos ou equipes de trabalho, enquanto as competências individuais são restritas à pessoa ou indivíduo.

Tratando, especificamente, de grupos de pesquisa, foram identificados os estudos de Haythornthwaite (2006), Odelius e Sena (2009), Higuita-López, Molano-Velandia e Rodríguez-Merchán (2011), Odelius et al. (2010), Odelius et al. (2011), e Fernandez e Odelius (2013). Mas a definição de competências em grupos de pesquisa mais explícita é a de Ono (2012). Esse pesquisador, fez uma transposição do conceito de competências em grupos de 
trabalho - com base na definição de Brandão, Bahry e Freitas (2008) - para o contexto de grupos de pesquisa:

Competências no contexto de grupos de pesquisa podem ser definidas como combinações sinérgicas de conhecimentos, habilidades e atitudes (CHA), expressas pelo desempenho individual no grupo, no âmbito de determinado contexto ou estratégia, que agregam valor tanto às pessoas, quanto ao grupo de pesquisa (ONO, 2012, p. 21).

Contudo, em detrimento dessa definição baseada no CHA, o escopo da presente pesquisa é mais condizente com o conceito proposto por Bergenhenegouwen, Horn e Mooijman (1997) e McMullan et al. (2003), o qual se adapta ao contexto de grupos de pesquisa nos seguintes termos: competências se referem a ações ou comportamentos ou resultados que um indivíduo do grupo demonstra com o seu desempenho em prol dos resultados do grupo de pesquisa.

Quanto às classificações de competências em grupos de pesquisa, os estudos revelam variados critérios de classificação. Haythornthwaite (2006), por exemplo, classificou essas competências em quatro grupos: 1) competências técnicas, relativas aos campos específicos de conhecimento, métodos de investigação e tecnologias computacionais; 2) competências relativas ao trabalho em equipe e em colaboração; 3) competências administrativas necessárias ao desenvolvimento de projetos de pesquisa; e 4) competências de socialização e de formação de redes sociais.

Já Barrachina, Sanz-Torrent e Serrat-Sellabona (2009) abordaram a existência de espaço de aprendizagem colaborativa em grupos de pesquisa, descrevendo e explicando a sua organização, orientação, desenvolvimento, monitoramento e avaliação. Esses autores identificaram as principais competências dos grupos de pesquisa estudados. A classificação proposta pelos autores subdividiu as competências em 1) instrumentais (capacidade de analisar e sintetizar; capacidade de organizar e planejar; comunicação oral e escrita na língua nativa; gerenciamento da capacidade de informação; solução de problemas; e tomada de decisão); 2) pessoais (trabalho em equipe; habilidades de relações interpessoais; e pensamento crítico); e 3) sistêmicas (aprendizagem autônoma ou autodidata; adaptação a novas situações; criatividade; liderança; iniciativa e espírito empreendedor; e motivação para a qualidade).

Sem se preocuparem em estabelecer uma classificação estruturada, Odelius e Sena (2009) e Odelius et al. (2011) identificaram as competências resultantes da participação em dois grupos de pesquisa, atuantes na área de psicologia organizacional e do trabalho e de nove grupos de pesquisa de uma instituição pública de ensino superior, respectivamente. Merecem destaque os seguintes aspectos: 1) os conhecimentos e habilidades técnicas necessários ao desenvolvimento de pesquisa; 2) aspectos relacionados a gestão: visão estratégica e visão sistêmica; gestão de 
pessoas, abrangendo a coordenação de atividades, o controle de diferentes ritmos, a valorização e ao aproveitamento das contribuições de integrantes menos instruídos; 3) valores e atitudes favoráveis ao trabalho em equipe e o respeito à diversidade humana, às limitações e aos interesses pessoais; 4) habilidades interpessoais: assertividade para trabalhar com pessoas com características diferentes, trabalho em equipe, relacionamento interpessoal, ponderação de aspectos políticos para tomada de decisão, desenvolvimento de autonomia para resolver problemas e comunicação; 5) habilidades sociais necessárias a socialização profissional; e 6) comportamentos e atitudes: disciplina; ética; motivação; proatividade; versatilidade; raciocínio lógico e a postura adequada para a atuação profissional, a geração de ideias, a socialização e a formação de redes sociais.

Já Higuita-López, Molano-Velandia e Rodríguez-Merchán (2011), ao buscarem identificar os elementos que geram inovação e melhorias no processo de pesquisa, propõem que as competências mais relevantes aos grupos de pesquisa se dividem em: 1) competências gerais: gestão, trabalho em equipe, planejamento de pesquisa, iniciativa para inovação, abertura a mudança, liderança, associatividade, manejo de conflitos e gestão de tecnologias; e 2) competências específicas ao processo de pesquisa: definição de problema de pesquisa, questionamento, hipótese de trabalho, preparação de campo, estado da arte, continuidade nos processos de pesquisa, formação em investigação, interação com outros grupos de pesquisa, gestão de recursos.

Fernandez e Odelius (2013), por fim, desenvolveram uma escala de domínio de competências em grupos de pesquisa e apresentaram indícios e evidências de sua validade, mediante um estudo sobre a percepção de estudantes e de pesquisadores, cadastrados na plataforma Lattes do CNPq, quanto a competências desenvolvidas com a atuação em grupos de pesquisa. A escala foi idealizada a partir de uma revisão da literatura da área, bem como da análise de dados empíricos (entrevistas semiestruturadas em estudo-piloto). Posteriormente, foi submetida à validação semântica e teórica de especialistas (juízes). Para a validação, os autores aplicaram um websurvey a 1.885 integrantes de grupos de pesquisa e seus resultados foram submetidos à estatística descritiva e à análise fatorial exploratória. Os resultados agruparam os 56 indicadores (competências relativas a atividades de pesquisa) em quatro fatores: planejamento de pesquisa; coleta e análise de dados; análise e revisão da literatura; e redação e comunicação de textos científicos. Essas duas últimas foram as competências de maior domínio, na percepção dos próprios respondentes. Adicionalmente, os resultados indicaram que o conjunto desses 4 fatores se refere a competências necessárias à pesquisa. 
Por todos os aspectos mencionados, nota-se que os membros de um grupo de pesquisa desenvolvem ou aprimoram suas competências técnicas de pesquisa, além de comportamentos e valores indispensáveis ao trabalho em equipe. O grupo de pesquisa mostra-se um espaço em que se encontram diversas oportunidades para praticar e suplementar a educação formal decorrente da formação acadêmica tradicional, revelando-se um fator motivacional para os seus membros (ALON, 2010).

\subsubsection{Competências Gerenciais}

A revisão de literatura relativa a competências gerenciais permitiu identificar que são vários os conceitos e as classificações elaborados para esse fenômeno. Identificou-se também que Quinn et al. (2003) fizeram uma revisão sistemática das teorias e de sua evolução, elaborando um modelo mais abrangente, o qual será apresentado neste tópico. Haverá espaço também para apresentar as análises que esses autores realizaram a respeito das Teorias Organizacionais e de como elas os influenciaram na confecção do Modelo. Por fim, serão apresentados estudos que se pautaram pelo Modelo de Quinn (1988) para o desenvolvimento de suas pesquisas e, ainda, outros estudos empíricos que tratam de competências gerencias, ainda que não tenham fundamentação direta no Modelo de Quinn (1988).

A temática gerencial acompanha a Teoria Geral da Administração desde seus primórdios. As premissas da Administração Científica, inauguradas pelo Taylorismo, enquadravam as competências gerenciais (embora não recebessem ainda esse título) como o conjunto de técnicas aplicadas por um supervisor da linha de produção no sentido de racionalizar o trabalho e torná-lo tão eficiente quanto possível. Citam-se como exemplos de competências gerenciais a seleção sistemática dos trabalhadores; a adequação dos melhores trabalhadores às tarefas; o treinamento; a composição e a oferta de incentivos; e o apoio aos trabalhadores, sobretudo, no planejamento da melhor forma com a qual uma tarefa poderia ser desempenhada (QUINN et al., 2003).

Os princípios gerais de Administração, cunhados por Henri Fayol, também contribuíram para a delimitação de competências gerenciais, no âmbito da Abordagem Clássica. Como prevalecia a orientação para a 'divisão do trabalho', o gerente era visto como um integrador que buscava eliminar as falhas da extrema especialização. As principais competências gerenciais elencadas pelos teóricos clássicos são: dar ordens; aplicar sanções justas; elaborar plano para que os subordinados executem; providenciar o pagamento de um 
salário justo; promover a ordem; e promover a harmonia entre as pessoas e as diversas unidades (QUINN et al., 2003).

Com a Teoria de Elton Mayo e colaboradores, acerca da influência da informalidade nas Relações Humanas nas organizações, os gerentes passaram a desenvolver outras competências gerencias como a mentoria; a postura empática; o fomento ao trabalho em equipe; a gestão de conflitos; a atenção aos fatores motivacionais; e a facilitação nos processos de desenvolvimento dos funcionários (QUINN et al., 2003).

A Teoria Burocrática, idealizada sobretudo por Max Weber, enfatizou em especial os processos internos e a divisão do trabalho, com isso, passou-se a considerar como competente o gerente que conseguia definir claramente as responsabilidades dos trabalhadores; que respeitavam a autoridade hierárquica; que selecionavam trabalhadores de modo objetivo e com base em seu mérito e domínio técnico; que decidiam objetivamente e fundamentavam seus argumentos por escrito; e que conseguiam padronizar as tarefas e compilá-las em manuais (QUINN et al., 2003).

Constatando-se que as teorias anteriores eram demasiadamente simplistas, as Teoria Contingencial e Sistêmica passaram a incorporar competências gerenciais voltadas à imprevisibilidade do ambiente e à flexibilidade, já que - na prática - os gerentes dispunham de pouco tempo para a organização e o planejamento. Decidir rapidamente; negociar com astúcia política; inovar continuamente; solucionar problemas com criatividade; e gerir mudanças e riscos são algumas competências gerenciais fomentadas por essas teorias (QUINN et al., 2003).

Ao tratar dessa influência do ambiente organizacional, vale registrar também que os gestores tomam decisões no âmbito interno das organizações de forma influenciada pelo ambiente externo. Duas Teorias tratam dessa relação mais especificamente: a Dependência de Recursos e o Institucionalismo.

A Teoria da Dependência de Recursos assume que as organizações não conseguiriam gerar, internamente, todos os recursos ou funções requeridas para se manterem, e, por isso, realizam transações e se relacionam com elementos do ambiente, de modo a suprir esses recursos ou serviços. Admite-se, nessa Teoria, que existe influência do ambiente externo, mas as intercorrências ambientais podem ser gerenciadas, sendo papel do líder gerenciar as conjecturas ambientais por meio da captação de recursos necessários à consecução dos resultados esperados pela organização (ALDRICH; PFEFFER, 1976; PFEFFER; SALANCIK, 2003). Nesse contexto, as competências gerenciais se voltam ao tratamento das intempéries ambientais e das interdependências, com o fito de potencializar o domínio de recursos 
(PFEFFER; SALANCIK, 2003), bem como às escolhas estratégicas a serem selecionadas com o intuito de gerenciar e até de manipular as dependências organizacionais (THOMPSON, 1967).

Já para os teóricos do Institucionalismo, as competências gerenciais enfatizam mais a atenção para a internalização dos regramentos e das demais normas impostos pelo ambiente institucional (DIMAGGIO; POWELL, 1983; MEYER; ROWAN, 1977). Tomando por base as regras e as estratégias legitimadas, os gestores acreditam modelar suas organizações em conformidade com as posturas previamente validadas pelas organizações-parâmetro. Com isso, os gestores não teriam outra saída a não ser realizar "mais do mesmo", ou seja, reiterar as práticas institucionalizadas (DIMAGGIO; POWELL, 1983). Assim, nessa perspectiva institucionalista, os executivos não agiriam com o fito de melhorar os resultados de suas organizações por meio do controle do fluxo de recursos, mas simplesmente porque outra forma de atuação não poderia sequer ser concebida, uma vez que os valores organizacionais já estariam arraigados e disseminados de uma forma muitas vezes até pré-consciente (DIMAGGIO; POWELL, 1983).

Além dessas contribuições para a temática das competências gerenciais, merecem destaque os estudos de Chester Barnard a respeito das funções do executivo em 1938; a contribuição de Herbert Simon sobre o processo decisório atrelado à atuação gerencial em 1960; a descrição do papel gerencial a partir das funções 'contato interpessoal', 'tomada de decisão' e 'processamento de informações' elaborada por Mintzberg em 1973 (LEITE, 2009); além do artigo clássico de Robert L. Katz (1955), publicado pela Harvard Business Review, em que o autor propôs uma subdivisão nas habilidades necessárias ao administrador: 1) habilidade técnica (conhecimento especializado ou domínio instrumental relativo a atividades típicas de um profissional que executa seu trabalho pessoalmente, podendo ser adquirida mediante experiência, educação e treinamento profissional); 2) habilidade humana (capacidade de trabalhar em equipe e de promover a cooperação); e 3) habilidade conceitual (capacidade de tratar de relações complexas e de visualizar a organização como um conjunto integrado e sistêmico tanto internamente quanto em relação ao ambiente externo) (LOPES et al., 2010).

Katz (1955) sugeriu que todas as três habilidades convivem na atuação do gerente, sendo que, à medida que se eleva o nível administrativo, são mais requeridas as habilidades conceituais, e, à proporção que se reduz o nível hierárquico, se requer mais habilidades técnicas. Já o nível intermediário requer praticamente a mesma proporção de habilidades técnicas, humanas e conceituais, conforme Figura 1. 
Figura 1 - Habilidades necessárias ao administrador propostas por KATZ(1955)

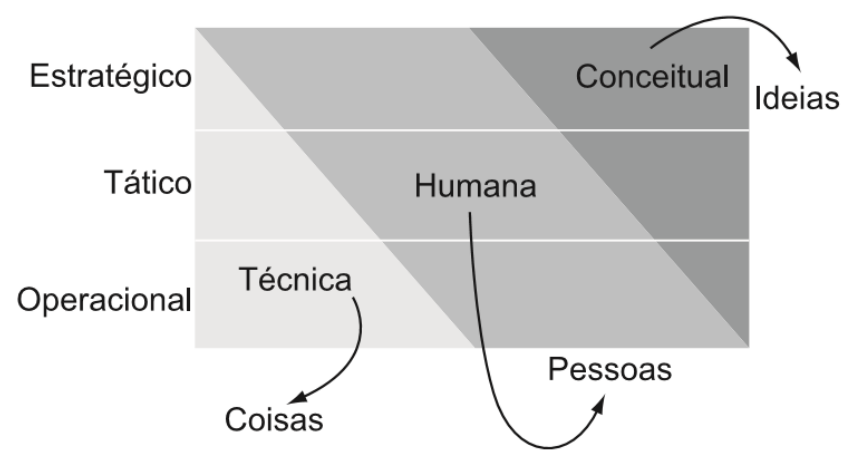

Fonte: Lopes et al. (2010, p. 127)

Contudo, a denominação "competências gerenciais" somente surgiu em 1982, quando o termo foi utilizado pela primeira vez por Richard Boyatizis. Seu livro, The competent manager: a model for effective performance, trazia 21 competências que deveriam compor o perfil ideal de um gestor (BRITO; PAIVA; LEONE, 2012) (Quadro 4).

Quadro 3 - As 21 Competências Gerenciais de Boyatizis (1982)

\begin{tabular}{|c|c|}
\hline Dimensão & Competências Gerenciais de Boyatizis (1982) \\
\hline Metas e Gestão pela Ação & $\begin{array}{l}\text { 1. } \text { Orientação eficiente; } \\
\text { 2. Produtividade; } \\
\text { 3. Diagnóstico e uso de conceitos; } \\
\text { 4. Preocupação com impactos (proativo) }\end{array}$ \\
\hline Liderança & $\begin{array}{ll}\text { 5. } & \text { Autoconfiança; } \\
\text { 6. } & \text { Uso de apresentações orais; } \\
\text { 7. } & \text { Pensamento lógico; } \\
\text { 8. } & \text { Conceitualização }\end{array}$ \\
\hline Recursos Humanos & $\begin{array}{l}\text { 9. Uso de poder socializado; } \\
\text { 10. Otimismo; } \\
\text { 11. Gestão de grupo; } \\
\text { 12. Autoavaliação e senso crítico }\end{array}$ \\
\hline Direção dos Subordinados & $\begin{array}{l}\text { 13. Desenvolvimento de outras pessoas; } \\
\text { 14. Uso de poder unilateral; } \\
\text { 15. Espontaneidade }\end{array}$ \\
\hline Foco em outros clusters & $\begin{array}{l}\text { 16. Autocontrole; } \\
\text { 17. Objetividade perceptual; } \\
\text { 18. Adaptabilidade; } \\
\text { 19. Preocupação com relacionamentos próximos }\end{array}$ \\
\hline Conhecimento especializado & $\begin{array}{l}\text { 20. Memória; } \\
\text { 21. Conhecimento especializado }\end{array}$ \\
\hline
\end{tabular}

Fonte: Adaptado de Brito, Paiva e Leone (2012, p. 197). 
Boyatizis partia do pressuposto behaviorista de que competências são 'comportamentos observáveis' que levam as organizações a melhores desempenhos e resultados, fato que justificaria a importância da formação gerencial (PELISSARI; GONZALEZ; VANELLE, 2011; BRITO; PAIVA; LEONE, 2012). A partir de Boyatizis, autor considerado precursor do fenômeno, começaram a se estabelecer distinções entre as competências gerenciais e as demais competências individuais. Para Godoy e D'Amelio (2012), por exemplo, a competência gerencial é distinta da apresentada pelos demais membros de uma organização pois o gerente precisa canalizar esforços para atingir os resultados esperados de sua área, mediante influência e liderança. Há, portanto, a necessidade de novas competências de maior responsabilidade, com ênfase nas relações interpessoais.

Atualmente, o fenômeno das competências gerenciais conta com inúmeras definições. A partir da análise dos textos identificados que tratam de competências gerenciais foram identificados os diferentes elementos usados pelos autores para definir as competências gerenciais. O resultado dessa análise está resumido no Quadro 4, que elenca a análise das definições de competências gerenciais constantes da literatura, com base no número de ocorrências tanto por elementos constitutivos das definições quanto por autor.

\section{Quadro 4 - Elementos constitutivos de definições para competências gerenciais}

\begin{tabular}{|c|c|c|c|c|c|c|c|c|c|c|c|c|c|c|c|c|}
\hline $\begin{array}{c}\text { Elementos da definição constitutiva: As } \\
\text { competências gerenciais... }\end{array}$ & 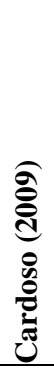 & 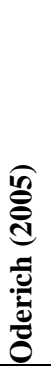 & 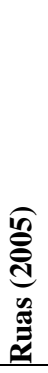 & 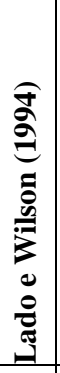 & 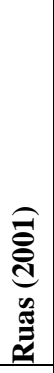 & 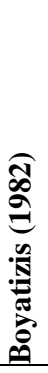 & 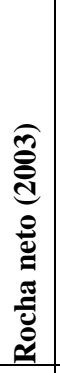 & 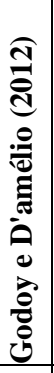 & 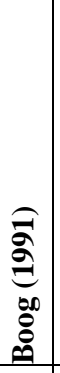 & 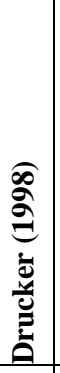 & 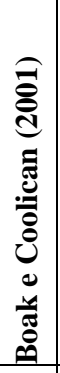 & 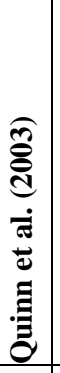 & 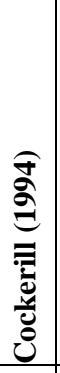 & 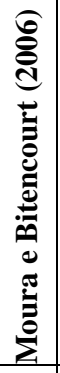 & 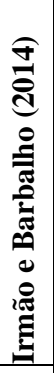 & 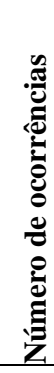 \\
\hline $\begin{array}{l}\text { Estão presentes nos gestores, diretores, gerentes, líderes ou } \\
\text { deles se espera }\end{array}$ & $\mathrm{X}$ & $\mathrm{X}$ & $\mathrm{X}$ & $\mathrm{X}$ & & $\mathrm{X}$ & $\mathrm{X}$ & $\mathrm{X}$ & $\mathrm{X}$ & & $\mathrm{X}$ & $\mathrm{X}$ & $\mathrm{X}$ & $\mathrm{X}$ & $\mathrm{X}$ & 14 \\
\hline $\begin{array}{l}\text { Melhoram resultados, desempenhos, tarefas, } \\
\text { responsabilidades, projetos, propostas, ambiente de } \\
\text { trabalho, agregando valor à organização e proporcionando } \\
\text { crescimento e desenvolvimento }\end{array}$ & $X$ & $\mathrm{X}$ & $\mathrm{X}$ & $\mathrm{X}$ & $\mathrm{X}$ & $\mathrm{X}$ & & $\mathrm{X}$ & $\mathrm{X}$ & & $\mathrm{X}$ & & & & & 10 \\
\hline $\begin{array}{l}\text { Possuem caráter situacional ou contextual, adaptando-se às } \\
\text { necessidades, oportunidades, desafios, problemas e } \\
\text { mudanças }\end{array}$ & $\mathrm{X}$ & $\mathrm{X}$ & $\mathrm{X}$ & & & & $X$ & & & $\mathrm{X}$ & & $X$ & & & & 7 \\
\hline São capacidades (potenciais) & & & $\mathrm{X}$ & $\mathrm{X}$ & $\mathrm{X}$ & & $\mathrm{X}$ & & & $\mathrm{X}$ & & $X$ & & & & 6 \\
\hline $\begin{array}{l}\text { São conhecimentos ou habilidades ou atitudes (formas de } \\
\text { atuar) ou ainda a sinergia entre eles }\end{array}$ & $X$ & $X$ & & $X$ & $X$ & & & & & & & & & $\mathrm{X}$ & $X$ & 6 \\
\hline $\begin{array}{l}\text { Possuem caráter estratégico (contribuem para missão, } \\
\text { visão, valores, objetivos) }\end{array}$ & & & $X$ & $X$ & $X$ & & & $X$ & & & & & & & & 4 \\
\hline São comportamentos & $X$ & & & & & $X$ & & & & & $X$ & & $\mathrm{X}$ & & & 4 \\
\hline $\begin{array}{l}\text { Podem estar relacionadas a apenas uma área ou à toda } \\
\text { organização }\end{array}$ & & & $X$ & & $X$ & & & $X$ & & & & & & & & 3 \\
\hline
\end{tabular}




\begin{tabular}{|c|c|c|c|c|c|c|c|c|c|c|c|c|c|c|c|c|}
\hline $\begin{array}{c}\text { Elementos da definição constitutiva: As } \\
\text { competências gerenciais... }\end{array}$ & 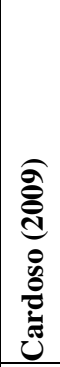 & 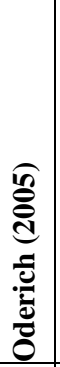 & 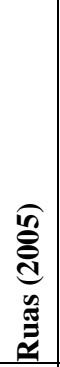 & 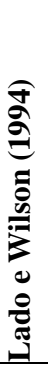 & 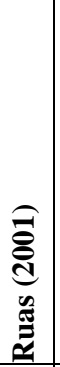 & 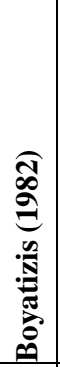 & 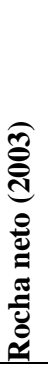 & 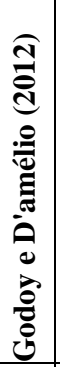 & 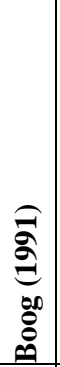 & 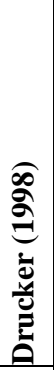 & 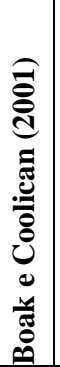 & 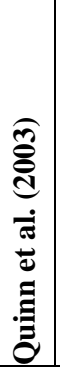 & 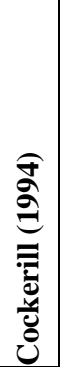 & 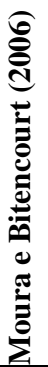 & 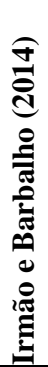 & 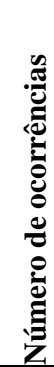 \\
\hline $\begin{array}{l}\text { Possibilitam que as pessoas desempenhem, cresçam e se } \\
\text { desenvolvam, individualmente e em conjunto, de acordo } \\
\text { com suas forças e fraquezas }\end{array}$ & & & & $\mathrm{X}$ & & & & & & $\mathrm{X}$ & & & & & & 3 \\
\hline São fenômeno de nível individual & & & $\mathrm{X}$ & & & & $\mathrm{X}$ & & & & & & & & & 2 \\
\hline São observáveis & $\mathrm{X}$ & & & & & $\mathrm{X}$ & & & & & & & & & & 2 \\
\hline $\begin{array}{l}\text { São um conjunto de qualidades, características ou } \\
\text { atributos }\end{array}$ & & $\mathrm{X}$ & & & & & & & $\mathrm{X}$ & & & & & & & 2 \\
\hline Agregam valor ao próprio gestor & & $\mathrm{X}$ & & & & & & & & & & & & & & 1 \\
\hline $\begin{array}{l}\text { Proporcionam o uso eficiente de recursos próprios e } \\
\text { organizacionais }\end{array}$ & $X$ & & & & & & & & & & & & & & & 1 \\
\hline São ações & & & & & & & & & & & & & & & & 1 \\
\hline São exclusivas dos líderes estratégicos & & & & $\mathrm{X}$ & & & & & & & & & & & & 1 \\
\hline São resultados & & $\mathrm{X}$ & & & & & & & & & & & & & & 1 \\
\hline Número de ocorrências & 7 & 7 & 7 & 7 & 5 & 4 & 4 & 4 & 3 & 3 & 3 & 3 & 2 & 2 & 2 & 68 \\
\hline
\end{tabular}

Fonte: Elaborado pelo autor com base na literatura

Considerando os principais elementos constitutivos constantes da literatura, vale ensaiar uma definição constitutiva própria para o fenômeno: Competências gerenciais são comportamentos observados ou potenciais, por meio dos quais os gerentes, enquanto indivíduos, podem demonstrar tanto seus conhecimentos, habilidades, atitudes ou a sinergia entre eles quanto seus atributos pessoais, gerando valor e melhores resultados a si próprios, a outros indivíduos e a equipes, departamentos, organizações ou redes, de modo compatível ao contexto, aos recursos disponíveis e à estratégia adotada.

A revisão de literatura realizada evidenciou que várias foram as formas de classificação ou categorização das competências gerenciais identificadas. Mais adiante, ficará demonstrado que esse tema já foi estudado teórica e empiricamente em diversos loci de pesquisa, desde pequenas empresas a multinacionais, com os mais variados objetivos, mediante abordagens quantitativas e qualitativas, seja no paradigma funcionalista seja na perspectiva interpretativista.

Antecipando a amplitude temática que perpassa as publicações que serão apresentadas, foram encontrados diversos estudos afetos ao serviço público (universidades e escolas públicas, instituições prisionais, prefeituras, organizações militares, companhias de energia elétrica, bancos públicos) e também à iniciativa privada (laboratórios, empresas de tecnologia da 
informação, indústria de eletrodomésticos, empresas de confecções, empresas de marketing, dentre outros).

Dentre os estudos de 2005 a 2015 identificados no levantamento bibliográfico, serão apresentados sucintamente apenas aqueles que atenderam ao critério de proposição de algum esquema, modelo, categorização, classificação ou, simplesmente, a identificação de competências gerenciais em determinado contexto.

Dentre os 46 estudos sobre competências gerenciais selecionados, 12 compartilhavam de um mesmo modelo teórico. Em contextos e com amostras diferentes, esses 12 estudos utilizaram explícita e diretamente o Modelo de Quinn (1988), o que indica a relevância desse framework para o estudo das competências gerenciais. Assim, inicialmente, será caracterizado o referido modelo e em seguida, serão apresentados os principais achados empíricos decorrentes da aplicação do modelo. Ao final, os outros 34 estudos sobre classificações de competências gerenciais serão apresentados e resumidos num quadro esquematizado.

O Modelo de Quinn (1988) está baseado nas principais teorias que tratam desse fenômeno: Teoria Clássica (modelo das metas racionais); Teoria Humanista (modelo das relações humanas); Teorias Burocrática (modelo dos processos internos); e Teoria dos Sistemas abertos (que considera a perspectiva sistêmica e a contingencial). Seu modelo integrado resume-se na Figura 2. Esses autores utilizam o termo 'papel' como um agrupamento de competências gerenciais alinhadas ao grau de flexibilidade ou controle (eixo vertical) e ao foco predominante, seja interno ou externo (eixo horizontal). 
Figura 2 - As competências e papéis dos líderes no quadro de valores competitivos

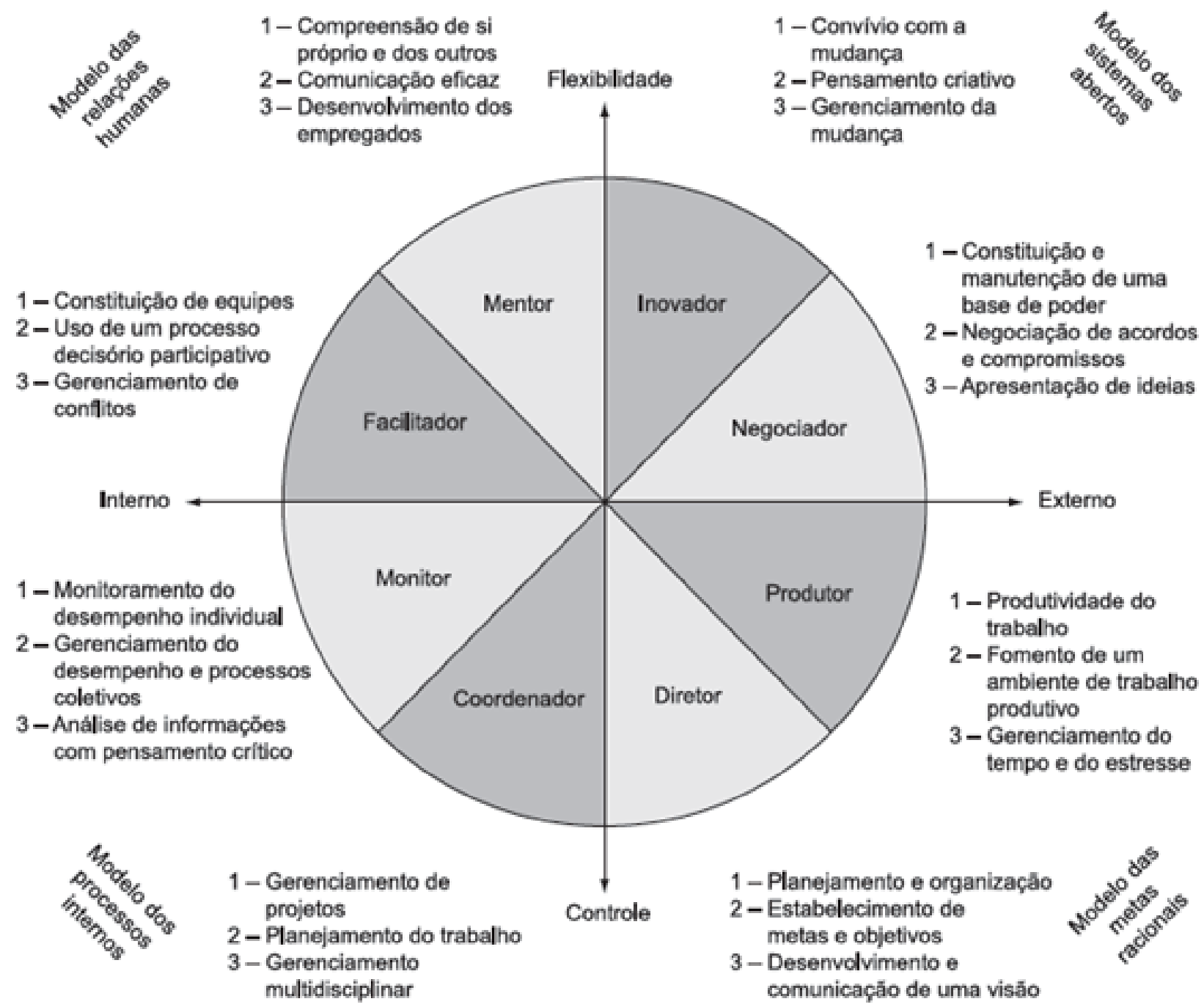

Fonte: QUINN, R. E. Beyond Rational Management. San Francisco: Jossey-Bass. P. 48, 1988.

Dispostas no quadrante direito-inferior estão as competências identificadas a partir do modelo das metas racionais, agregadas nos papéis de produtor e diretor, com foco em competências para o controle e para os resultados externos (Quadro 5). 
Quadro 5 - Papéis Gerenciais afetos ao modelo das metas racionais

\begin{tabular}{|l|l|}
\hline \multicolumn{1}{|c|}{ Papel } & \multicolumn{1}{c|}{ Caracterização do Papel } \\
\hline Produtor & $\begin{array}{l}\text { O gerente está orientado para tarefas, mantém o foco no trabalho e exibe um alto grau de interesse, } \\
\text { motivação, energia e ímpeto. Aceita responsabilidades, realiza tarefas e sustenta uma elevada } \\
\text { produtividade pessoal - o que costuma envolver a motivação dos membros da equipe, de modo a } \\
\text { aumentar a produção e a atingir as metas estabelecidas }\end{array}$ \\
\hline Diretor & $\begin{array}{l}\text { O gerente explicita expectativas por meio de processos, tais como planejamento e delimitação de } \\
\text { metas, e é um deflagrador decisivo: delimita problemas, seleciona alternativas, estabelece } \\
\text { objetivos, define papéis e tarefas, gera regras e políticas e fornece instruções }\end{array}$ \\
\hline
\end{tabular}

Fonte: elaborado pelo autor com base em QUINN, et al. (2003)

No quadrante oposto, esquerdo-superior, prevalecem as competências destacadas pelo modelo das relações humanas, que privilegiam a flexibilidade e o ambiente interno, e estão agrupadas nos papéis de mentor e facilitador (Quadro 6).

\section{Quadro 6 - Papéis afetos ao modelo das relações humanas}

\begin{tabular}{|l|l|}
\hline \multicolumn{1}{|c|}{ Papel } & \multicolumn{1}{c|}{ Caracterização do Papel } \\
\hline Mentor & $\begin{array}{l}\text { O gerente dedica-se ao desenvolvimento das pessoas mediante uma orientação cuidadosa e de } \\
\text { empatia. Ele é solícito, atencioso, amigável, sensível, afável, aberto e justo. Apoia reivindicações } \\
\text { legítimas, transmite apreciação e distribui elogios e reconhecimentos. Contribui para o } \\
\text { aprimoramento de competências, proporciona oportunidades de treinamento e planeja o } \\
\text { desenvolvimento individual dos empregados }\end{array}$ \\
\hline Facilitador & $\begin{array}{l}\text { O gerente fomenta os esforços coletivos, promove a coesão e o trabalho em equipe e administra } \\
\text { os conflitos interpessoais. É orientado para processos. Os comportamentos dele esperados } \\
\text { incluem a intervenção em disputas interpessoais, o uso de técnicas de resolução de conflitos, o } \\
\text { reforço da coesão do moral coletivo, a obtenção de colaborações e participação e a ajuda na } \\
\text { solução dos problemas do grupo }\end{array}$ \\
\hline
\end{tabular}

Fonte: elaborado pelo autor com base em QUINN, et al. (2003)

No quadrante esquerdo-inferior, estão agrupadas as competências concernentes aos papéis de coordenador e monitor (Quadro 7), que foram identificadas a partir do modelo dos processos internos e privilegiam o controle e o ambiente interno. 
Quadro 7 - Papéis Gerenciais afetos ao modelo dos processos internos

\begin{tabular}{|l|l|}
\hline \multicolumn{1}{|c|}{ Papel } & \multicolumn{1}{c|}{ Caracterização do Papel } \\
\hline Coordenador & $\begin{array}{l}\text { O gerente dá sustentação à estrutura e ao fluxo do sistema. Deve ser digno de confiança e crédito; } \\
\text { entre os seus traços comportamentais figuram recursos diversos para a facilitação do trabalho - } \\
\text { como, por exemplo, o agendamento, organização e coordenação dos esforços da equipe, o } \\
\text { enfrentamento de crises e a resolução de dificuldades de ordem tecnológica, logística e doméstica }\end{array}$ \\
\hline Monitor & $\begin{array}{l}\text { O gerente deve saber o que se passa em sua unidade, determinar se as pessoas estão cumprindo } \\
\text { as regras e averiguar se o setor está fazendo sua parte. Ele domina todos os fatos e detalhes, e é } \\
\text { um bom analista }\end{array}$ \\
\hline
\end{tabular}

Fonte: elaborado pelo autor com base em QUINN, et al. (2003)

E, com foco externo e adotando uma postura de mais flexibilidade, as competências destacadas pelo modelo dos sistemas abertos estão no quadrante direito-superior e se configuram nos papéis de inovador e negociador (Quadro 8).

\section{Quadro 8 - Papéis Gerenciais afetos ao modelo dos sistemas abertos}

\begin{tabular}{|l|l|}
\hline \multicolumn{1}{|c|}{ Papel } & \multicolumn{1}{c|}{ Caracterização do Papel } \\
\hline Inovador & $\begin{array}{l}\text { O gerente é encarregado de facilitar a adaptação e a mudança; deve prestar atenção ao ambiente } \\
\text { em transformação, identificar tendências significativas, conceitualizar e projetar mudanças } \\
\text { necessárias e tolerar as incertezas e riscos. Baseia-se na indução, em ideias e em insights } \\
\text { intuitivos. Espera-se que sejam sonhadores inteligentes e criativos, capazes de enxergar longe, } \\
\text { vislumbrar inovações, apresentá-las em embalagens convidativas e convencer os demais de que } \\
\text { são necessárias e desejáveis }\end{array}$ \\
\hline Negociador & $\begin{array}{l}\text { O gerente preocupa-se particularmente com a sustentação da legitimidade exterior e a obtenção } \\
\text { de recursos externos. Deve ter astúcia política, capacidade de persuasão, influência e poder. Atua } \\
\text { como intermediário ou porta-voz. Encontra-se com pessoas de fora de sua própria unidade para } \\
\text { representar, negociar, vender e adquirir recursos }\end{array}$ \\
\hline
\end{tabular}

Fonte: elaborado pelo autor com base em QUINN, et al. (2003)

Conhecidos os principais elementos que constituem o modelo de Quinn (1988), passase aos achados empíricos dos 12 estudos que o utilizaram. Antes de seu detalhamento, o Quadro 9 os resume com informações a respeito dos autores e anos de publicação; dos diversos contextos organizacionais, e das diferentes amostras que subsidiaram os estudos. 
Quadro 9 - Contexto e Amostra de estudos empíricos que usaram o modelo de Quinn (1988)

\begin{tabular}{|c|c|c|}
\hline $\begin{array}{c}\text { Estudos baseados no } \\
\text { Modelo de Quinn (1988) } \\
\end{array}$ & Contexto/setor da pesquisa & Amostra \\
\hline Picchiai (2008) & Instituição hospitalar & $\begin{array}{l}26 \text { ocupantes de cargos de direção no } \\
\text { hospital }\end{array}$ \\
\hline Leite (2009) & Agências bancárias & 140 gerentes gerais de agências \\
\hline Baráth (2009) & $\begin{array}{l}\text { Instituições de educação pública } \\
\text { húngara }\end{array}$ & $\begin{array}{l}4906 \text { professores e } 346 \text { gestores de } 123 \\
\text { instituições de ensino de Budapeste }\end{array}$ \\
\hline Dias e Paiva (2009) & $\begin{array}{l}\text { Instituição privada de ensino superior } \\
\text { de Belo Horizonte-MG }\end{array}$ & 57 estudantes de enfermagem \\
\hline Lopes et al. (2010) & $\begin{array}{l}\text { Empresa têxtil brasileira de médio } \\
\text { porte }\end{array}$ & 127 gerentes de nível tático operacional \\
\hline Dias e Paiva (2011) & Hospital da rede privada & $\begin{array}{l}4 \text { enfermeiros e } 6 \text { técnicos e auxiliares de } \\
\text { enfermagem }\end{array}$ \\
\hline Nóbrega et al. (2012) & $\begin{array}{l}\text { Empresas com Unidades de } \\
\text { Alimentação e Nutrição terceirizadas }\end{array}$ & 12 nutricionistas-gestores \\
\hline Barros et al. (2013) & $\begin{array}{l}\text { Organizações em que atuam } \\
\text { secretários executivos }\end{array}$ & 25 secretários executivos \\
\hline Paiva e Ferreira (2013) & $\begin{array}{l}\text { Organizações situadas no Triângulo } \\
\text { Mineiro }\end{array}$ & $\begin{array}{l}27 \text { líderes da área de tecnologia de } \\
\text { informação }\end{array}$ \\
\hline Pinto et al. (2014) & $\begin{array}{l}\text { Rede de comércio varejista da região } \\
\text { Sul do Brasil }\end{array}$ & 35 gestores de comércio varejista \\
\hline $\begin{array}{l}\text { Paiva, Santos e Lacerda } \\
(2014)\end{array}$ & $\begin{array}{l}\text { Setor hoteleiro de Minas Gerais, São } \\
\text { Paulo, Rio de Janeiro }\end{array}$ & 28 gestores hoteleiros \\
\hline Seabra, Paiva e Luz (2015) & $\begin{array}{l}\text { Instituições de ensino superior de } \\
\text { Belo Horizonte-MG }\end{array}$ & $\begin{array}{l}14 \text { coordenadores de cursos de graduação } \\
\text { em Enfermagem }\end{array}$ \\
\hline
\end{tabular}

Fonte: elaborado pelo autor com base na revisão da literatura

Picchiai (2008) utilizou o Modelo idealizado por Quinn (1988) como base para descrição e comparação das competências apresentadas por chefias de uma instituição hospitalar, segundo a percepção de 26 ocupantes de cargos de direção no hospital. A partir de um questionário com 48 itens de múltipla escolha e de entrevistas dirigidas, apurou-se que: 1) os papéis facilitador-mentor, que privilegia as relações humanas, são os mais evidentes no contexto do hospital (o autor especula que esse resultado se deva ao fato de o hospital tratar de crianças e de estar particularmente voltado ao ensino e à pesquisa; 2) as competências inerentes aos papéis inovador-negociador, relacionados ao modelo de sistemas abertos, são requeridas dos gestores porque o hospital recebe forte influência do ambiente externo, sobretudo nos campos social, técnico e cultural, como é o caso das influências da universidade e do sistema de saúde; e 3) as competências dos papéis diretor-produtor, vinculados às metas racionais, e monitor-coordenador, baseadas no modelo dos processos internos, foram percebidas em menor 
grau. A Figura 3 retrata o mapeamento das 24 competências de Quinn (1988) segundo a autopercepção dos gestores estudados.

Figura 3 - Competências apresentadas por chefias de uma instituição hospitalar

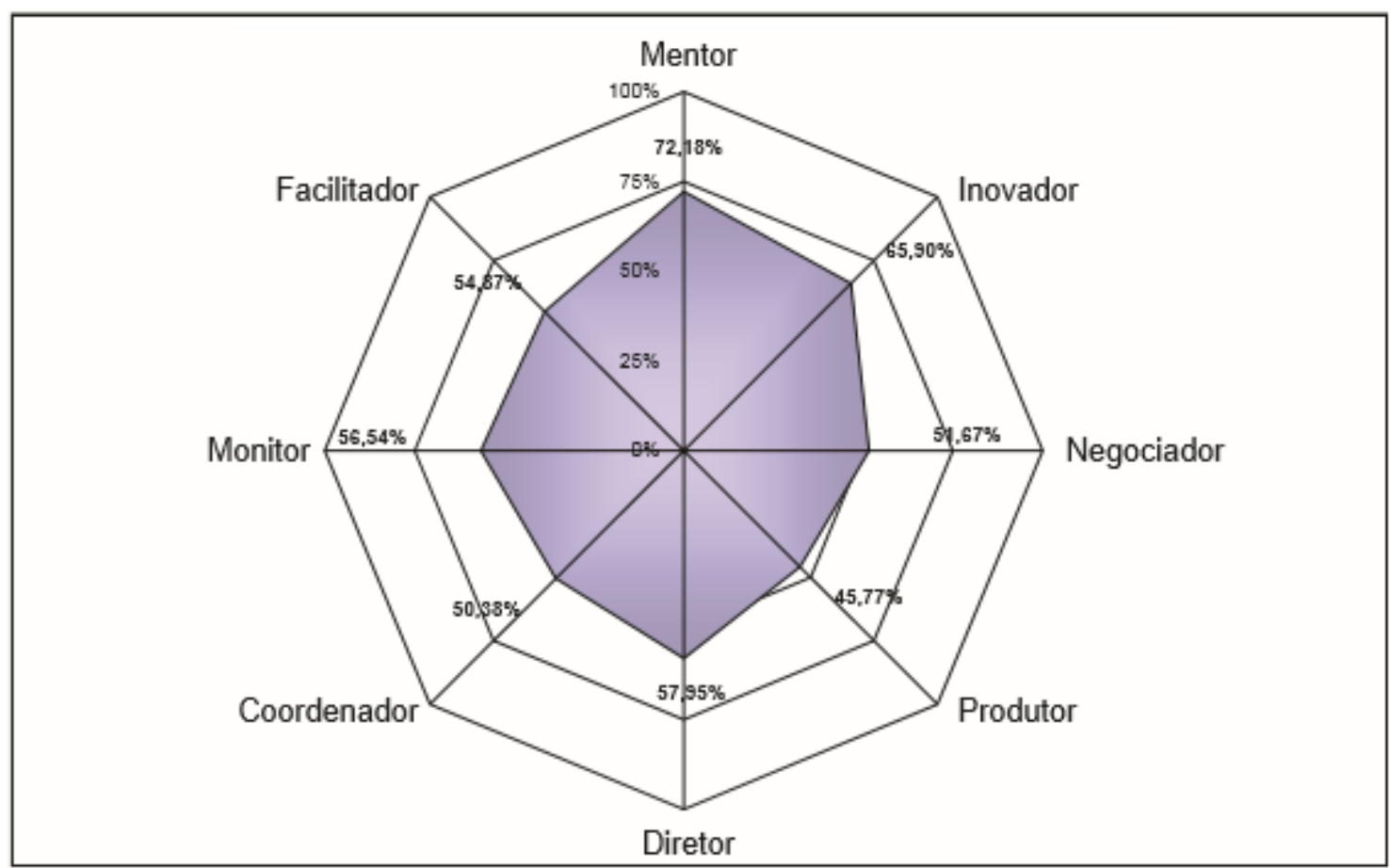

Fonte: Picchiai (2008, p. 36)

Leite (2009), buscando investigar qual a contribuição da aprendizagem experiencial para o desenvolvimento das competências requeridas dos gerentes gerais de agências bancárias e não supridas pela abordagem formal de desenvolvimento, aplicou um survey a 140 gerentes, que continha 25 questões em uma escala Likert de 5 pontos. Como resultado, ficou demonstrado que desempenho dos gestores era compatível com o esperado pelo banco; que as competências gerenciais estão primordialmente atreladas aos papéis de mentor e facilitador (no âmbito do modelo das Relações Humanas); que $81 \%$ das competências gerenciais eram desenvolvidas pela via experiencial; e que as competências formalmente instituídas pelo banco não eram as mesmas requeridas no dia-a-dia de trabalho dos gestores.

Baráth (2009) estudou a eficácia na educação pública húngara e a sua relação com o modelo de gestão escolar adotado, à luz do Modelo de Quinn (1988). Mediante questionário com escala de cinco pontos aplicado a 4906 professores e 346 gestores de 123 instituições de ensino de Budapeste, pôde-se concluir que: 1) os professores caracterizavam a gestão escolar como afeta ao modelo das metas racionais (papéis de produtor e diretor); 2) os próprios gestores afirmaram se pautar mais por competências do modelo de sistemas abertos (papéis de inovador e negociador) e de relações humanas (papéis de mentor e facilitador), neste último caso, como 
forma de gerar um bom clima, empatia, atenção e os incentivos dos professores; e 3) os professores reconhecem mais as características do modelo de sistemas abertos na atividade dos gestores do que os próprios gestores.

Dias e Paiva (2009) recorreram ao modelo de Quinn (1988) para descrever e comparar as competências profissionais e gerenciais de estudantes de enfermagem, antes e depois de cursarem duas disciplinas de gestão em uma instituição de ensino superior privada, em Belo Horizonte-MG. Para tanto, realizou-se uma pesquisa baseada em levantamento documental, observação direta e questionário, o qual foi respondido por 57 alunos. Os autores concluíram que, em geral, as disciplinas de gestão contribuíram para o desenvolvimento de competências gerenciais dos estudantes de enfermagem, já que houve aumento na percepção de domínio dessas competências; que as disciplinas não foram eficazes para ampliar o domínio do papel de mentor, que não revelou variação significante após as disciplinas; que os papéis de coordenador e diretor sofreram apenas pequenas mudanças; o que ensejou sugestões de aprimoramento das práticas pedagógicas da universidade, com relação a esses três papéis. A Tabela 1 retrata as médias gerais de cada papel antes e depois das disciplinas.

Tabela 1 - Médias gerais de cada papel antes e depois das disciplinas gerenciais cursadas por estudantes de enfermagem

\begin{tabular}{lcc}
\hline Papeis & Antes & Depois \\
\hline Monitor & 3,3 & 4,9 \\
\hline Coordenador & 4,0 & 4,8 \\
\hline Diretor & 3,8 & 4,5 \\
\hline Produtor & 3,7 & 4,9 \\
\hline Mentor & 4,7 & 4,9 \\
\hline Facilitador & 3,9 & 5,4 \\
\hline Inovador & 3,6 & 5,4 \\
\hline Negociador & 3,4 & 4,8 \\
\hline Fonte: Dias e Paiva (2009, p. 5)
\end{tabular}

Lopes et al. (2010) analisaram a relação entre aptidões cerebrais - escala de Miranda (1997) - e competências gerenciais - escala de Quinn (1988) - com base numa amostra de 127 gerentes de nível tático-operacional de uma empresa têxtil brasileira de médio porte. Pautandose por uma abordagem descritiva quantitativa, concluiu-se pela aceitação das seguintes hipóteses: a) os gerentes que lidam com processos criativos, cujas competências estão relacionadas ao modelo de sistemas abertos, têm suas aptidões dominantes em nível conceitual; 
b) os gerentes que lidam com processos comunicativos, cujas competências estão relacionadas ao modelo das relações humanas, têm suas aptidões dominantes em nível relacional; c) os gerentes dos setores de Materiais, Planejamento e Controle da Produção, Produção e Segurança no Trabalho, que lidam com processos produtivos ou que requeiram organização/sistematização, cujas competências estão relacionadas ao modelo de processos internos, têm suas aptidões dominantes em nível organizacional; e d) os gerentes do setor Financeiro que lidam com processos analíticos, cujas competências estão relacionadas ao modelo de metas racionais, têm suas aptidões dominantes em nível lógico.

Dias e Paiva (2011) fizeram novo estudo baseado no Modelo de Quinn (1988). Desta vez, visando a analisar as diferenças entre as competências gerenciais, exigidas e reais, dos enfermeiros de um hospital da rede privada em Belo Horizonte-MG, na percepção de quatro enfermeiros e de seis membros da equipe de enfermagem (técnicos de enfermagem e auxiliares de enfermagem). A partir de levantamento documental e entrevistas estruturadas, concluiu-se que há diferenças entre as competências gerenciais exigidas dos enfermeiros e aquelas praticadas, de fato. As análises documental e de conteúdo mostraram que: 1) entre as competências gerenciais exigidas pelo hospital, há predominância das contidas no papel de monitor, seguido dos papéis de produtor e mentor; 2) na esfera real, os enfermeiros deixam a desejar nos papéis de monitor e facilitador, mas se destacam no papel de produtor; 3) curiosamente, esse papel de produtor foi recursivamente citado e criticado por não representar a complexidade das atividades e do exercício da função no hospital; e 4) os profissionais de áreas afins à enfermagem consideraram que os enfermeiros exercem mais o papel de facilitador, dedicando-se, sobretudo, a aspectos assistenciais.

Nóbrega et al. (2012) recorreram a Quinn (1988) para avaliar a percepção dos nutricionistas gestores de Unidades de Alimentação e Nutrição Terceirizadas a respeito de seu domínio quanto a competências gerenciais. A partir de entrevistas e questionário semiestruturado aplicado a doze nutricionistas-gestores, concluiu-se que eles apresentavam, sobretudo, competências relacionadas ao modelo de metas racionais, como o desenvolvimento de um ambiente de trabalho produtivo, e o foco em resultados. Em contrapartida, o estudo revelou déficits em competências voltadas à coordenação das equipes (Figura 4). 


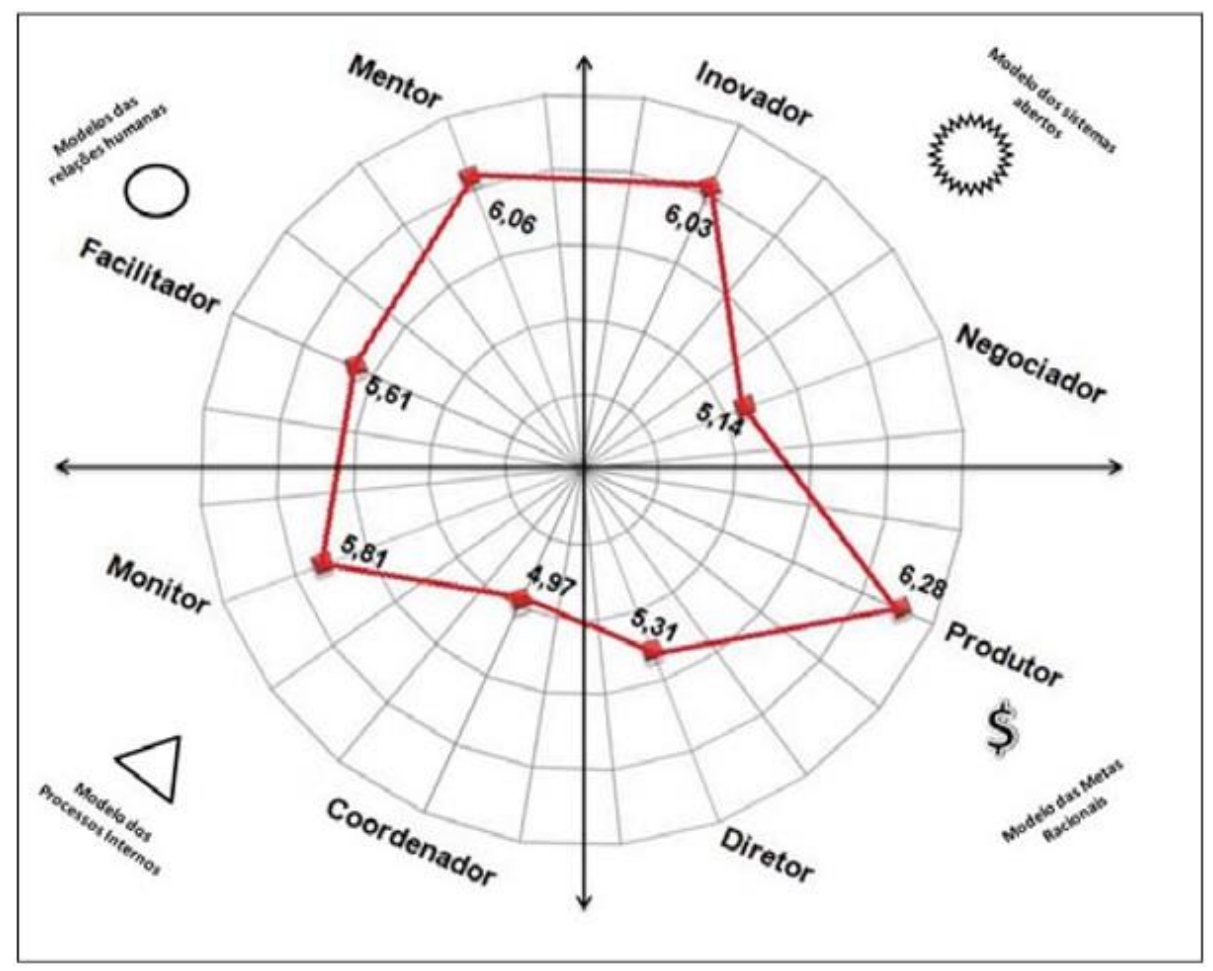

Fonte: Nóbrega et al. (2012, p. 57)

Barros et al. (2013) recorreram ao Modelo de Quinn (1988), buscando identificar as competências gerenciais desenvolvidas por uma amostra de secretários executivos, tendo em vista que esses profissionais possuem grande influência na gestão das organizações, embora não exerçam cargos ditos gerenciais. Com base em levantamento bibliográfico e pesquisa de campo, e com ênfase na abordagem quantitativa, pôde-se concluir que os secretários executivos detém e aplicam competências de gestão, atuando no planejamento, na coordenação, na motivação das pessoas, e nos mecanismos de controle. Com isso, o estudo demonstrou que esses profissionais contribuem para que as organizações tenham um melhor desempenho e atinjam seus objetivos; e que há uma tendência de expansão no rol de competências requerido desses profissionais.

Paiva e Ferreira (2013), a fim de descrever as configurações das competências gerenciais de líderes da área de tecnologia de informação em organizações situadas no Triângulo Mineiro, também recorreram à classificação de Quinn (1988). Mediante pesquisa descritiva e com abordagem quantitativa, adaptou-se a escala de Vilkinas (2000) e foram aplicados questionários a 27 gestores de TI. Como resultado, apurou-se que os respondentes consideravam ter desempenho gerencial real superior ao exigido pelas empresas onde trabalhavam; que o papel de produtor foi percebido como o de maior domínio, como era 
esperado pelos autores, devido a características de profissões da área de TI; que o papel de monitor foi percebido como o de menor domínio, o que surpreendeu os autores, uma vez que se esperava que a área-meio da organização estivesse mais focada no ambiente interno e na integração interáreas (Figura 5).

Figura 5 - Competências exigidas e reais de líderes da área de tecnologia de informação

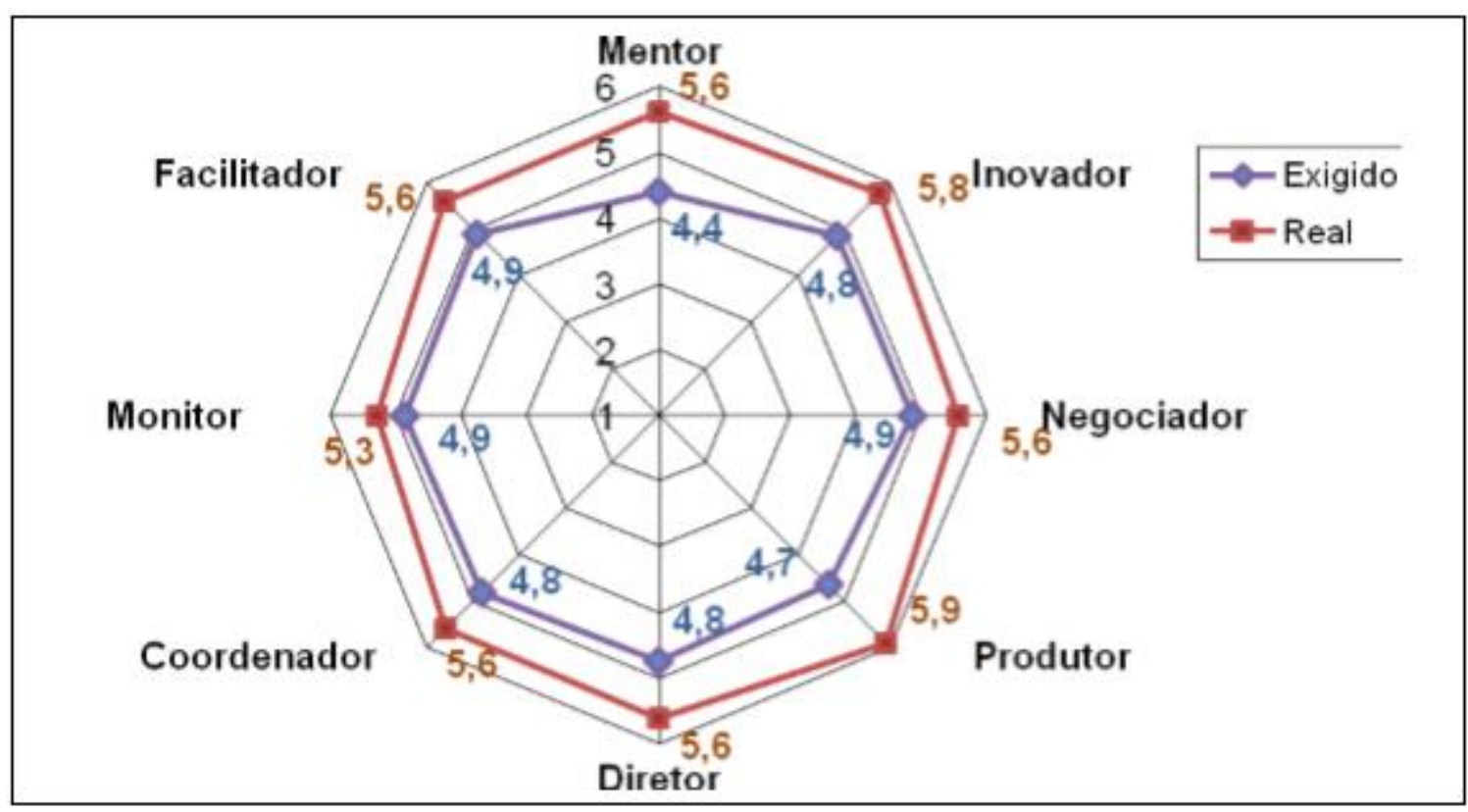

Fonte: Paiva e Ferreira (2013, p. 223)

Pinto et al. (2014) estudaram competências gerenciais numa rede de comércio varejista, com base nos papéis gerenciais idealizados por Quinn (1988). As autoras identificaram as competências gerenciais mais importantes na percepção dos próprios gerentes de uma organização de varejo, atuante nos três estados da região Sul do Brasil. Mediante pesquisa descritiva, baseada na aplicação de questionários a 35 gestores, concluiu-se que planejamento do trabalho; estabelecimento de metas e objetivos; e planejamento e organização são as competências gerenciais de nível mais elevado, enquanto que o desenvolvimento e comunicação de uma visão; a Administração da informação por meio de um pensamento crítico; e o monitoramento do desempenho individual e coletivo são as competências gerenciais mais deficitárias (Figura 6). 
Figura 6 - Grau médio de percepção de competências gerenciais no comércio varejista

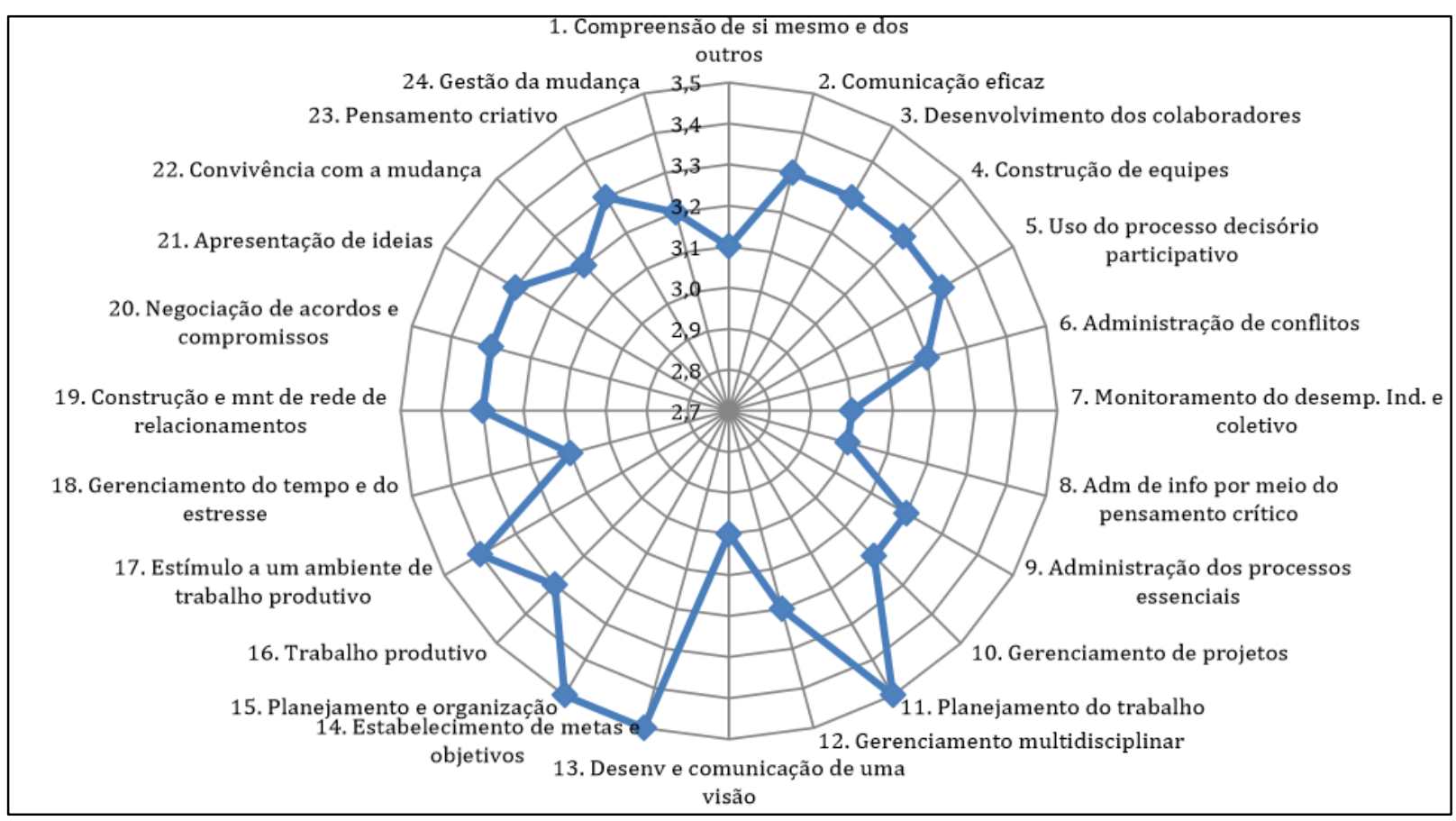

Fonte: Pinto et al (2014, p. 35)

Paiva, Santos e Lacerda (2014) com vistas a analisar competências gerenciais e sua gestão no setor hoteleiro, recorreu ao Modelo de Quinn (1988) em uma pesquisa descritiva, de campo e de abordagem mista. Mediante a mesma escala usada por Paiva e Ferreira (2013), adaptada de Vilkinas (2000), foram consultados 28 gestores hoteleiros de três estados brasileiros (Minas Gerais, São Paulo, Rio de Janeiro). Como resultado, apurou-se que: 1) na pesquisa quantitativa, os papéis que prevaleceram no âmbito ideal foram mentor, produtor e coordenador; já na qualitativa, foram mentor, coordenador, facilitador e inovador; 2) competências ideais (exigidas) de maior destaque foram compreender a si mesmo e aos outros, comunicar-se eficazmente, contribuir no desenvolvimento dos empregados, gerenciar projetos, planejar o trabalho e gerenciar de modo multidisciplinar; 3) na pesquisa quantitativa, as competências reais mais aplicadas no dia-a-dia do gestor hoteleiro estavam contidas nos papéis de mentor e produtor, enquanto que, na qualitativa, foram destacados os de mentor, coordenador, produtor e facilitador; 4) as competências efetivas estavam muito próximas das ideais, sobretudo, quanto ao papel de coordenador (Figura 7). 
Figura 7 - Competências ideais e reais de gestores do setor hoteleiro

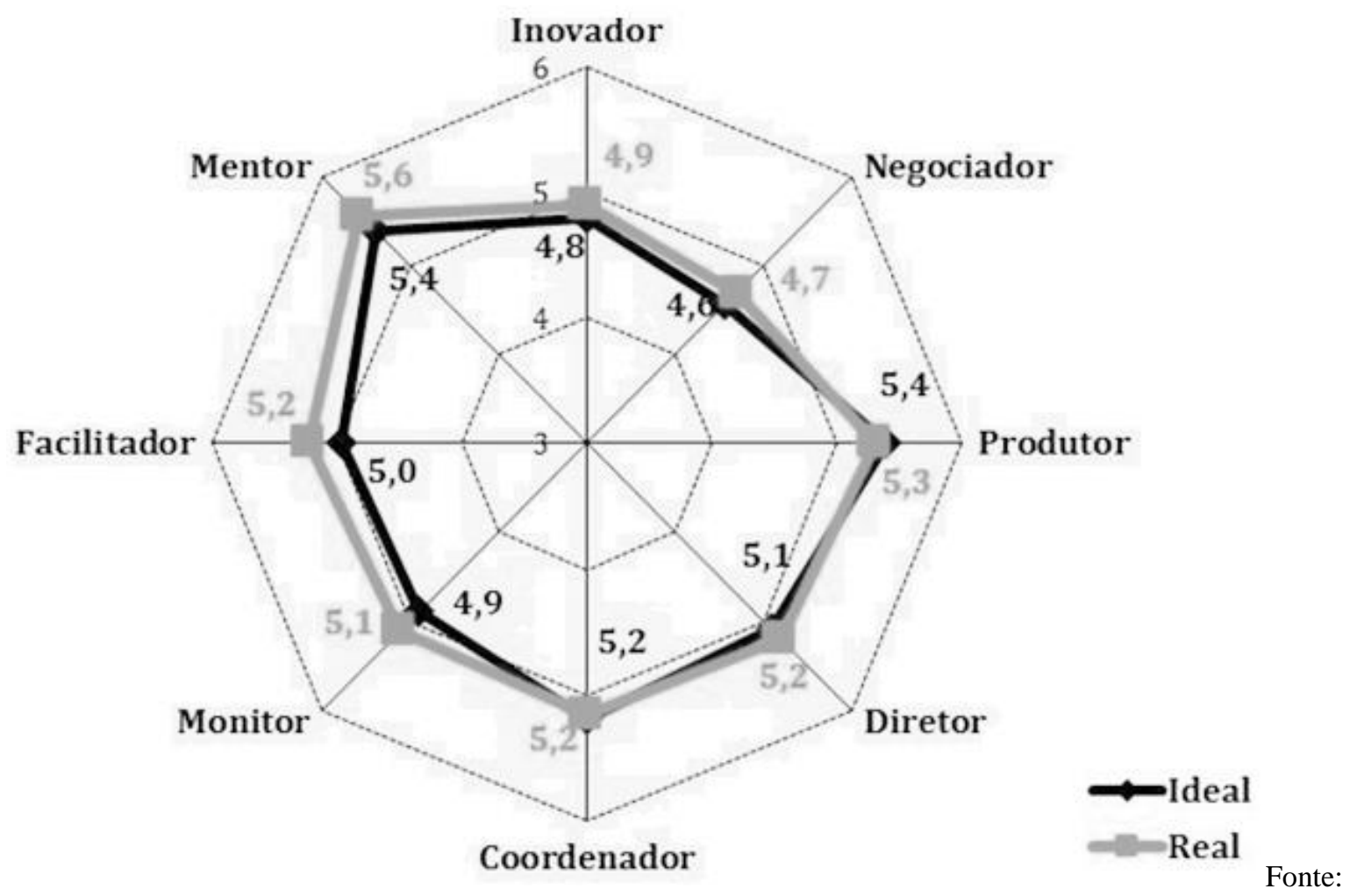

Paiva, Santos e Lacerda (2014, p. 88)

E o estudo de Seabra, Paiva e Luz (2015), que analisou como são vivenciadas as competências gerenciais, ideais e reais, de coordenadores de cursos de graduação em Enfermagem na cidade de Belo Horizonte, Minais Gerais. Com base no Modelo de Quinn (1988), as autoras analisaram os oito papéis gerenciais (diretor, produtor, monitor, coordenador, mentor, facilitador, inovador e negociador) e elaboraram uma pesquisa descritiva e qualitativa, baseada em 14 entrevistas semiestruturadas, seguidas de análise de conteúdo. Como resultado, apurou-se que os referidos coordenadores experimentam destacadamente os papéis de mentor, diretor e facilitador.

Por fim, é possível concluir que os estudos que recorreram ao Modelo de Quinn (1988) parecem perseguir pelo menos um dos três propósitos essenciais, a saber:

1) a identificação de domínio ou de lacunas de competências gerenciais por parte de gerentes ou de outros profissionais cujas atribuições requeiram atividade de gestão;

2) a verificação de compatibilidade entre as competências gerenciais apresentadas e as, de fato, necessárias ao contexto, ou ainda, as requeridas por autoridades ou executivos de hierarquia superior (real x desejado); e

3) o desenvolvimento de um questionário-padrão capaz de identificar o domínio de competências gerenciais independentemente do contexto estudado. 
Com relação a esse último propósito (terceiro), julga-se um equívoco desconsiderar o contexto como elemento constitutivo da definição de competência. Embora se saiba que algumas competências gerenciais possam ser genéricas ou transversais, a adequação ao contexto pesquisado é fundamental, uma vez que interfere veementemente na redação e na clareza dos itens de uma escala. Assim, em que pese o Modelo de Quinn (1988) ser considerado robusto, explicitando as mais diversas competências gerenciais, e possuir uma escala validada, desenvolvida por Denison, Hooijberg e Quinn (1995) e aplicada por diversos pesquisadores, como Vilkinas (2000), Paiva e Ferreira (2013) e Paiva, Santos e Lacerda (2014), não se fará uso de seus itens diretamente, já que não estão ajustados ao contexto de grupos de pesquisa.

Nesta dissertação, optou-se por tomar o Modelo de Quinn (1988) como base inicial, mas também agregar elementos de outros estudos sobre competências em contextos diversos, bem como somar elementos-chave oriundos de pesquisas qualitativas de campo, para a confecção de uma escala mais aderente ao contexto de grupos de pesquisa.

Para tanto, apresentam-se, a seguir, outros 34 outros estudos e classificações de competências gerenciais que merecem destaque: Félix (2005); Moura e Bitencourt (2006); Godoy e Forte (2007); Santos, Caetano e Jesuíno (2008); Moraes e Corrêa (2008); Jansen, Vera e Crossan (2009); Cardoso (2009); Brandão et al. (2010); Noro e Abbade (2010); Teixeira, Silva e Lima (2011); Ésther (2011); Pelissari, Gonzalez e Vanelle (2011); Fleck e Pereira (2011); Mithas, Ramasubbu e Sambamurthy (2011); Bündchen, Rossetto e Silva (2011); Brandão, Borges-Andrade e Guimarães (2012); Godoy e D'amelio (2012); Baisch et al. (2012); Galvão, Silva e Silva (2012); Brito e Leone (2012); Brito, Paiva e Leone (2012); Sousa e Valadão Jr. (2013); Paula et al. (2013); Ferigotti e Fernandes (2014); Almeida e Muniz Jr. (2014); Cardoso (2014); Irmão e Barbalho (2014); Mello e Melo (2014); Regio et al. (2014); Santos e Honório (2014); Silva, Gil e Okabayashi (2014); Tosta e Dalmau (2014); Nascimento e Alves (2015); e Peixoto e Souza (2015).

Félix (2005), em pesquisa realizada numa prefeitura, para avaliar o Programa de Desenvolvimento Gerencial conduzido no período de 1997 a 2001, verificou o impacto do referido programa na aquisição de conhecimentos e na prática de competências requeridas para o uso do modelo de gestão adotado na cidade. Nesse contexto, identificou cinco grupos de competências gerenciais: competências inerentes à gestão estratégica; à gestão compartilhada; à gestão descentralizada; à gestão intersetorial; e à gestão voltada para resultados.

Moura e Bitencourt (2006) se propuseram a analisar as articulações entre as estratégias e o desenvolvimento de competências gerenciais, verificando como ocorre a aprendizagem 
organizacional. O método utilizado foi estudo de caso único, de caráter exploratório, de uma empresa de serviços, em que, mapeadas as estratégias adotadas pela empresa, foram três as categorias estabelecidas para classificar as competências gerenciais: competências gerenciais relacionadas ao foco no produto; competências gerenciais relacionadas ao foco no cliente; e competências gerenciais relacionadas ao foco no negócio.

Godoy e Forte (2007), a partir do modelo idealizado por Cheetham e Chivers (1996), realizaram um estudo em que se pretendia identificar e analisar as opiniões de alunos em relação às competências adquiridas no curso de graduação em Administração de Empresas de uma universidade privada. A análise dos resultados obtidos possibilitou afirmar que, para os alunos pesquisados, as competências adquiridas estão organizadas em quatro construtos: competência social, competência para solução de problemas, competência técnico-profissional e competências básicas (estas últimas consideradas fundamentos para as demais).

Santos, Caetano e Jesuíno (2008), visando testar a relevância de um modelo teórico de liderança funcional, verificaram a relação de um conjunto de competências de liderança com a eficácia das equipes lideradas. Para esses autores, a gama de competências gerenciais pode ser categorizada nos seguintes aspectos: clarificar a situação; clarificar a estratégia; coordenação; e facilitação da aprendizagem.

Moraes e Corrêa (2008), no âmbito de uma pesquisa que contou com entrevistas semiestruturadas associadas à técnica de desenho projetivo, aplicadas em equipes de uma empresa de tecnologia da informação, objetivavam identificar as competências comunicativas dos gestores que mobilizam as equipes no sentido de gerar resultados para a organização. Com esse propósito, destacaram as seguintes categorias de competências gerenciais: planejar e organizar o que disse e como disse; conhecer o público com o qual fala; conhecer as técnicas de expressão verbal e oratória; saber ouvir, dar e receber feedback com propriedade, cortesia e respeito, mesmo quando for predominantemente crítico; preocupar-se em manter a equipe atualizada sobre acontecimentos, rotinas e mudanças; buscar aproximação com as pessoas; e ser receptivo aos contatos.

Jansen, Vera e Crossan (2009) classificaram as competências gerenciais a partir de sua atuação mais propensa a riscos e a inovações radicais ou da atuação mais avessa a riscos e adepta a pequenas adaptações e melhorias incrementais. Quando a ênfase se dava na melhoria da eficiência, a competência do líder se aproximou mais de repertórios comportamentais que promoviam consistência, estabilidade e controle. Diferentemente, quando havia foco predominante em inovações radicais, o gerente tendeu a agir por meio do incentivo à paixão, à 
assunção de riscos e à criatividade e a estabelecer estruturas de rede que delineassem os direitos e responsabilidades dos membros que ocupavam a posição de centralidade na criação e partilha do conhecimento.

Cardoso (2009) procurou compreender como os gestores avaliavam as suas competências em dois diferentes cenários: estabilidade e mudança organizacional. A pesquisa se deu com gestores pertencentes a diversas áreas de uma empresa multinacional de origem alemã, com sede no Brasil, atuante na área de telecomunicações. Nesse estudo, identificaramse as seguintes categorias de competências gerenciais: liderança; planejamento e organização; persuasão e organização; criatividade e inovação; trabalho em equipe; autodesenvolvimento e aprendizagem; carreira; tomada de decisão e solução de problemas; personalidade; determinação e motivação.

Brandão et al. (2010) propuseram uma escala para avaliar competências gerenciais. Buscou-se identificar quais as competências relevantes ao desempenho de gestores de um banco, bem como verificar em que medida esses gestores expressavam essas competências no trabalho. Como resultado, foram identificadas competências relacionadas a: a) estratégias e operações; b) resultado econômico; c) clientes; d) comportamento organizacional; d) processos internos; e e) sociedade.

Noro e Abbade (2010) executaram estudo em uma empresa distribuidora de energia com o objetivo de verificar se havia alinhamento entre os tipos de projetos e competências possuídas por seus gerentes de projeto, e como essa relação agregava valor à organização. A pesquisa rendeu a seguinte categorização de competências de gestores de projeto: liderança; liderança situacional; iniciativa; criatividade; visão sistêmica; habilidades técnicas; orientação para o mercado; pensamento crítico e analítico; gerenciamento de mudanças; gestão de conflitos; negociação; percepção e intuição; e habilidade de colaboração.

Teixeira, Silva e Lima (2011) identificaram as competências que gerentes prisionais demonstraram diante de um novo modelo de gestão pública adotado em um ente público. Conhecimentos sobre o sistema; habilidades estratégicas; habilidades técnicas/gerenciais; postura ética; habilidade de liderança; habilidade de inovação; participação na mudança; percepção das mudanças; e foco nos resultados foram as competências mapeadas nesse estudo.

Ésther (2011) visando analisar as competências atribuídas aos reitores de universidades federais, com a expectativa de contribuir para maior compreensão de sua atuação, entrevistou reitores, vice-reitores e pró-reitores de oito universidades federais. Nesse estudo, as competências gerenciais identificadas foram liderança política (representação); flexibilidade; 
diálogo (comunicação); trabalho em equipe; conhecimento da instituição; habilidade política (negociação); liderança acadêmica (legitimidade decorrente da notória especialização em sua área de atuação); competência acadêmica; captação de oportunidades gerenciais; liderança gerencial; visão de futuro; discernimento entre prioridades e rotinas; firmeza de propósitos; lidar com conflitos; saber decidir; cooperação; habilidade política (articulação); tolerância; ética; ousadia; paciência; ponderação; e confiabilidade.

Pelissari, Gonzalez e Vanelle (2011) analisaram as competências gerenciais consideradas essenciais na visão dos gestores de pequenas empresas de confecções. Dos resultados, surgiu a seguinte classificação: competências técnicas (domínio técnico dos processos; capacidade de identificar e solucionar problemas; orientação para custos e resultados; capacidade de inovar tecnologicamente); competências humanas (capacidade de liderar e participar de equipes para atingimento das metas; prática da competência social, comunicação; capacidade de motivar e envolver a equipe; abertura para adaptar-se às mudanças); competências conceituais (visão do negócio em sua totalidade; capacidade de interrelacionar a realidade externa com a condução do negócio; capacidade de entender conceitos e transferi-los para a realidade do negócio; capacidade de integrar as áreas da organização para contribuir no negócio como um todo); e competências gerais (negociação, mobilização para a mudança; sensibilidade cultural e trabalho em times; habilidades gerenciais para manejar os recursos materiais e humanos disponíveis; atitudes adequadas; ética responsável e humana para com o grupo com o qual atua; aprendizagem experiencial; compreensão do negócio e de seus objetivos na relação com o mercado; como lidar com os clientes e competidores, assim como, com o ambiente político e social).

Fleck e Pereira (2011), ao verificarem o perfil de competências gerenciais dos coordenadores dos Programas de pós-Graduação de universidades públicas, recorreram ao modelo teórico de Gary Yukl, publicado em 1998, que divide o perfil de competências gerenciais entre administrar o trabalho (planejar; solucionar problemas; esclarecer papéis e objetivos; informar; e monitorar informações) e administrar relações (apoiar; desenvolver; reconhecer; recompensar; e administrar conflitos).

Mithas, Ramasubbu e Sambamurthy (2011) ao estudarem como recursos de tecnologia da informação contribuem para desempenho organizacional, desenvolveram uma classificação de competências dos gerentes em três capacidades: gestão de clientes; gestão de processos; e gestão de desempenho. Os resultados do estudo apontaram que essas três capacidades são desenvolvidas quando associadas à capacidade de gestão da informação. Por isso, segundo esses 
autores, os líderes devem se concentrar em ferramentas de apuração das informações, além de primar pela infraestrutura em tecnologia da informação, com o fito de melhorarem o desempenho organizacional.

Bündchen, Rossetto e Silva (2011) identificaram as competências gerenciais mais importantes para atuação nas agências do Banco do Brasil, com base numa pesquisa descritiva e exploratória, aplicada a 248 gerentes. Qualitativamente, foi apontado um conjunto de 27 competências gerenciais divididas em três blocos: sociais, técnicas e de negócio (Tabela 2). Quantitativamente, auferiu-se o grau de importância e de encorajamento (formação/desenvolvimento) delas na percepção dos próprios gestores. Constatou-se ainda que o banco encoraja e desenvolve competências gerenciais em nível inferior à sua importância e que as competências gerenciais sociais são consideradas mais importantes que as técnicoprofissionais e as de negócios, na opinião dos gerentes.

Tabela 2 - Competências gerenciais para a atuação dos gerentes de agência Indicadores de competências em três perspectivas distintas

\begin{tabular}{|c|c|}
\hline Competências Sociais & $\begin{array}{l}\text { 1- Suportar pressões e adaptar-se a situações e contextos variados; } \\
\text { 2- Investir no fortalecimento da equipe; } \\
\text { 3- Tornar claros para a equipe os objetivos a serem atingidos; } \\
\text { 4- Adaptar a linguagem à situação e ao ouvinte; } \\
\text { 5- Ouvir os interlocutores com atenção; } \\
\text { 6- Manter as pessoas informadas sobre planos e processos; } \\
\text { 7- Comunicar-se de modo a gerar entusiasmo; } \\
\text { 8- Apresentar-se positivamente (estado de espírito); } \\
\text { 9- Desenvolver relacionamentos com clientes e colegas. }\end{array}$ \\
\hline $\begin{array}{c}\text { Competências Técnico- } \\
\text { profissionais }\end{array}$ & $\begin{array}{l}\text { 10- Utilizar técnicas de planejamento estratégico; } \\
\text { 11- Monitorar a qualidade e o andamento dos serviços; } \\
\text { 12- Conhecer técnicas de negociação; } \\
\text { 13- Gerenciar conflitos; } \\
\text { 14- Fazer escolhas a partir de recursos escassos; } \\
\text { 15- Delegar atividades de trabalho; } \\
\text { 16- Conhecer os produtos e serviços do Banco do Brasil; } \\
\text { 17- Acionar pessoalmente rotinas e processos organizacionais; } \\
\text { 18- Utilizar método para conduzir reuniões de trabalho. }\end{array}$ \\
\hline Competência de Negócios & $\begin{array}{l}\text { 19- Compreender como a Agência interage com os clientes; } \\
\text { 20- Manter-se atento às oportunidades negociais; } \\
\text { 21- Focalizar a atenção nos resultados financeiros; } \\
\text { 22- Desenvolver uma rede de informações estratégicas; } \\
\text { 23- Procurar informações em várias fontes; } \\
\text { 24- Orientar as ações pelas necessidades dos clientes; } \\
\text { 25- Estabelecer parcerias com os clientes; } \\
\text { 26- Integrar-se e participar dos eventos na comunidade (cidade); } \\
\text { 27- Pesquisar sobre os costumes e tradições que afetam a comunidade e os } \\
\text { clientes. }\end{array}$ \\
\hline
\end{tabular}

Fonte: Bündchen, Rossetto e Silva (2011, p. 408) 
Brandão, Borges-Andrade e Guimarães (2012) se propuseram a verificar a existência de relações preditivas entre as competências expressas por gerentes de agências bancárias e a percepção deles sobre o suporte organizacional, o número de horas dedicadas por eles a treinamentos e o desempenho das agências em que atuavam. A pesquisa valeu-se de questionários estruturados para coleta de dados primários, sendo a amostra constituída por 186 gerentes de agências e 77 superintendentes regionais de um banco público. A pesquisa demonstrou que as competências dos gerentes se subdividiam em gestão financeira de negócios; gestão estratégica; gestão socioambiental; relacionamento com o cliente; gestão de processos; e gestão de pessoas.

Godoy e D'amelio (2012), com base em Cheetham e Chivers (2005), buscaram identificar quais competências são desenvolvidas e utilizadas por gestores de origens profissionais distintas (engenharia, psicologia e administração de empresas) em uma empresa do setor de saneamento ambiental. Por meio de uma pesquisa qualitativa, concluíram que as competências gerenciais perpassam: conhecimentos (serviço da unidade; visão sistêmica do negócio; e competências globais); competências comportamentais/pessoais (gestão de pessoas; relacionamentos com parceiros, superiores e fornecedores; características pessoais); e competências funcionais (orientação/gestão de/para cliente, resultados, processos, projetos; tomada de decisão; e mudança/inovação). Ademais, vale destacar os aspectos similares e específicos de cada formação apontados por essas autoras (Quadro 10).

Quadro 10 - Semelhanças e Peculiaridades nas Competências Gerenciais de diferentes profissões

\begin{tabular}{|c|c|}
\hline $\begin{array}{l}\text { Aspectos } \\
\text { semelhantes entre as } \\
\text { três profissões }\end{array}$ & $\begin{array}{l}\text { - valorização do domínio de conhecimento técnico da unidade gerenciada; } \\
\text { - } \quad \text { visão estratégica desenvolvida durante a carreira; } \\
\text { - } \text { orientação para clientes e resultados; } \\
\text { - } \text { consciência da importância e da complexidade da gestão de pessoas; } \\
\text { - ética e valores como direcionadores das condutas; } \\
\text { - } \text { reflexão como facilitadora do desenvolvimento gerencial; } \\
\text { - consciência do valor do autodesenvolvimento e da responsabilidade em relação à } \\
\text { própria carreira. }\end{array}$ \\
\hline $\begin{array}{l}\text { Peculiaridades dos } \\
\text { Engenheiros }\end{array}$ & $\begin{array}{l}\text { - visão sistêmica desenvolvida após tornarem-se gerentes; } \\
\text { - valorizam conhecimentos específicos de engenharia; } \\
\text { - habilidade de comunicação não foi mencionada. }\end{array}$ \\
\hline $\begin{array}{l}\text { Peculiaridade dos } \\
\text { Administradores }\end{array}$ & - enfatizam \\
\hline
\end{tabular}


Continuação

\begin{tabular}{|l|ll|}
\hline Peculiaridades dos & $\begin{array}{l}\bullet \\
\text { Psicólogos }\end{array}$ & $\begin{array}{l}\text { empenham-se na gestão de resultados de acordo com as exigências dos processos } \\
\text { •rganizacionais; }\end{array}$ \\
& $\begin{array}{l}\text { - } \\
\text { develam-se mais hábeis na seleção, treinamento e avaliação de pessoas; }\end{array}$ \\
\hline
\end{tabular}

Fonte: elaborado pelo autor com base em Godoy e D'amelio (2012)

Baisch et al. (2012), por meio de um estudo de caso em uma indústria que utiliza o planejamento estratégico em suas atividades, tinha o propósito de identificar as competências gerenciais do gerente de marketing. Suas competências agrupavam-se em conhecimentos (marketing e comunicação; gestão de pessoas; planejamento estratégico; gestão estratégica; técnicas de negociação; administração de empresas; técnicas de liderança; técnicas de negociação; economia; legislação tributária; e sistemas de informação); habilidades (visão sistêmica; persuasão; incentivo e proatividade; flexibilidade; língua estrangeira; gestão de conflitos; trabalhar sob pressão; finanças; negociação; tomada de decisão; liderança; implementação de novas ideias; relacionamento interpessoal; finanças); e atitudes (senso de responsabilidade; autocontrole; flexibilidade; paciência; comunicação; trabalhar em equipe; organização; dinamismo; noção de prioridades; e análise).

Galvão, Silva e Silva (2012) buscavam identificar a influência da educação formal, da experiência profissional e da experiência social no desenvolvimento das competências gerenciais de diretores de 58 escolas públicas. Nesse contexto identificou-se o seguinte conjunto de competências gerenciais de diretores escolares: competência técnica (coordenar a ação pedagógica; administrar recursos materiais e financeiros; aprender a aprender; planejar e implementar mudanças); competência social (articular parcerias; promover a integração família-escola); e competência comportamental (assumir riscos; gerenciar relações conflituosas; promover a colaboração; e disciplinar a equipe).

Brito e Leone (2012) identificaram o perfil de competência de gestoras de empresas familiares. Baseando-se em estudos sobre mulheres no comando de empresas familiares e gestão da competência, essas autoras estudaram empresas brasileiras familiares sediadas em Natal-RN, e concluíram que o perfil das gestoras valoriza a capacitação profissional e gerencial; o desenvolvimento pessoal; a ética (respeito ao outro; honestidade; justiça e coerência entre discurso e prática); e a busca por conhecimento técnico específico do setor de atuação. Dentre as maiores dificuldades enfrentadas pelas gestoras, destacam-se o desafio de criticar e de sintetizar dados e informações sobre processos e pessoas para tomada de decisões. Essas autoras 
prepararam um esquema que sintetiza objetivos da pesquisa, variáveis e indicadores utilizados, o qual está apresentado na Tabela 3.

Tabela 3 - Esquema geral da pesquisa Brito e Leone (2012)

\begin{tabular}{|c|c|c|}
\hline Obejtivos & Variáveis & Indicadores \\
\hline \multirow{3}{*}{$\begin{array}{l}\text { Identificar o Perfil de Competência } \\
\text { percebido pelas mulheres } \\
\text { proprietárias, dirigentes, empresárias } \\
\text { e/ou herdeiras de empresas } \\
\text { familiares. }\end{array}$} & $\begin{array}{l}\text { Nível de } \\
\text { importância do } \\
\text { Indicador } \\
\text { Cognitivo } \\
\text { Conhecimentos }\end{array}$ & $\begin{array}{l}\text { Área/Setor de atuação da empresa familiar (Política, } \\
\text { sistema, mercado); Administração/Finanças; } \\
\text { Planejamento Estratégico e Operacional; Gestão de } \\
\text { pessoas; Técnico Específico; Informática; Processo } \\
\text { de Tomada de Decisão; Gestão de Qualidade; } \\
\text { Psicologia Organizacional; Produto/Mercado de } \\
\text { atuação da Empresa/Instituição. }\end{array}$ \\
\hline & $\begin{array}{l}\text { Nível de } \\
\text { importância do } \\
\text { Indicador } \\
\text { Comportamental } \\
\text { Habilidades }\end{array}$ & $\begin{array}{l}\text { Planejamento; Organização; Liderança; Decisão; } \\
\text { Comunicação/saber ouvir; Análise e Síntese; } \\
\text { Trabalho em Equipe; Criatividade/Inovação; } \\
\text { Execução; Inspiração e Motivação da Equipe; } \\
\text { Administração de Conflito e Negociação; Relações } \\
\text { Interpessoais. }\end{array}$ \\
\hline & $\begin{array}{l}\text { Nível de } \\
\text { importância do } \\
\text { Indicador } \\
\text { Comportamental } \\
\text { Atitudes }\end{array}$ & $\begin{array}{l}\text { Ético; Autoconfiante; Determinado; Flexível; } \\
\text { Responsável; Servidor/Cuidadoso; Comprometido. }\end{array}$ \\
\hline $\begin{array}{l}\text { Caracterizar as gestoras de empresas } \\
\text { familiares de acordo com os papeis } \\
\text { desempenhados e perfil } \\
\text { socioeconômico. }\end{array}$ & $\begin{array}{l}\text { Perfil } \\
\text { socioeconômico }\end{array}$ & $\begin{array}{l}\text { Nível de escolaridade; Área de formação acadêmica; } \\
\text { Formação em nível de pós-graduação; Idade; Estado } \\
\text { Civil; número de filhos; }\end{array}$ \\
\hline
\end{tabular}

Fonte: Brito e Leone (2012, p.56)

Brito, Paiva e Leone (2012) mapearam o perfil de competências gerenciais no Ensino Superior Tecnológico, considerando preceitos teóricos da gestão do conhecimento e da aprendizagem organizacional, como complementares à literatura sobre competências gerenciais. A pesquisa censitária, descritiva e qualitativa teve como universo as instituições de ensino superior (IES) públicas e privadas que ofertam cursos superiores de tecnologia numa cidade do Nordeste do Brasil. Por meio de um questionário, pôde-se concluir que, nesse ramo, o planejamento é a habilidade gerencial mais importante, enquanto a ética é o indicador comportamental (atitude), de maior relevo. Concluiu também o estudo que as IES não dispõem de programas de desenvolvimento gerencial, sendo o aprimoramento gerencial uma iniciativa aleatória e autônoma, oriunda dos próprios gestores.

Sousa e Valadão Jr. (2013), aspirando identificar e analisar as competências gerenciais contempladas em ementas de disciplinas dos cursos superiores de Administração que, direta ou indiretamente, contribuem para o desenvolvimento de competências relevantes ao gestor que pretende assumir designações internacionais, mapearam as seguintes competências: 
administrador de conflito; agilidade; capacidade de decisão; capacidade de delegação; capacidade de liderança; capacidade de negociação; coordenação de trabalho em equipe; desenvolvedor de pessoas; dimensionamento do tempo; foco no resultado; habilidade interpessoal; integração das diversas áreas funcionais; "resolvedor" de problemas; capacidade para tratar com culturas diversas; capacidade de correlação de fatos com repercussões para a empresa; antecipação de ameaças e oportunidades; e visão estratégica.

Paula et al. (2013) mapearam o processo de trabalho de enfermeiros atuantes no programa de saúde da família, visando a identificar competências necessárias para o desenvolvimento de atividades gerenciais. Por meio de observação não-participante, durante 160 horas de trabalho de quatro enfermeiros, apurou-se que o processo de trabalho desses profissionais contempla atividades de assistência à saúde (42\% do tempo), gerenciais (33\%), educativas (20\%), e de participação política (2,5\%). Quanto às competências gerenciais, merecem destaque comunicação, liderança, tomada de decisão e educação permanente (competência relacionada à articulação de diversos saberes, segundo as autoras). Ademais, pôde-se concluir que as competências gerenciais estão relacionadas entre si e que os enfermeiros as aplicam também em conjunto com as funções administrativas: planejamento, coordenação, direção e controle.

Ferigotti e Fernandes (2014) examinaram as relações entre competências individuais de líderes e membros de projeto, rotinas/processos organizacionais e inovação tecnológica, por meio de um estudo de caso numa indústria de eletrodomésticos no período de 1999 a 2011 . Ao todo, 30 projetos e seus resultados foram considerados. Esses autores, recorreram aos ensinamentos de Mohrman e Worley (2009) - a respeito da capacidade de sobrevivência e prosperidade nas organizações - e classificaram as competências gerenciais dos líderes da empresa estudada em três segmentos: competência para alocar recursos, gerenciar equipe e contribuir para a estratégia. Destaque-se que as funções gerenciais se diferenciavam, a depender do nível de atuação, conforme mostra o Quadro 11. 
Quadro 11 - Matriz de Competências Gerenciais no estudo de Ferigotti e Fernandes (2014)

\begin{tabular}{|c|c|c|c|}
\hline \multirow{2}{*}{$\begin{array}{c}\text { Níveis de } \\
\text { complexidade } \\
\text { das atividades }\end{array}$} & \multicolumn{3}{|c|}{ Atividades em grupos de projeto } \\
\hline & Função Alocação de recursos & Função Gestão de equipe & $\begin{array}{c}\text { Função Contribuição à } \\
\text { estratégia }\end{array}$ \\
\hline Nível (4) & 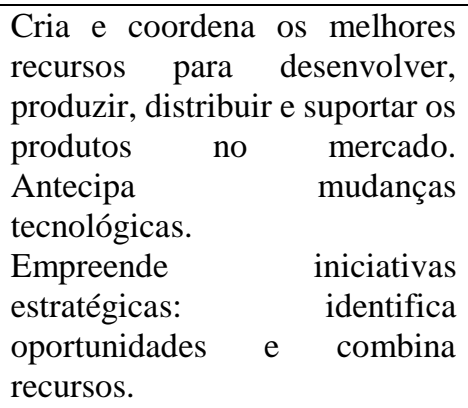 & 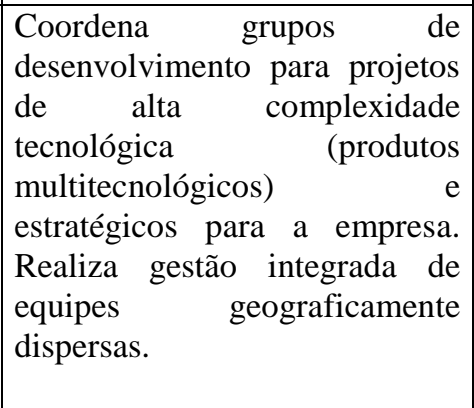 & $\begin{array}{l}\text { Realiza o redesign do modelo de } \\
\text { negócios (processo de } \\
\text { realinhamento de ativos). } \\
\text { Constrói competências centrais } \\
\text { para vantagem distintiva; realiza } \\
\text { upgrade em tecnologias ainda } \\
\text { não desenvolvidas. } \\
\text { Molda a evolução da indústria, } \\
\text { incluindo desings dominantes. }\end{array}$ \\
\hline Nível (3) & $\begin{array}{l}\text { Acessa um conjunto de recursos } \\
\text { específicos para gerenciar } \\
\text { ameaças. } \\
\text { Coordena esses recursos com } \\
\text { níveis de gestão financeira para } \\
\text { acelerar a criação de produtos e } \\
\text { a realização de processos. }\end{array}$ & $\begin{array}{l}\text { Participa em diferentes números } \\
\text { de projetos simultaneamente, } \\
\text { interagindo entre e intragrupos } \\
\text { funcionais e especializados e } \\
\text { projetos de média a alta } \\
\text { complexidade tecnológica. } \\
\text { Integra e coordena diferentes } \\
\text { tipos de especialidades (gestores } \\
\text { com mestrado e especialização, } \\
\text { com domínio de várias línguas, } \\
\text { etc.). Estimula a aprendizagem } \\
\text { do time de trabalho. }\end{array}$ & $\begin{array}{l}\text { Desenvolve estratégias } \\
\text { tecnológicas com base em } \\
\text { conhecimento muito } \\
\text { especializado (qualificações em } \\
\text { TI). Cria rotinas específicas para } \\
\text { mudança. } \\
\text { Realiza alianças, parcerias e join- } \\
\text { ventures intra e interorganização. } \\
\text { Gerencia sistema de propriedade } \\
\text { intelectual. }\end{array}$ \\
\hline Nível (2) & $\begin{array}{l}\text { Acessa um conjunto de recursos } \\
\text { específicos para criar a realizar } \\
\text { produtos e a produção. } \\
\text { Usa e desenvolve tecnologias } \\
\text { (softwares para gerenciamento, } \\
\text { familiaridade com pesquisas e } \\
\text { métodos, interação com o } \\
\text { usuário, consumer experience, } \\
\text { perspectivas tecnológicas). }\end{array}$ & $\begin{array}{l}\text { Participa em diferentes números } \\
\text { de projetos simultaneamente, } \\
\text { interagindo entre intragrupos } \\
\text { funcionais e especializados e } \\
\text { projetos de baixa a média } \\
\text { complexidade tecnológica. }\end{array}$ & $\begin{array}{l}\text { Gerencia problemas de projeto } \\
\text { por meio de combinação, } \\
\text { recombinação e reconfiguração } \\
\text { de recursos existentes. } \\
\text { Explora e avalia um conjunto de } \\
\text { opções tecnológicas, com base } \\
\text { em comparação. } \\
\text { Monitora eventos tecnológicos } \\
\text { (compara as competências atuais } \\
\text { com a necessidade de } \\
\text { desenvolver ou adquirir novas). }\end{array}$ \\
\hline Nível (1) & $\begin{array}{l}\text { Acessa um conjunto de recursos } \\
\text { para antecipar-se a problemas } \\
\text { operacionais (custos, qualidade, } \\
\text { prazos). Usa tecnologias para } \\
\text { design (para modelagem e } \\
\text { prototipia rápida), produção } \\
\text { (ferramentas de simulação e } \\
\text { para modelagem) e coordenação } \\
\text { do processo de inovação } \\
\text { (utilização de tecnologias de } \\
\text { coordenação, como ERPs). }\end{array}$ & $\begin{array}{l}\text { Participa em número limitado } \\
\text { de projetos com baixa } \\
\text { complexidade. } \\
\text { Integra e coordena pequenas } \\
\text { equipes de operadores, } \\
\text { engenheiros e técnicos. }\end{array}$ & $\begin{array}{l}\text { Utiliza rotinas preexistentes para } \\
\text { gerenciar atividades em unidades } \\
\text { especializadas. } \\
\text { Estabelece estratégias para } \\
\text { influenciar a outra parte (exercida } \\
\text { nas fronteiras inter e } \\
\text { intraorganizacionais). }\end{array}$ \\
\hline
\end{tabular}

Fonte: Ferigotti e Fernandes (2014, p. 81)

Almeida e Muniz Jr. (2014) descreveram a relação entre competências gerenciais e requisitos estabelecidos para cumprimento da norma de qualidade VDA 6.3, apontando quais comportamentos dos líderes repercutem mais no alcance dos padrões de qualidade exigidos. As 
competências gerenciais de maior importância identificadas no estudo foram: comunicar responsabilidades; delegar com responsabilidade; treinar e acompanhar o desenvolvimento individual e da equipe; preparar substitutos; proporcionar um ambiente adequado às atividades; verificar o cumprimento dos procedimentos por parte de seus liderados; exigir excelência e rigor; estabelecer mecanismos de rastreabilidade e controle; monitorar documentos, registros e processos; analisar resultados e formular planos de ação deles decorrentes.

Cardoso (2014) comparou a percepção de (ex-)alunos e (ex-)alunas de mestrado e doutorado em administração sobre suas competências gerenciais. Com o estudo quantitativo, baseado em 227 questionários aplicados em uma universidade particular do Estado do Paraná, que retornaram 130 respostas válidas, concluiu-se que há diferenças estatisticamente significativas entre as percepções de homens e mulheres para a maioria das competências, enquanto que outras variáveis demográficas (idade, escolaridade e experiências funcionais e gerenciais) não apresentaram diferenças significativas. Esse autor observou que as mulheres se percebiam mais competentes nos seguintes comportamentos gerenciais: "Persuasão e Assertividade Negocial", “Autodesenvolvimento e Autoaprendizagem”, “Trabalho em equipe e Empreendedorismo", "Planejamento, organização e Tomada de Decisão" e "Liderança estratégica". Destarte, o autor questionou se há viés nos modelos de competências que tratam igualmente gestores e gestoras, adotando uma mesma trilha de aprendizagem.

Irmão e Barbalho (2014) investigaram as competências gerenciais dos bibliotecários gestores que atuam em bibliotecas universitárias de instituições de ensino público. Por meio de uma pesquisa descritiva e exploratória, recorreu-se a um questionário com escala Likert, composto por dezessete variáveis: 1) conduzir esforços para um propósito comum em unidades, sistemas e serviços de informação; 2) usar de forma racional os recursos disponíveis em unidades, sistemas e serviços de informação; 3) formular e gerenciar projetos de informação; 4) aplicar técnicas do composto de marketing, produto, preço, praça e promoção nos serviços; 5) usar técnicas de liderança e de relações públicas; 6) desenvolver atividades no sentido de assessorar no planejamento de recursos econômico-financeiro e humanos da biblioteca; 7) planejar, constituir e manipular redes globais de informação; 8) coordenar o grupo de colaboradores para elaboração do planejamento estratégico; 9) utilizar as informações do relatório de atividades no Planejamento Estratégico; e as que foram consideradas mais importantes as capacidades: 10) de designar aos colaboradores atividades; 11) de coordenar unidades, sistemas e serviços de informação; 12) de buscar, registrar, avaliar e difundir informações com fins acadêmicos e profissionais; 13) de elaborar produtos de informação 
(bibliografia, catálogos, guias, índices etc.); 14) de traçar planos de ação necessários para a preservação e conservação de acervos documentais; 15) de coordenar e avaliar a preservação e conservação de acervos documentais; 16) de planejar e executar estudos de usuários e formação de usuários da informação; e 17) de acompanhar a realização de atividades de colaboradores.

Mello e Melo (2014) mapearam as competências gerenciais dos integrantes do fórum de gestão de pessoas da Rede federal de educação profissional, científica e tecnológica, mediante estudo qualitativo, baseado em entrevistas e análise de conteúdo, que evidenciou os seguintes aspectos: comunicação, liderança, gestão de conflitos, organização, planejamento, comprometimento, iniciativa, conhecimento técnico, visão estratégica, cria ferramentas de controle, transmite confiança, avaliação de resultados, visão sistêmica dos processos, paciência e tranquilidade. Como resultados, foram apontados os principais desafios enfrentados pelos gestores da referida Rede (excesso de trabalho e carência de servidores), bem como as competências mais relevantes (comunicação, liderança e gestão de conflitos) e as mais desejadas (organização do tempo, comunicação, motivação e liderança).

Regio et al. (2014) estudaram a contribuição do curso de Administração na Universidade Federal de Santa Maria para o desenvolvimento de competências profissionais exigidas de administradores. Num estudo de caso descritivo e quantitativo, aplicaram-se dois questionários estruturados a 121 egressos formados no período de 2005 a 2009. Os autores recorreram à análise fatorial, que indicou quatro fatores, com o seguinte agrupamento:

Fator 1 - Padrões e Valores: Respeitar o próximo, ser autocrítico, buscar aperfeiçoamento contínuo, considerar os valores éticos da profissão e comunicar-se de forma clara e objetiva;

Fator 2 - Adaptação e Negociação: Tomar decisões a partir da análise dos vários aspectos nas mudanças de processos de trabalho, manter-se produtivo apesar dos obstáculos, buscar soluções originais e criativas bem como adaptar-se às novas situações e/ou pressões de trabalho;

Fator 3 - Conhecimento: Realizar tarefas e atividades de consultoria em gestão e administração, elaborar e implementar projetos, respeitar as pessoas com senso de responsabilidade pelos direitos e deveres, e transferir e aplicar conhecimentos técnicos para solução de problemas;

Fator 4 - Técnico-Profissional: Raciocinar de forma lógica e analítica com embasamento matemático e estabelecer relações formais e causais entre os fenômenos produtivos. 
Santos e Honório (2014) estudaram as competências gerenciais em uma rede de farmácias em Minas Gerais, com base no modelo proposto por Brandão (2009), cuja classificação de competências gerenciais apontou os seguintes fatores: gestão do relacionamento com o cliente; gestão de pessoas; gestão estratégica; gestão de processos; gestão financeira de negócios; e gestão socioambiental. Por meio de abordagem mista, baseada em questionários e entrevistas semiestruturadas, seguida de análise estatística (uni e bivariada) e de conteúdo, os autores concluíram que a gestão de relacionamento com o cliente é a competência gerencial mais significativa para o ramo, sobretudo, no que concerne ao estabelecimento de negociações transparentes e baseadas no "ganha-ganha". Outros achados interessantes são que mulheres se percebem mais competentes quanto ao relacionamento com o cliente e que o domínio da competência para administração de conflitos é maior entre os gerentes com mais tempo de atuação.

Silva, Gil e Okabayashi (2014) estudaram as competências gerenciais de servidores públicos do Grande ABC paulista. Foram aplicados 100 questionários, que investigavam o grau de importância de 11 características dos administradores públicos (liderança; comunicação; habilidade em negociação e administração de conflitos; capacidade de decisão; interesse por pessoas; competência para planejar e organizar; disposição para delegar; espírito inovador; flexibilidade; competência técnica na área; e disposição para trabalhar em equipe). Calculados o nível de significância (teste de $\mathrm{X}^{2}$ ) e a correlação dos dados (coeficiente de Q de Yule), os autores concluíram que a comunicação e a disposição para trabalhar em equipe são as competências gerencias mais importantes para os gestores públicos estudados. Outros achados interessantes são que as mulheres valorizam mais o interesse pelas pessoas, o planejamento e a organização, o espírito inovador, a flexibilidade e a disposição de trabalhar em equipe; que as competências de negociação e administração de conflitos, de interesse por pessoas, de planejamento e organização, de ter a capacidade de delegar, bem como as competências técnicas são mais valorizadas pelos servidores públicos de maior idade; e que planejamento e organização e liderança são competências gerenciais mais valorizadas por servidores que possuem formação superior.

Tosta e Dalmau (2014) competências gerenciais requeridas de gestores intermediários na Universidade Federal da Fronteira Sul. Mediante pesquisa qualitativa, exploratória, aplicada e descritiva, os autores recorreram a pesquisa documental, entrevistas semiestruturadas e questionários do tipo misto. Com base em análise de conteúdo, e à luz da literatura da área, concluiu-se que as competências necessárias aos gestores estudados podem ser agrupadas em 
três categorias: interpessoal (emocional, liderança e relacionamento); informacional (legal e comunicação) e decisória (administrativa, negociação, geopolítica, global e empreendedorismo).

Nascimento e Alves (2015) compararam a percepção do mercado (16 gestores de lojas e indústrias paraibanas) e da academia (40 professores do curso de Administração de universidades públicas da Paraíba) quanto às competências dos administradores, numa pesquisa de campo com caráter descritivo e abordagem mista. A partir de questionários aplicados às duas subamostras, as autoras concluíram que comunicação, pensamento estratégico, reconhecimento de problemas e oportunidades e comportamento ético são competências consideradas importantes tanto pelo mercado quanto pela academia. Contudo, o mercado privilegia a comunicação interpessoal e o uso da comunicação estruturada; enquanto que a academia preza a adaptabilidade, a atitude de tomar iniciativa, o conhecimento do ambiente organizacional, a habilidade em adquirir novos conhecimentos, a motivação e a visão de projetos.

E, por fim, o estudo de Peixoto e Souza (2015), que identificaram os desafios de gestão de uma universidade pública a partir da percepção dos seus gestores. Visando analisar como os próprios gestores avaliam a gestão da universidade, os autores aplicaram um websurvey a 272 servidores que ocupam cargo de direção ou função gratificada, e, embora esse não fosse o foco do estudo, puderam identificar as seguintes competências gerenciais: capacidade para solucionar problemas; conhecimento das potencialidades e deficiências da equipe; acompanhamento periódico do desempenho da equipe; habilidades para o gerenciamento de conflitos; distribuição de tarefas e responsabilidades; definição de metas e objetivos; transmissão das orientações necessárias; e busca constante de qualificação para o exercício da função. Merece destaque o domínio das seguintes competências: solucionar os problemas; conhecer a equipe que lideram; e buscar se qualificar para o exercício da função. Quanto aos gaps, destacaram-se as falhas relacionadas ao processo de comunicação e à gestão do tempo.

Encerrada a revisão da literatura que trata de esquemas, modelos, categorizações, classificações ou ainda da mera identificação de competências gerenciais em determinado contexto, vê-se que não há consenso nas classificações adotadas pelos autores e na inclusão de diferentes aspectos nas diversas categorias de competências gerenciais estabelecidas. Para uma melhor constatação dessa ausência consensual, vale apresentar um quadro-síntese (

Quadro 12), contendo os autores recorridos e os anos de suas publicações e também as competências gerenciais abordadas. Vale destacar que a nomenclatura e os termos utilizados 
para aglutinar as competências se deu por aproximação temática, com fins meramente didáticos, tendo por base definiçõoes constitutivas e/ou operacionais apresentadas pelos próprios autores.

Quadro 12 - Classificação das Competências Gerenciais segundo diferentes autores

\begin{tabular}{|c|c|c|c|c|c|c|c|c|c|c|c|c|c|c|c|c|c|c|c|}
\hline 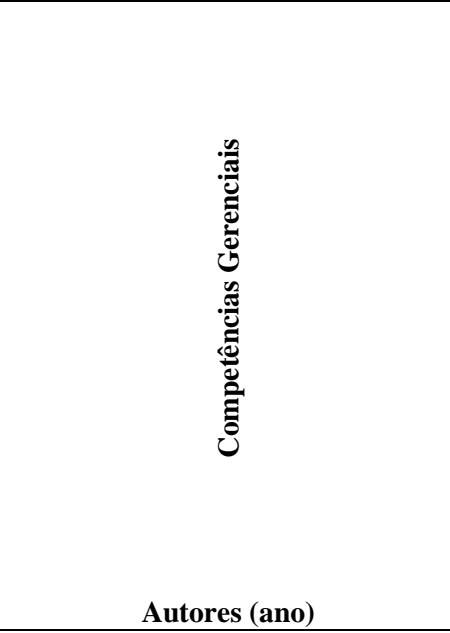 & 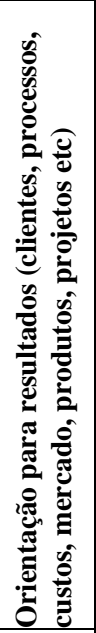 & 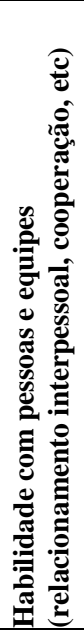 & 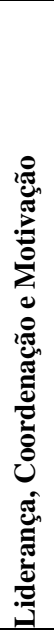 & 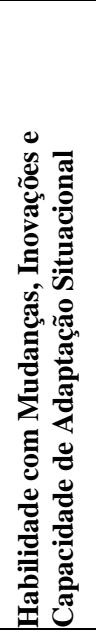 & 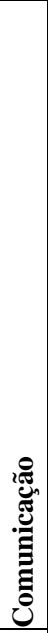 & 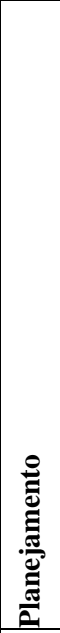 & 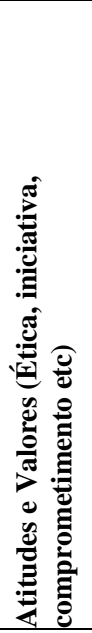 & 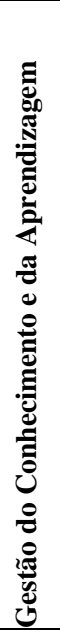 & 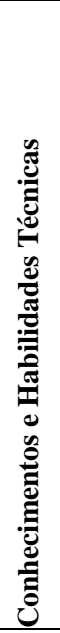 & 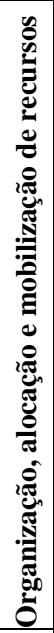 & 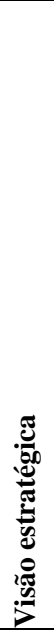 & 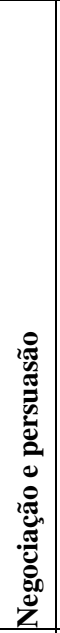 & 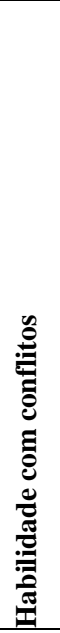 & 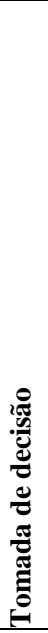 & 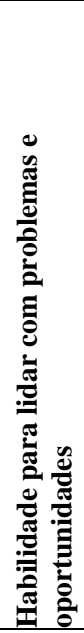 & 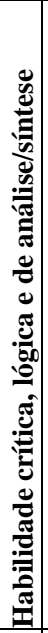 & 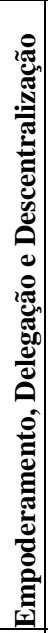 & 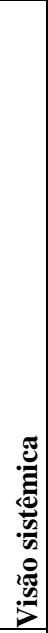 & 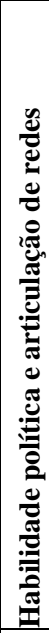 \\
\hline Félix (2005) & $\mathrm{x}$ & & & & & & & & & & $\mathrm{x}$ & & & & & & $\mathrm{x}$ & $\mathrm{x}$ & \\
\hline Moura e Bitencourt (2006) & $\mathrm{x}$ & & & & & & & & & & & & & & & & & & \\
\hline Godoy e Forte (2007) & & $\mathrm{x}$ & & & & & $\mathrm{x}$ & & $\mathrm{x}$ & & & & & & $\mathrm{x}$ & & & & \\
\hline Santos, Caetano e Jesuíno (2008) & & & $\mathrm{x}$ & $\mathrm{x}$ & & & & $\mathrm{x}$ & & & $\mathrm{x}$ & & & & & & & & \\
\hline Moraes e Corrêa (2008) & $\mathrm{x}$ & $\mathrm{x}$ & & $\mathrm{x}$ & $\mathrm{x}$ & $\mathrm{x}$ & & & & $\mathrm{x}$ & & & & & & & & & \\
\hline Jansen, Vera e Crossan (2009) & & & & $\mathrm{x}$ & & & & & & & & & & & & & & & $\mathrm{x}$ \\
\hline Cardoso (2009) & & $\mathrm{x}$ & $\mathrm{x}$ & $\mathrm{x}$ & & $\mathrm{x}$ & $\mathrm{x}$ & $\mathrm{x}$ & & $\mathrm{x}$ & & $\mathrm{x}$ & & $\mathrm{x}$ & $\mathrm{x}$ & & & & \\
\hline Brandão et al. (2010) & $\mathrm{x}$ & & & & & & & & $\mathrm{x}$ & & $\mathrm{x}$ & & & & & & & & \\
\hline Noro e Abbade (2010) & $\mathrm{x}$ & $\mathrm{x}$ & $\mathrm{x}$ & $\mathrm{x}$ & & & $\mathrm{x}$ & & $\mathrm{x}$ & & & $\mathrm{x}$ & $\mathrm{x}$ & & & $\mathrm{x}$ & & $\mathrm{x}$ & \\
\hline Teixeira, Silva e Lima (2011) & $\mathrm{x}$ & & $\mathrm{x}$ & $\mathrm{x}$ & & & $\mathrm{x}$ & & $\mathrm{x}$ & & $\mathrm{x}$ & & & & & & & & \\
\hline Ésther (2011) & $\mathrm{x}$ & $\mathrm{x}$ & & $\mathrm{x}$ & $\mathrm{x}$ & $\mathrm{x}$ & $\mathrm{x}$ & & $\mathrm{x}$ & & & $\mathrm{x}$ & $\mathrm{x}$ & $\mathrm{x}$ & & $\mathrm{x}$ & & & $\mathrm{x}$ \\
\hline Pelissari, Gonzalez e Vanelle (2011) & $\mathrm{x}$ & $\mathrm{x}$ & $\mathrm{x}$ & $\mathrm{x}$ & $\mathrm{x}$ & & $\mathrm{x}$ & $\mathrm{x}$ & & $\mathrm{x}$ & & $\mathrm{x}$ & & & $\mathrm{x}$ & & & $\mathrm{x}$ & \\
\hline Fleck e Pereira (2011) & $\mathrm{x}$ & $\mathrm{x}$ & $\mathrm{x}$ & & $\mathrm{x}$ & $\mathrm{x}$ & & $\mathrm{x}$ & $\mathrm{x}$ & & & & $\mathrm{x}$ & & $\mathrm{x}$ & & & & \\
\hline $\begin{array}{l}\text { Mithas, Ramasubbu e Sambamurthy } \\
\text { (2011) }\end{array}$ & $\mathrm{x}$ & & & & $\mathrm{x}$ & & & & & & & & & & & & & & \\
\hline Bündchen, Rossetto e Silva (2011) & $\mathrm{x}$ & $\mathrm{x}$ & $\mathrm{x}$ & $\mathrm{x}$ & $\mathrm{x}$ & $\mathrm{x}$ & $\mathrm{x}$ & $\mathrm{x}$ & $\mathrm{x}$ & $\mathrm{x}$ & & $\mathrm{x}$ & $\mathrm{x}$ & $\mathrm{x}$ & & & $\mathrm{x}$ & & $\mathrm{x}$ \\
\hline $\begin{array}{l}\text { Brandão, Borges-Andrade e } \\
\text { Guimarães (2012) }\end{array}$ & $\mathrm{x}$ & $\mathrm{x}$ & & & & & $\mathrm{x}$ & & & & $\mathrm{x}$ & & & & & & & & \\
\hline Godoy e D'amelio (2012) & $\mathrm{x}$ & $\mathrm{x}$ & & $\mathrm{x}$ & & & $\mathrm{x}$ & & & & & & & $\mathrm{x}$ & & & & $\mathrm{x}$ & \\
\hline Baisch et al. (2012) & $\mathrm{x}$ & $\mathrm{x}$ & $\mathrm{x}$ & $\mathrm{x}$ & $\mathrm{x}$ & $\mathrm{x}$ & $\mathrm{x}$ & & $\mathrm{x}$ & $\mathrm{x}$ & $\mathrm{x}$ & $\mathrm{x}$ & $\mathrm{x}$ & & & $\mathrm{x}$ & & $\mathrm{x}$ & \\
\hline Galvão, Silva e Silva (2012) & $\mathrm{x}$ & $\mathrm{x}$ & & $\mathrm{x}$ & & $\mathrm{x}$ & & $\mathrm{x}$ & $\mathrm{x}$ & $\mathrm{x}$ & & & $\mathrm{x}$ & & & & & & $\mathrm{x}$ \\
\hline Brito e Leone (2012) & $\mathrm{x}$ & $\mathrm{x}$ & $\mathrm{x}$ & $\mathrm{x}$ & $\mathrm{x}$ & $\mathrm{x}$ & $\mathrm{x}$ & & $\mathrm{x}$ & $\mathrm{x}$ & $\mathrm{x}$ & $\mathrm{x}$ & $\mathrm{x}$ & $\mathrm{x}$ & & $\mathrm{x}$ & & & \\
\hline Brito, Paiva e Leone (2012) & $\mathrm{x}$ & $\mathrm{x}$ & $\mathrm{x}$ & $\mathrm{x}$ & $\mathrm{x}$ & $\mathrm{x}$ & $\mathrm{x}$ & $\mathrm{x}$ & $\mathrm{x}$ & $\mathrm{x}$ & $\mathrm{x}$ & $\mathrm{x}$ & $\mathrm{x}$ & $\mathrm{x}$ & & $\mathrm{x}$ & & & \\
\hline Sousa e Valadão Jr. (2013) & $\mathrm{x}$ & $\mathrm{x}$ & $\mathrm{x}$ & $\mathrm{x}$ & & $\mathrm{x}$ & $\mathrm{x}$ & $\mathrm{x}$ & & & $\mathrm{x}$ & $\mathrm{x}$ & $\mathrm{x}$ & $\mathrm{x}$ & $\mathrm{x}$ & $\mathrm{x}$ & $\mathrm{x}$ & & \\
\hline Paula et al. (2013) & $\mathrm{x}$ & & $\mathrm{x}$ & & $\mathrm{x}$ & $\mathrm{x}$ & & $\mathrm{x}$ & & & & & & $\mathrm{x}$ & & & & & \\
\hline Ferigotti e Fernandes (2014) & & $\mathrm{x}$ & & & & & & & & $\mathrm{x}$ & $\mathrm{x}$ & & & & & & & & \\
\hline Almeida e Muniz Jr. (2014) & $\mathrm{x}$ & $\mathrm{x}$ & & & $\mathrm{x}$ & $\mathrm{x}$ & & $\mathrm{x}$ & & $\mathrm{x}$ & & & & & & $\mathrm{x}$ & $\mathrm{x}$ & & \\
\hline Cardoso (2014) & & $\mathrm{x}$ & $\mathrm{x}$ & & & $\mathrm{x}$ & & $\mathrm{x}$ & & $\mathrm{x}$ & $\mathrm{x}$ & $\mathrm{x}$ & & $\mathrm{x}$ & & & & & \\
\hline Irmão e Barbalho (2014) & $\mathrm{x}$ & $\mathrm{x}$ & $\mathrm{x}$ & & & $\mathrm{x}$ & & $\mathrm{x}$ & $\mathrm{x}$ & $\mathrm{x}$ & & & & & & & $\mathrm{x}$ & & $\mathrm{x}$ \\
\hline
\end{tabular}




\begin{tabular}{|c|c|c|c|c|c|c|c|c|c|c|c|c|c|c|c|c|c|c|c|}
\hline \multicolumn{20}{|c|}{ Continuação } \\
\hline 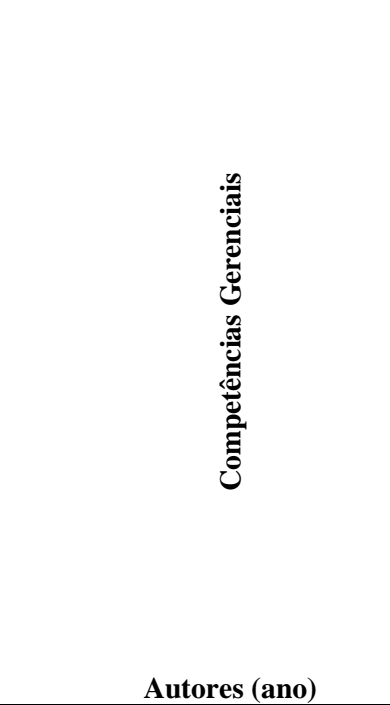 & 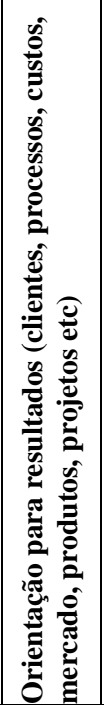 & 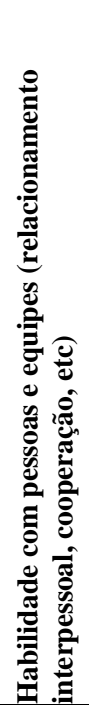 & 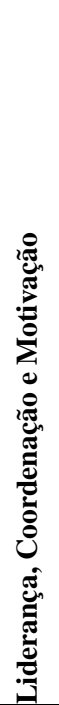 & 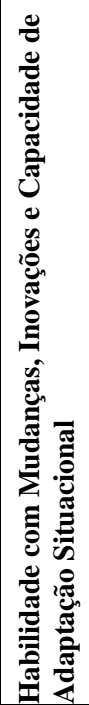 & 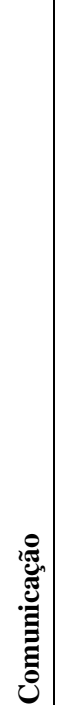 & 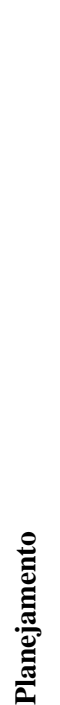 & 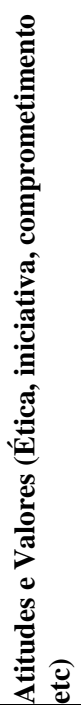 & 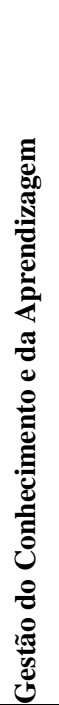 & 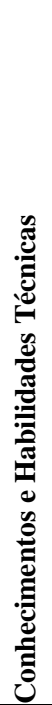 & 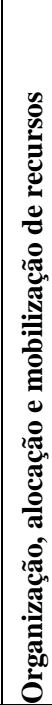 & 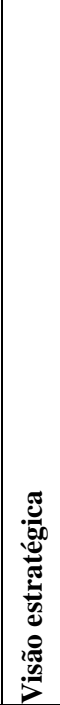 & 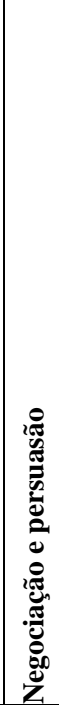 & 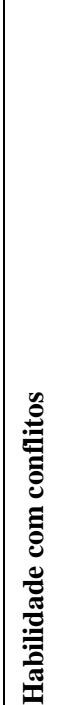 & 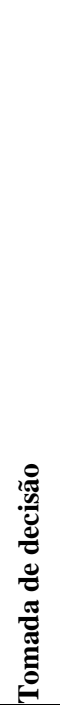 & 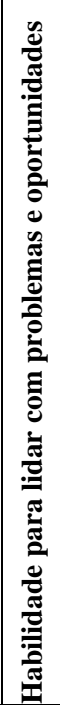 & 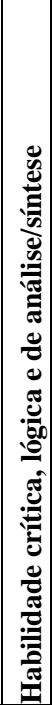 & 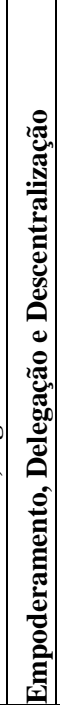 & 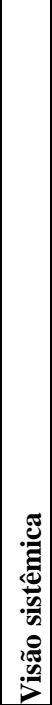 & \\
\hline Mello e Melo (2014) & $\mathrm{x}$ & & $\mathrm{x}$ & & $\mathrm{x}$ & $\mathrm{x}$ & $\mathrm{x}$ & & $\mathrm{x}$ & $\mathrm{x}$ & $\mathrm{x}$ & & $\mathrm{x}$ & & & & & $\mathrm{x}$ & \\
\hline Regio et al. (2014) & $\mathrm{x}$ & $\mathrm{x}$ & & $\mathrm{x}$ & $\mathrm{x}$ & & $\mathrm{x}$ & $\mathrm{x}$ & $\mathrm{x}$ & & & $\mathrm{x}$ & & $\mathrm{x}$ & $\mathrm{x}$ & $\mathrm{x}$ & & & \\
\hline Santos e Honório (2014) & $\mathrm{x}$ & & $\mathrm{x}$ & & & & & & & $\mathrm{x}$ & $\mathrm{x}$ & & & & & & & & \\
\hline Silva, Gil e Okabayashi (2014) & & $\mathrm{x}$ & $\mathrm{x}$ & $\mathrm{x}$ & $\mathrm{x}$ & $\mathrm{x}$ & & & $\mathrm{x}$ & $\mathrm{x}$ & & $\mathrm{x}$ & $\mathrm{x}$ & $\mathrm{x}$ & & & $\mathrm{x}$ & & \\
\hline Tosta e Dalmau (2014) & & $\mathrm{x}$ & $\mathrm{x}$ & & $\mathrm{x}$ & & & & & & & $\mathrm{x}$ & & $\mathrm{x}$ & & & & $\mathrm{x}$ & \\
\hline Nascimento e Alves (2015) & $\mathrm{x}$ & $\mathrm{x}$ & $\mathrm{x}$ & $\mathrm{x}$ & $\mathrm{x}$ & & $\mathrm{x}$ & $\mathrm{x}$ & & & $\mathrm{x}$ & & & & $\mathrm{x}$ & & & & \\
\hline Peixoto e Souza (2015) & $\mathrm{x}$ & $\mathrm{x}$ & & & $\mathrm{x}$ & & & $\mathrm{x}$ & & & & & $\mathrm{x}$ & & $\mathrm{x}$ & & $\mathrm{x}$ & & \\
\hline Somatório das ocorrências & 26 & 24 & 19 & 18 & 17 & 16 & 16 & 15 & 15 & 15 & 14 & 13 & 12 & 12 & 8 & 8 & 7 & 7 & \\
\hline
\end{tabular}

Fonte: elaborado pelo autor com base na literatura

\section{Com base no}

Quadro 12, ressalvando-se os estudos baseados no Modelo de Quinn (1988), verifica-se que as dez competências gerenciais com maior incidência nos estudos da última década (2005 a 2015) são: Orientação para resultados (clientes, processos, custos, mercado, produtos, projetos etc); Habilidade com pessoas e equipes (relacionamento interpessoal, cooperação etc); Liderança, Coordenação e Motivação; Habilidade com Mudanças, Inovações e Capacidade de Adaptação Situacional; Comunicação; Planejamento; Atitudes e Valores (Ética, iniciativa, comprometimento etc); Gestão do Conhecimento e da Aprendizagem; Conhecimentos e Habilidades Técnicas; e Organização, alocação e mobilização de recursos.

Finalizada a exposição dos trabalhos sobre competências gerenciais selecionados, há que se fazer considerações a respeito de algumas possíveis imprecisões identificadas.

Primeiro, o elemento constitutivo de competências gerenciais "são exclusivos de líderes estratégicos", mencionado no Quadro 4, tomou por base a definição de Lado e Wilson (1994). Em que pese o respeito aos autores, que agregaram aos estudos de gestão de pessoas, compreendendo competências como fonte de vantagem competitiva sustentável, é importante 
frisar que esse elemento está atualmente superado, já que não apenas líderes estratégicos exercem competências gerenciais. Afinal, líderes operacionais ou de quaisquer níveis, ou ainda pessoas que não exercem liderança formal podem exercer comportamentos atribuídos precipuamente a gestores.

Segundo, o modelo de Quinn et al (1988) se refere a papéis como conjuntos ou agrupamentos de competências gerenciais afins. Contudo, essa não é a única possibilidade de entendimento. Por exemplo, um negociador competente pode exercer essa competência em seus diversos papéis na sociedade: como pai, chefe, filho, estudante, consumidor, amigo, entre outros. Ou seja, a lógica pode ser inversa: uma competência pode ser desempenhada em múltiplos papéis (KONRATH; TAROUCO; BEHAR, 2009; LITTO; FORMIGA, 2009). Neste ponto, não há certo ou errado, mas é importante frisar que existem diferentes óticas para a relação papel-competência.

Terceiro, em que pese Brandão (2007) criticar os estudos que conceituam competências usando o elemento "combinações sinérgicas de conhecimentos, habilidades e atitudes - CHAs" e realizam mapeamentos de competências de forma segregada, alguns estudos selecionados neste referencial teórico continuam a diagnosticar as competências recorrendo a CHAs isoladamente. Melhor seria que os instrumentos e modelos sobre competências conjugassem CHAs em "comportamentos", abordagem que se sugere como mais apropriada enquanto elemento agregador-sinérgico para os elementos do CHA.

E, por último, muitos estudos se revelam imprecisos na distinção entre valores organizacionais e componentes atitudinais das competências. De fato, os valores humanos interferem e compõem as atitudes e o comportamento dos indivíduos (SCHWARTZ; BILSKY, 1990) mas os valores organizacionais guiam o comportamento humano desejável de modo extrínseco, visando a subordinar interesses individuais aos coletivos, na consecução de metas compartilhadas (OLIVEIRA; TAMAYO, 2004; TAMAYO, 2008).

Apresentado o quadro teórico atual a respeito das competências (mormente, as de atuação em grupos de pesquisa e as gerenciais), no próximo tópico, apresentar-se-á o contexto teórico no que tange aos resultados em grupos de pesquisa e os aspectos que os influenciam.

\subsection{Resultados em grupos de pesquisa e aspectos que os influenciam}

Nesta seção, serão abordados diversos aspectos que influenciam os resultados alcançados por grupos de pesquisa. Inicialmente, será apresentada a definição do termo 
'resultado', distinguindo-o do fenômeno do 'desempenho'. Em seguida, tratar-se-á da importância dos indicadores e da avaliação de resultados. E, por fim, serão listados e resumidos os estudos que indicam aspectos que influenciam resultados em grupos de pesquisa, com destaque para pesquisas que consideram as competências gerenciais como um desses aspectos.

Em se tratando de resultados, faz-se necessário recorrer ao fenômeno do desempenho, que pode associar diversas dimensões psicossociais, como a individual (afetos, disposições, habilidades, competências), a interpessoal e a situacional (BENDASSOLLI, 2012). Especificamente, no âmbito das organizações, há crescimento no número de estudos sobre o desempenho nas últimas décadas; no entanto, as formas de verificação desse fenômeno ainda não alcançaram um consenso. Embora a literatura apresente diversas medidas de desempenho, nenhuma, isoladamente, conseguiu contemplar as influências mais significativas ao desempenho organizacional (VISWESVARAN; ONES, 2000; COMBS; CROOK; SHOOK, 2005).

Segundo Cameron e Whetten (2013) e Carvalho (2014), essa ausência de consenso já era percebida no século passado, o que justificava (à época) a previsão de um iminente abandono do construto da efetividade organizacional pela academia, em decorrência de tamanha amplitude conceitual e multiplicidade de instrumentos. Hoje, já se pode constatar que esse prognóstico é improvável, devido à sua importância teórica e empírica (CARVALHO, 2014).

Existe, por exemplo, grande divergência conceitual entre desempenho e resultado. Resultados são "estados ou condições de pessoas ou coisas que são modificados pelo desempenho e, consequentemente, contribuem ou se distanciam do alcance dos objetivos das organizações" (BENDASSOLLI, 2012, p. 173). Já desempenho consiste num construto do comportamento, que se refere a uma ação ou a um conjunto de ações pessoais que leva as organizações a atingirem resultados significativos (SONNENTAG; FRESE, 2002).

Em suma, o resultado é consequência do desempenho, que, a princípio, é uma variável individual. Mas, por influência da economia e dos estudos na área de administração estratégica, passou-se a adotar o termo 'desempenho organizacional' ou 'efetividade organizacional' para se referir aos resultados em nível organizacional (MATITZ, 2009). Segundo Silveira-Martins, Rossetto, Añaña (2014), esse desempenho em nível organizacional (ou resultado) pode ser auferido basicamente de duas formas: em comparação com uma expectativa anterior firmada pela própria organização - perspectiva subjetiva proposta por Pelham e Wilson (1996) - ou pela comparação com os concorrentes - perspectiva objetiva cunhada por Chakravarthy (1986). 
Seja qual for a forma de avaliação, a mensuração dos resultados de uma organização é uma característica eminente do ideal positivista. Com base nos fundamentos dessa abordagem é que autores clássicos da Teoria Organizacional empenharam-se no estudo dos tempos e movimentos, visando alcançar a produtividade, sobretudo, em atividades operacionais. (CUNHA; CORREAA, 2013). Segundo Ridgway (1956), na primeira metade do século XX, a Teoria Organizacional buscava explorar medidas operacionais quantificáveis, com o intuito de conferir aos gestores as ferramentas necessárias para o monitoramento do desempenho em suas atividades.

Essa apuração do desempenho apenas no âmbito operacional passou a expandir-se para as diversas áreas e níveis hierárquicos com o advento da administração por objetivos preconizada por Peter Drucker (1954). Essa metodologia recomendava que os resultados deveriam ser acompanhados em diversas áreas da organização mediante um conjunto de indicadores de desempenho relativos e específicos a cada área (CUNHA; CORRÊA, 2013; SANTOS; CARNEIRO, 2013).

A obtenção da validade objetiva de dados para medir os resultados organizacionais e a definição de quais indicadores melhor representam o desempenho da organização é um desafio de pesquisadores do fenômeno (VENKATRAMAN; RAMANUJAM, 1986). Por tradição, a maioria das organizações se limitava a mensurar seus resultados financeiros e contábeis, baseando-se em séries históricas e privilegiando os interesses dos acionistas ou dos sócios, em detrimento das demais partes interessadas (HENRI, 2004). Os críticos argumentam que esse modelo é desprovido de visão estratégica, oferece baixo poder de previsibilidade dos resultados futuros, inibe a inovação, além de não estimular a visão de longo prazo, de voltar-se prioritariamente para o ambiente interno, e de negligenciar os clientes e concorrentes (BUCHELE, 1962; KENNERLEY; NEELY, 2003).

Fundando-se nessas críticas, por volta da década de 1960, as organizações passaram a incorporar indicadores não-financeiros (JOHNSON; KAPLAN, 1987; MARSICK; WATKINS, 2003; MACEDO; SILVA, 2005; CUNHA; CORREAA, 2013). Grande parte do mérito para se ir além aos indicadores financeiros se deve à Qualidade Total, que contribuiu para superar o pensamento de curto prazo e para priorizar a qualidade e a padronização de produtos e processos (JURAN, 1964). Mas, ainda assim, a verificação de resultados ainda costumava negligenciar a percepção dos clientes e dos empregados, além de desconsiderar o impacto da qualidade e da inovação (ITTNER; LARCKER, 1998). Somente no final dos anos 1980 é que começaram a 
surgir modelos de avaliação de resultados baseados em diversas dimensões organizacionais, os chamados scorecards (BOURNE et al., 2000; LOHMAN; FORTUIN, WOUTERS, 2004).

Dentre os referidos modelos, destaca-se o balanced scorecard (BSC), idealizado por Kaplan e Norton (1992), que mensura o resultado da organização a partir de indicadores como rentabilidade e crescimento (perspectiva financeira); participação do mercado e satisfação dos consumidores (perspectiva clientes); tempo de ciclo operacional e qualidade (perspectiva processos internos); e infraestrutura, sistemas de informação e desenvolvimento de pessoas (perspectiva aprendizagem e crescimento). A proposta desses autores é que existe uma relação causal entre essas perspectivas: a aprendizagem e o crescimento melhoram os processos internos, que proporcionam a satisfação dos clientes, o que tende a melhorar as finanças e a lucratividade (ALMEIDA; MARÇAL; KOVALESKI, 2004).

Passando-se ao âmbito dos grupos de pesquisa (enquanto "micro-organizações"), recorrer-se-á ao conteúdo teórico relativo à temática dos resultados, em estudos que adotaram grupos de pesquisa como locus.

De antemão, vale destacar que os estudos científicos por meio de grupos de pesquisa têm crescido ao longo dos últimos anos. Tratando da área de enfermagem, por exemplo, Erdmann e Lanzoni (2008) elaboraram um estudo documental, constituindo um banco de dados coletados no Diretório dos Grupos de Pesquisa no Brasil do CNPq. Os resultados indicaram que, no Brasil, houve um crescimento significativo dos grupos de pesquisa da área da Enfermagem com o incremento da produção, qualificação dos integrantes, bem como o fortalecimento das bases de investigação e a maior visibilidade e reconhecimento da inovação da Enfermagem. A partir desse estudo, identificam-se como lacunas de pesquisa estudos sobre o que tem levado os grupos de pesquisa a esse aumento de produtividade e, mais que isso, é fundamental o estabelecimento de formas, métricas e aspectos capazes de aferir resultados de grupos de pesquisa.

Berche et al. (2015) criticaram o uso de indicadores simplistas e meramente relativos à produtividade de grupos de pesquisa, em detrimento de indicadores que expressem a qualidade e a "massa crítica" resultante do grupo. Segundo esses autores, os gestores universitários no mundo inteiro têm se limitado a considerar apenas rankings e tabelas classificatórias de instituições, grupos e pesquisadores. Contudo, esses instrumentos normalmente são elaborados por organismos inexperientes, como jornais e revistas, mediante medidas e critérios bastante arbitrários e sem uma compreensão adequada de suas reais contribuições. 
$\mathrm{O}$ interesse em se estabelecerem formas mais robustas e capazes de mensurar os resultados de grupos de pesquisa é evidenciado em alguns estudos. No contexto das universidades, por exemplo, Hollis (2001) estudou como a coautoria influencia os resultados de grupos de pesquisa. Se por um lado a coautoria está associada com maior qualidade, tamanho, e com uma maior frequência de publicações; por outro, os resultados líquidos ou a saída atribuível a um indivíduo é negativa. Os resultados sugerem que as universidades e agências financiadoras que recompensam preferencialmente a colaboração de pesquisa podem estar minando seus objetivos reais de maximizar resultados da investigação.

Harvey, Pettigrew e Ferlie (2002) estudaram os fatores determinantes do desempenho de grupos de pesquisa no contexto da emergência do conhecimento como um ativo intangível fundamental. Pesquisando grupos de pesquisa localizados dentro e na interface da pesquisa universitária e se concentrando em grupos de investigação médica, esses autores encontraram evidências de que os principais fatores para o resultado em grupos de pesquisa são liderança forte; atração, motivação e retenção de talentos; estratégias relacionadas à diversificação; forte ligação entre teoria e prática e, em particular, conectividade em redes.

Diante da notória aproximação temática do estudo citado no parágrafo anterior para a presente Dissertação, vale tecer maiores considerações sobre cada um dos fatores mencionados, e, para tratar especificamente da liderança como influenciadora dos resultados de grupos de pesquisa, será aberta uma seção exclusiva, ao final desse tópico.

Quanto à atração, motivação e retenção de talentos, os autores consideram esse um fator-chave para o resultado de grupos de pesquisa, uma vez que a consolidação do conhecimento produzido depende sobremaneira das pessoas e da manutenção de uma massa crítica em áreas específicas. Ademais, não adiantaria o investimento em formação sem a posterior obtenção de retorno para os grupos de pesquisa. A falta de continuidade nos grupos de pesquisa implica a perda de experiência de pesquisa, o enfraquecimento do investimento em formação de investigação, além do prejuízo à rede de contatos feitos pelo pesquisador (HARVEY; PETTIGREW; FERLIE, 2002).

Quanto às estratégias relacionadas à diversificação, Harvey, Pettigrew e Ferlie (2002) consideram que se deve garantir a coerência contínua do portfólio temático de um grupo de pesquisa. Porém, isso não significa “engessar" a criatividade e a curiosidade dos pesquisadores. É preciso diversificar as variáveis estudadas sem perder de vista o(s) fenômeno(s) principal(is). Garantir uma linha uniforme de pesquisa representa a manutenção de uma massa crítica na resolução de problemas de pesquisa e facilita saídas de investigação eficazes. Além disso, 
proporciona clareza na identidade externa do grupo e garante a continuidade de competências essenciais identificáveis. Para corroborar esse fator de desempenho em grupos de pesquisa, esses autores recorrem a Teece e Pisano (1994) e também ao trabalho de Prahalad e Hamel (1990), que argumentam que uma organização deve concentrar-se em suas competências essenciais para obter melhores resultados.

Quanto à ligação entre a teoria e a prática, Harvey, Pettigrew e Ferlie (2002) explicam que essa ligação deve ser tanto material quanto intelectual. Material porque o grupo de pesquisa precisa subsidiar os investigadores de todos os recursos necessários à produção do conhecimento possibilitando a prática e os experimentos. Intelectual porque permite descobertas científicas cujos resultados sejam aproveitados de forma concreta não só para a academia, mas para a sociedade como um todo. Essa relação entre teoria e prática é também tangenciada por Scott (1998), ao afirmar que a base mais geral de divergência entre aqueles que estudam as organizações reside na adoção de um olhar básico (conceitual e descritivo das relações organizacionais) ou de uma orientação de pesquisa aplicada (pragmática e direcionada a fatos concretos). Fato é que a pesquisa aplicada tem ganhado espaço e, por demonstrar comumente interesse em diversos tipos de variáveis (econômica, psicológica ou cultural), está mais propensa a estudos interdisciplinares, já que problemas práticos não respeitam as fronteiras disciplinares (SCOTT, 1998). Ademais, achados mais recentes indicam que os benefícios entre teoria e prática são recíprocos, pois, ao mesmo tempo que a teoria desenvolvida em grupos de pesquisa proporciona melhorias à prática organizacional, as pesquisas em organizações colaboram com o desenvolvimento do conhecimento teórico (SANTOS et al., 2014).

Destarte, Harvey, Pettigrew e Ferlie (2002) sugerem que os grupos de pesquisa precisam criar e aprimorar suas redes incluindo parceiros externos, de forma a suprir as disciplinas que escapam ao seu escopo de pesquisa teórica. Sobre essa temática - conectividade em redes -, esses autores elencam os aspectos que influenciam os grupos de pesquisa a trabalharem em colaboração, quais sejam: a) ênfase dos Conselhos de Pesquisa sobre investigações em rede; b) concentração de recursos e competências, que está associada com especialização, juntamente com a colaboração para permitir maior acesso a recursos especializados; c) necessidade de colaboração com especialistas; e d) disponibilidade de tecnologia com o potencial de facilitar este processo, sobretudo, dispositivos reduzem o impacto da distância geográfica (HARVEY; PETTIGREW; FERLIE, 2002). 
Outros estudos são também importantes no que tange à relação entre grupos de pesquisa e seus resultados. Viotti (2003), limitando-se a dados quantitativos, propôs que a quantidade de artigos e trabalhos publicados e o impacto dessas publicações entre os pares podem ser indicadores para a avaliação dos resultados de grupos de pesquisa. Esse autor considera que a adoção de indicadores em grupos de pesquisa é uma ferramenta de monitoração da produção e disseminação dos conhecimentos gerados, além de servir como justificativa para o estímulo a novas pesquisas e manutenção das já existentes.

Morris e Goldstein (2007) estudaram o quanto o fenômeno da colaboração interfere na produtividade, investigando como se dá a publicação de estudos científicos por grupos de pesquisa em determinadas áreas de conhecimento (matemática, química e biomedicina) a depender do grau de colaboração do grupo. Esses autores compararam a colaboração e os resultados quantitativos do grupo com dados secundários obtidos mediante pesquisas bibliográficas e chegaram à conclusão de que: a) o sucesso na realização de uma tarefa leva à atribuição de novas tarefas aos participantes do grupo de pesquisa; b) resultados positivos do grupo contribuem para obtenção de financiamento de instituições de fomento; c) os grupos de pesquisa solicitaram apoio externo quando não dispunham de conhecimentos ou recursos adequados a determinada atividade, sendo esse auxílio um fator propulsor de colaborações aleatórias de pesquisadores externos.

Já Garviria-Velásquez; Mejía-Correa; Henao-Henao (2007) investigaram o que leva os grupos de pesquisa a atuarem em conformidade com os indicadores estabelecidos pelo Instituto Colombiano para Desenvolvimento da Ciência e Tecnologia - Colciencias dentro dos padrões de produção e qualidade. Para tanto, as pesquisadoras primaram por uma abordagem complexa, recorrendo a alguns instrumentos de pesquisa-ação e à triangulação, pelos quais se evidenciou a falta de comunidades de prática, de inovações nos métodos de trabalho, de sistematização no planejamento dos grupos e de formalização do conhecimento produzido nas bases de dados. Chegou-se à conclusão de que há muitas possibilidades para a gestão do conhecimento em grupos de pesquisa, mas muitos grupos não conseguem mensurar o conhecimento gerado, o que acaba limitando a aferição de resultados a indicadores quantitativos.

Restrepo e Villegas (2007) propõem uma forma de analisar os dados de grupos de pesquisa da Faculdade de Engenharia da Universidade de Antioquia mediante ferramenta para medir a produtividade e, posteriormente, classificar os grupos de pesquisa colombianos. Para realizar essa classificação, foram considerados como indicadores de eficiência os seguintes resultados dos grupos de pesquisa: 1) produtos ou resultados que geram novos conhecimentos 
(artigos científicos, livros, pesquisas, produtos ou processos tecnológicos patenteados, ou registrados, etc.); 2) produtos relacionados com a formação de investigação (teses, dissertações e trabalhos de graduação e de programas de pós-graduação acadêmicos); e 3 ) apropriação social do conhecimento (relacionada a serviços técnicos e consultoria qualificada, produtos de divulgação e de popularização dos resultados das pesquisas).

Para Mauthner e Doucet (2008), os resultados de um grupo de pesquisa dependem de diversos fatores, entre os quais a organização dos processos de pesquisa, liderança e recursos. Esses autores defendem o resultado do grupo depende do desempenho dos indivíduos e da sua identificação com o ambiente do grupo de pesquisa, o qual pode propiciar relacionamentos mais eficazes. Alguns aspectos contribuem para que os membros apresentem desempenho superior: 1) afetividade (coesão, compromisso); 2) motivação (assegurar e manter a autoestima positiva); 3) cognição compartilhada; e 4) comportamentos esperados para a atuação intragrupo e intergrupos.

Compartilhando do mesmo objetivo de determinar que fatores influenciam a aprovação de uma proposta de Pesquisa, no contexto de uma agência de cooperação internacional, Mejía, Sánchez e Leza (2008) enviaram um questionário eletrônico via e-mail a 411 líderes de grupos de pesquisa da Argentina, Brasil, Chile, Colômbia e Venezuela. Os itens tratavam de características gerais, motivações, políticas e estratégias de cooperação e internacionalização dos grupos. A partir de análise fatorial e multivariada das 113 respostas obtidas, esses autores identificaram os aspectos diferenciadores de grupos de pesquisa, quanto a seus resultados, e elencaram os influenciadores dos resultados em grupos de pesquisa: interdisciplinaridade, anos de existência do grupo e produção anterior (que influenciam positivamente os resultados do grupo) e não ter estruturas de suporte de informação e de comunicação (que influencia negativamente). Outro achado interessante desse estudo é que, quando a motivação para cooperações internacionais se funda no objetivo de alcançar maiores visibilidade e prestígio, surge uma relação de desconfiança entre os partícipes, fato que acaba prejudicando a cooperação com outras agências internacionais.

Weijden et al. (2008) acreditam que compreender os determinantes do desempenho de pesquisa é um pré-requisito para a concepção de políticas de investigação eficazes e examinaram a relação entre o controle gerencial e desempenho dos grupos acadêmicos na área de pesquisa médica e de saúde na Holanda. Para tanto, utilizaram uma abordagem quantitativa para coletar dados de líderes de pesquisa em 160 grupos. A análise de correlação e análise de regressão linear múltipla mostraram que vários aspectos da gestão (processos de comunicação, 
estrutura de recompensas e coordenação de práticas de pesquisa) têm uma relação positiva com o desempenho da pesquisa. Esses autores identificaram seis fatores como cruciais à obtenção de financiamentos externos e à publicação de artigos científicos: 1) o tempo que um líder de pesquisa atribuiu à supervisão de alunos de doutorado; 2) o tamanho do grupo; 3 ) a quantidade de tempo destinada pelas equipes e pelo líder às atividades de pesquisa; 4) as menções e prêmios dados às equipes; 5) a influência da prática; e 6) a eficácia da pré-avaliação interna de propostas de pesquisa.

Num estudo de campo e exploratório, direcionado a coordenadores e integrantes de grupos de pesquisa na área acadêmica, Odelius e Sena (2009) se propuseram a realizar um estudo que visava descrever a formação e atuação de dois grupos de pesquisa na área acadêmica, com foco em processos de aprendizagem e desenvolvimento de competências individuais, e identificar aspectos que influenciavam esses processos.

A partir de uma amostra não-probabilística (definida por conveniência e acesso), coordenadores e integrantes de grupos de pesquisa foram entrevistados individualmente, mediante o suporte de roteiros semiestruturados, que tratavam do aprendizado de conhecimentos; habilidades para desempenho das atividades, e atitudes de convívio em grupo, bem como do desenvolvimento de atribuições e; processos de aprendizagem presentes nos grupos de pesquisa. Os dados coletados nas entrevistas foram submetidos à análise de conteúdo, cujo resultado apontou alguns indutores do desenvolvimento de competências, abrangendo processos formais e informais de aprendizagem e também a interação entre as pessoas.

Quanto às habilidades para desempenho de atividades em grupos de pesquisa, destacaram-se: planejamento de pesquisa, revisão da literatura, coleta de dados, análise de dados, comunicação de dados e coordenação de atividades de pesquisa. Quanto às atitudes mais relevantes, o trabalho em equipe recebeu destaque seja na relação entre indivíduos com características diferentes ou antagônicas; na coordenação de suas atividades com a dos colegas; na ponderação dos aspectos políticos da tomada de decisão no grupo ou na ação proativa na busca por oportunidades.

Ademais, esse estudo também serviu para confirmar achados de estudos anteriores quanto à área de atuação do grupo; metodologia de pesquisa; uso de tecnologias computacionais e de processamento de dados; realização de atividades administrativas; e desenvolvimento de atitudes necessárias ao trabalho em equipe, à atuação profissional e à geração de ideias, bem como à socialização e à formação de redes sociais. 
Dando continuidade aos estudos em grupos de pesquisa, Odelius et al. (2010) buscaram descrever as atividades realizadas por 31 participantes em nove grupos de pesquisa de diferentes áreas de conhecimento, assim como competências necessárias para a atuação no grupo e processos de aprendizagem. Por meio de questionários compostos de perguntas demográficofuncionais e questões abertas, os referidos autores abordaram aspectos que influenciam a aprendizagem em grupos de pesquisa, identificando que as atividades desenvolvidas pelos membros grupos de pesquisa estudados podem ser resumidas em: leitura de textos; análise crítica de documentos; e a apoio a atividades em grupo.

Como resultado, Odelius et al. (2010) indicaram que a aprendizagem, nos grupos estudados, decorria das interações sociais e da construção coletiva de saberes comuns. Os membros dos grupos relataram a aquisição de importantes competências técnicas e interpessoais nos grupos de pesquisa, entre as quais habilidades típicas de pesquisadores, relacionadas à produção e disseminação de conhecimentos, além de habilidades interpessoais necessárias ao trabalho em equipe e atitudes favoráveis à solução colaborativa de problemas e respeito à diversidade humana. Outrossim, o respeito ao ritmo de cada um dos membros, a busca de sintonia e a articulação interna entre os pesquisadores foram habilidades de coordenação consideradas essenciais a quaisquer unidades sociais que compartilham objetivos comuns de trabalho.

Um ano mais tarde, Odelius et al. (2011) descreveram como ocorrem processos de funcionamento, aprendizagem, armazenagem, e compartilhamento de informações em grupos de pesquisa, e executaram pesquisa exploratória e de campo em uma instituição pública de ensino superior brasileira. Os pesquisadores coletaram dados junto a líderes de dez grupos de pesquisa da referida instituição por meio de entrevistas com roteiros semiestruturados, as quais foram gravadas, transcritas, organizadas e analisadas, tanto individualmente quanto em seu conjunto.

Quanto à caracterização e modo de funcionamento dos dez grupos de pesquisa estudados, de modo geral, os grupos foram criados para facilitar a produção de conhecimentos, reunindo pesquisadores com interesses comuns, visando à produção e divulgação de conhecimentos e à busca de reconhecimento e visibilidade. Os principais aspectos identificados como importantes para os resultados dos grupos foram a qualidade do trabalho em equipe; o apoio institucional; a participação em congressos e a formação de redes interinstitucionais de pesquisa. 
Quanto ao compartilhamento, armazenamento e acúmulo de conhecimento, o referido estudo apontou que a memória do grupo parece ser transmitida, principalmente, por meio de conversas entre os membros, por relatos e pelo registro dos resultados de pesquisa em artigos e livros. Destacam-se, portanto, a transmissão oral dos conhecimentos por iniciativa de integrantes mais experientes em apoio aos menos experientes, e também a consulta a documentos e repositórios virtuais de conhecimento.

Quanto à aprendizagem de competências, esse estudo aponta que, segundo os líderes, a aprendizagem de competências ocorre informalmente e em situações de realização conjunta de pesquisas e na discussão de resultados. Os participantes dos grupos aprendem por transmissão oral, por leituras dirigidas e pela solução de problemas ocorridos durante as atividades de pesquisa. Novos valores e atitudes favoráveis ao trabalho em equipe e de respeito à diversidade humana também são aprendidos nos grupos. Esses pesquisadores ainda expõem achados referentes a habilidades de gestão de pessoas, ligadas à coordenação de atividades, ao controle de diferentes ritmos, à valorização e ao aproveitamento das contribuições de integrantes menos instruídos.

Por fim, Odelius et al. (2011) identificaram alguns elementos-chave para que grupos de pesquisa atinjam resultados mais eficazes: 1) esforço, interesse e empenho de seus integrantes; 2) apoio material; e 3) financiamento recebido para a realização das pesquisas.

Já González-Alcaide, Aleixandre-Benavent e Granda-Orive (2010), com o objetivo de analisar o padrão de 'produção científica em colaboração', no âmbito de uma especialidade da área de saúde, e a visibilidade (número de citações recebidas) gerada por artigos em coautoria, pesquisaram 3.484 artigos oriundos de 5.008 instituições de 79 países. Como resultado, esses autores identificaram que artigos interinstitucionais e em colaboração internacional receberam mais citações em comparação com aqueles sem qualquer colaboração; que as redes de colaboração estavam totalmente conectadas mediante um único componente, e que o aumento anual do tamanho dessas redes entre países decorreu do ingresso de novos países na periferia da rede.

Vasquez-Rizo (2010) estudou 29 grupos de pesquisa em uma universidade privada colombiana e propôs um conjunto de indicadores para medir a capacidade produtiva desses grupos: livros, resultados da investigação, patentes, artigos em revistas internacionais homologados como "A", artigos em revistas internacionais homologados como "B", artigos em revistas nacionais indexadas "A", capítulos de livros, artigos em revistas internacionais homologados "C", artigos em periódicos nacionais indexados "B", artigos em periódicos 
nacionais indexados "C", registros de software, artigos em revistas internacionais não aprovados, artigos em periódicos nacionais não indexados, artigos em eventos, memórias de pesquisa, documentos técnicos, manuais, notas técnicas, módulos de classe e documentos de análise. Para tanto, esse autor utilizou análise documental de produtos de conhecimento desenvolvidos nos grupos segundo a definição do instituto Colciencias, entrevistas nãoestruturadas para validação da construção dos indicadores de desempenho e questionários com o uso de escala de 5 pontos para ponderação de indicadores. Segundo esse autor, os indicadores de produtividade mais importantes são livros, patentes e artigos publicados em revistas internacionais classificadas como A e B e nacionais classificadas como A. Esse autor, ao se ver diante de significativa variedade de preditores, sugere a unificação dos critérios institucionais como solução de grande importância para a verificação dos resultados em grupos de pesquisa. Propõe a criação de novos instrumentos que analisem variáveis capazes de identificar a real participação dos membros nas atividades do grupo, e que possam verificar se os investimentos financeiros na capacitação de pesquisadores, de fato, melhoram a sua produtividade em grupos de pesquisa.

Erdmann et al. (2012) estudaram os modos de organização e funcionamento dos Grupos de Pesquisa de Gestão de Enfermagem, cadastrados no Conselho Nacional de Desenvolvimento Científico e Tecnológico - CNPq. As autoras estavam interessadas em identificar os aspectos que levavam um grupo a ser funcional (longevo e produtivo). Com base em doze entrevistas com líderes de grupos de pesquisa, distribuídos em 2 grupos amostrais, as autoras descreveram como os diferentes grupos estruturavam suas atividades, quais os principais aportes teóricometodológicos; o ambiente da pesquisa; as relações intragrupais; as atitudes do líder; as dificuldades enfrentadas, bem como as estratégias de sobrevivência. Nesse ínterim, as autoras puderam identificar aspectos que proporcionam a sobrevivência dos grupos de pesquisa: interações estabelecidas intra e interinstitucionais, inclusão de novos membros, aplicação das potencialidades e habilidades individuais de forma interativa, oportunidades de produção científica e fortalecimento das linhas de pesquisa.

Mendes, Caliari e Santos (2014) ressaltaram a importância da interação de universidades/institutos de pesquisa com as empresas, como forma de gerar novas tecnologias. Mediante pesquisas nos cinco censos disponibilizados, até então, na Base de Dados dos Grupos de Pesquisa do CNPQ, os autores concluíram que: a) há relação positiva e altamente significante entre a geração de tecnologia e a interação entre os grupos de pesquisas e empresas; b) os grupos que possuem relacionamentos com o maior número de empresas possível consegue gerar mais 
tecnologias; c) um maior número de publicações está associado à criação de tecnologia; d) as publicações de artigos em periódicos internacionais e em anais de congresso possuem correlação positiva e significante com a tecnologia gerada pelos grupos; e) a correlação entre a publicação em periódicos nacionais, livros e capítulos de livros com a tecnologia gerada por esses grupos são considerados não significantes; f) orientações de mestrandos e doutorandos têm relação positiva e significante com o incremento tecnológico dos grupos; e g) orientações de monografias e/ou trabalhos de conclusão de curso possuem correlação negativa com o incremento tecnológico dos grupos.

Pinto e Dornelas (2014) estudaram a colaboração enquanto propulsora de resultados em grupos de pesquisa. Esses autores, visando identificar os aspectos colaborativos relacionados à interação, comunicação e colaboração entre os membros de grupos de pesquisa vinculados à Universidade Federal de Pernambuco, aplicaram 464 questionários por e-mail e obtiveram 71 respostas efetivas. Como resultado, concluiu-se que: a) todos os respondentes afirmaram manter interações em seu grupo de pesquisa, sendo 18,3\%, diariamente, 22,5\% semanalmente, 22,5\% mensalmente, e 36,6\%, ad hoc, isto é, sempre que necessário; b) 94,4\% dos grupos estudados declararam utilizar ferramentas tecnológicas em prol da colaboração; e c) a colaboração se dá mediante elaboração de trabalhos científicos $(97,0 \%)$, execução de projetos de pesquisa $(88,1 \%)$, elaboração de projetos de pesquisa $(86,6 \%)$, realização de reuniões de pesquisa $(83,6 \%)$, realização de apresentações $(73,1 \%)$ e busca por bibliografia de interesse do grupo $(71,6 \%)$

Santana et al. (2014) sinalizaram e discutiram sobre alguns indicadores de grupos de pesquisa na área de Gestão da Informação na Região Nordeste, também com foco na colaboração, sobretudo na produção de artigos de periódicos. Foram considerados os históricos e as produções de dezoito grupos de pesquisa, no período de 2000 a 2012, com base em dados secundários constantes do Currículo Lattes. Como resultado, foram apontados alguns aspectos que interferem nos resultados dos grupos de pesquisa estudados, tais como: a produção científica considerando-se tanto os periódicos quanto os seus estratos Qualis; o tempo de existência do grupo; a coautoria; e a atuação em redes de colaboração entre pesquisadores de diferentes grupos. Outro achado interessante é que os grupos de pesquisa mais produtivos são os que estabelecem parcerias externas e agregam membros exteriores em suas pesquisas e publicações.

Garcia et al. (2015) apontaram alguns aspectos que influenciam os resultados de grupos de pesquisa, no que tange às interações universidade-empresa, uma vez que a aproximação entre academia e mercado gera inovações que beneficiam as organizações. Os autores 
desenvolveram um modelo que sugere que o número de interações com empresas ocorre em função das seguintes variáveis: 1) média da nota atribuída aos programas de pós-graduação da área de avaliação em que o grupo de pesquisa está inserido; 2) número de docentes do departamento associado ao grupo de pesquisa; 3) total de integrantes do grupo de pesquisa; 4) dummies para áreas do conhecimento; 5) número de trabalhadores com grau superior completo; e 6) densidade populacional urbana da microrregião em 2007 em 10.000, cujas fontes constam do

Quadro 13.

Quadro 13 - Descrições das variáveis do Modelo de Garcia et al. (2015)

\begin{tabular}{|c|c|c|}
\hline Variável & Descrição & Fonte \\
\hline $\mathrm{N}^{\mathrm{o}}$ Int & Número de interações com empresas relatadas pelo grupo & Survey \\
\hline Quali & $\begin{array}{l}\text { Média da nota atribuída aos programas de pós-graduação da área de avaliação em } \\
\text { que o grupo de pesquisa está inserido }\end{array}$ & CAPES,2007 \\
\hline Tam $_{\text {dep }}$ & Número de docentes do departamento associado ao grupo de pesquisa & CAPES,2006 \\
\hline Tam $_{\text {grup }}$ & Total de integrantes do grupo de pesquisa & Survey \\
\hline Area $_{\text {conhec }}$ & Dummies para áreas de conhecimento & Survey \\
\hline CapHum & Número de trabalhadores com grau superior completo em 2007 & RAIS,2007 \\
\hline DensUrb & $\begin{array}{l}\text { Densidade populacional urbana (pop. urbana/área urbanizada) da microrregião em } \\
2007 \text { em } 10.000 .\end{array}$ & IBGE,2007 \\
\hline
\end{tabular}

Fonte: Garcia et al. (2015, p. 138)

O referido modelo avalia como as características dos grupos de pesquisa impactam suas interações com empresas e aplicaram um survey a grupos de pesquisa brasileiros. Como resultado, esses autores concluíram que os grupos de pesquisa que mais proporcionam interação com o mercado são os que possuem melhor rendimento acadêmico, que têm maior número de integrantes e que estão ligados a maiores departamentos universitários. Ademais, pôde-se identificar que áreas de Engenharia e Ciências Agrárias são as que mais interagem com empresas.

As interações entre empresas e grupos de pesquisa também foram o objeto de estudo de Araújo et al. (2015), os quais buscaram correlacioná-las com as percepções de benefícios, resultados e dificuldades dos grupos de pesquisa. A partir de um survey, estimou-se um modelo para identificar como essas percepções influenciam na quantidade de interações dos grupos. Pode-se afirmar, segundo os autores, que a interlocução com empresas enseja uma melhor reputação ao grupo de pesquisa, além de proporcionar maior acesso a benefícios tangíveis, como equipamentos, instrumentos de uso compartilhado, insumos para as pesquisas e recursos financeiros. Ademais, a interação com empresas proporciona resultados de conhecimento (novas descobertas científicas e projetos de pesquisa); resultados acadêmicos (formação das pessoas, trabalhos acadêmicos, publicações e softwares); e resultados de inovação (produtos, 
artefatos, patentes, design, criação de novas empresas, processos e produtos industriais). Os achados indicam que o tamanho do grupo interfere positiva e significativamente nas interações com empresas, as quais são ainda maiores quando os membros valorizam benefícios intangíveis e conseguem visualizar os resultados de conhecimentos provenientes das interações. Outrossim, os grupos de pesquisa que não dispõem de competências para negociação (dificuldades transacionais) interagem menos com empresas.

Ferraz e Dornelas (2015) consideraram que o uso de recursos da tecnologia da informação é um indicativo de maiores resultados em grupos de pesquisa, enquanto organismos equiparados a comunidades de prática. Por isso, estudaram o compartilhamento de recursos em comunidades virtuais de prática (grupos de pesquisa científica de uma Universidade Federal), bem como seus mecanismos de interação, organização e controle. Segundo esses autores, comunidades de prática se caracterizam por relações informais, pela formação de rede e pela autogestão. E quando prevalecem as interações via recursos da tecnologia da informação, estáse diante de comunidades virtuais de prática. Numa abordagem mista, composta por aplicação de survey e de estudo de caso, concluiu-se que a interação é um fator a ser considerado para os resultados do grupo, e, na amostra pesquisada, a colaboração se explicitou por meio de seminários, reuniões, eventos, produções científicas, notícias veiculadas sobre os grupos em canais da imprensa e parcerias ou projetos com outras instituições. Essa interação também é fortemente proporcionada por meio de listas de e-mail, MSN®, Skype®, Google Talk®, Google Docs ${ }^{\circledR}$, home page, webconferência, videoconferência e redes sociais.

Henderson et al. (2015) destacaram a importância da disponibilização de uma equipe de suporte informacional para os resultados de um grupo interdisciplinar de pesquisa, sobretudo, pela geração de maior colaboração entre os membros. A partir de subvenções da US National Library of Medicine, a Virginia Commonwealth University disponibilizou uma equipe de suporte informacional para fazer face ao crescente número de grupos de pesquisa interdisciplinares e interprofissionais. Entrevistas revelaram que a pesquisa da literatura, a gestão de citações bibliográficas, o compartilhamento e o gerenciamento de dados são os aspectos que possuem grande importância para os resultados dos grupos. Além disso, apurouse houve melhorias para os grupos que dispunham de bibliotecários como integrantes da equipe de suporte informacional, já que participavam das reuniões do grupo, esclareciam dúvidas em sua área de domínio e gerenciavam ferramentas de colaboração.

Ramos-Vielba, Sánchez-Barrioluengo e Woolley (2015) estudaram sobre as motivações e os obstáculos para a cooperação dos grupos de investigação científica com empresas e 
agências governamentais na Espanha, uma vez que a cooperação interfere positivamente nos resultados do grupo. Mediante questionário eletrônico dirigido a 851 líderes de grupos de pesquisa, indagou-se sobre características do grupo de pesquisa; relações entre o grupo e outros agentes do sistema de inovação; a cooperação com as empresas; e sobre o contexto regional para a cooperação intersetorial com organizações não-acadêmicas. Os achados que indicaram que a maioria dos grupos de pesquisa cooperam tanto com empresas quanto com os governos, sendo que a cooperação entre grupos de pesquisa e órgãos públicos decorre do compartilhamento de objetivos de pesquisa comuns, enquanto que a parceria entre grupos de pesquisa e empresas privadas é motivada por oportunidades para aplicar o conhecimento. Vale destacar que, diferentemente do que ocorre com a cooperação entre parceiros externos nas organizações em geral, os Grupos de pesquisa não se sentem ameaçados com a possibilidade de perda de autonomia científica. Outro achado interessante é que os grupos motivados para avançar com as pesquisas sentem menores impactos oriundos dos entraves à cooperação.

Elencados os principais aspectos que interferem nos resultados de grupos de pesquisa, segundo a literatura mais recente, e conforme anunciado anteriormente, passa-se a tratar, especificamente da influência do líder na obtenção de resultados em grupos de pesquisa, principalmente à luz dos achados de Harvey, Pettigrew e Ferlie (2002), mas também de outros estudos correlatos.

Dentre os aspectos que afetam os resultados de grupos de pesquisa, a liderança é um dos mais comumente citados (HARVEY; PETTIGREW; FERLIE, 2002; MAUTHNER; DOUCET, 2008; WEIJDEN ET AL., 2008; BUENO, 2014). É o caso de um estudo conduzido por HiguitaLópez, Molano-Velandia e Rodríguez-Merchán (2011), que buscava demonstrar a articulação entre a aquisição de competências em grupos de pesquisa e o processo de pesquisa. Com a participação de 52 líderes de grupos de pesquisa da Universidad Nacional de Colombia, esses pesquisadores indicaram a existência de oito competências gerais e nove competências específicas relevantes para processo de pesquisa. No âmbito das competências gerais está a liderança, especificada nos seguintes termos: liderar e direcionar estrategicamente as atividades e projetos para o benefício do grupo, em conexão com os recursos e equipamentos específicos de trabalho.

A consideração da liderança como um aspecto influenciador do desempenho de grupos de pesquisa ocorre porque as interações dos integrantes de grupos de pesquisa são regidas por princípios hierárquicos, que valorizam tanto a experiência quanto a competência técnicocientífica de líderes (ODELIUS et al., 2010). Segundo Freitas Jr. et al. (2003), essa interação 
entre a liderança e os demais pesquisadores de um grupo de pesquisa acarreta diferenças significativas no formato do grupo, na composição dos objetivos a serem perseguidos e no nível de cooperação, aspetos sobremaneira relevantes a obtenção de resultados superiores. Segundo esses autores, essa relação, no contexto de grupos de pesquisa, ocorre naturalmente e sem excessivas formalidades. Isso contribui para que o compartilhamento do conhecimento aconteça mediante conversas casuais e pela observação de membros mais experientes.

Outrossim, os resultados do grupo dependem de um líder sensível ao contexto. Estudos de caso indicam que as competências indispensáveis para a atuação do líder de grupo de pesquisa estão mudando, uma vez que é perceptível que os líderes estejam cada vez mais interagindo com um ambiente notadamente complexo e similar ao dos negócios (PETTIGREW; WHIPP, 1991). Na mesma linha, Jansen, Vera e Crossan, (2009) sugerem, inclusive, a adoção do dinamismo ambiental como um moderador nos estudos sobre o modo como as organizações aprendem, porque, em ambientes turbulentos, o estilo de liderança tende a ser nitidamente diferente do adotado em contextos estáveis.

Segundo Pettigrew e Whipp (1991), quando há mudanças seja no contexto intraorganizacional seja no ambiente externo competitivo, é requerido do líder de grupo de pesquisa que aja de modo a adaptar seu estilo de liderança. Os autores exemplificam a afirmação comparando a postura do líder de grupo em um departamento de ensino de uma universidade durante uma época de estabilidade financeira, com a postura do mesmo líder durante um período financeiro instável. Neste último caso, o líder precisará, seguramente, de mais habilidades de empreendedorismo e de aguçar suas competências políticas para atingir os resultados pretendidos pelo grupo.

Corroborando essa perspectiva situacional, Grinyer, Mayes e Mckiernan (1988) advogam que, se os líderes permanecerem com o mesmo perfil de liderança sob diferentes circunstâncias organizacionais, sob o argumento de que determinada postura foi bem-sucedida no passado, estarão contribuindo para o declínio organizacional. Mejía-Correa (2007), por exemplo, descreveu, em seu estudo, as mudanças por que passaram grupos de pesquisa de uma universidade da Colômbia, e, em decorrência delas, o modo como os líderes adotaram estilos de liderança diversos, mas sem comprometerem os resultados a que pretendiam chegar. $\mathrm{O}$ contexto da universidade requeria líderes que propiciassem uma estrutura organizacional contemporânea, que privilegiasse a estrutura de projetos, a gestão do conhecimento e da aprendizagem, e o trabalho em equipe, em detrimento de perfis tradicionais, voltados ao controle e a estruturas mecanicistas. 
O exercício da liderança em grupos de pesquisa também interfere fortemente no estabelecimento de redes. Segundo Robson e Shove (1999), para ser capaz de ascender na carreira, o líder de grupo de pesquisa precisa desenvolver redes tanto acadêmicas quanto extraacadêmicas, e deve equilibrar ambas as relações.

Outro fator importante é o modo como os líderes conduzem as reuniões e a interação dos grupos de pesquisa. Melhores resultados são obtidos caso o líder evite o retrabalho dos pesquisadores e o redescobrimento de achados previamente descobertos por outros integrantes do grupo. Isso confere economia de tempo e disponibiliza maior tempo livre para realização de novos estudos (VINCENT, 2009).

Por fim, vale destacar que cabe principalmente ao líder a atração, motivação e retenção de pesquisadores. Compete ao líder delimitar ou ampliar a diversificação temática de seu grupo. Além disso, o líder tem papel crucial em proporcionar forte ligação entre teoria e prática seja materialmente (captando recursos) seja intelectualmente (fomentando a concretude e a relevância prática das pesquisas em benefício da ciência e da sociedade), bem como de fomentar a conectividade em redes, investindo em parcerias na própria instituição em que atua, na rede de pesquisadores do país e até internacionalmente. Ademais, é também do líder o papel de viabilizar a construção de redes com os investidores e patrocinadores (HARVEY; PETTIGREW; FERLIE, 2002).

Em suma, os quatro aspectos tratados por Harvey, Pettigrew e Ferlie (2002) na seção anterior (atração, motivação e retenção de talentos; estratégias relacionadas à diversificação; forte ligação entre teoria e prática e conectividade em redes) dependem ou parecem ser fortemente influenciados pelas competências gerenciais do líder do grupo de pesquisa. Assim, o quinto aspecto citado por esses autores (liderança forte) acaba influenciando os demais, além de interferir diretamente no desempenho do grupo.

Para concluir o referencial teórico, apresenta-se o Quadro 14, em que constam os autores recorridos, os anos de suas publicações e os aspectos que influenciam os resultados em grupos de pesquisa, dentre os quais se destacam Trabalho em equipe, colaboração e coautoria; Conectividade em redes; Liderança e competências gerenciais; Obtenção de recursos (apoio, fomento, patrocínio); Produção anterior; Gestão do conhecimento e da aprendizagem; Atração, motivação e retenção de talentos; Ligação entre teoria e prática; Habilidade de pesquisa acadêmica; e Estruturas de suporte de informação e de comunicação. 
Quadro 14 - Estudos relativos a aspectos que influenciam resultados de grupos de pesquisa

\begin{tabular}{|c|c|c|c|c|c|c|c|c|c|c|c|c|c|c|c|c|c|c|c|}
\hline $\begin{array}{l}\text { Aspectos que influenciam os } \\
\text { resultados em grupos de pesquisa }\end{array}$ & 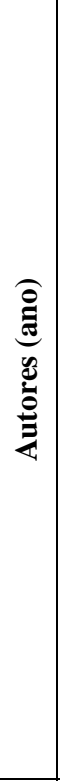 & 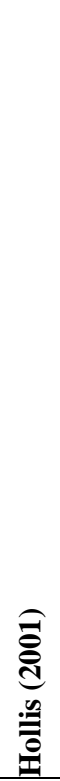 & 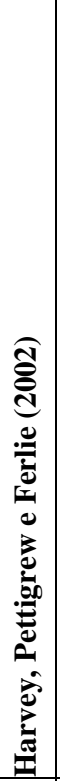 & 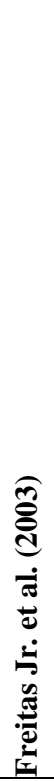 & 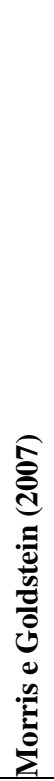 & 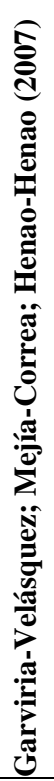 & 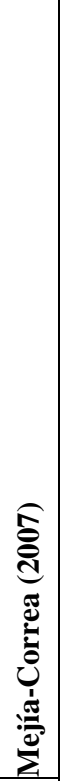 & 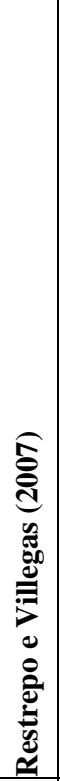 & 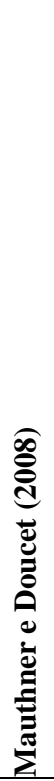 & 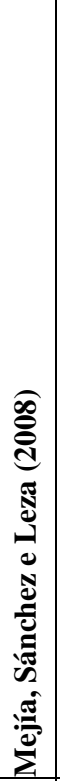 & 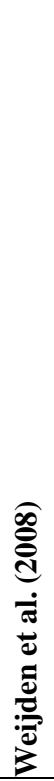 & 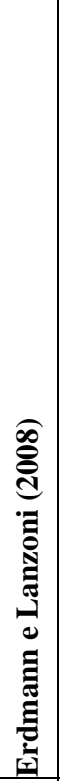 & 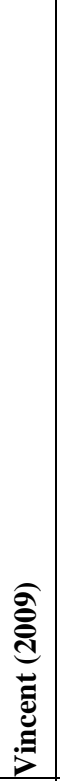 & 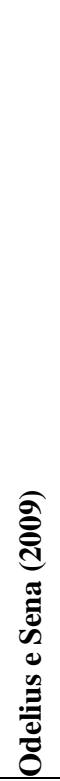 & 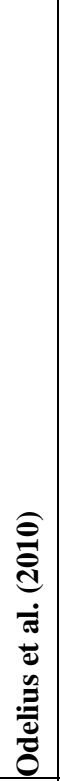 & 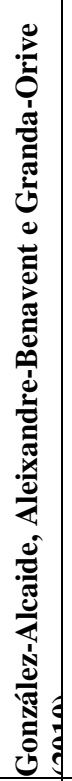 & 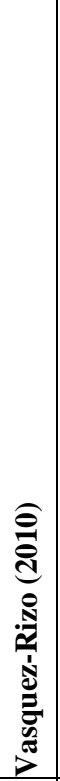 & 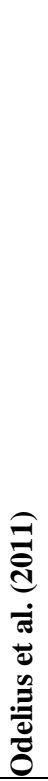 & 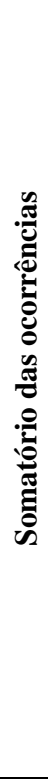 \\
\hline $\begin{array}{l}\text { Trabalho em equipe, colaboração e } \\
\text { coautoria }\end{array}$ & & $\mathrm{x}$ & & $\mathrm{x}$ & $\mathrm{x}$ & & $\mathrm{x}$ & & $\mathrm{x}$ & & $\mathrm{x}$ & & & $\mathrm{x}$ & $\mathrm{x}$ & $\mathrm{x}$ & & $\mathrm{x}$ & 10 \\
\hline Conectividade em redes & & & $\mathrm{x}$ & & $\mathrm{x}$ & & & & $\mathrm{x}$ & $\mathrm{x}$ & & & & $\mathrm{x}$ & & $\mathrm{x}$ & & $\mathrm{x}$ & 7 \\
\hline Liderança e competências gerenciais & & & $\mathrm{x}$ & $\mathrm{x}$ & & & $\mathrm{x}$ & & $\mathrm{x}$ & & $\mathrm{x}$ & & & & $\mathrm{x}$ & & & $\mathrm{x}$ & 7 \\
\hline $\begin{array}{l}\text { Gestão do conhecimento e da } \\
\text { aprendizagem }\end{array}$ & & & & $\mathrm{x}$ & & $\mathrm{x}$ & $\mathrm{x}$ & & $\mathrm{x}$ & & & & & & & & & $\mathrm{x}$ & 5 \\
\hline $\begin{array}{l}\text { Obtenção de recursos (apoio, fomento, } \\
\text { patrocínio) }\end{array}$ & & & & & $\mathrm{x}$ & & & & $\mathrm{x}$ & & $\mathrm{x}$ & & & & & & & $\mathrm{x}$ & 4 \\
\hline $\begin{array}{l}\text { Atração, motivação e retenção de } \\
\text { talentos }\end{array}$ & & & $\mathrm{x}$ & & & & & & $\mathrm{x}$ & & & & & & & & & $\mathrm{x}$ & 3 \\
\hline Ligação entre teoria e prática & & & $\mathrm{x}$ & & & & & $\mathrm{x}$ & & & $\mathrm{x}$ & & & & & & & & 3 \\
\hline Habilidade de pesquisa acadêmica & & & & & & & & & $\mathrm{x}$ & & & & & $\mathrm{x}$ & & & $\mathrm{x}$ & & 3 \\
\hline Produção anterior & & & & & & & & & & $\mathrm{x}$ & & $\mathrm{x}$ & $\mathrm{x}$ & & & & & & 3 \\
\hline Diversificação Temática & & & $\mathrm{x}$ & & & & & & & $\mathrm{x}$ & & & & & & & & & 2 \\
\hline Especificação de objetivos & & & & $\mathrm{x}$ & & & & & & & & & & & $\mathrm{x}$ & & & & 2 \\
\hline $\begin{array}{l}\text { Estruturas de suporte de informação e de } \\
\text { comunicação }\end{array}$ & & & & & & & & & & $\mathrm{x}$ & & & & $\mathrm{x}$ & & & & & 2 \\
\hline $\begin{array}{l}\text { Visibilidade e reconhecimento da área de } \\
\text { atuação }\end{array}$ & & & & & & & & & & $\mathrm{x}$ & & $\mathrm{x}$ & & & & & & & 2 \\
\hline Apoio institucional & & & & & & & & & & & & & & & & & & $\mathrm{x}$ & 1 \\
\hline Formato do grupo & & & & $\mathrm{x}$ & & & & & & & & & & & & & & & 1 \\
\hline Menções e prêmios & & & & & & & & & & & $\mathrm{x}$ & & & & & & & & 1 \\
\hline Participação em congressos & & & & & & & & & & & & & & & & & & $\mathrm{x}$ & 1 \\
\hline Qualificação dos integrantes & & & & & & & & & & & & $\mathrm{x}$ & & & & & & & 1 \\
\hline Tamanho do grupo & & & & & & & & & & & $\mathrm{x}$ & & & & & & & & 1 \\
\hline Tempo de existência do grupo & & & & & & & & & & $\mathrm{x}$ & & & & & & & & & 1 \\
\hline $\begin{array}{l}\text { Tempo destinado às atividades de } \\
\text { pesquisa }\end{array}$ & & & & & & & & & & & $\mathrm{X}$ & & & & & & & & 1 \\
\hline
\end{tabular}

Fonte: elaborado pelo autor com base na literatura

Por fim, vale salientar novamente que, para melhor exposição dos achados do referencial teórico, e com os mesmos critérios utilizados para o 
Quadro 12 - Classificação das Competências Gerenciais segundo diferentes autores, os aspectos que influenciam os resultados de grupos de pesquisa foram concatenados por proximidade dos temas, a partir das definições constitutivas e/ou operacionais apresentadas pelos próprios autores.

Encerrada a revisão teórica sobre competências gerenciais e resultados de grupos de pesquisa, bem como de seus aspectos influenciadores, o próximo capítulo tratará do percurso metodológico trilhado visando ao alcance dos objetivos traçados. 


\section{METODOLOGIA}

Assim como mencionado na justificativa institucional, os dados coletados previamente pelo Grupo Inovação e Aprendizagem em Organizações foram revisitados e versões iniciais de instrumentos de pesquisa (Anexos A, B e C) foram adaptadas e aprimoradas com base no referencial teórico recorrido, submetidas à avaliação de juízes e a um pré-teste. Posteriormente, procedeu-se a coleta, processamento e análise dos dados, mediante análise fatorial, diferenças de médias e medianas e estudos de correlação, que foram a base para as discussões, resultados e conclusões.

No presente capítulo, passa-se a discorrer a respeito do caminho metodológico percorrido para a concretização dos objetivos gerais e específicos delineados para este estudo. Para tanto, apresentar-se-ão, a seguir, informações a respeito do desenho da pesquisa (natureza, escopo, recorte, abordagem e delineamento); da população e amostra; e da origem dos dados (instrumentos, amostragem, coleta e análise de dados).

\subsection{Desenho da Pesquisa}

A presente pesquisa possui natureza explicativa-exploratória (classificação quanto aos fins), porque visa identificar os fatores que contribuem ou determinam a ocorrência ou a maneira de ocorrer dos fatos e fenômenos, mas, ao mesmo tempo, não se indentificou pesquisas que estudassem concomitantemente os fenômenos 'competências gerenciais' e 'resultados', no contexto de grupos de pesquisa (SANTOS, 2002; RICHARDSON, 2010).

Adotando o escopo estatístico, este estudo pretende alcançar validade externa e generalização. Contudo, essa generalização não deve ser considerada do tipo 'estatística', uma vez que os sujeitos foram acionados por acessibilidade e pela estratégia da bola-de-neve (compartilhamento do instrumento de pesquisa por parte dos primeiros participantes acionados a outros possíveis respondentes que atendam aos requisitos de participação) (POLIT; BECK; HUNGLER, 2004).

Diante de seu caráter exploratório, considera-se que a generalização perseguida por este estudo é do tipo 'analítica', na qual o pesquisador consegue ensaiar proposições teóricas ou hipóteses com o potencial de serem testadas ou replicadas em contextos diferentes do orinalmente aplicado (YIN, 1994; ALVES-MAZZOTTI, 2006). Pode-se esperar, também a 
generalização do tipo 'naturalística', em que fica a cargo do leitor definir para que populações ou contextos os achados podem ser generalizados, ou seja, a partir da narrativa e do relato dos resultados de um pesquisador, os futuros pesquisadores conseguem estabelecer associações e conexões a respeito do fenômeno observado, analisando-as em novos contextos (STAKE, 1978; 2000; ALVES-MAZZOTTI, 2006).

Por meio de um recorte transversal, a coleta dos dados ocorreu num único instante no tempo, gerando um recorte momentâneo do fenômeno investigado (JUNG, 2011). Em simples palavras, trata-se de uma "fotografia" de como resultados em grupos de pesquisa estão relacionadas com competências gerenciais de seus líderes.

Quanto à natureza, a pesquisa se desenvolveu segundo uma abordagem mista, porque, no mesmo trabalho, dados qualitativos e quantitativos foram coletados e analisados, permitindo-se a obtenção de dados complementares ao entendimento dos fenômenos estudados (CRESWELL, 2013).

O delineamento correlacional foi adotado, uma vez que as relações entre os fenômenos foi investigada, verificando-se as variáveis referentes ao domínio de competências gerenciais por líderes de grupos de pesquisa interferiam nas variáveis relativas a resultados de grupos (GRESSLER, 2007).

\subsection{População e Amostra}

Segundo Odelius et al. (2011), no Brasil, é o CNPq o responsável por organizar e divulgar os dados relativos a grupos de pesquisa em um diretório acessível a toda a sociedade, visando proporcionar o intercâmbio de informações e simplificar o acesso para a comunidade acadêmica e científica: iniciativa que contribui para a manutenção da memória da atividade científico-tecnológica brasileira.

O CNPq mantém uma base de dados denominada "Diretório de Grupos de Pesquisa no Brasil", a qual possibilita o acesso a informações referentes a grupos de pesquisa, pesquisadores, líderes e estudantes cadastrados na plataforma Lattes entre outras. Desde 1993, a cada dois anos, aproximadamente, o CNPq realiza um censo e disponibiliza dados descritivos dos grupos, objetivos, linhas de pesquisa, localização, participantes dos grupos, áreas de conhecimento vinculada, instituição vinculada entre outras informações. Todos seus resultados estão na Internet, em formato aberto. 
É com base no último censo publicado pelo CNPq (2014) que as informações sobre a população foram apuradas. No Brasil, há registro de 35.424 grupos de pesquisa e deles participam 180.262 pesquisadores (sujeitos para o instrumento relativo às competências gerenciais), sendo 30.155 líderes (sujeitos relativos ao instrumento de resultados de grupos de pesquisa).

Os líderes são pesquisadores que, normalmente, recebem bolsas de produtividade do CNPq ou estão vinculados a (pelo menos) um programa de pós-graduação stricto sensu; costumam ser doutores com projeto de pesquisa ou de extensão aprovado nos últimos cinco anos na instituição; e, geralmente, têm indicação formal do departamento acadêmico ou da coordenação de curso para a constituição de grupo emergente com a finalidade específica de pesquisa ligada a essa unidade acadêmica. Vale destacar que, para ser cadastrado no CNPq, o grupo de pesquisa precisa estar vinculado a universidades (federais, estaduais, municipais e privadas), instituições de educação superior não-universitárias que possuam pelo menos um curso de pós-graduação reconhecido pelo MEC, institutos públicos de pesquisa científica, institutos tecnológicos públicos, centros federais de educação tecnológica ou laboratórios de pesquisa e desenvolvimento de empresas estatais (CNPq, 2015). Além disso, o líder e os demais membros do grupo devem, obrigatoriamente, estar cadastrados na Plataforma Lattes (CNPq, 2015).

Passa-se então à caracterização da população, especialmente, no que tange aos líderes de grupos de pesquisa, enquanto sujeitos principais deste estudo. Mas também serão explicitados alguns dados demográficos e informações relevantes sobre pesquisadores, grupos de pesquisa e seus resultados, já que esse é o foco desta Dissertação.

Quanto à faixa etária, 74\% dos líderes de grupo possuem entre 34 e 59 anos de idade, sendo $8 \%$ os líderes com menos de 35 anos e $18 \%$ os com 60 anos ou mais, nos termos da Tabela 4.

Tabela 4 - Faixa etária da população de Líderes de grupos de pesquisa

\begin{tabular}{cccc}
\hline Idade & $\begin{array}{c}\text { Quantidade de } \\
\text { Líderes }\end{array}$ & \% & \% Acumulado \\
\hline Até 24 & 15 & $0,05 \%$ & $0 \%$ \\
25 a 29 & 381 & $1,3 \%$ & $1 \%$ \\
30 a 34 & 2065 & $6,8 \%$ & $8 \%$ \\
35 a 39 & 3745 & $12,4 \%$ & $21 \%$
\end{tabular}


Continuação

\begin{tabular}{cccc}
\hline Idade & $\begin{array}{c}\text { Quantidade de } \\
\text { Líderes }\end{array}$ & \% & \% Acumulado \\
\hline 40 a 44 & 4383 & $14,5 \%$ & $35 \%$ \\
45 a 49 & 4886 & $16,2 \%$ & $51 \%$ \\
50 a 54 & 5198 & $17,2 \%$ & $69 \%$ \\
55 a 59 & 3991 & $13,2 \%$ & $82 \%$ \\
60 a 64 & 2775 & $9,2 \%$ & $91 \%$ \\
65 ou mais & 2716 & $9,0 \%$ & $100 \%$ \\
\hline Total & 30155 & $100,00 \%$ & \\
\hline
\end{tabular}

Fonte: Adaptada de CNPq (2015).

Quanto ao sexo, os homens ainda são a maioria dos líderes (16.281 líderes do sexo masculino versus 13.874 do sexo feminino). Mas os percentuais de líderes do sexo masculino apresentam uma tendência de redução, enquanto que a representação das mulheres vem aumentando, pelo menos, desde 1995 (Figura 8).

Figura 8 - Comparação entre o percentual de líderes homens e mulheres

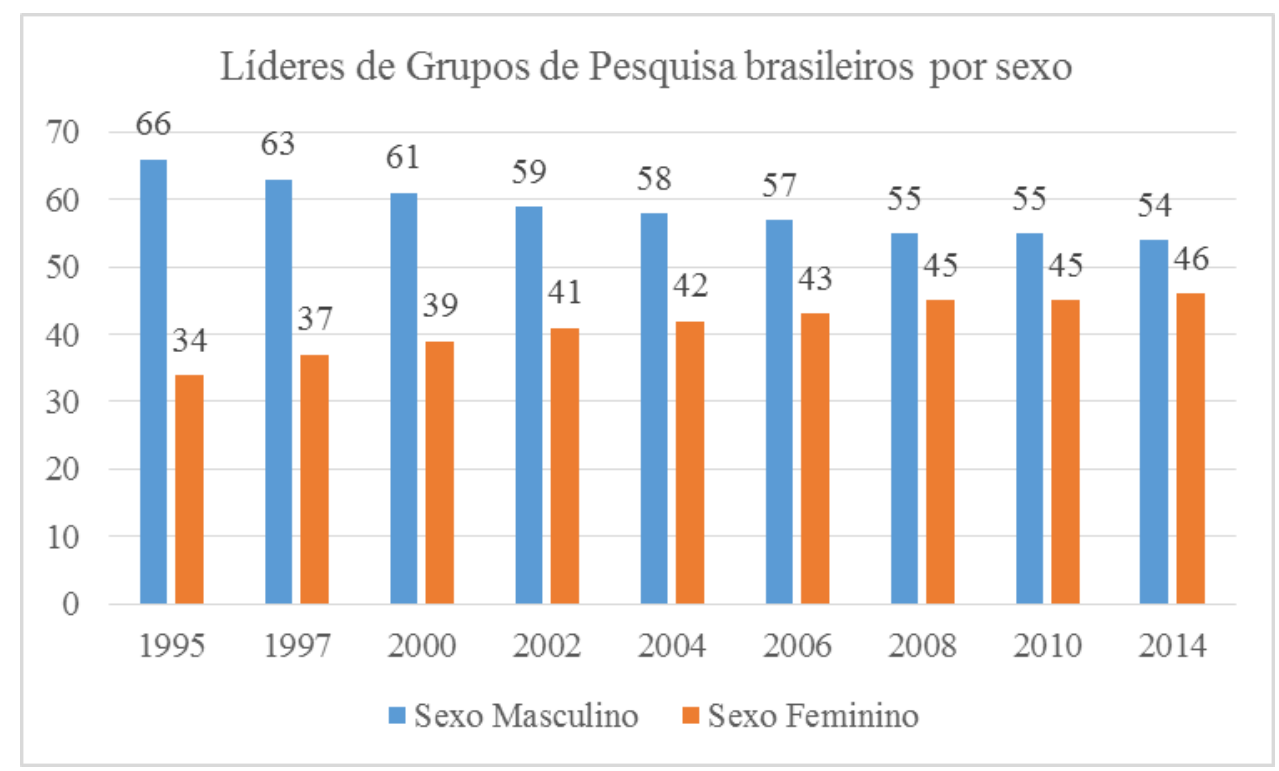

Fonte: Elaborada pelo autor com base em CNPq (2015).

Embora não façam referência especificamente a líderes de grupo, outra variação que merece ser destacada é o incremento no percentual de pesquisadores com a titulação de doutorado ao longo dos anos. Em aproximadamente duas décadas, o percentual partiu de $51 \%$ para $65 \%$. Houve apenas ligeira queda no censo realizado em 2010, retomando-se a tendência 
de aumento no censo de 2014 (Figura 9). A Titulação máxima dos pesquisadores segundo o último censo consta da Tabela 5 .

Figura 9 - Percentual de Doutores entre os Pesquisadores de Grupos de Pesquisa brasileiros

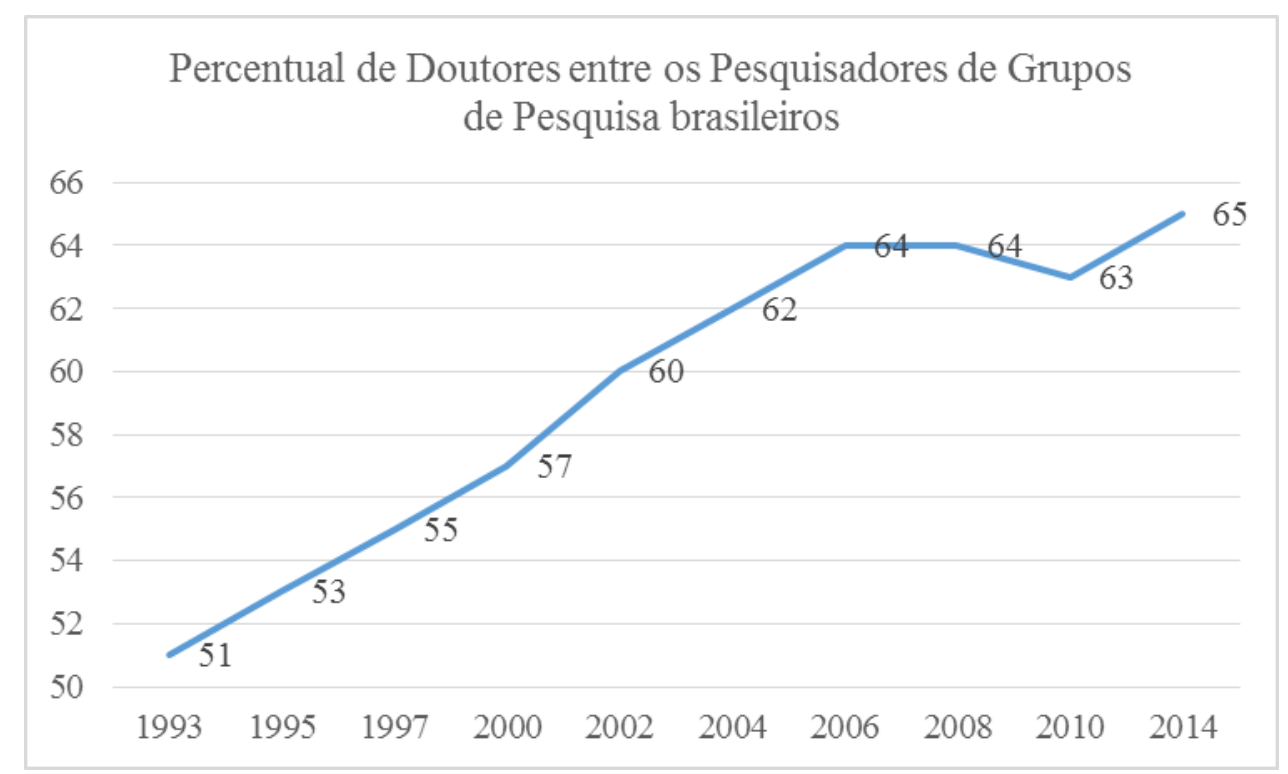

Fonte: Elaborada pelo autor com base em CNPq (2015).

Tabela 5 - Titulação máxima dos Pesquisadores

\begin{tabular}{lrr}
\hline \multicolumn{1}{c}{$\begin{array}{c}\text { Titulação máxima dos } \\
\text { pesquisadores }\end{array}$} & \multicolumn{1}{c}{ Pesq. } & \multicolumn{1}{c}{$\%$} \\
\hline Doutorado & 116.427 & 64,59 \\
Especialização & 8.308 & 4,61 \\
Graduação & 6.008 & 3,33 \\
Mestrado & 45.929 & 25,48 \\
Outros & 3.590 & 1,99 \\
\hline Total & 180.262 & 100 \\
\hline Fonte: CNPq (2015). & &
\end{tabular}

Os grupos de pesquisa brasileiros se concentram, em sua maioria, nas Regiões Sul e Sudeste, perfazendo $67 \%$ do total. As Regiões Centro-Oeste e Norte dispõem apenas de pouco mais de 14\% dos grupos existentes (2654 e 2068 grupos, respectivamente). A Região Nordeste conta com 7215 grupos de pesquisa, cerca de 19\% do total (Figura 10). 
Figura 10 - Grupos de pesquisa por Região

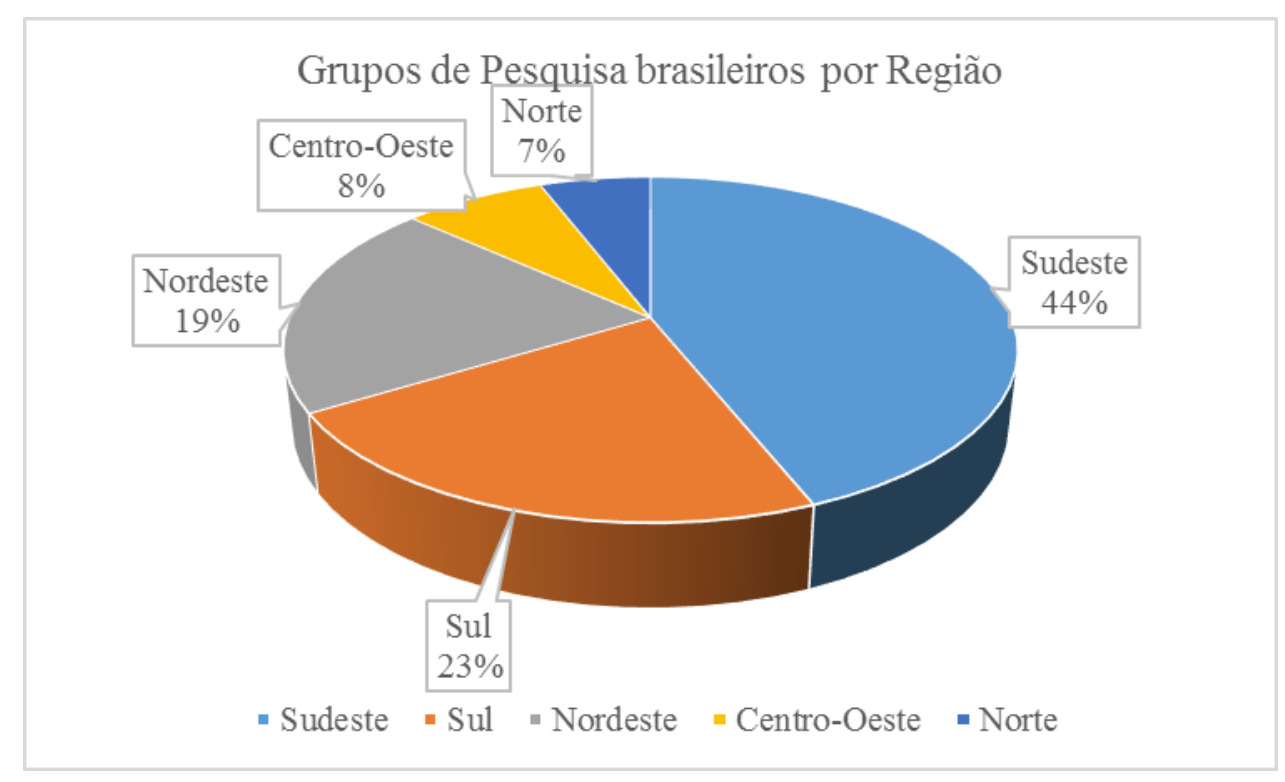

Fonte: Elaborada pelo autor com base em CNPq (2015).

A Tabela 6 detalha melhor a localização dos grupos de pesquisa nas diversas Regiões, explicitando a quantidade de grupos por unidade da federação e os percentuais respectivos

Tabela 6 - Grupos de pesquisa por Unidade da Federação

\begin{tabular}{|c|c|c|c|c|}
\hline Região & UF & Grupo & $\%$ & \% por Região \\
\hline \multirow{4}{*}{ Sudeste } & Espírito Santo & 642 & 1,8 & \multirow{4}{*}{44} \\
\hline & Minas Gerais & 3.482 & 9,8 & \\
\hline & Rio de Janeiro & 4.147 & 11,7 & \\
\hline & São Paulo & 7.278 & 20,6 & \\
\hline \multirow{3}{*}{ Sul } & Paraná & 3.011 & 8,5 & \multirow{3}{*}{23} \\
\hline & Rio Grande do Sul & 3.315 & 9,4 & \\
\hline & Santa Catarina & 1.612 & 4,6 & \\
\hline \multirow{8}{*}{ Nordeste } & Alagoas & 442 & 1,3 & \multirow{8}{*}{19} \\
\hline & Bahia & 1.763 & 5 & \\
\hline & Ceará & 946 & 2,7 & \\
\hline & Maranhão & 366 & 1 & \\
\hline & Paraíba & 1.006 & 2,8 & \\
\hline & Pernambuco & 1.251 & 3,5 & \\
\hline & Piauí & 395 & 1,1 & \\
\hline & Rio Grande do Norte & 641 & 1,8 & \\
\hline \multirow{4}{*}{$\begin{array}{l}\text { Centro- } \\
\text { Oeste }\end{array}$} & Distrito Federal & 808 & 2,3 & \multirow{4}{*}{8} \\
\hline & Goiás & 659 & 1,9 & \\
\hline & Mato Grosso & 538 & 1,5 & \\
\hline & Mato Grosso do Sul & 649 & 1,8 & \\
\hline
\end{tabular}


Continuação

\begin{tabular}{|c|c|c|c|c|}
\hline Região & UF & Grupo & $\%$ & \% por Região \\
\hline \multirow{9}{*}{ Norte } & Acre & 100 & 0,3 & \multirow{8}{*}{7} \\
\hline & Amapá & 141 & 0,4 & \\
\hline & Amazonas & 527 & 1,5 & \\
\hline & Pará & 800 & 2,3 & \\
\hline & Rondônia & 116 & 0,3 & \\
\hline & Roraima & 124 & 0,4 & \\
\hline & Sergipe & 405 & 1,1 & \\
\hline & Tocantins & 260 & 0,7 & \\
\hline & Total & 35.424 & 100 & 100 \\
\hline
\end{tabular}

Fonte: Elaborada pelo autor com base em CNPq (2015).

Quanto à área do conhecimento a que o grupo de pesquisa se vincula, destacam-se as Ciências Humanas (com 7.408 grupos) e as Ciências da Saúde (com 5.609 grupos), das Ciências Sociais Aplicadas (com 4.841 grupos); das Engenharias e Ciências da Computação (com 4.676 grupos); das Ciências Exatas e da Terra; Ciências Agrárias; e Ciências Biológicas (cada uma com mais de 3 mil grupos); e, por fim, Linguística, Letras e Artes (com mais de 2 mil grupos) (Figura 11).

Figura 11 - Grupos de pesquisa por Grande Área do Conhecimento

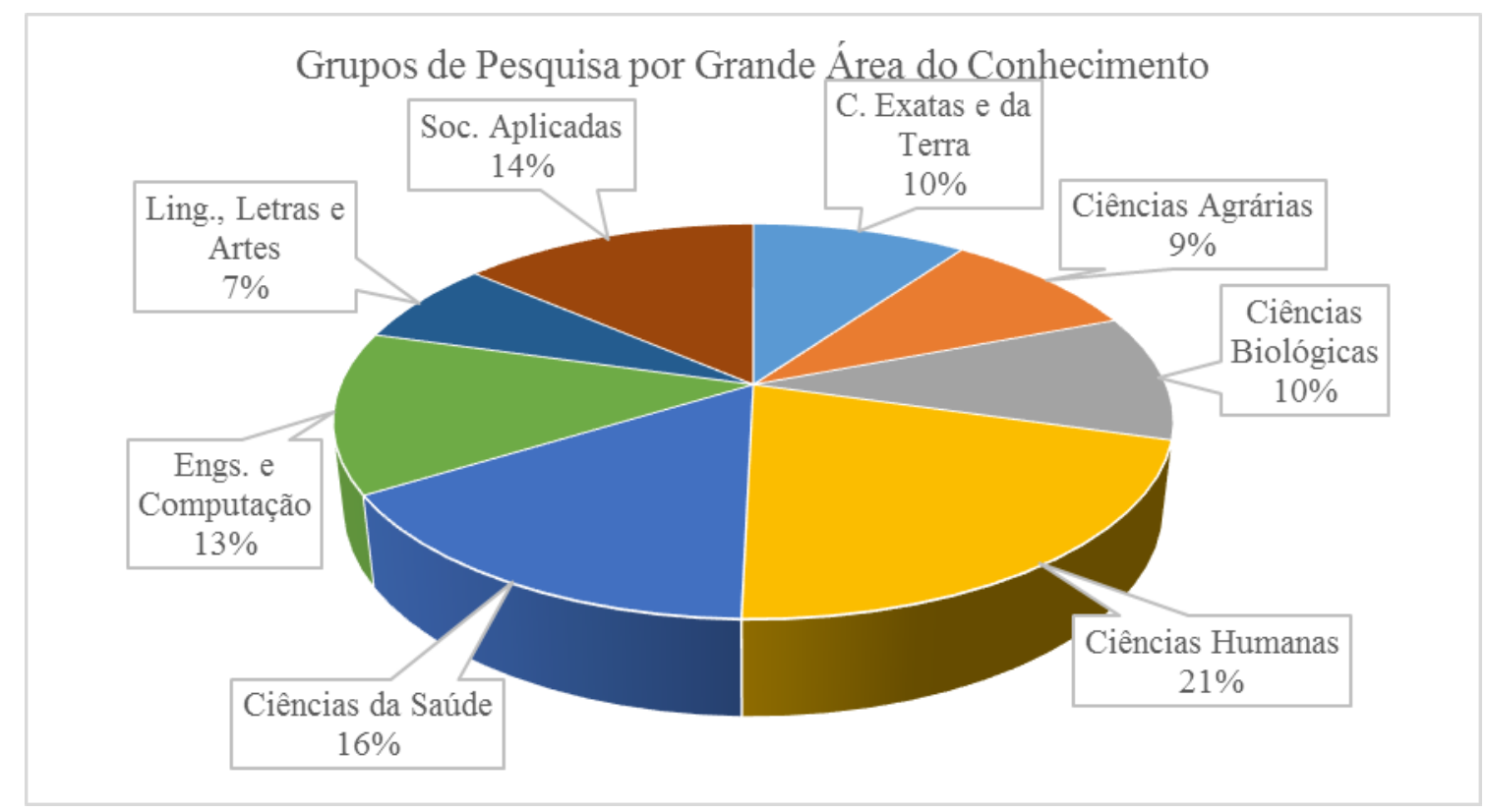

Fonte: Elaborada pelo autor com base em CNPq (2015).

Quanto ao tamanho dos grupos de pesquisa brasileiros, destaca-se que 53\% dos grupos são compostos por 3 a 8 membros. Somente $12 \%$ dos grupos possuem mais de 15 pesquisadores (Tabela 7). Frise-se que, embora o CNPq considere o registro de 1.426 "grupos" 
compostos por apenas um integrante, julga-se que esses não deveriam ser definidos como grupos, assim como foi anunciado no referencial teórico desta Dissertação.

Tabela 7 - Grupos de pesquisa por número de Integrantes

\begin{tabular}{|c|c|c|c|}
\hline \multicolumn{4}{|c|}{ Quantidade de Integrantes por Grupo de Pesquisa } \\
\hline Integrantes & Grupos & $\%$ & $\%$ acumulado \\
\hline 1 & 1426 & 4 & 4 \\
\hline 2 & 2337 & 6,6 & 10,6 \\
\hline 3 & 3013 & 8,5 & 19,1 \\
\hline 4 & 3462 & 9,8 & 28,9 \\
\hline 5 & 3434 & 9,7 & 38,6 \\
\hline 6 & 3209 & 9,1 & 47,7 \\
\hline 7 & 2872 & 8,1 & 55,8 \\
\hline 8 & 2673 & 7,6 & 63,4 \\
\hline 9 & 2180 & 6,2 & 69,6 \\
\hline 10 & 2029 & 5,7 & 75,3 \\
\hline 11 & 1485 & 4,2 & 79,5 \\
\hline 12 & 1239 & 3,5 & 83 \\
\hline 13 & 941 & 2,7 & 85,7 \\
\hline 14 & 819 & 2,3 & 88 \\
\hline 15 ou mais & 4305 & 12,2 & 100 \\
\hline Total & 35424 & 100 & - \\
\hline
\end{tabular}

Fonte: CNPq (2015).

Quanto ao tempo de existência (Tabela 8), os grupos de pesquisa brasileiros possuem em média 7,6 anos de existência, sendo 5 anos o valor mediano. Destaca-se que 10,7\% dos grupos (3.803 grupos) foram criados a menos de um ano contado da coleta de dados para o censo divulgado em 2014, enquanto que os grupos mais longevos (que excedem 20 anos) representam $7,6 \%$ do total.

Tabela 8 - Grupos de pesquisa por Tempo de Existência

\begin{tabular}{lrr}
\hline \multicolumn{1}{c}{$\begin{array}{c}\text { Anos de existência do Grupo de } \\
\text { Pesquisa }\end{array}$} & Grupos & \multicolumn{1}{c}{$\%$} \\
\hline Menos de 1 & 3.803 & 10,7 \\
1 a 4 & 11.953 & 33,7 \\
5 a 9 & 8.409 & 23,7 \\
10 a 14 & 6.201 & 17,5
\end{tabular}


Continuação

\begin{tabular}{lrr}
\hline $\begin{array}{c}\text { Anos de existência do Grupo de } \\
\text { Pesquisa (Continuação) }\end{array}$ & Grupos & $\%$ \\
\hline 15 a 19 & 2.376 & 6,7 \\
20 ou mais & 2.682 & 7,6 \\
\hline Total & 35.424 & 100 \\
\hline Fonte: CNPq (2015). & &
\end{tabular}

Quanto às produções dos grupos de pesquisa brasileiros, o CNPq divulga dados consolidados relativos às Produções Técnicas, que é um agrupador de informações a respeito de produtos não bibliográficos como softwares, processos técnicos, cartas, maquetes, editorações entre outros. De 2000 a 2014, a produção Técnica dos grupos, praticamente, se multiplicou por cinco, passando de 6.674 para 32.215 (Figura 12).

Figura 12 - Quantidade de Produções Técnicas ao longo dos anos

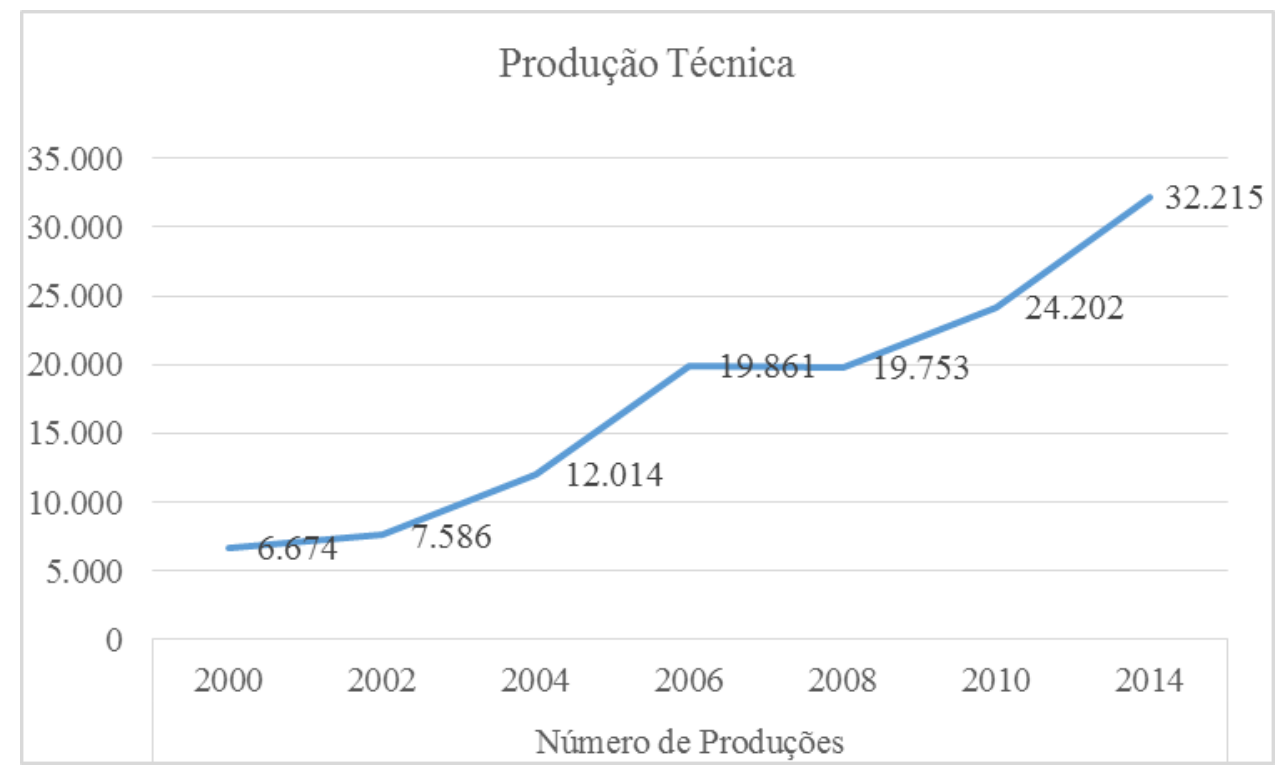

Fonte: Elaborada pelo autor com base em CNPq (2015).

E, por fim, em relação às publicações, o CNPq divulga a quantidade de artigos completos publicados pelos grupos de pesquisa seja com circulação nacional (escritos por brasileiros em língua portuguesa) seja no âmbito internacional (escrito por brasileiros em idiomas diferentes do português). De 2000 a 2014, o número de publicações é crescente, sendo que em a série histórica que possuía maior quantidade de artigos com circulação nacional se inverteu em 2010, quando as produções com repercussão internacional passaram a ter maior montante, o que evidencia a valorização das produções internacionais (Figura 13). Destaca-se 
que as inclinações das retas indicam uma tendência de acréscimo de publicações internacionais para os próximos anos.

Figura 13 - Comparação entre artigos de circulação nacional e internacional

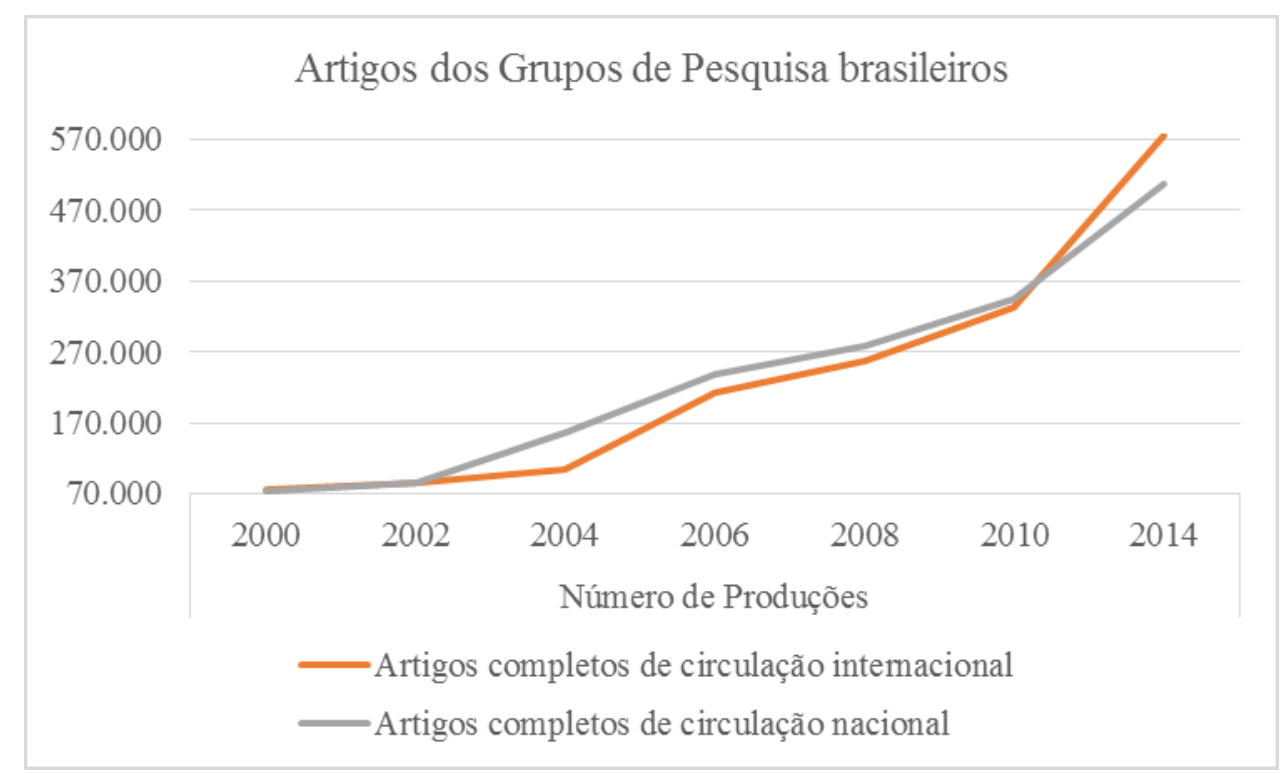

Fonte: Elaborada pelo autor com base em CNPq (2015).

Para identificar os indícios ou evidências de validade de uma escala de competências gerenciais aplicável a grupos de pesquisa (variáveis independentes), é indispensável investigar uma amostra representativa. Vale reforçar que quaisquer participantes de grupo de pesquisa brasileiros puderam participar da pesquisa, uma vez que não somente os líderes exercem competências de gestão. Além do mais, o fato de alguns respondentes não dominarem certas competências gerenciais contribuiu para conferir variabilidade aos dados coletados.

Assim, para o instrumento de competências gerenciais, a população estudada abrange 180.262 pesquisadores. E, embora muito expressiva, pode ser considerada finita, já que se sabe a quantidade censitária de indivíduos que a compõem.

Para o cálculo do tamanho amostral, considerou-se a fórmula de Cochran (1963), que é aconselhável para grandes populações. Segundo esse autor, $\left.n=\left[Z^{2} \cdot p \cdot(1-p)\right]\right) / e^{2}$. Onde $n$ é o tamanho da amostra; $Z^{2}$ é o intervalo de confiança (valor encontrado em quadros estatísticos que contêm a área sob a curva normal); $p$ é a proporção enquanto atributo da população; e $e^{2}$ é o quadrado do erro que se pretende assumir.

No caso, trata-se de uma população de tamanho $\mathrm{n}=180.262$, o nível de confiança de $95 \%(Z=1,96)$, e margem de erro permissível e $=0,05$. Ademais, como não foram identificados estudos anteriores que apontassem a o valor da proporção aplicável ao fenômeno das 
competências gerenciais, optou-se pela proporção $p=0.5$, que é a abordagem mais conservadora e mais rígida (COCHRAN, 1977, p. 72; ISRAEL, 1992, p.3). A partir desses parâmetros, chegou-se a uma amostra mínima de 384 indivíduos.

Já para o instrumento relativo aos resultados de grupos de pesquisa (variáveis dependentes), resolveu-se limitar as respostas apenas a líderes, uma vez que, se mais de um integrante participasse, poderia haver dados duplicados a respeito de resultados do grupo, além disso, a comparação entre a percepção de líderes e demais participantes sobre o alcance de resultados não foi traçada como objetivo desta Dissertação.

Por isso, para o cálculo da amostra concernente a resultados, foram considerados como sujeitos apenas os líderes, que somam 30.155, segundo o censo de 2014, divulgado pelo CNPq.

Assim, usando a mesma fórmula para o cálculo anterior, foram utilizados os seguintes parâmetros: tamanho $\mathrm{n}=30.155$; nível de confiança de $95 \%(\mathrm{Z}=1,96)$, e margem de erro permissível e $=0,05$. Ressalte-se que também não foram identificados estudos anteriores que apontassem a o valor da proporção aplicável a resultados de grupos de pesquisa, então, mais uma vez, optou-se pela proporção mais rígida p=0.5 (COCHRAN, 1977, p. 72; ISRAEL, 1992, p.3). Com esses dados, chegou-se a uma amostra mínima de 380 indivíduos.

Em suma, a coleta de dados satisfez as condições de amostra mínima para a generalização dos dados, já que 528 participantes de grupos de pesquisa responderam ao questionário relativo a competências gerenciais e 387 líderes manifestaram-se no questionário que trata de resultados de grupos de pesquisa.

\subsection{Coleta e Análise de dados}

Para uma melhor exposição da origem dos dados, vale explicitar que esta pesquisa se deu em duas macroetapas: pesquisa documental (crucial para identificar tanto os comportamentos que demonstram o domínio de competências gerenciais em líderes de grupos de pesquisa quanto os aspectos que evidenciam seus resultados) a e pesquisa de levantamento (base para a apresentação de indícios ou evidências de validade das escalas de domínio de competências gerenciais em líderes de grupos de pesquisa e de aspectos que evidenciam resultados de grupos de pesquisa, bem como para identificar as relações entre competências gerenciais dos líderes e aspectos que evidenciam resultados em grupos de pesquisa brasileiros, além de possíveis influências sociodemográficas e funcionais). 


\subsubsection{Pesquisa Documental}

$\mathrm{Na}$ pesquisa documental, recorreu-se a relatórios e instrumentos para coleta de dados utilizados em pesquisas anteriores do Grupo Inovação e Aprendizagem em Organizações. Houve o exame de materiais de natureza diversa, que ainda não haviam recebido um tratamento analítico ou que poderiam ser complementados, de forma que se pudesse ir além das percepções dos membros a respeito do tema de pesquisa (FLICK, 2009; GODOY, 1995). Para essa primeira macroetapa da pesquisa, a amostragem foi flexível, já que os documentos foram selecionados por acessibilidade.

A pesquisa documental ocorreu sobretudo nos sites da CAPES, do CNPq e da Plataforma Lattes e no repositório de arquivos e documentos do Grupo de Pesquisa 'Inovação e Aprendizagem em organizações', o qual vem desenvolvendo uma série de estudos no âmbito dos grupos de pesquisa brasileiros. Em especial, a pesquisa documental se deu em arquivos que deram subsídio a quatro publicações mencionadas no referencial teórico deste estudo e atribuídas a membros do referido grupo de pesquisa - Odelius e Sena (2009); Odelius et al. (2010); Odelius et al. (2011); e Fernandez e Odelius (2013) - nos temas afetos à presente pesquisa (competências e resultados de grupos de pesquisa).

Recorreu-se, por exemplo, às diversas versões dos roteiros de entrevistas e questionários; às transcrições das entrevistas realizadas por pesquisadores do grupo; às manifestações de especialistas e juízes em seus pareceres, entre outros documentos. Outrossim, buscou-se compreender os motivos que levaram à inclusão, modificação e exclusão de itens nos instrumentos, bem como analisar as categorizações dos fatores.

Os principais documentos estudados foram os esboços de um instrumento de domínio de "Competências relativas à coordenação das atividades de pesquisa" (Anexo A), cuja existência já havia sido mencionada por Odelius e Sena (2009) e por Ono (2012), porém, sem indícios ou evidências de validade da escala, sobretudo, por insuficiência de amostra mínima em tentativa anterior; e de resultados alcançados por grupos de pesquisa (Anexo B). Além disso, um instrumento sobre indicativos de inserção em atividades do meio acadêmico (Anexo C) também foi considerado em conjunto com o questionário-prévio de resultados, uma vez que seus itens englobavam diversos aspectos apontados pela literatura como indicativos de resultados de grupos.

A versão mais antiga do questionário-prévio sobre competências relativas a coordenação de atividades de pesquisa localizada foi elaborada no primeiro semestre de 2012, e era composta por 27 itens. No início de 2013 foi reduzida para 24 itens, mas, no final do 
mesmo ano o questionário retornou a 27 itens. No ano seguinte, 2014, a partir de novas entrevistas e revisões teóricas, o instrumento passou a conter 46 itens.

Já o questionário sobre resultados alcançados por grupos de pesquisa - analisado conjuntamente ao de inserção em atividades do meio acadêmico - possuía 26 itens no primeiro semestre de 2012, perdeu um item no início de 2013, e o recuperou na versão do final do mesmo ano.

Assim, a partir dessas duas últimas versões, alguns itens foram ajustados e acrescentados, com base em uma nova revisão da literatura constante do referencial teórico e na pesquisa documental ora apresentada, já no âmbito desta disseração. Os instrumentos finais contam com 51 itens para identificar o domínio de competências gerenciais e 31 itens relativos a resultados de grupos de pesquisa e constam do Apêndice A e Apêndice B, respectivamente.

Finalizada essa macroetapa, começaram as ações preparatórias para a pesquisa de levantamento, que é muito comum na coleta e análise de dados em Ciências Sociais (FOWLER, 2011).

\subsubsection{Pesquisa de Levantamento}

A pesquisa de levantamento constitui a segunda macroetapa da pesquisa e foi precedida por duas fases preparatórias: avaliação teórica e semântica por juízes ou especialistas; e préteste (PASQUALI, 2010).

\subsubsection{Avaliação de Juízes}

A validação do conteúdo dos itens por especialistas é importante porque reduz a incidência de possíveis erros ou equívocos em instrumentos psicométricos, tornando-os mais claros, aplicáveis, além de mais relevantes e representativos do fenômeno. Embora essa avaliação possa ser considerada subjetiva e pessoal, o parecer de juízes é crucial para verificar se o instrumento é apto a aferir ao que se propõe (CASSEPP-BORGES; BALBINOTTI; TEODORO, 2010). Ademais, essa avaliação semântica e teórica é recomendada para que determinados termos ou palavras que dificultem a compreensão de itens ou que estejam descontextualizadas sejam ajustados ou eliminados (PASQUALI, 2010).

Atendendo à orientação de Pasquali (2010) de que avaliação de juízes deve contar com 3 a 5 integrantes, o instrumento preliminar foi submetido a 5 juízes, sendo 2 deles pesquisadores seniores (um com doutorado em administração e outro em sociologia, mas ambos com vasta 
experiência em instrumentos no campo da Administração) e 3 doutorandos em administração com experiência na elaboração de escalas psicométricas para estudos organizacionais.

Esses juízes foram convidados a contribuírem com a pesquisa via e-mail e, para tanto, receberam o instrumento preliminar em versão similar à que seria aplicada posteriormente. Os juízes receberam instruções para que estipulassem uma nota entre 1 (mínima) e 5 (máxima), com relação à 'Clareza da Linguagem', 'Pertinência do Item', e ‘Relevância Teórica', para cada um dos 82 itens. Além disso, foram questionados se as formas de indagar sobre o grau de domínio de competências gerenciais de líderes de grupo de pesquisa ( 0 - nenhum domínio a 5 - domínio completo) e sobre resultados de grupos de pesquisa, por meio de uma escala Likert, indagando sobre o grau de concordância para a seguinte afirmação "É um resultado alcançado, nos últimos 5 anos, pelo grupo de pesquisa em que atuo" (0 - discordo totalmente a 5 - concordo totalmente) estariam compatíveis aos objetivos da dissertação. Ao lado de cada item também havia espaço para que os juízes pudessem sugerir nova redação ou a eliminação de itens, bem como para observações em geral.

Quanto ao instrumento relativo a resultados de grupos de pesquisa, o coeficiente de validade do conteúdo - CVC (índice calculado pela média das notas atribuídas pelos juízes, dividida pela maior nota possível) foi igual ou superior a 0,8 para todos os itens, o que atesta a adequação do conteúdo (CASSEPP-BORGES; BALBINOTTI; TEODORO, 2010).

Já com relação ao instrumento de competências gerenciais no contexto de grupos de pesquisa, o CVC apresentou 18 dos 51 itens com índices inferiores a 0,8. Destarte, foram realizados os ajustes contantes dos campos de observações, e nenhum dos item foi excluído, uma vez que o "ponto de corte" para o CVC pode ser relativizado, desde que haja adequações nos itens, devido a divergências de formação ou a vieses interpretativos nos pareceres emitidos pelos juízes (CASSEPP-BORGES; BALBINOTTI; TEODORO, 2010).

Finalizada a avaliação por juízes, optou-se pela manutenção dos 82 itens com alguns ajustes na redação de 18 deles. Ao questionário preliminar foram agregadas indagações sobre dados sociodemográficos e funcionais, bem como uma breve apresentação do instrumento e dos objetivos da pesquisa, contendo também informações sobre a confidencialidade dos dados, além do termo de livre esclarecimento.

\subsubsection{Pré-teste}

Foram convidados a participar do Pré-teste nove integrantes do grupo de pesquisa 'Inovação e Aprendizagem em Orgnaizações', os quais receberam o questionário por meio de 
um link do SurveyMonkey, que é um site especializado em coleta de dados via internet, disponibilizando os formulários por meio de links, correio eletrônico e redes sociais, como o Facebook, e possibilita o controle da quantidade de respondentes (SCORNAVACCA JR.; BECKER; ANDRASCHKO, 2001).

Como decorrência do Pré-teste, configuraram-se três alterações mais significativas:

1) formas de perguntar alguns dados sociodemográficos e funcionais foram alteradas (por exemplo, o tempo de experiência do respondente em atividades de pesquisa e no grupo de pesquisa de que participa atualmente ficaram com a possibilidade de resposta em quaisquer unidades de tempo, já a idade fixou-se em anos);

2) houve a inclusão de respostas "Não se aplica" tanto junto aos itens de competências gerenciais quanto no de resultados. No instrumento de competências gerenciais, além de marcar o grau de domínio (0 - nenhum domínio a 5 - domínio completo), o respondente passou a poder assinalar "Considero que esta Competência Gerencial NÃO se aplica a Grupos de pesquisa), enquanto que no instrumento sobre resultados de grupos de pesquisa, além de marcar o nível de concordância com a afirmação "É um resultado alcançado, nos últimos 5 anos, pelo grupo de pesquisa em que atuo" (0 - discordo totalmente a 5 - concordo totalmente), o respondente passou a poder assinalar também "Considero que este resultado seja meu (enquanto líder) e NÃO do grupo como um todo"; e

3) por fim, foi acrescentada uma questão sobre o nível de contribuição de algumas atividades (como projeto de iniciação científica, projeto de extensão universitária, estágio, trabalho voluntário, atuação em empresa júnior, projeto de consultoria, atuação profissional em geral e a própria participação em grupo de pesquisa) para o desenvolvimento de competências gerenciais relativas a grupos de pesquisa.

Como decorrência da Pesquisa documental, da avaliação de juízes e do Pré-teste, foram concebidas duas escalas preliminares: Competências Gerenciais em Grupos de Pesquisa (Apêndice A) e Resultados alcançados por Grupos de Pesquisa (Apêndice B), compostas por 51 e 31 itens, respectivamente.

\subsubsection{Coleta de Dados}

Definida a versão final do instrumento, aplicou-se o Questionário (Apêndice C), o qual recebeu respostas no período de 2 de novembro de 2015 até 4 de janeiro de 2016. 
Conseguiram-se 6.630 endereços eletrônicos de líderes, sendo 4.406 e-mails localizados em uma base de dados constante do diretório do grupo de pesquisa 'Inovação e Aprendizagem em organizações' e 2.224 novos e-mails localizados na internet. Essa frente (convites por e-mail) rendeu 539 respondentes, dos quais 420 eram líderes de grupo.

Adicionalmente, foram criados links para o questionário eletrônico, de forma que os participantes inicialmente acionados pudessem encaminhar o instrumento a outros interessados, desde que fizessem parte do público-alvo da pesquisa. Inicialmente, os links foram encaminhados a pesquisadores da Universidade de Brasília - UnB por e-mail e o convite foi reforçado por mensagem de texto encaminhadas aos telefones celulares de coordenadores de 93 programas de pós-graduação das mais diversas áreas do conhecimento, numa estratégia metodológica que tem sido denominada "bola de neve" (POLIT; BECK; HUNGLER, 2004). A pesquisa logo extrapolou as fronteiras da $\mathrm{UnB}$, atingindo não só pesquisadores de universidades privadas, bem como de diversas unidades da federação, nas mais diversas áreas do conhecimento. O envio de links atrelados à estratégia metodológica da "bola de neve" rendeu 254 respostas ao questionário, sendo 111 delas manifestações de líderes de grupos de pesquisa.

Por fim, registre-se que houve ainda uma terceira frente para a coleta de dados. Criouse um link no Facebook, que foi encaminhado a grupos de pesquisa localizados por meio das ferramentas de busca da referida rede social. Essa estratégia, menos efetiva, rendeu 32 respostas, das quais apenas 13 foram completamente preenchidas.

A

Tabela 9 resume as informações inerentes à delimitação e caracterização dos respondentes, a partir dos seguintes dados: tamanho da população; número de respondentes; forma de seleção da amostra; e meio de acesso, conforme recomendações de Creswell (2013).

Tabela 9 - Detalhamento da coleta de dados

\begin{tabular}{lcc}
\hline Escala & $\begin{array}{c}\text { Competências } \\
\text { Gerenciais em Grupos } \\
\text { de Pesquisa }\end{array}$ & $\begin{array}{c}\text { Resultados de Grupos } \\
\text { de Pesquisa }\end{array}$ \\
\hline Forma de Seleção & Acessibilidade e indicação (bola-de-neve) \\
\hline Meio de Acesso & $\begin{array}{c}\text { E-mail, mensagem de texto via telefonia móvel e } \\
\text { rede social }\end{array}$ \\
\hline Tamanho da População & 180.262 & 30.155 \\
\hline Amostra direta & 6.630 & 6.630 \\
\hline Representatividade da Amostra direta $(\boldsymbol{\%})$ & $4 \%$ & $22 \%$ \\
\hline $\mathbf{N}^{\mathbf{0}}$ de Respondentes diretos & 539 & 420 \\
\hline
\end{tabular}




\begin{tabular}{lcc}
\multicolumn{1}{l}{ Taxa de Resposta (\%) } & $8,13 \%$ & $6,33 \%$ \\
\hline \multicolumn{1}{l}{ Respondentes suplementares por indicação } & 254 & 111 \\
\hline \multicolumn{1}{l}{ Continuação } & & \\
\hline $\begin{array}{l}\text { Taxa de Resposta (\%) com respondentes } \\
\text { suplementares }\end{array}$ & $11,96 \%$ & $8,01 \%$ \\
\hline Total de respostas & 793 & 531 \\
\hline Respostas completas & 528 & 387 \\
\hline Respondentes completos excluídos os Outliers & 515 & 374 \\
\hline
\end{tabular}

Fonte: Elaborada pelo autor com base em Dados da Pesquisa

Dessa forma, obteve-se 793 respostas, sendo 265 casos considerados incompletos pelo próprio SurveyMonkey. Dos 528 casos restantes, a maioria integra o público principal desta pesquisa: líderes de grupo (387), havendo ainda a particição de 41 líderes de projeto e 100 demais participantes de grupos de pesquisa, conforme ilustra a Figura 14.

Figura 14 - Respondentes por tipo de atuação no grupo de pesquisa

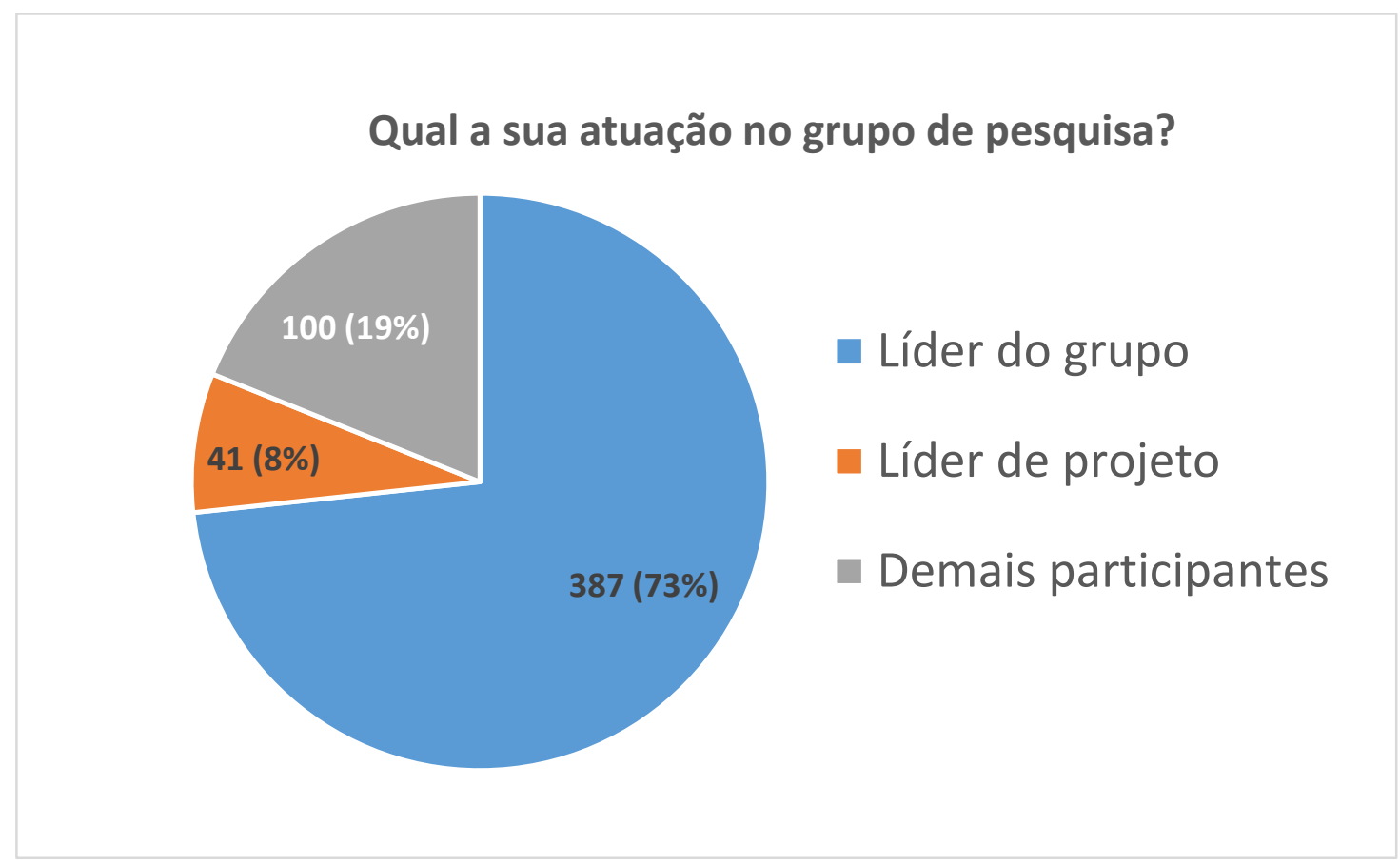

Fonte: Dados da Pesquisa

Em suma, recorreu-se ao questionário como a forma de instrumentação mais adequada ao caso, já que esse instrumento consegue atingir grande número de respondentes, mesmo estando dispersos em um país de proporções continentais. E adotou-se uma amostragem nãoprobabilística, uma vez que a amostra não foi aleatórea e os dados analisados dependeram do 
interesse dos pesquisados em responderem ao questionário eletrônico (MATTAR, 1996). De qualquer forma, vale destaquar que, apesar da não-aleatoriedade da amostragem, a análise dos dados dos respondentes indica que a composição da amostra acompanha e aproxima-se de características da população, como será apresentado no capítulo de resultados.

Por fim, frisa-se que a coleta eletrônica via internet revelou-se a mais adequada, uma vez que havia potenciais respondentes em vários municípios brasileiros. Assim, como se esperava coletar dados de uma grante quantidade de grupos de pesquisa, uma aplicação presencial ficaria inviabilizada pela dispersão dos respondentes numa grante área geográfica e por limitações fiananceiras. Nascimento Neto (2004) enumera as principais vantagens do uso da Internet na aplicação de questionários:

a) a conveniência: o respondente pode acessar o questionário de qualquer lugar, desde que tenha um microcomputador [smartphone ou tablet] conectado à Internet;

b) o custo: o acesso virtual torna-se mais barato;

c) a escala: é possível de trabalhar com grandes amostras;

d) a velocidade: é possível obter as respostas mais rapidamente; e

e) a estética e a atratividade: é possível utilizar imagens, sons e hipertexto na construção dos questionários.

\subsubsection{Análise dos Dados}

Inicialmente, esta pesquisa baseou-se em Análise Fatorial, que foi antecedida por análises exploratórias para tratamento dos dados, conforme será relatado na seção 4.2. Em seguida, procederam-se às técnicas para diferenças entre médias e medianas, no que tange às influências sociodemográficas e funcionais. E, por fim, recorreu-se à análise de correlação entre a escala de competências gerenciais em grupos de pesquisa como variável independente e a escala de resultados alcançados em grupos de pesquisa como variável dependente; e entre estas e as variáveis sociodemográficas e funcionais.

Quando se quer analisar múltiplas medidas que investigam a percepção humana, o emprego de técnicas estatísticas multivariadas é o mais indicado (HAIR JR. et al., 2010). Por isso, fez-se o emprego de análise fatorial, combinada com apuração de diferenças entre medianas e análise de correlação. 
A análise da validade fatorial é o conjunto de técnicas estatísticas de análise de dados científicos para avaliar a validade de construto que será reforçada se a estrutura fatorial da escala for consistente com os construtos que o instrumento propõe medir (LAROS, 2012). Nas Ciências Sociais, existe uma tendência de emprego dessa técnica estatística (TABACHNICK; FIDELL, 2007; FIELD, 2009), uma vez que esse ramo da ciência comumente trabalha com variáveis manifestas (itens) como formadores de variáveis latentes ou não-observáveis (fatores), e o grau da relação entre esses dois grupos de variáveis, bem como a natureza dessa associação, pode ser apurada com base na estrutura subjacente de uma matriz de dados empíricos (BROWN, 2006; DAMÁSIO, 2012).

É por meio da Análise Fatorial que se torna possível evidenciar o compartilhamento de variância entre as variáveis mensuradas, agrupando-as em um mesmo fator (HAIR JR. et al., 2010; TABACHNICK; FIDELL, 2007). Essa técnica estatística revelou-se a mais adequada ao propósito desta Dissertação, já que há necessidade de compreender a estrutura do conjunto de itens; de construir um questionário capaz de medir variáveis subjacentes; e de reduzir o conjunto de dados a um tamanho mais manejável, mantendo-se o máximo de informação original possível (FIELD, 2009).

Finalizada a análise fatorial, cuja interpretação será apresentada no capítulo de resultados e discussões, passou-se a trabalhar com foco no objetivo específico que visa a identificar aspectos que influenciam o domínio de competências gerenciais e o alcance de resultados em grupos de pesquisa, a depender de dados sociodemográficos e funcionais, tais como tipo de instituição, unidade da federação e grande área do conhecimento a que o grupo se vincula; sexo, faixa etária, tempo de experiência, recebimento de bolsa de produtividade do CNPq e titulação/escolaridade do líder; entre outros. Para tanto, recorreu-se a técnicas viáveis para comparar e evidenciar eventuais diferenças ou semelhanças entre médias ou medianas.

Fez-se uso, principalmente, dos testes não-paramétricos U de Mann-Whitney (que compara duas condições independentes) e $\mathrm{H}$ de Kruskall-Wallis (que compara vários grupos independentes). Esses testes são aptos a explicitar possíveis diferenças entre um grupo de fatores, bem como para detalhar os casos com diferenças consideradas estatisticamente significativas, não se exigindo o pressuposto de normalidade (FIELD, 2009).

Finalizada a etapa de diferenciação entre medianas, passou-se ao processamento das análises de correlação, visando-se, sobretudo, ao alcance do objetivo específico que busca relacionar competências gerenciais dos líderes com os aspectos que evidenciam resultados em grupos de pesquisa brasileiros. A análise de correlação revelou-se a forma mais apropriada para 
a compreensão dos dados oriundos dos questionários, uma vez estudos de correlação são capazes de explicitar o grau de associação entre variáveis contínuas. Utilizaram-se correlações bivariadas entre uma variável principal - como o domínio de determinada competência gerencial - e a variável composta criada por um conjunto de outras variáveis - como os diversos resultados obtidos pelos grupos de pesquisa (TABACHNICK; FIDEL, 2007). Merece destaque o método de Correlação de Kendall-Tau, por ser uma técnica equivalente à Correlação de Pearson ou à Regressão, porém, é mais apropriada para dados disprovidos de normalidade, como é o caso do presente estudo.

Antes de passar ao capítulo de Resultados e Discussões, vale verificar o Quadro 15 resume, por fim, os métodos predominantes a depender dos objetivos específicos estipulados.

\section{Quadro 15 - Relação entre os objetivos específicos e o método}

\begin{tabular}{|l|c|}
\hline \multicolumn{1}{|c|}{ Objetivo Específico } & Método Predominante \\
\hline $\begin{array}{l}\text { Identificar os comportamentos que demonstram o domínio de competências } \\
\text { gerenciais em grupos de pesquisa }\end{array}$ & Pesquisa documental \\
\hline $\begin{array}{l}\text { Apresentar indícios ou evidências de validade para uma escala de domínio de } \\
\text { competências gerenciais em grupos de pesquisa }\end{array}$ & Análise Fatorial Exploratória \\
\hline Identificar os aspectos que evidenciam resultados de grupos de pesquisa & \multicolumn{1}{c|}{ Pesquisa documental } \\
\hline $\begin{array}{l}\text { Apresentar indícios ou evidências de validade para uma escala de aspectos } \\
\text { que evidenciam resultados de grupos de pesquisa }\end{array}$ & Análise Fatorial Exploratória \\
\hline $\begin{array}{l}\text { Identificar eventuais diferenças ou semelhanças entre grupos com relação a } \\
\text { competências gerenciais ou resultados em grupos de pesquisa, a depender de } \\
\text { dados sociodemográficos e funcionais. }\end{array}$ & $\begin{array}{c}\text { Testes não-paramétricos U de } \\
\text { Mann-Whitney e H de Kruskall- } \\
\text { Wallis }\end{array}$ \\
\hline $\begin{array}{l}\text { Identificar relações existentes entre competências gerenciais e aspectos que } \\
\text { evidenciam resultados de grupos de pesquisa brasileiros }\end{array}$ & \begin{tabular}{c} 
Correlação de Kendall-Tau \\
\hline
\end{tabular} \\
\hline
\end{tabular}

Fonte: Elaborado pelo autor 


\section{APRESENTAÇÃO E DISCUSSÃO DOS RESULTADOS}

Em que pese Günther (2004) sugerir que resultados e discussões estejam em espaços distintos e respectivamente subsequentes, optou-se por manter essas partes da Dissertação em um mesmo capítulo, como forma de evitar fazer referências desnecessárias aos resultados a cada vez em que fosse preciso mencioná-los na discussão.

De qualquer forma, a fim de se evitarem equívocos, as discussões, guiadas pela interpretação dos achados à luz da literatura, ficarão em parágrafos posteriores aos resultados, norteados pelos objetivos.

Inicialmente, será caracterizada a amostra e realizada a sua comparação com a população, já que a descrição dos participantes da pesquisa pode ser considerada parte integrante dos resultados (GÜNTHER, 2004).

Em seguida, serão apresentadas e interpretadas as escalas de competências gerenciais e de resultados em grupos de pesquisa, em atenção aos objetivos específicos de 1 a 4, como resultados da Pesquisa Documental e da Análise Fatorial Exploratória.

Posteriormente, a partir dos Testes não-paramétricos $\mathrm{U}$ de Mann-Whitney e $\mathrm{H}$ de Kruskall-Wallis, serão relatadas e discutidas as diferenças estatisticamente significativas entre grupos com relação a competências gerenciais ou resultados em grupos de pesquisa, a depender de dados sociodemográficos e funcionais, conforme estabelecido no quinto objetivo específico.

Por fim, serão expostas e exploradas as relações existentes entre competências gerenciais e aspectos que evidenciam resultados de grupos de pesquisa brasileiros, previstas como produto do sexto objetivo específico, e identificadas por meio da análise de Correlação de Kendall-Tau.

\subsection{Caracterização dos Respondentes}

Conforme mencionado no terceiro capítulo, foram aplicados diferentes questionários para líderes e para demais participantes de grupo de pesquisa, o que resultou em um número diferente de respondentes para as escalas de competências gerenciais e de resultados em grupos de pesquisa. Enquanto a escala de competências contou com 515 respostas de quaisquer participantes de grupos de pesquisa brasileiros, após as exclusões que serão relatadas; a escala de resultados é fruto da manifestação de 374 respondentes válidos, considerando-se apenas os líderes. O Quadro 16 resume as principais informações a respeito dos respondentes (atuação no grupo, sexo, idade, escolaridade, experiência com pesquisa, tempo de participação no grupo 
atual, e recebimento de bolsa de produtividade do CNPQ) e dos grupos de pesquisa (região geográfica onde as reuniões ocorrem, tipo de instituição de ensino ou pesquisa a que estão vinculados, e grande área do conhecimento a que pertencem).

Quadro 16 - Variáveis Sociodemográficas e funcionais

\begin{tabular}{|c|c|c|c|c|c|c|c|}
\hline \multirow[b]{2}{*}{$\begin{array}{c}\text { Variável } \\
\text { Sociodemográfica ou } \\
\text { funcional }\end{array}$} & \multirow[b]{2}{*}{ Categorias } & \multicolumn{3}{|c|}{$\begin{array}{c}\text { Escala de Competências } \\
\text { Gerenciais }\end{array}$} & \multicolumn{3}{|c|}{ Escala de Resultados } \\
\hline & & Frequência & $\%$ & $\begin{array}{c}\% \\
\text { acumulado } \\
\text { (válidos) } \\
\end{array}$ & Frequência & $\%$ & $\begin{array}{c}\% \\
\text { acumulado } \\
\text { (válidos) }\end{array}$ \\
\hline \multirow{4}{*}{ Atuação no grupo } & Líder do grupo & 374 & 72,6 & 72,6 & 374 & 100,0 & 100,0 \\
\hline & Líder de projeto & 41 & 8,0 & 80,6 & 0 & 100,0 & 100,0 \\
\hline & $\begin{array}{l}\text { Demais } \\
\text { participantes }\end{array}$ & 100 & 19,4 & 100,0 & 0 & 100,0 & 100,0 \\
\hline & Total & 515 & 100,0 & & 374 & 100,0 & \\
\hline \multirow{5}{*}{ Sexo } & Masculino & 303 & 58,8 & 59,4 & 230 & 61,5 & 62,3 \\
\hline & Feminino & 207 & 40,2 & 100,0 & 139 & 37,2 & 100,0 \\
\hline & Total & 510 & 99,0 & & 369 & 98,7 & \\
\hline & Não respondeu & 5 & 1,0 & & 5 & 1,3 & \\
\hline & Total 2 & 515 & 100,0 & & 374 & 100,0 & \\
\hline \multirow{9}{*}{ Idade } & Até 25 anos & 8 & 1,6 & 1,6 & 0 & 0 & 0 \\
\hline & De 26 a 35 anos & 40 & 7,8 & 9,5 & 8 & 2,1 & 2,2 \\
\hline & De 36 a 45 anos & 82 & 15,9 & 25,7 & 53 & 14,2 & 16,6 \\
\hline & De 46 a 55 anos & 159 & 30,9 & 57,1 & 122 & 32,6 & 49,7 \\
\hline & De 56 a 65 anos & 163 & 31,7 & 89,3 & 136 & 36,4 & 86,7 \\
\hline & 66 anos ou mais & 54 & 10,5 & 100,0 & 49 & 13,1 & 100,0 \\
\hline & Total & 506 & 98,3 & & 368 & 98,4 & \\
\hline & Não respondeu & 9 & 1,7 & & 6 & 1,6 & \\
\hline & Total & 515 & 100,0 & & 374 & 100,0 & \\
\hline \multirow{9}{*}{ Nível de escolaridade } & Ensino Médio & 3 & ,6 & ,6 & 0 & 0,0 & 0 \\
\hline & Ensino Superior & 11 & 2,1 & 2,7 & 0 & 0,0 & 0,0 \\
\hline & Especialização & 8 & 1,6 & 4,3 & 0 & 0,0 & 0,0 \\
\hline & Mestrado & 39 & 7,6 & 11,8 & 0 & 0,0 & 0,0 \\
\hline & Doutorado & 177 & 34,4 & 46,2 & 132 & 35,3 & 35,6 \\
\hline & Pós-doutorado & 277 & 53,8 & 100,0 & 239 & 63,9 & 100,0 \\
\hline & Total & 515 & 100,0 & & 371 & 99,2 & \\
\hline & Não respondeu & 0 & & & 3 &, 8 & \\
\hline & Total 2 & 515 & 100,0 & & 374 & 100,0 & \\
\hline \multirow{6}{*}{$\begin{array}{c}\text { Tempo de } \\
\text { Experiência com } \\
\text { Pesquisa }\end{array}$} & Menos de 1 ano & 5 & 1,0 & 1,0 & 0 & 0 & 0 \\
\hline & De 1 a 4 anos & 45 & 8,7 & 9,7 & 2 &, 5 &, 5 \\
\hline & De 5 a 9 anos & 30 & 5,8 & 15,5 & 15 & 4,0 & 4,5 \\
\hline & De 10 a 29 anos & 257 & 49,9 & 65,4 & 195 & 52,1 & 56,7 \\
\hline & $\begin{array}{l}\text { Mais de } 30 \\
\text { anos }\end{array}$ & 178 & 34,6 & 100,0 & 162 & 43,3 & 100,0 \\
\hline & Total & 515 & 100,0 & & 374 & 100,0 & \\
\hline \multirow{6}{*}{$\begin{array}{c}\text { Tempo de } \\
\text { participação no } \\
\text { Grupo atual }\end{array}$} & Menos de 1 ano & 60 & 11,7 & 11,7 & 21 & 5,6 & 5,6 \\
\hline & De 1 a 4 anos & 151 & 29,3 & 41,0 & 99 & 26,5 & 32,1 \\
\hline & De 5 a 9 anos & 45 & 8,7 & 49,7 & 37 & 9,9 & 42,0 \\
\hline & De 10 a 29 anos & 237 & 46,0 & 95,7 & 195 & 52,1 & 94,1 \\
\hline & $\begin{array}{l}\text { Mais de } 30 \\
\text { anos }\end{array}$ & 22 & 4,3 & 100,0 & 22 & 5,9 & 100,0 \\
\hline & Total & 515 & 100,0 & & 374 & 100,0 & \\
\hline
\end{tabular}


Continuação

\begin{tabular}{|c|c|c|c|c|c|c|c|}
\hline \multirow[b]{2}{*}{$\begin{array}{c}\text { Variável } \\
\text { Sociodemográfica ou } \\
\text { funcional }\end{array}$} & \multirow[b]{2}{*}{ Categorias } & \multicolumn{3}{|c|}{$\begin{array}{c}\text { Escala de Competências } \\
\text { Gerenciais }\end{array}$} & \multicolumn{3}{|c|}{ Escala de Resultados } \\
\hline & & Frequência & $\%$ & $\begin{array}{c}\% \\
\text { acumulado } \\
\text { (válidos) }\end{array}$ & Frequência & $\%$ & $\begin{array}{c}\% \\
\text { acumulado } \\
\text { (válidos) }\end{array}$ \\
\hline \multirow{9}{*}{$\begin{array}{c}\text { Bolsa da } \\
\text { Produtividade em } \\
\text { Pesquisa }\end{array}$} & $1 \mathrm{~A}$ & 69 & 13,4 & 13,4 & 63 & 16,8 & 16,8 \\
\hline & $1 \mathrm{~B}$ & 47 & 9,1 & 22,5 & 38 & 10,2 & 27,0 \\
\hline & $1 \mathrm{C}$ & 62 & 12,0 & 34,6 & 52 & 13,9 & 40,9 \\
\hline & $1 \mathrm{D}$ & 71 & 13,8 & 48,3 & 60 & 16,0 & 56,9 \\
\hline & 2 & 90 & 17,5 & 65,8 & 72 & 19,3 & 76,2 \\
\hline & $\begin{array}{l}\text { Não possuo } \\
\text { bolsa. }\end{array}$ & 173 & 33,6 & 99,4 & 88 & 23,5 & 99,7 \\
\hline & Total & 512 & 99,4 & & 373 & 99,7 & \\
\hline & Não respondeu & 3 & ,6 & 100,0 & 1 & ,3 & 100,0 \\
\hline & Total 2 & 515 & 100,0 & & 374 & 100,0 & \\
\hline \multirow{6}{*}{$\begin{array}{l}\text { Região Geográfica } \\
\text { onde as reuniões do } \\
\text { Grupo ocorrem }\end{array}$} & Norte & 16 & 3,1 & 3,1 & 11 & 2,9 & 2,9 \\
\hline & Nordeste & 83 & 16,1 & 19,2 & 68 & 18,2 & 21,1 \\
\hline & Centro-Oeste & 79 & 15,3 & 34,6 & 36 & 9,6 & 30,7 \\
\hline & Sudeste & 245 & 47,6 & 82,1 & 183 & 48,9 & 79,7 \\
\hline & Sul & 92 & 17,9 & 100,0 & 76 & 20,3 & 100,0 \\
\hline & Total & 515 & 100,0 & & 374 & 100,0 & \\
\hline \multirow{3}{*}{$\begin{array}{l}\text { Tipo de Instituição } \\
\text { de Ensino/Pesquisa a } \\
\text { que o grupo se } \\
\text { vincula }\end{array}$} & Pública & 465 & 90,3 & 90,3 & 343 & 91,7 & 91,7 \\
\hline & Privada & 50 & 9,7 & 100,0 & 31 & 8,3 & 100,0 \\
\hline & Total & 515 & 100,0 & & 374 & 100,0 & \\
\hline \multirow{9}{*}{$\begin{array}{c}\text { Grande Área de } \\
\text { Conhecimento do } \\
\text { Grupo }\end{array}$} & $\begin{array}{l}\text { Ciências Exatas } \\
\text { e da Terra }\end{array}$ & 96 & 18,6 & 18,6 & 80 & 21,4 & 21,4 \\
\hline & $\begin{array}{l}\text { Ciências } \\
\text { Biológicas }\end{array}$ & 69 & 13,4 & 32,0 & 58 & 15,5 & 36,9 \\
\hline & Engenharias & 39 & 7,6 & 39,6 & 25 & 6,7 & 43,6 \\
\hline & $\begin{array}{l}\text { Ciências da } \\
\text { Saúde }\end{array}$ & 65 & 12,6 & 52,2 & 51 & 13,6 & 57,2 \\
\hline & $\begin{array}{l}\text { Ciências } \\
\text { Agrárias }\end{array}$ & 74 & 14,4 & 66,6 & 56 & 15,0 & 72,2 \\
\hline & $\begin{array}{l}\text { Ciências } \\
\text { Sociais } \\
\text { Aplicadas }\end{array}$ & 99 & 19,2 & 85,8 & 52 & 13,9 & 86,1 \\
\hline & $\begin{array}{l}\text { Ciências } \\
\text { Humanas }\end{array}$ & 60 & 11,7 & 97,5 & 42 & 11,2 & 97,3 \\
\hline & $\begin{array}{l}\text { Linguística, } \\
\text { Letras e Artes }\end{array}$ & 13 & 2,5 & 100,0 & 10 & 2,7 & 100,0 \\
\hline & Total & 515 & 100,0 & & 374 & 100,0 & \\
\hline
\end{tabular}

Fonte: Elaborado pelo autor com base em Dados da Pesquisa

Quanto aos respondentes em geral, são em sua maioria líderes de grupo (72,6\%), do sexo masculino (58,8\%), com 52,4 anos de idade em média, com pós-doutorado $(53,8 \%)$, não possuem bolsa de produtividade em pesquisa fornecida pelo $\mathrm{CNPq}(33,6 \%)$, contam com 23,4 anos de experiência em pesquisa, em média, e 14,4 anos de tempo médio de participação no grupo de pesquisa atual. Esses participantes atuam em grupos de pesquisa que, em sua maioria, 
funcionam na Região Sudeste (47,6\%), vinculados a instituições públicas de ensino e pesquisa (90,3\%), e atuam na área das Ciências Sociais Aplicadas (19,2\%).

Limitando os resulatados apenas aos líderes, são em sua maioria do sexo masculino (61,5\%), com 55,3 anos de idade em média, com pós-doutorado (63,9\%), não possuem bolsa de produtividade em pesquisa fornecida pelo CNPq (23,5\%), contam com 26,7 anos de experiência em pesquisa, em média, e 17,4 anos de tempo médio de participação no grupo de pesquisa atual. Esses participantes atuam em grupos de pesquisa que em sua maioria funcionam na Região Sudeste (48,9\%), vinculados a instituições públicas de ensino e pesquisa $(91,7 \%)$, e atuam na área das Ciências Exatas e da Terra $(21,4 \%)$.

Neste ponto, é importante ressaltar que a amostra investigada é qualitativamente representativa da população, à medida que as medidas passíveis de comparação estão distribuídas de modo aproximado ao que caracteriza a população.

Primeiro, destaca-se que a escolaridade da população dos participantes de grupos de pesquisa também apresenta a maioria de pesquisadores com o título de doutorado: $88,2 \%$ de doutores na amostra e 65\% de doutores, segundo o último censo do CNPq (Tabela 10). Porém, vale alertar para a existência de uma proporção maior de doutores na amostra, excedendo o percentual da população, o que pode resultar, por exemplo, em ter um maior número de respondentes relatando ter maior domínio de competências ou em uma menor variabilidade dos dados.

Isso provavelmente também irá ocorrer para idade e tempo de participação nos grupos assim como na amostra estudada,

Tabela 10 - Comparação entre População e Amostra quanto à Titulação Máxima dos pesquisadores

\begin{tabular}{lrrrc}
\hline \multicolumn{1}{c}{ Titulação máxima dos pesquisadores } & População & \multicolumn{1}{c}{$\%$} & Amostra & \multicolumn{1}{c}{$\%$} \\
\hline Doutorado & 116.427 & 64,59 & 454 & 88,16 \\
Especialização & 8.308 & 4,61 & 8 & 1,55 \\
Graduação & 6.008 & 3,33 & 11 & 2,14 \\
Mestrado & 45.929 & 25,48 & 39 & 7,57 \\
Outros & 3.590 & 1,99 & 3 & 0,58 \\
\hline Total & 180.262 & 100 & 515 & 100 \\
\hline
\end{tabular}

Fonte: Dados da Pesquisa comparados a dados do CNPq (2015)

Segundo, a idade e o sexo dos líderes respondetes também se aproximam. A população possui idade média de 49,1 anos, enquanto a amostra relativa aos líderes tem 55, 3 anos, em 
média. Os homens são 54\% na população de líderes, e 61,5\% na amostra equivalente (Figura $15)$.

Figura 15 - Comparação entre população e amostra quanto ao sexo dos respondentes

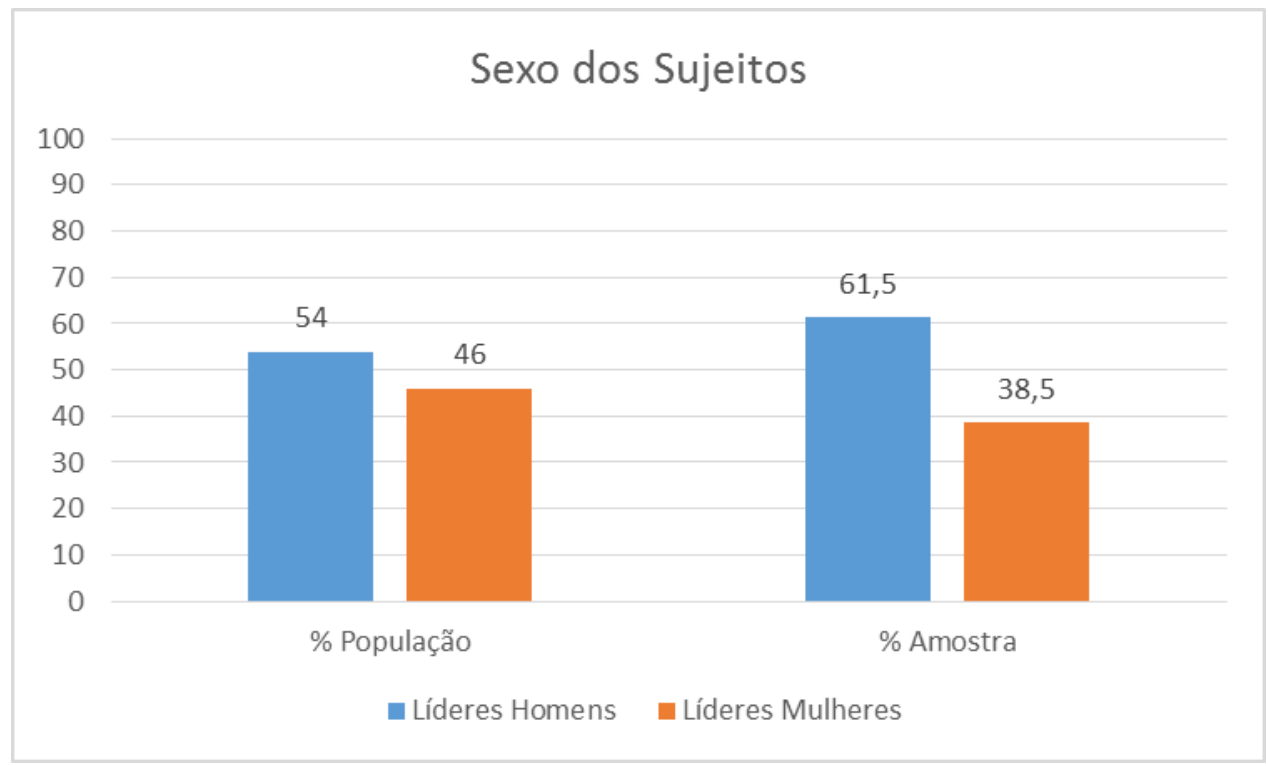

Fonte: Dados da Pesquisa comparados a dados do CNPq (2015)

Quanto à distribuição geográfica, vê-se que a amostra estudada acompanha a população, no que tange ao quantitativo de grupos de pesquisa em cada Região do Brasil (Figura 16).

Figura 16 - Comparação entre população e amostra quanto à localização dos grupos

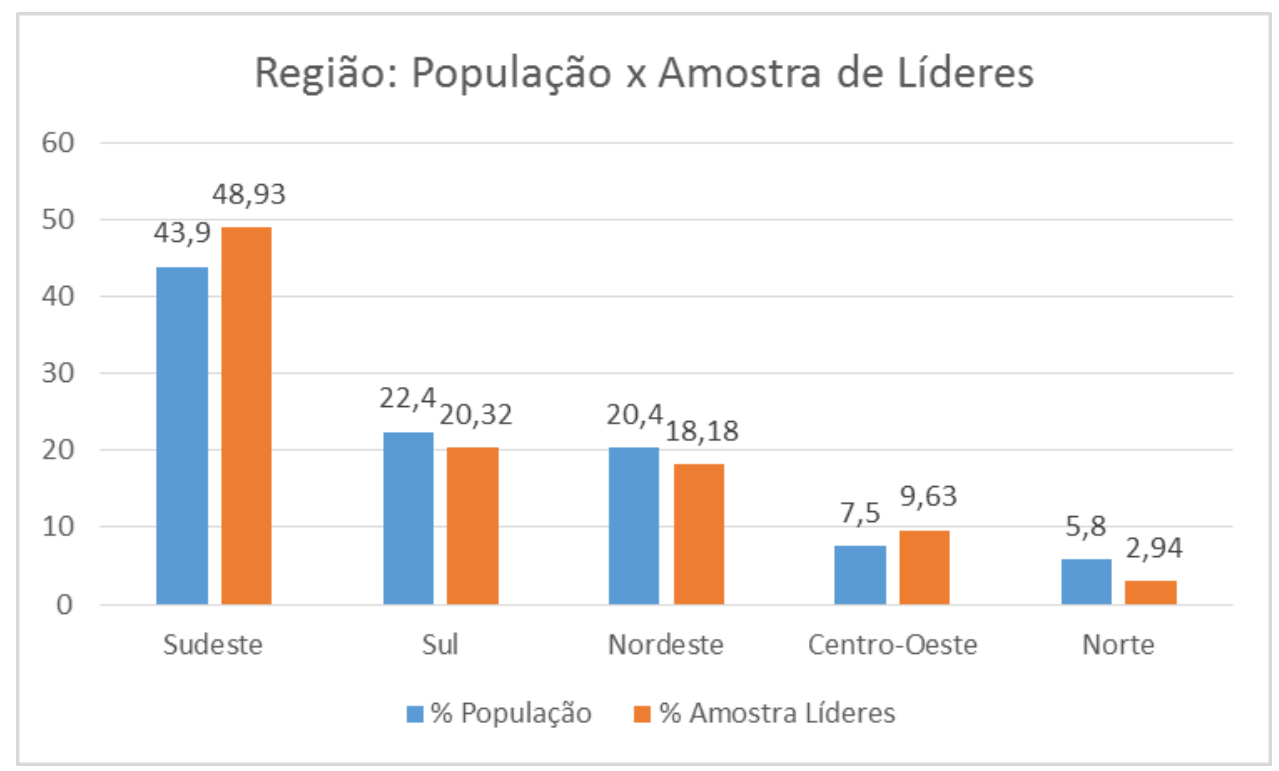

Fonte: Dados da Pesquisa comparados a dados do CNPq (2015) 
O Estado de São Paulo e do Rio de Janeiro são os que mais possuem grupos de pesquisa tanto na população quanto na amostra estudada. A Tabela 11 compara o número de grupos e os respectivos percentuais na população e na amostra relativa aos líderes.

Tabela 11 - População e amostra por Unidade da Federação

\begin{tabular}{|c|c|c|c|c|}
\hline $\mathbf{U F}$ & $\begin{array}{l}\text { Grupos na } \\
\text { População }\end{array}$ & $\%$ & $\begin{array}{c}\text { Grupos na } \\
\text { Amostra de } \\
\text { Líderes }\end{array}$ & $\%$ \\
\hline São Paulo & 7.278 & 20,6 & 101 & 27,0 \\
\hline Rio de Janeiro & 4.147 & 11,7 & 56 & 15,0 \\
\hline Minas Gerais & 3.482 & 9,8 & 24 & 6,4 \\
\hline Rio Grande do Sul & 3.315 & 9,4 & 43 & 11,5 \\
\hline Paraná & 3.011 & 8,5 & 24 & 6,4 \\
\hline Bahia & 1.763 & 5 & 3 & 0,8 \\
\hline Santa Catarina & 1.612 & 4,6 & 9 & 2,4 \\
\hline Pernambuco & 1.251 & 3,5 & 38 & 10,2 \\
\hline Paraíba & 1.006 & 2,8 & 4 & 1,1 \\
\hline Ceará & 946 & 2,7 & 6 & 1,6 \\
\hline Distrito Federal & 808 & 2,3 & 26 & 7,0 \\
\hline Pará & 800 & 2,3 & 2 & 0,5 \\
\hline Goiás & 659 & 1,9 & 4 & 1,1 \\
\hline Espírito Santo & 642 & 1,8 & 2 & 0,5 \\
\hline Mato Grosso do Sul & 649 & 1,8 & 2 & 0,5 \\
\hline Rio Grande do Norte & 641 & 1,8 & 4 & 1,1 \\
\hline Amazonas & 527 & 1,5 & 3 & 0,8 \\
\hline Mato Grosso & 538 & 1,5 & 4 & 1,1 \\
\hline Alagoas & 442 & 1,3 & 3 & 0,8 \\
\hline Piauí & 395 & 1,1 & 4 & 1,1 \\
\hline Sergipe & 405 & 1,1 & 5 & 1,3 \\
\hline Maranhão & 366 & 1 & 1 & 0,3 \\
\hline Tocantins & 260 & 0,7 & 2 & 0,5 \\
\hline Amapá & 141 & 0,4 & 0 & 0,0 \\
\hline Roraima & 124 & 0,4 & 1 & 0,3 \\
\hline Acre & 100 & 0,3 & 0 & 0,0 \\
\hline Rondônia & 116 & 0,3 & 3 & 0,8 \\
\hline Total & 35.424 & 100 & 374 & 100,0 \\
\hline
\end{tabular}

Fonte: Dados da Pesquisa comparados a dados do CNPq (2015)

Ainda sobre as unidades da federação, vale frisar que é possível que as diferenças nos percentuais de respondentes relativos ao Estado de Pernambuco (10,2\% na amostra e 3,5\% na população) e ao Distrito Federal (7\% na amostra e 2,3\% na população) se devam ao fato de o primeiro ser o Estado de origem do pesquisador e o segundo ser a unidade da federação a que se vincula o pesquisador atualmente, o que pode ter proporcionado maior quantidade de respondentes. Além disso, a estratégia da "bola-de-neve" se iniciou com pesquisadores da Universidade de Brasília, localizada no Distrito Federal, como foi relatado no terceiro capítulo. 
Quanto às grandes áreas do conhecimento, percebem-se algumas variações nos percentuais distribuidos entre a população e a amostra de líderes (Figura 17). Alguns hiatos entre os percentuais parecem ser mais evidentes, como é o caso da quantidade de grupos vinculados às Ciências Exatas e da Terra (que na população representam 10\% e na amostra de líderes, 21,4\%) e às Ciências Humanas (que perfazem 21\% da população e 11,2\% da amostra de líderes). De toda forma, há de se frisar que o estudo conseguiu atingir todas as grandes áreas do conhecimento.

Figura 17 - Comparação entre população e amostra quanto à Grande área do conhecimento

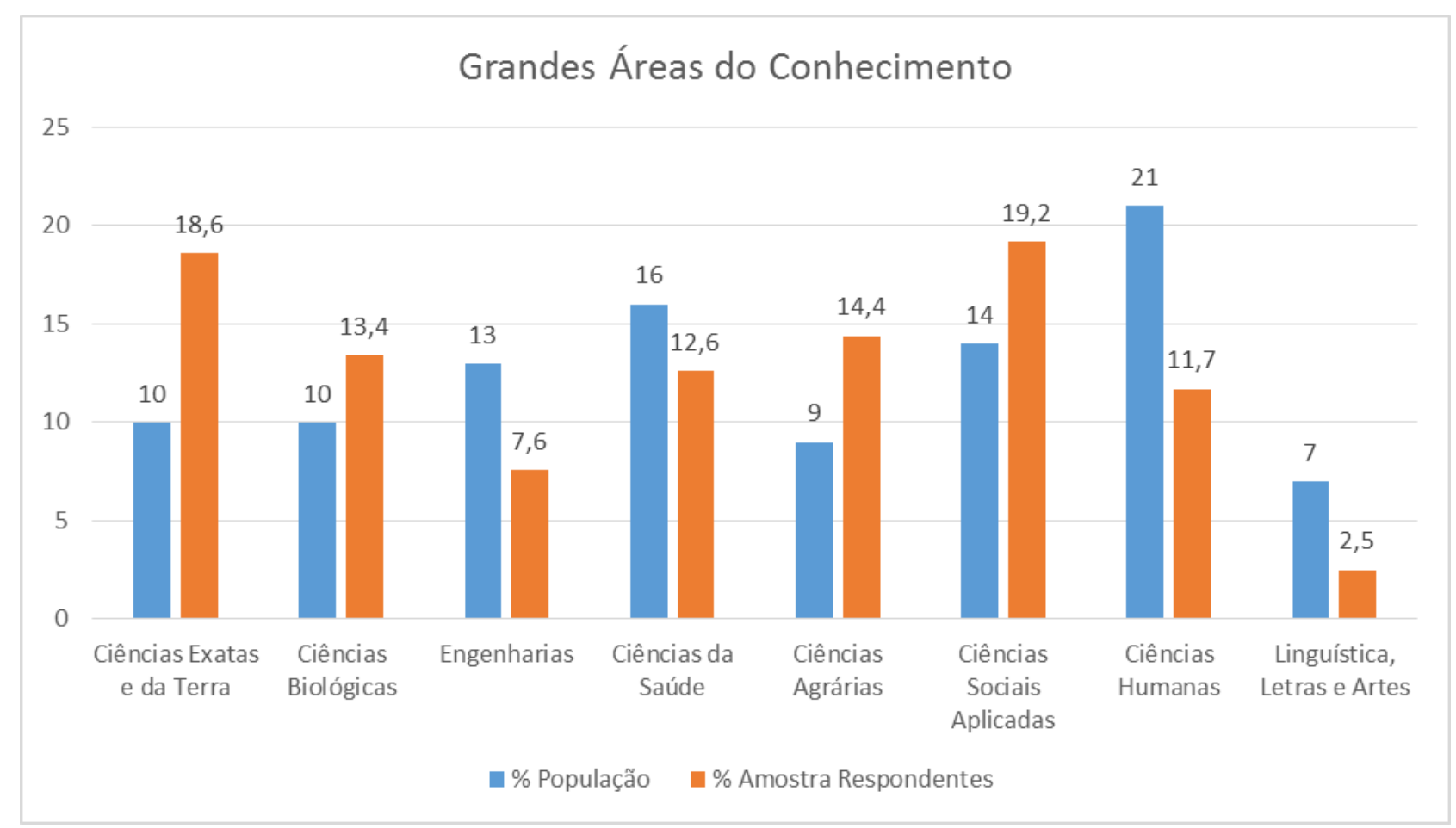

Fonte: Dados da Pesquisa comparados a dados do CNPq (2015)

Enfim, em que pese haver algumas diferenças em dados isolados, acredita-se que a distribuição da amostra pode servir como parâmetro da população estudada, uma vez que os graus são minimamente equivalentes. Isso é relevante porque, como se trata de um estudo com escopo estatístico, espera-se o alcance de validade externa, para efeito de generalização, ainda que do tipo naturalístico ou analítico (STAKE, 1978; YIN, 1994; ALVES-MAZZOTTI, 2006).

Finalizados a caracterização da amostra e o seu cotejamento com relação à população, apresentada no terceiro capítulo, passa-se aos resultados relativos aos objetivos 1 a 4 , que tratam da identificação e da apresentação de indícios ou evidências de validade de escalas sobre o 
domínio de competências gerenciais e os aspectos que evidenciam resultados em grupos de pesquisa.

\subsection{Análise exploratória e Tratamento inicial dos dados}

Finalizada a fase de coleta, os dados foram exportados do SurveyMonkey para o Statistical Package for the Social Sciences - SPSS, para a exploração. Inicialmente, foram ajustados: notórios erros de digitação; respostas incompatíveis; e algumas adaptações planejadas previamente, como exemplo, as questões que tratavam do tempo de experiência em atividades de pesquisa e do tempo de participação no grupo de pesquisa atual foram unificadas em uma mesma unidade de tempo (meses), já que, de modo proposital, essa informação não ficou restrita a uma única unidade, para que os participantes não precisassem efetuar conversões matemáticas, o que poderia causar evasões ou equívocos nas respostas.

Em seguida, foram realizados a análise e o tratamento dos valores ausentes. Sobre esse aspecto vale esclarecer que, embora a participação e o preenchimento do questionário fossem facultativos, as respostas aos itens relativos às competências gerenciais e aos resultados eram de caráter obrigatório para todos e para os líderes de grupo, respectivamente. Com isso, solicitou-se a exportação para o SPSS apenas as respostas completas, no que tange aos itens obrigatórios. Assim, os 528 respondentes que foram considerados para análise só apresentaram valores ausentes para respostas facultativas. Ademais, a resposta equivalente ao "Não se aplica" foi recodificada no SPSS, de forma que fosse considerada um valor ausente.

Assim, analisando os dados das respostas "não se aplica" a grupos de pesquisa (recodificada para dados ausentes) relativos a competências gerenciais, verificou-se que todos os itens possuíam o percentual de valores ausentes inferior a $10 \%$, sendo que apenas 2 dos 51 itens possuíam percentual de ausência superior a 5\%: "Realizar a gestão de pessoas do grupo considerando características individuais" (5,3\% de ausentes) e "Estabelecer parcerias com empresas do setor produtivo" (6,3\% de ausentes) (HAIR JR. et al., 2010; TABACHNICK; FIDEL, 2007).

Neste ponto, cabe a seguinte discussão. $\mathrm{O}$ estabelecimento de parcerias com o setor produtivo, de fato, é uma competência gerencial não condizente com o ofício de muitos líderes de grupos de pesquisa, em que pese essa ser uma competência incentivada pela política brasileira de ciência e tecnologia. Por exemplo, é de se esperar que grupos integrantes de grandes áreas do conhecimento como Engenharias, Ciências Exatas e da Terra e Ciências da 
Saúde interajam mais com indústrias e com o setor de serviços, se comparados com grupos de Ciências Humanas e Linguística, Letras e Artes. Todavia, é preocupante perceber que justamente a gestão de pessoas também é apontada como uma competência gerencial não aderente a grupos de pesquisa. Afinal, gerir pessoas é uma competência tradicional que permeia as mais diversas classificações tradicionais de liderança e que está presente em praticamente todos os estudos citados na revisão de literatura, nos mais distintos contextos de pesquisa. Estudos qualitativos capazes de apurar o que leva líderes de grupo a negligenciarem a gestão de pessoas como uma competência aplicável ao seu contexto seriam muito bem-vindos.

Já as respostas relativas a resultados de grupos de pesquisa que indicavam que determinado resultado seria do líder (enquanto indivíduo) e não do grupo como um todo (recodificados como dados ausentes) apresentaram percentuais mais expressivos: 16 dos 31 possuíam valores ausentes em percentual superior a 10\% (Tabela 12).

Tabela 12 - Percentual de Líderes que consideram que o resultado é decorrente de uma ação individual e não do grupo

\begin{tabular}{lc}
\hline \multicolumn{1}{c}{ Itens de Resultados } & Percentual \\
\hline Participação em corpo editorial de periódicos. & $32 \%$ \\
\hline Atuação na revisão de projetos submetidos a agências de fomento. & $31 \%$ \\
\hline Participação, como avaliador externo, de comissões julgadoras de concursos. & $30 \%$ \\
\hline Atuação na revisão de periódicos científicos. & $29 \%$ \\
\hline Participação, como avaliador externo, de comissões examinadoras de dissertações ou teses. & $29 \%$ \\
\hline Participação em comitês de agências de fomento. & $28 \%$ \\
\hline Participação em diretorias de sociedades científicas. & $27 \%$ \\
\hline Participação em eventos para proferir conferência, coordenar mesa ou simpósio. & $22 \%$ \\
\hline Curso ministrado. & $18 \%$ \\
\hline Prestação de assessoria ou consultoria técnica para organizações públicas ou privadas. & $18 \%$ \\
\hline Participação em entrevistas, mesas redondas, programas de rádio ou TV e similares. & $15 \%$ \\
\hline Coordenação de grupos de trabalho em eventos científicos. & $13 \%$ \\
\hline Estabelecimento de parcerias com outros grupos ou pesquisadores. & $13 \%$ \\
\hline Elaboração de material didático ou instrucional. & $11 \%$ \\
\hline Publicação de artigos “não-científicos” para a mídia em geral (ex.: jornais, revistas, redes & $11 \%$ \\
\hline Pociais, websites ou blogs) & $11 \%$ \\
\hline Ponlicação de livro, capítulo de livro, prefácio ou posfácio. & Elabo \\
\hline
\end{tabular}

Fonte: Elaborada pelo autor com base em Dados da Pesquisa 
Em que pese a maioria dos respondentes terem considerado esses itens como resultados do grupo como um todo, deve-se frisar que há altos percentuais (11\% a 32\%) que consideram os itens como resultados individuais. Destaque-se ainda que estudos específicos que tratam da produtividade acadêmica do pesquisador, usam muitos desses itens como indicadores próprios do nível individual, a exemplo do recente estudo de Neiva, Fussi e Corradi (2016), que identificaram características estruturais, relacionais e posicionais das redes sociais de pesquisadores em Psicologia no Brasil e as relacionaram com vários indicadores do CNPq, os quais também serviram como base para a redação de itens usados nesta Dissertação. Ou seja, em grupos de pesquisa, parece haver algum grau de sobreposição entre resultados individuais e grupais. Futuros estudos poderiam investigar que elementos coincidem e que elementos divergem no que tange a essa sobreposição nos resultados e se há aspectos relacionados a áreas de conhecimento ou características individuais que influenciam nessa percepção.

Embora esses percentuais de valores ausentes excedam os patamares estabelecidos por Hair Jr. et al. (2010) e Tabachnick e Fidel (2007), que limitam os percentuais de ausência a 5\% ou $10 \%$ dos dados, optou-se pela manutenção desses indivíduos. Primeiro, porque a exclusão poderia comprometer o tamanho da amostra mínima; segundo, porque esses dados não eram propriamente ausentes, mas expressavam as respostas equivalentes a "Não se aplica"; e terceiro, porque, a partir da a análise de valores ausentes (Missing values analysis - MVA), não foi identificado qualquer indicativo de que os valores ausentes configurassem uma subamostra (por exemplo, indivíduos pertencentes às mesmas áreas do conhecimento, unidades da federação, idade ou tempo de experiência com pesquisa). De qualquer forma, considerando que percentuais expressivos nos casos omissos podem representar problemas, foi adotado o procedimento de estimação de dados ausentes, segundo o método listwise, já que revelou melhores saídas para as cargas fatoriais dos itens. De qualquer forma, os itens com elevado percentual de ausentes foram analisados, quanto aos valores das cargas na análise fatorial e quanto à consistência teórica para o agrupamento dos itens em fatores, conforme será relatado mais adiante.

A partir da MVA, somada à análise de gráficos Boxplot e de diagramas ramo-e-folhas, também foi possível detectar casos atípicos (Outlines) e extremos (Outliers) univariados. Como decorrência, foram excluídos os casos 108, 109, 149, 355, 362, 382, 402, 407, 427, 461, 498, 519 e 521. Destaque-se que esse último caso (521) também foi identificado como Outlier multivariado, mediante o cálculo da distância Mahalanobis. Para tanto, simulou-se uma regressão linear, na qual a variável identificadora dos casos foi equiparada à variável 
dependente enquanto as 51 competências gerenciais e os 31 resultados foram considerados variáveis independentes, perfazendo 82 variáveis independentes (número de graus de liberdade). Por meio de consulta à tabela de valores críticos do Qui Quadrado segundo o número de graus de liberdade, verificou-se que, com 82 graus de liberdade e probabilidade $p<0,001$, deveria ser utilizado o valor de 127.324 (distância de Mahalanobis). O único caso que apresentou distância Mahalanobis superior a esse valor foi o sujeito 521 (distância de 129.472). Destarte, apurou-se que o caso 521 além de outlier univariado, seria também multivariado.

Diferentemente dos valores ausentes, decidiu-se por excluir os outliers, primeiro, porque a retirada de apenas 13 indivíduos não afetaria a representatividade da amostra; segundo, porque, normalmente, outliers reduzem ou maximizam a magnitude das relações entre as variáveis; terceiro, porque essas alterações na magnitude representam grande impacto na matriz de correlações (HAIR JR. et al., 2010; PASQUALI, 2010; TABACHNICK; FIDELL, 2007); e quarto, porque, segundo Neiva, Abbad e Tróccoli (2011), a permanência de dados extremos tende a minimizar os resultados e a fatorabilidade, durante a análise fatorial, uma vez que dados díspares ensejam a exclusão de potenciais itens por possuírem cargas fatoriais baixas.

De modo semelhante ao tratamento dado aos valores ausentes, também se procurou identificar características comuns que pudessem servir para diagnóstico de uma subamostra entre os outliers, todavia, nenhuma relação demonstrou estar atrelada a dados sociodemográficos e funcionais como área do conhecimento, idade, sexo, região entre outros. Entretanto, há de se informar que os treze casos foram classificados como outliers inferiores às medias das variáveis que compõem as escalas. Nesse sentido, é possível cogitar que esses sujeitos tenham demonstrado menor domínio de competências gerenciais e que seus grupos não tenham alcançado os resultados elencados pelo instrumento.

Em resumo, nenhum caso foi excluído sob a justificativa de excesso de valores ausentes (mas foi utilizado o método listwise para o tratamento de missings) e treze indivíduos foram excluídos por representarem valores extremos inferiores, sendo um deles também outlier multivariado. Destaque-se que todos os excluídos atuavam como líderes de grupos de pesquisa, assim, o total de líderes reduziu de 387 para 374, e o de pesquisadores reduziu de 528 para 515.

Superada a análise de valores atípicos e extremos, mas antes de dar seguimento à análise fatorial propriamente dita, foram verificadas a normalidade, a linearidade e a fatorabilidade da matriz.

Quanto à normalidade, os histogramas com exibição da curva normal revelaram a predominância de assimetria negativa, ou seja, as ocorrências dos dados predominavam na 
cauda direita, indicando a possibilidade de supervalorização do domínio de competências e também da ocorrência de resultados, o que é compreensível em função das características da amostra. Os índices de assimetria e curtose foram diferentes de zero em todas as 82 variáveis; além disso, em um nível de significância de 0,05, os itens apresentaram Score $\mathrm{Z}$ que extrapolavam $\pm 1,96$ em 49 das 51 variáveis relativas a competências gerenciais e em 24 dos 31 itens de resultados, indicando a inexistência de normalidade para essas variáveis. Por fim, o Teste Kolmogorov-Smirnov (K-S) com a correção de Lilliefors foi aplicado, já que a amostra excede 30 indivíduos, e apontou que todas as 82 variáveis eram significativamente diferentes de uma distribuição normal.

Fez-se, então, a tentativa de parametrização das variáveis mediante a técnica do BoxCox (OSBORNE, 2010; TABACHNICK; FIDELL, 2007), contudo, essa técnica - que é a considerada a mais efetiva - não revelou melhorias, e, assim, optou-se pela utilização de dados brutos, até porque a inexistência de normalidade não é impeditiva para a realização da Análise fatorial, diante da robustez dessa técnica (PASQUALI, 2010; LAROS, 2012; NEIVA; ABBAD; TRÓCCOLI, 2011), sobretudo, quando há mais de 200 sujeitos (PASQUALI, 2010; HAIR JR. et al., 2010).

Quanto à linearidade, foram analisados os gráficos de dispersão bivariada entre pares de itens, bem como das correlações entre eles. Quando analisados dois a dois, os itens apresentaram correlações com intensidades entre 0,211 e 0,764, o que indica a não-linearidade dos dados. Todavia, destaque-se que não houve sequer aproximação ao patamar crítico de 0,900, a partir do qual se diagnosticaria a multicolinearidade (PASQUALI, 2010). Assim, não se justificou qualquer proposta de exclusão de itens sob essa alegação.

Quanto à fatorabilidade da matriz, foram observados cinco aspectos:

- a inspeção visual da matriz de correlações apontou que apenas $0,5 \%$ das correlações interitem eram inferiores a 0.3 entre as variáveis relativas a competências gerenciais e $17,7 \%$ entre os itens relativos a resultados de grupos de pesquisa; ambos percentuais atenderam às recomendações de Clark e Watson (1995) e Pasquali (2010), segundo os quais $50 \%$ das correlações devem assumir valores superiores a 0.3 ;

- os determinantes das matrizes apresentaram valores baixos e diferentes de zero $(2,063 \mathrm{e}-$ ${ }^{21}$ para competências gerenciais e $6,935 \mathrm{e}^{12}$ para resultados), o que indica a pertinência da fatoração da matriz;

- o cálculo do índice de adequação da amostra, Kaiser-Meyer-Olkin (KMO), confirmou a possibilidade de fatorabilidade dos instrumentos $(0,980$ para competências gerenciais 
e 0,904 para resultados), ambos considerados maravilhosos, segundo a classificação de Kaiser (1974) (HAIR JR. et al., 2010; TABACHNICK; FIDELL, 2007);

- a análise da diagonal da Matriz de Anti-imagem apontou média de 0,322 para as competências gerenciais e 0,304 para os resultados, valores considerados moderados para a fatorabilidade, segundo Kaiser (1974); e

- as comunalidades ou índices de regressão da variável, que correspondem à soma dos quadrados das cargas fatoriais, não apresentaram valores extremos $(0$ - 1) nem para competências gerenciais nem para resultados, indicando não haver problemas para fatoração.

\subsection{Análise Fatorial}

Após a limpeza dos dados e verificação de normalidade, linearidade e a fatorabilidade da matriz, o processamento da Análise fatorial considerou as seguintes orientações de Laros (2012): a seleção de variáveis a serem submetidas à análise fatorial; o número de fatores a serem extraídos; o tipo de análise fatorial a ser utilizado para extrair os fatores; o procedimento de rotação a ser usado a fim de direcionar os fatores; a interpretação dos resultados da análise fatorial; a necessidade e a forma de calcular os escores fatoriais; e a seleção dos resultados mais relevantes da análise fatorial para a publicação da pesquisa.

Encerrada a fase preparatória para o processamento da Análise Fatorial, passa-se a discorrer sobre os procedimentos específicos atinentes à confecção de cada uma das escalas.

\subsubsection{Escala de Domínio de Competências Gerenciais em Grupos de Pesquisa}

Visando a apresentar indícios ou evidências de validade para a escala domínio de competências gerencias em grupos de pesquisa, e já efetuados os procedimentos relativos à limpeza dos dados e verificação de normalidade, linearidade e a fatorabilidade da matriz (ROZZETT; DEMO, 2010), passa-se, nesta seção, a apresentar os resultados e as discussões concernentes à Escala de Domínio de Competências Gerenciais em Grupos de Pesquisa, que se baseou na amostra de 515 respondentes (e não apenas de líderes), já que as competências gerenciais não se limitam ao exercício da liderança formal do grupo. 
Inicialmente, procedeu-se à da análise do Scree plot (diagrama da sedimentação ou gráfico do cotovelo), que apontou a existência de três possíveis fatores, com eigenvalues superiores a 1, conforme relatado na Figura 18.

\section{Figura 18 - Fatores das Competências Gerenciais segundo o Scree plot}

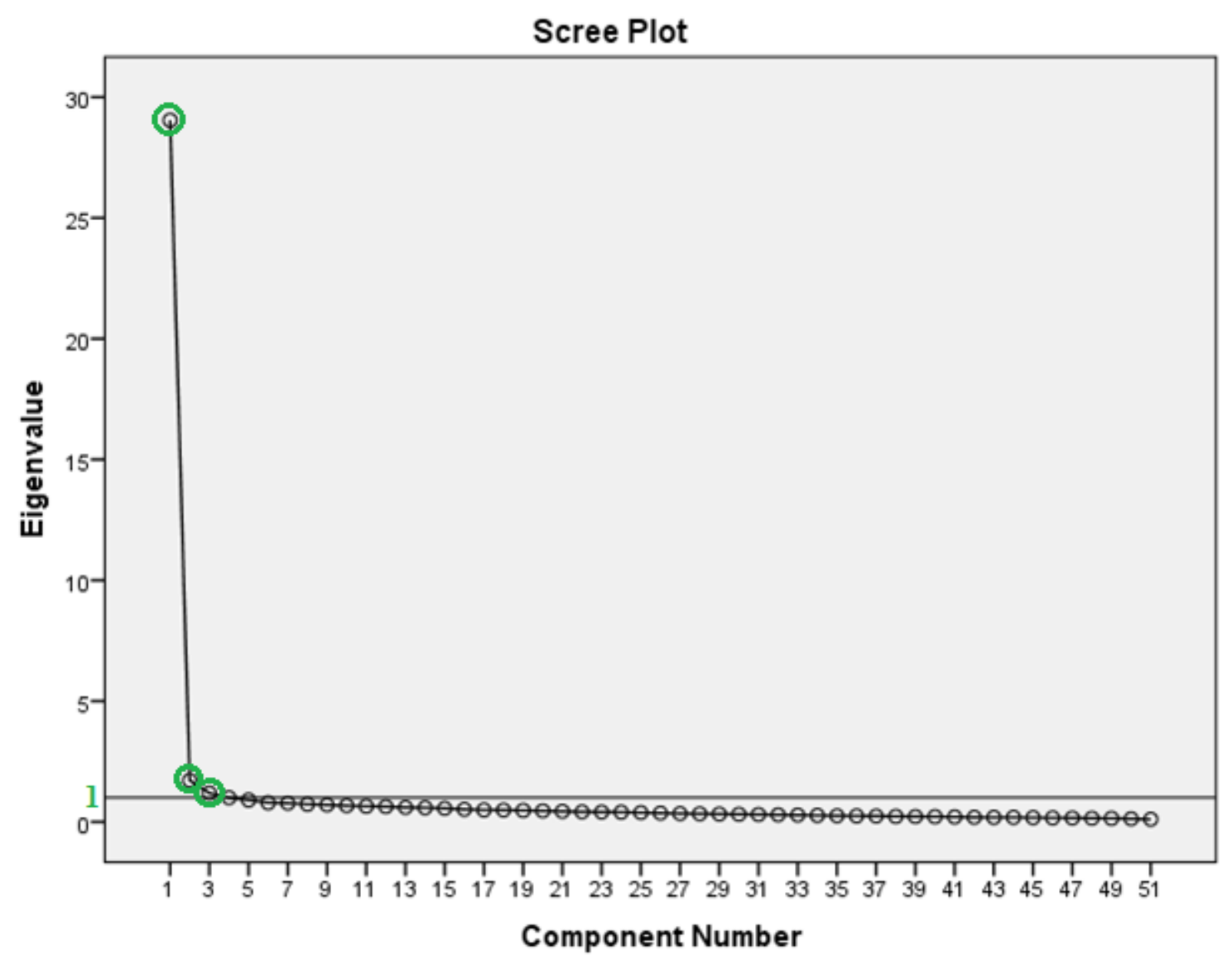

Fonte: Dados da Pesquisa

Entretanto, o terceiro fator sugerido pela análise do Scree plot explicava menos de 3\% da variância, no âmbito da solução inicial, via método dos componentes principais. Assim, recorreu-se à análise paralela de Horn, considerada mais precisa na determinação do número correto de fatores a extrair (Laros, 2012). Essa análise consiste na comparação entre os eigenvalues obtidos empiricamente, por meio do output do SPSS denominado "Variância total explicada", e os autovalores obtidos nas matrizes que contêm variáveis randômicas nãocorrelacionadas, disponíveis no site http://ires.ku.edu/ smishra/parallelengine.htm, tendo tamanhos de amostra de 515 pesquisadores e 51 itens (com relação a competências gerenciais).

A partir desse cotejamento, optou-se pela manutenção apenas dos dois primeiros fatores, já que o terceiro possível fator apresentou eigenvalue empírico menor que o randômico (Tabela 
13), sendo descartados para as análises seguintes os fatores com eigenvalues empíricos menores ou iguais aos randômicos.

Tabela 13 - Comparação dos Eigenvalues das Competências Gerenciais durante a Análise Paralela

\begin{tabular}{lrrrr}
\hline & \multicolumn{3}{c}{ Eigenvalues iniciais } \\
\cline { 2 - 4 } Fator & Total & $\begin{array}{c}\text { \% de } \\
\text { variância }\end{array}$ & $\begin{array}{c}\text { \% de } \\
\text { variância } \\
\text { acumulada }\end{array}$ & Valor aleatório \\
\hline 1 & 25,205 & 49,421 & 49,421 & 1,719543 \\
2 & 2,102 & 4,121 & 53,542 & 1,648979 \\
3 & 1,310 & 2,569 & 56,111 & 1,583324 \\
4 & 1,207 & 2,367 & 58,478 & 1,550444 \\
5 & 1,198 & 2,348 & 60,826 & 1,511388 \\
$\vdots$ & $\vdots$ & $\vdots$ & $\vdots$ & $\vdots$ \\
\hline Fonte: Elaborada pelo autor com base em Dados da Pesquisa
\end{tabular}

Definida a quantidade de dois fatores, passou-se à redução de dimensão, mediante o método dos mínimos quadrados não ponderados (ou ordinários), já que é o mais indicado em caso de não-normalidade dos dados (BOWEN; GUO, 2011).

Destaque-se que, para o estabelecimento da carga fatorial mínima a ser considerada nas análises, foi adotado o patamar de 0,300, que é o valor considerado importante para a maioria dos pesquisadores (FIELD, 2009) e está adequado ao tamanho da amostra de 300 a 599 indivíduos (STEVENS, 2012), mas é ligeiramente menos rigoroso que os patamares preconizados por Hair Jr. et al. (2010), que recomendam desprezar cargas inferiores a 0,350, e por Tabachnick e Fidell (2007), que propõem a desconsideração de cargas absolutas inferiores a 0,320 .

Como as correlações empíricas entre competências gerenciais foram diferentes de zero e como a literatura revisada ratifica que as competências gerenciais não constituem subunidades independentes (SCHMITT; SASS, 2011), nem sequer se cogitou a aplicação de rotações ortogonais, já que não configuram uma boa opção para itens correlacionados. Assim, foram comparadas a solução inicial (sem rotações) e as soluções rotacionadas oblíquas Promax e Oblimin - esta última é preferível segundo Field (2009). Seguindo o critério da interpretabilidade (PASQUALI, 2010), a solução oblíqua rotacionada via Oblimin com delta padrão em zero - conforme proposto por Pedhazur e Schmelkin (1991) - foi considerada a alternativa mais apropriada. 
Após a rotação dos fatores, o item "Apoiar o grupo na busca por recursos necessários à realização de atividades" apresentou indicação de exclusão em virtude de possuir carga fatorial com diferença menor que 0,100 entre os valores absolutos nos dois fatores, 0,409 no primeiro fator e de 0,368 no segundo, nos termos do Quadro 17 (GORSUCH, 1983; LAROS; PUENTEPALÁCIOS, 2004). Com isso, a escala antes contava com 51 passou a perfazer 50 itens.

Quadro 17 - Competência gerencial com indicativo de exclusão

\begin{tabular}{|c|c|c|c|}
\hline $\begin{array}{c}\text { Item relativo a competências gerenciais com } \\
\text { indicação de exclusão }\end{array}$ & $\begin{array}{c}\text { Diferença das } \\
\text { cargas fatoriais } \\
\text { quando em mais } \\
\text { de um fator }\end{array}$ & $\begin{array}{c}\text { Consistência } \\
\text { teórica para o } \\
\text { agrupamento } \\
\text { dos itens em } \\
\text { fatores? }\end{array}$ & $\begin{array}{c}\text { Decisão: } \\
\text { Excluir ou } \\
\text { Manter? }\end{array}$ \\
\hline $\begin{array}{l}\text { Apoiar o grupo na busca por recursos necessários à } \\
\text { realização de atividades. }\end{array}$ & Houve 0,041 & Sim & Excluir \\
\hline
\end{tabular}

Fonte: Elaborado pelo autor com base em Dados da Pesquisa

Embora o referido item possuísse adesão teórica aos demais integrantes do primeiro fator e a captação de recursos seja um atributo importante para grupos de pesquisa, que, inclusive, tem ganhado destaque diante das novas políticas brasileiras de ciência e tecnologia, fez-se a opção por, de fato, excluir esse item, uma vez que há outros itens que sustentam a relevância do tema e apresentam cargas fatoriais consideráveis, como por exemplo, "Obter financiamento para as pesquisas de agências externas de fomento" e "Estabelecer parcerias com empresas do setor produtivo" com cargas fatoriais de 0,735 e 0,508 , respectivamente.

Após a exclusão do referido item, a análise fatorial foi efetuada novamente para confirmação e eventual reacomodação dos itens em fatores. Como não ocorreu mais nenhum "empate" entre cargas fatoriais ou carência de adesão teórica entre os itens de um mesmo fator, passou-se à análise de confiabilidade dos fatores, com base no cálculo do índice alfa de Cronbach, que é uma técnica estatística que aponta o quanto os fatores estão refletindo o construto que se está medindo (FIELD, 2009; ROZZETT; DEMO, 2010).

Há diferentes interpretações para o alfa de Cronbach: Pasquali (2010) considera 0,7 um patamar confiável e 0,8, muito confiável; Nunnally e Bernstein (1994) consideram 0,8 um patamar significativo; Field (2009) indica que são confiáveis valores entre 0,7 e 0,8; Kline (2015) recomenda valores acima de 0,7 para testes de habilidade, e aceita valores menores que 0,7 para tratar de construtos psicológicos; Hair Jr. et al. (2010) indicam 0,7 como limite inferior, mas fazem uma concessão para 0,6 no caso de análises fatoriais exploratórias.

Além disso, Hair Jr. et al (2010) e Field (2009) alertam que quanto mais itens possui um fator, maior deve ser o rigor em relação ao alfa de Cronbach. Nesse sentido, a extração dos fatores demonstra ser muito confiável, na classificação de Pasquali (2010) e significativo, na 
categorização de Nunnally e Bersntein (1994), pois os valores para ambos fatores excederam 0,9, conforme Tabela 14.

Tabela 14 - Análise do Alfa de Cronbach para os fatores das Competências Gerenciais

\begin{tabular}{ccccc}
\hline Escala & Itens & Fator & Itens & $\begin{array}{c}\text { Alfa de } \\
\text { Cronbach }\end{array}$ \\
\hline $\begin{array}{c}\text { Competências } \\
\begin{array}{c}\text { Gerenciais em Grupos } \\
\text { de Pesquisa }\end{array}\end{array}$ & 50 & $\begin{array}{c}\text { Gestão de Pessoas e de } \\
\text { Resultados de Pesquisa }\end{array}$ & 41 & 0,983 \\
\cline { 2 - 4 } & & $\begin{array}{c}\text { Captação de Recursos e de } \\
\text { Pessoas }\end{array}$ & 9 & 0,903 \\
\hline
\end{tabular}

Fonte: Elaborada pelo autor com base em Dados da Pesquisa

Por fim, os itens relativos às competências gerenciais agruparam-se em dois fatores: Fator 1 - Gestão de Pessoas e de Resultados de Pesquisa (48,2 \% de explicação) e Fator 2 Captação de Recursos e de Pessoas (2,9\% de explicação), perfazendo 51,1\% de variância total explicada. A Tabela 15 resume a variância total explicada.

Tabela 15 - Análise da variância explicada relativa aos fatores das Competências Gerenciais

\begin{tabular}{ccccc}
\hline Escala & $\begin{array}{c}\text { Variância } \\
\text { total } \\
\text { explicada }\end{array}$ & Fator & $\begin{array}{c}\text { Quantidade } \\
\text { de Itens }\end{array}$ & $\begin{array}{c}\text { Variância } \\
\text { explicada }\end{array}$ \\
\hline $\begin{array}{c}\text { Competências } \\
\text { Gerenciais em Grupos } \\
\text { de Pesquisa }\end{array}$ & $51,1 \%$ & $\begin{array}{c}\text { Gestão de Pessoas e de } \\
\text { Resultados de Pesquisa }\end{array}$ & 41 & $48,2 \%$ \\
\cline { 3 - 5 } & & $\begin{array}{c}\text { Captação de Recursos e de } \\
\text { Pessoas }\end{array}$ & 9 & $2,9 \%$ \\
\hline
\end{tabular}

Fonte: Elaborada pelo autor com base em Dados da Pesquisa

Com relação a qualidade dos itens, Comrey e Lee (1992) sugerem uma classificação baseada no valor da carga fatorial. De acordo com esses autores, itens excelentes possuem cargas a partir de 0,71 ; muito bons a partir de 0,63 ; bons a partir de 0,55 ; razoáveis acima de 0,45; e pobres a partir de 0,32. Diante dessa categorização, obteve-se 21 itens excelentes, 10 muito bons, 14 bons, 5 razoáveis, e nenhum foi considerado pobre.

Por fim, como forma de concretizar o alcance do segundo objetivo específico, apresentam-se 50 itens que compõem a escala de domínio de Competências Gerenciais em Grupos de Pesquisa, processada mediante o método de rotação oblíqua Oblimin, com delta padrão em zero. A Tabela 16 contempla os dois fatores, os códigos dos itens, os itens, as cargas fatoriais, a classificação dos itens segundo Comrey e Lee (1992), a variância explicada total e por fator, o alfa de Cronbach, e os Autovalores. 
Tabela 16 - Escala de Competências Gerenciais em grupos de pesquisa

\begin{tabular}{|c|c|c|c|c|}
\hline Fator & $\begin{array}{l}\text { Código } \\
\text { do Item }\end{array}$ & Item & $\begin{array}{c}\text { Carga } \\
\text { Fatorial }\end{array}$ & $\begin{array}{c}\text { Qualificação do item } \\
\text { - Comrey e Lee } \\
\text { (1992) }\end{array}$ \\
\hline \multirow{34}{*}{ 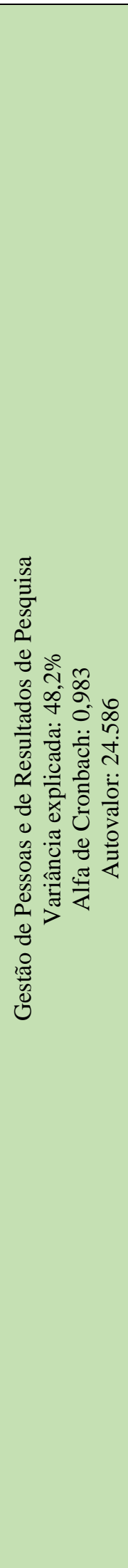 } & GPRP1 & $\begin{array}{l}\text { Zelar pelo cumprimento de prazos de realização de } \\
\text { atividades. }\end{array}$ & ,916 & Excelente \\
\hline & GPRP2 & $\begin{array}{l}\text { Estimular a troca de informações entre os integrantes do } \\
\text { grupo. }\end{array}$ & 860 & Excelente \\
\hline & GPRP3 & Planejar atividades a serem realizadas. & 859 & Excelente \\
\hline & GPRP4 & $\begin{array}{l}\text { Debater assuntos relativos à pesquisa com integrantes do } \\
\text { grupo. }\end{array}$ & ,854 & Excelente \\
\hline & GPRP5 & $\begin{array}{l}\text { Estimar prazos, estabelecendo cronograma de atividades de } \\
\text { pesquisa. }\end{array}$ & 845 & Excelente \\
\hline & GPRP6 & $\begin{array}{l}\text { Reelaborar as próprias ideias e conceitos com base em } \\
\text { críticas de membros do grupo. }\end{array}$ & 831 & Excelente \\
\hline & GPRP7 & Definir tarefas de acordo com a demanda de projeto. & ,818 & Excelente \\
\hline & GPRP8 & $\begin{array}{l}\text { Orientar membros da equipe quanto a atitudes eticamente } \\
\text { corretas. }\end{array}$ & ,813 & Excelente \\
\hline & GPRP9 & $\begin{array}{l}\text { Facilitar processos de comunicação entre os membros do } \\
\text { grupo. }\end{array}$ & ,766 & Excelente \\
\hline & GPRP10 & $\begin{array}{l}\text { Conhecer o projeto de pesquisa como um todo, } \\
\text { identificando a etapa em curso. }\end{array}$ & ,757 & Excelente \\
\hline & GPRP11 & Promover um ambiente produtivo no grupo. & ,756 & Excelente \\
\hline & GPRP12 & Distribuir tarefas de acordo com sua complexidade. & ,750 & Excelente \\
\hline & GPRP13 & $\begin{array}{l}\text { Solucionar problemas imprevistos, buscando garantir a } \\
\text { realização da pesquisa. }\end{array}$ & ,746 & Excelente \\
\hline & GPRP14 & $\begin{array}{l}\text { Distribuir atividades a realizar de forma equilibrada entre os } \\
\text { membros do grupo. }\end{array}$ & ,744 & Excelente \\
\hline & GPRP15 & Acompanhar a realização de tarefas. & ,738 & Excelente \\
\hline & GPRP16 & Verificar se resultados pretendidos são alcançados. & ,735 & Excelente \\
\hline & GPRP17 & $\begin{array}{l}\text { Assegurar fácil acesso às informações do grupo (relatórios, } \\
\text { diretórios, bases de dados, memória do grupo, etc). }\end{array}$ & ,727 & Excelente \\
\hline & GPRP18 & $\begin{array}{l}\text { Buscar a solução de problemas em conjunto com os } \\
\text { integrantes do grupo. }\end{array}$ & ,723 & Excelente \\
\hline & GPRP19 & $\begin{array}{l}\text { Administrar o ritmo de desenvolvimento das atividades de } \\
\text { pesquisa. }\end{array}$ & ,722 & Excelente \\
\hline & GPRP20 & $\begin{array}{l}\text { Resolver conflitos surgidos entre os membros do grupo de } \\
\text { pesquisa. }\end{array}$ & ,716 & Excelente \\
\hline & GPRP21 & Respeitar o ritmo de trabalho de cada um. & ,705 & Muito bom \\
\hline & GPRP22 & Conciliar os horários de todo o grupo. & 698 & Muito bom \\
\hline & GPRP23 & Prestar suporte frequente aos integrantes do grupo. & ,694 & Muito bom \\
\hline & GPRP24 & Ter visão sistêmica das atividades executadas. & 682 & Muito bom \\
\hline & GPRP25 & Sensibilizar o grupo para as mudanças. & 676 & Muito bom \\
\hline & GPRP26 & $\begin{array}{l}\text { Distribuir atividades de pesquisa de acordo com as } \\
\text { competências dos membros do grupo. }\end{array}$ & 676 & Muito bom \\
\hline & GPRP27 & Respeitar a diversidade de opiniões. & 649 & Muito bom \\
\hline & GPRP28 & Acompanhar a implementação das mudanças no grupo. & 644 & Muito bom \\
\hline & GPRP29 & $\begin{array}{l}\text { Tomar decisões acerca do andamento da pesquisa com } \\
\text { autonomia. }\end{array}$ & 641 & Muito bom \\
\hline & GPRP30 & $\begin{array}{l}\text { Analisar informações para diagnósticos ou tomada de } \\
\text { decisão. }\end{array}$ & ,628 & Bom \\
\hline & GPRP31 & $\begin{array}{l}\text { Realizar a gestão de pessoas do grupo considerando } \\
\text { características individuais. }\end{array}$ & 617 & Bom \\
\hline & GPRP32 & Coordenar esforços da equipe para obtenção de resultados. & ,611 & Bom \\
\hline & GPRP33 & Avaliar resultados de mudanças ocorridas no grupo. & 611 & Bom \\
\hline & GPRP34 & $\begin{array}{l}\text { Estimular o interesse de integrantes do grupo na } \\
\text { continuidade da pesquisa. }\end{array}$ & 607 & Bom \\
\hline
\end{tabular}




\begin{tabular}{|c|c|c|c|c|}
\hline & GPRP35 & Expor ideias e opiniões com clareza, concisão e coerência. & ,601 & Bom \\
\hline & GPRP36 & $\begin{array}{l}\text { Propor ajustes em acordos estabelecidos nos momentos } \\
\text { adequados. }\end{array}$ & ,598 & Bom \\
\hline & GPRP37 & $\begin{array}{l}\text { Implementar ações visando à permanência dos integrantes } \\
\text { no grupo. }\end{array}$ & ,596 & Bom \\
\hline & GPRP38 & $\begin{array}{l}\text { Capacitar membros do grupo em tarefas técnicas necessárias } \\
\text { às pesquisas. }\end{array}$ & ,580 & Bom \\
\hline & GPRP39 & $\begin{array}{l}\text { Conduzir reuniões do grupo, coordenando apresentações, } \\
\text { debates e processos decisórios. }\end{array}$ & ,567 & Bom \\
\hline & GPRP40 & $\begin{array}{l}\text { Estimular a flexibilidade do grupo no desenvolvimento de } \\
\text { processos de trabalho. }\end{array}$ & ,552 & Bom \\
\hline & GPRP41 & $\begin{array}{l}\text { Reconhecer potenciais de aprendizagem dos membros do } \\
\text { grupo. }\end{array}$ & ,550 & Bom \\
\hline \multirow{9}{*}{ 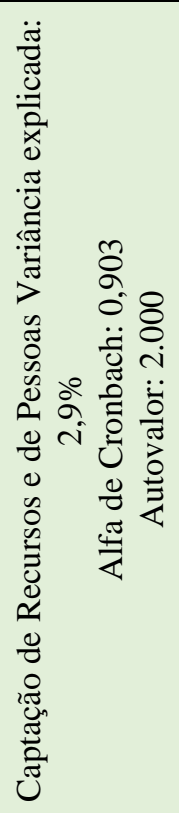 } & CRPE 1 & $\begin{array}{l}\text { Estabelecer parcerias com outros pesquisadores ou grupos } \\
\text { de pesquisa. }\end{array}$ & ,820 & Excelente \\
\hline & CRPE 2 & $\begin{array}{l}\text { Obter financiamento para as pesquisas de agências externas } \\
\text { de fomento. }\end{array}$ & ,694 & Muito bom \\
\hline & CRPE 3 & $\begin{array}{l}\text { Selecionar novos integrantes para o grupo com base em } \\
\text { critérios técnicos. }\end{array}$ & ,558 & Bom \\
\hline & CRPE 4 & $\begin{array}{l}\text { Administrar recursos utilizados na pesquisa (materiais, } \\
\text { equipamentos, dinheiro etc). }\end{array}$ & ,550 & Bom \\
\hline & CRPE 5 & $\begin{array}{l}\text { Buscar ajuda de pesquisadores e outros profissionais para } \\
\text { atualização e aprofundamento de temas de interesse do } \\
\text { grupo. }\end{array}$ & ,542 & Razoável \\
\hline & CRPE 6 & $\begin{array}{l}\text { Implementar ações estratégicas para um melhor } \\
\text { desempenho das atividades de pesquisa. }\end{array}$ & ,522 & Razoável \\
\hline & CRPE 7 & Estabelecer parcerias com empresas do setor produtivo. & ,511 & Razoável \\
\hline & CRPE 8 & $\begin{array}{l}\text { Reconhecer os elementos fundamentais para o } \\
\text { desenvolvimento da pesquisa e a sustentabilidade do grupo } \\
\text { de pesquisa: recursos humanos e materiais/financeiros. }\end{array}$ & ,498 & Razoável \\
\hline & CRPE 9 & $\begin{array}{l}\text { Atrair novos integrantes para o grupo (alunos da graduação, } \\
\text { mestrado, doutorado, pesquisadores) por diferentes meios } \\
\text { de recrutamento. }\end{array}$ & ,495 & Razoável \\
\hline
\end{tabular}

Fonte: Elaborada pelo autor com base em Dados da Pesquisa

Os nomes dos nomes dos fatores, com suas respectivas definições constam também da

Tabela 17.

Tabela 17 - Definições para os fatores relativos a Competências Gerenciais

\section{Fator relativo a Competências \\ Gerenciais em Grupos de Pesquisa \\ Definição}

É o conjunto de competências gerenciais essenciais à gestão de

Gestão de Pessoas e de Resultados de equipes que interagem visando ao alcance de resultados Pesquisa decorrentes da realização de atividades e projetos de pesquisa do grupo.

É o conjunto de competências gerenciais que visam ao

Captação de Recursos e de Pessoas suprimento de recursos, à captação de pesquisadores e à colaboração de especialistas que possam contribuir para as atividades e projetos de pesquisa do grupo.

Fonte: Elaborada pelo autor com base em Dados da Pesquisa e na revisão da literatura 
O primeiro fator, Gestão de Pessoas e de Resultados de Pesquisa, tem a ver com o conceito de Core Competence (competências essenciais) de Prahalad e Hamel (1990). Esse fator agrupou itens relativos a competências gerenciais essenciais à atividade de pesquisa, de modo semelhante a classificações citadas na revisão de literatura. Pode-se afirmar que esse fator assume configurações muito próximas a competências administrativas necessárias ao desenvolvimento de projetos de pesquisa de Haythornthwaite (2006); competências para gerenciar equipe Ferigotti e Fernandes (2014); competências relativas à gestão de pessoas, coordenação e controle de atividades de pesquisa de Odelius et al. (2011); coordenação de atividades de pesquisa de Odelius e Sena (2009); competências para administrar o trabalho e relações de Gary Yukl (1998), utilizada por Fleck e Pereira (2011); e liderar e direcionar estrategicamente as atividades e projetos de Higuita-López, Molano-Velandia e RodríguezMerchán (2011).

Já o segundo fator, Captação de Recursos e de Pessoas, agrupou os itens residuais, que, em sua maioria, possuem relação com o suprimento de recursos e a função de agregar pessoas, evitando-se riscos à continuidade da pesquisa (HARVEY; PETTIGREW; FERLIE, 2002). A denominação do fator também está alinhada com diversos estudos apresentados no referencial teórico, a exemplo da função Alocação de recursos de Ferigotti e Fernandes (2014); competências para interação com outros grupos de pesquisa e gestão de recursos de HiguitaLópez, Molano-Velandia e Rodríguez-Merchán (2011); o acesso a recursos especializados e colaboração de especialistas de Harvey, Pettigrew e Ferlie (2002); e competências para solicitação de apoio externo para suprimento de conhecimentos e recursos de Morris e Goldstein (2007).

Por fim, ao se fazer um contraponto dos fatores com o Modelo de Quinn (1988), recorrido por 12 estudos constantes do referencial teórico, pode-se afirmar que as Competências para gestão de pessoas e de resultados de pesquisa estão mais alinhadas com os papéis facilitador, mentor, diretor, produtor, monitor, coordenador e inovador, enquanto que as Competências para captação de recursos e de pessoas é mais aderente ao papel de negociador.

\subsubsection{Escala de Resultados alcançados por Grupos de Pesquisa}

Esta seção se dedica à concretização do quarto objetivo específico, que visa à apresentação de indícios ou evidências de validade de uma escala de Resultados alcançados por grupos de pesquisa. 
Considerando que os procedimentos foram praticamente os mesmos utilizados para a confecção da escala relativa a competências gerenciais, serão apresentas apenas as distinções e especificidades da escala de resultados. Assim, o que não for mencionado neste tópico, podese considerar que o processamento se deu de modo idêntico à escala já apresentada.

A primeira especificidade se deu na análise do Scree plot (diagrama da sedimentação ou gráfico do cotovelo), que apontou existirem 5 fatores para os de resultados em grupos de pesquisa, segundo o critério de extração pela variância explicada, com base nos eigenvalues superiores a 1, conforme Figura 19.

\section{Figura 19 - Fatores de Resultados segundo o Scree plot}

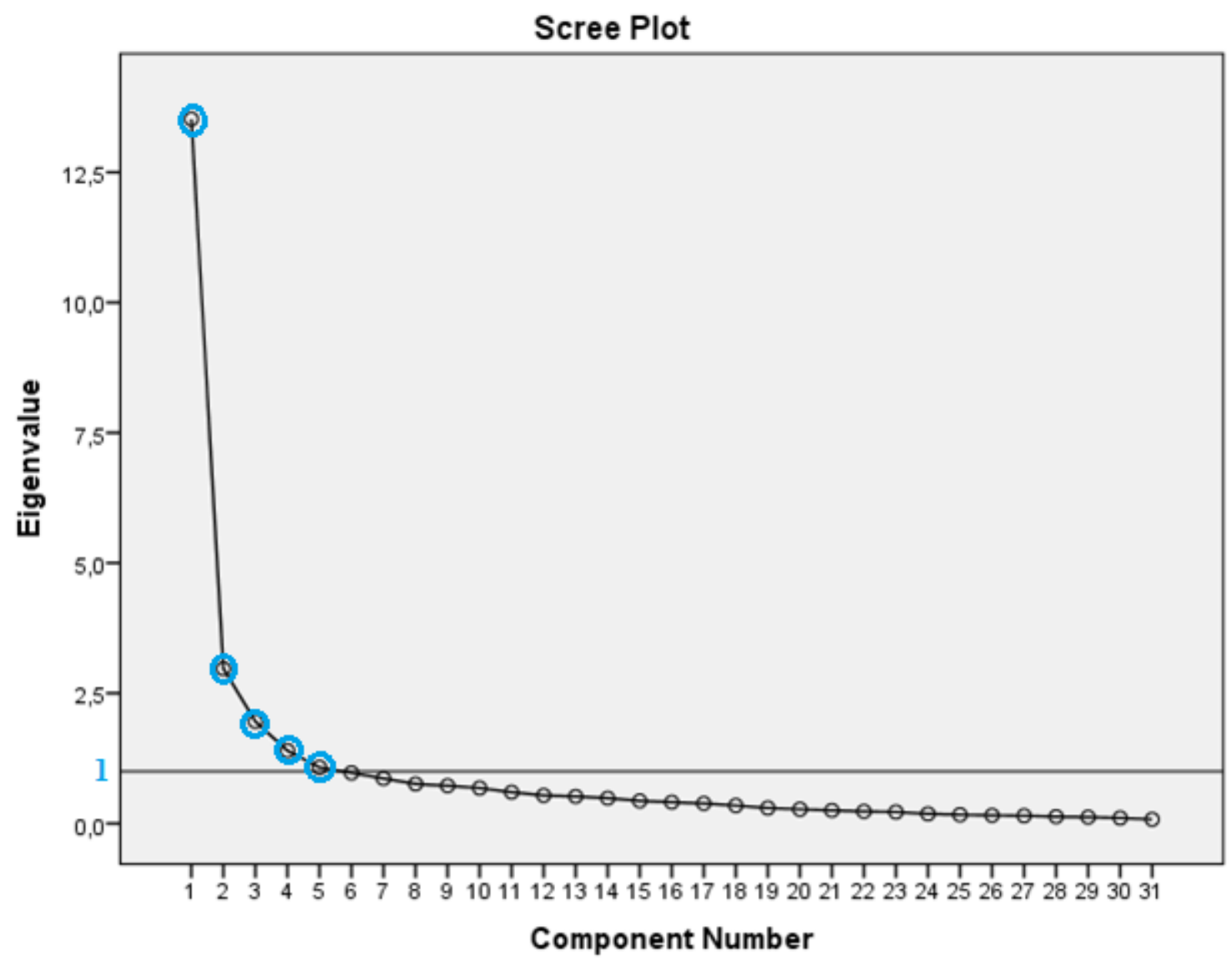

Fonte: Elaborada pelo autor com base em Dados da Pesquisa

De forma semelhante à escala de competências gerenciais, nem todos os 5 fatores em potencial apresentaram explicação da variância igual ou maior que 3\%, no âmbito da solução inicial, via método dos componentes principais. Assim, recorreu-se também à análise paralela de Horn, confrontando-se os autovalores iniciais com uma amostra randômica para 374 pesquisadores e 31 itens (referentes aos resultados), já que para este instrumento, considerou- 
se apenas as manifestações dos líderes, como forma de se evitar duplicidades e vieses. A análise paralela de Horn indicou a permanência dos três primeiros fatores, descartando-se a partir do quarto, conforme Tabela 18.

Tabela 18 - Comparação dos Eigenvalues dos Resultados durante a Análise Paralela

\begin{tabular}{lrrrr}
\hline & \multicolumn{3}{c}{ Eigenvalues iniciais } \\
\cline { 2 - 4 } Fator & Total & $\begin{array}{c}\text { \% de } \\
\text { variância }\end{array}$ & $\begin{array}{c}\text { \% de } \\
\text { variância } \\
\text { acumulada }\end{array}$ & Valor aleatório \\
\hline 1 & 13,400 & 43,226 & 43,226 & 1,646550 \\
2 & 2,972 & 9,586 & 52,812 & 1,554331 \\
3 & 1,975 & 6,370 & 59,183 & 1,481962 \\
4 & 1,408 & 4,542 & 63,724 & 1,432192 \\
5 & 1,083 & 3,494 & 67,218 & 1,378012 \\
$\vdots$ & $\vdots$ & $\vdots$ & $\vdots$ & $\vdots$ \\
\hline Fonte: Elaborada pelo autor com base em Dados da Pesquisa
\end{tabular}

Definido o quantitativo de 3 fatores para os itens de resultados, efetuou-se a redução de dimensão pelo método dos mínimos quadrados não ponderados (ou ordinários), com rotação Oblimin, com delta padrão em zero, sendo esta também a solução mais ajustada.

O resultado inicial apontou a possibilidade de exclusão de sete itens. Cinco deles poderiam ser excluídos sob justificativa de haver diferenças menores que 0,100 entre os valores absolutos das cargas fatoriais (GORSUCH, 1983; LAROS; PUENTE-PALÁCIOS, 2004). Dentre eles, optou-se por suprimir, de fato, o que se mostrava carente de adesão teórica, conforme resume o Quadro 18.

Quadro 18 - Resultados com indicativo de exclusão - Parte 1

\begin{tabular}{|l|c|c|c|}
\hline Item relativo a resultados de grupos com indicação de exclusão & $\begin{array}{c}\text { Diferença das } \\
\text { cargas fatoriais } \\
\text { quando em mais } \\
\text { de um fator }\end{array}$ & $\begin{array}{c}\text { Consistência } \\
\text { teórica para o } \\
\text { agrupamento } \\
\text { dos itens em } \\
\text { fatores? }\end{array}$ & $\begin{array}{c}\text { Decisão: } \\
\text { Excluir ou } \\
\text { Manter o } \\
\text { Item? }\end{array}$ \\
\hline Curso ministrado. & Houve 0,037 & Sim & Manter \\
\hline $\begin{array}{l}\text { Elaboração de produtos (ex.: protótipos; artefatos; patentes; } \\
\text { maquetes; programas de computador etc). }\end{array}$ & Houve 0,047 & Sim & Manter \\
\hline $\begin{array}{l}\text { Mobilização da rede de relacionamentos para executar atividades } \\
\text { de pesquisa. }\end{array}$ & Houve 0,049 & Nanter \\
\hline $\begin{array}{l}\text { Participação, como avaliador externo, de comissões examinadoras } \\
\text { de dissertações ou teses. }\end{array}$ & Houve 0,021 & Excluir \\
\hline $\begin{array}{l}\text { Reconhecimento de membros do grupo como referências } \\
\text { acadêmicas ou profissionais. }\end{array}$ & Houve 0,046 & Sim & Manter \\
\hline
\end{tabular}

Fonte: Elaborado pelo autor com base em Dados da Pesquisa 
Os outros dois itens com possibilidade de exclusão destoavam dos demais itens integrantes do mesmo fator, (SMITH; MCCARTHY, 1995) e, ao mesmo tempo, apresentaram alto percentual de respondentes que os consideravam como resultados seus, enquanto líderes, e não do grupo como um todo ( $29 \%$ e $31 \%$, respectivamente). A partir dessas análises, decidiuse pela exclusão de ambos, nos termos do Quadro 19.

Quadro 19 - Resultados com indicativo de exclusão - Parte 2

\begin{tabular}{|l|c|c|c|}
\hline Item relativo a resultados de grupos com indicação de exclusão & $\begin{array}{c}\text { Alto \% de } \\
\text { "Não se } \\
\text { aplica"? }\end{array}$ & $\begin{array}{c}\text { Consistência } \\
\text { teórica para o } \\
\text { agrupamento } \\
\text { dos itens em } \\
\text { fatores? }\end{array}$ & $\begin{array}{c}\text { Decisão: } \\
\text { Excluir ou } \\
\text { Manter o } \\
\text { Item? }\end{array}$ \\
\hline Atuação na revisão de periódicos científicos. & Sim. 29\% & Não & Excluir \\
\hline Atuação na revisão de projetos submetidos a agências de fomento. & Sim. 31\% & Não & Excluir \\
\hline
\end{tabular}

Fonte: Elaborado pelo autor com base em Dados da Pesquisa

Em suma, decidiu-se por excluir 3 dos 31 itens iniciais: "Participação, como avaliador externo, de comissões examinadoras de dissertações ou teses"; “Atuação na revisão de periódicos científicos"; e "Atuação na revisão de projetos submetidos a agências de fomento".

Processando-se novamente a análise fatorial, verificou-se a inexistência de novas sugestões de supressão, assim, foi calculado o índice alfa de Cronbach, cujos resultados constam da Tabela 19.

Tabela 19 - Análise do Alfa de Cronbach para os fatores de Resultados alcançados por Grupos de Pesquisa

\begin{tabular}{ccccc}
\hline \multirow{2}{*}{ Escala } & \multirow{2}{*}{ Itens } & Fator & Itens & $\begin{array}{c}\text { Alfa de } \\
\text { Cronbach }\end{array}$ \\
\hline $\begin{array}{c}\text { Resultados em } \\
\text { Grupos de } \\
\text { Pesquisa }\end{array}$ & \multirow{2}{*}{28} & Resultados Distais de Repercussão Externa & 15 & 0,927 \\
\cline { 3 - 5 } & & Resultados Proximais da Pesquisa & 10 & 0,872 \\
\cline { 3 - 5 } & & Resultados Tangíveis de Pesquisa & 3 & 0,624 \\
\hline
\end{tabular}

Fonte: Elaborada pelo autor com base em Dados da Pesquisa

Os dois primeiros fatores revelaram-se confiáveis e significativos por excederem o patamar de 0,8 na medida do alfa de Cronbach, segundo as categorizações mencionadas na seção anterior (PASQUALI; 2010; NUNNALLY; BERSNTEIN, 1994). Já o terceiro fator é 
equiparável a um nível de confiabilidade aceitável já que se trata de uma análise fatorial exploratória (KLINE, 2015; HAIR JR. et al., 2010).

No mais, as variáveis manifestas relativas a resultados reuniram-se em três fatores: Fator 1 - Resultados Distais de Repercussão Externa (39,3\% de explicação); Fator 2 - Resultados Proximais da Pesquisa (8,6\% de explicação); e Fator 3 - Resultados Tangíveis de Pesquisa (3,9\% de explicação), configurando 51,9\% de variância total explicada, conforme relatado na Tabela 20.

Tabela 20 - Análise da variância explicada relativa aos fatores de Resultados alcançados por grupos de Pesquisa

\begin{tabular}{ccccc}
\hline Escala & $\begin{array}{c}\text { Variância } \\
\text { total } \\
\text { explicada }\end{array}$ & Fator & $\begin{array}{c}\text { Quantidade } \\
\text { de Itens }\end{array}$ & $\begin{array}{c}\text { Variância } \\
\text { explicada }\end{array}$ \\
\hline & & Resultados Distais de Repercussão Externa & 15 & $39,3 \%$ \\
\cline { 3 - 5 } $\begin{array}{c}\text { Resultados em } \\
\text { Grupos de } \\
\text { Pesquisa }\end{array}$ & $51,9 \%$ & Resultados Proximais da Pesquisa & 10 & $8,6 \%$ \\
\cline { 3 - 5 } & & Resultados Tangíveis de Pesquisa & 3 & $3,9 \%$ \\
\hline
\end{tabular}

Fonte: Elaborada pelo autor com base em Dados da Pesquisa

A classificação qualitativa de Comrey e Lee (1992) apontou 8 itens excelentes, 5 muito bons, 6 bons, 5 razoáveis, e 4 pobres. Todavia, mesmo para as cargas fatoriais consideradas pobres, optou-se pela manutenção de todos esses itens, porque excedem 0,300 , que é o valor considerado parâmetro para a maior parte dos pesquisadores (FIELD, 2009) e, mesmo as cargas pobres, nenhuma delas foi inferior ao mínimo de 0,320 recomendado por Tabachnick e Fidell (2007) ou de 0,350, indicado por Hair Jr. et al. (2010).

Alcançado o quarto objetivo específico, a Tabela 21 abrange os três fatores, os códigos dos itens, os itens, as cargas fatoriais, a classificação dos itens segundo Comrey e Lee (1992), a variância explicada total e por fator, o alfa de Cronbach, e os Autovalores. 
Tabela 21 - Escala de Resultados alcançados por grupos de pesquisa

\begin{tabular}{|c|c|c|c|c|}
\hline Fator & $\begin{array}{l}\text { Código } \\
\text { do Item }\end{array}$ & Item & $\begin{array}{l}\text { Carga } \\
\text { Fatorial }\end{array}$ & $\begin{array}{c}\text { Qualificação } \\
\text { do item - } \\
\text { Comrey e } \\
\text { Lee (1992) }\end{array}$ \\
\hline \multirow{15}{*}{ 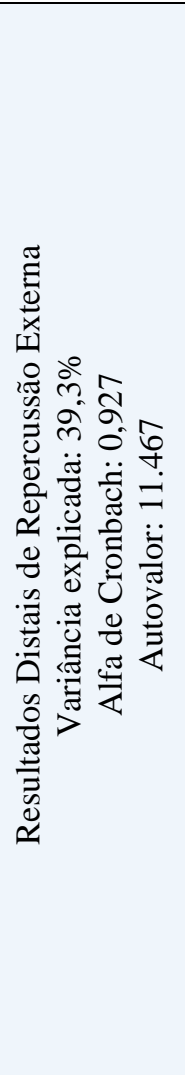 } & RDRE1 & $\begin{array}{l}\text { Participação em entrevistas, mesas redondas, } \\
\text { programas de rádio ou TV e similares. }\end{array}$ & ,863 & Excelente \\
\hline & RDRE2 & $\begin{array}{l}\text { Participação em diretorias de sociedades } \\
\text { científicas. }\end{array}$ & ,773 & Excelente \\
\hline & RDRE3 & $\begin{array}{l}\text { Publicação de artigos "não-científicos" para a } \\
\text { mídia em geral (ex.: jornais, revistas, redes } \\
\text { sociais, websites ou blogs) }\end{array}$ & ,750 & Excelente \\
\hline & RDRE4 & $\begin{array}{l}\text { Participação em eventos para proferir } \\
\text { conferência, coordenar mesa ou simpósio. }\end{array}$ &, 700 & Muito bom \\
\hline & RDRE5 & $\begin{array}{l}\text { Participação, como avaliador externo, de } \\
\text { comissões julgadoras de concursos. }\end{array}$ & ,695 & Muito bom \\
\hline & RDRE6 & Organização de eventos científicos. & ,668 & Muito bom \\
\hline & RDRE7 & Participação em comitês de agências de fomento. & 657 & Muito bom \\
\hline & RDRE8 & $\begin{array}{l}\text { Coordenação de grupos de trabalho em eventos } \\
\text { científicos. }\end{array}$ & ,641 & Muito bom \\
\hline & RDRE9 & $\begin{array}{l}\text { Mobilização da rede de relacionamentos para } \\
\text { executar atividades de pesquisa. }\end{array}$ & ,612 & Bom \\
\hline & RDRE10 & Participação em corpo editorial de periódicos. & 606 & Bom \\
\hline & RDRE11 & $\begin{array}{l}\text { Prestação de assessoria ou consultoria técnica } \\
\text { para organizações públicas ou privadas. }\end{array}$ & ,602 & Bom \\
\hline & RDRE12 & Curso ministrado. &, 562 & Bom \\
\hline & RDRE13 & Elaboração de material didático ou instrucional. & ,542 & Razoável \\
\hline & RDRE14 & $\begin{array}{l}\text { Reconhecimento de membros do grupo como } \\
\text { referências acadêmicas ou profissionais. }\end{array}$ & ,413 & Pobre \\
\hline & RDRE15 & Formação de redes profissionais. & ,367 & Pobre \\
\hline \multirow{10}{*}{ 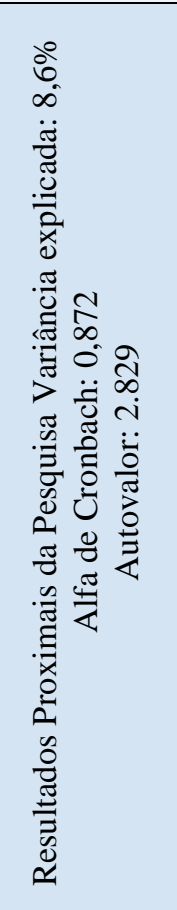 } & RPPE1 & $\begin{array}{l}\text { Avanço nos conhecimentos relativos aos estudos } \\
\text { realizados. }\end{array}$ & ,866 & Excelente \\
\hline & RPPE2 & $\begin{array}{l}\text { Conclusão de trabalhos acadêmicos } \\
\text { (monografias, dissertações ou teses). }\end{array}$ & ,844 & Excelente \\
\hline & RPPE3 & $\begin{array}{l}\text { Desenvolvimento de competências técnicas } \\
\text { associadas à atuação do grupo (ex.: } \\
\text { conhecimentos relativos ao tema; realização }\end{array}$ & ,760 & Excelente \\
\hline & RPPE4 & $\begin{array}{l}\text { Formação de profissionais para atuarem em uma } \\
\text { área de conhecimento. }\end{array}$ & ,734 & Excelente \\
\hline & RPPE5 & $\begin{array}{l}\text { Publicação (ou aprovação para publicação) de } \\
\text { artigos científicos em periódico. }\end{array}$ & ,715 & Excelente \\
\hline & RPPE6 & $\begin{array}{l}\text { Publicação de trabalhos em anais de eventos } \\
\text { científicos. }\end{array}$ & ,579 & Bom \\
\hline & RPPE7 & $\begin{array}{l}\text { Desenvolvimento de competências sociais (ex.: } \\
\text { relacionamento interpessoal; trabalho em equipe; } \\
\text { respeito à diversidade e }\end{array}$ &, 572 & Bom \\
\hline & RPPE8 & $\begin{array}{l}\text { Estabelecimento de parcerias com outros grupos } \\
\text { ou pesquisadores. }\end{array}$ &, 511 & Razoável \\
\hline & RPPE9 & $\begin{array}{l}\text { Inserção de integrantes do grupo de pesquisa no } \\
\text { mercado de trabalho. }\end{array}$ & ,463 & Razoável \\
\hline & RPPE10 & $\begin{array}{l}\text { Elaboração de diagnósticos relativos ao campo de } \\
\text { estudo. }\end{array}$ & ,421 & Pobre \\
\hline
\end{tabular}




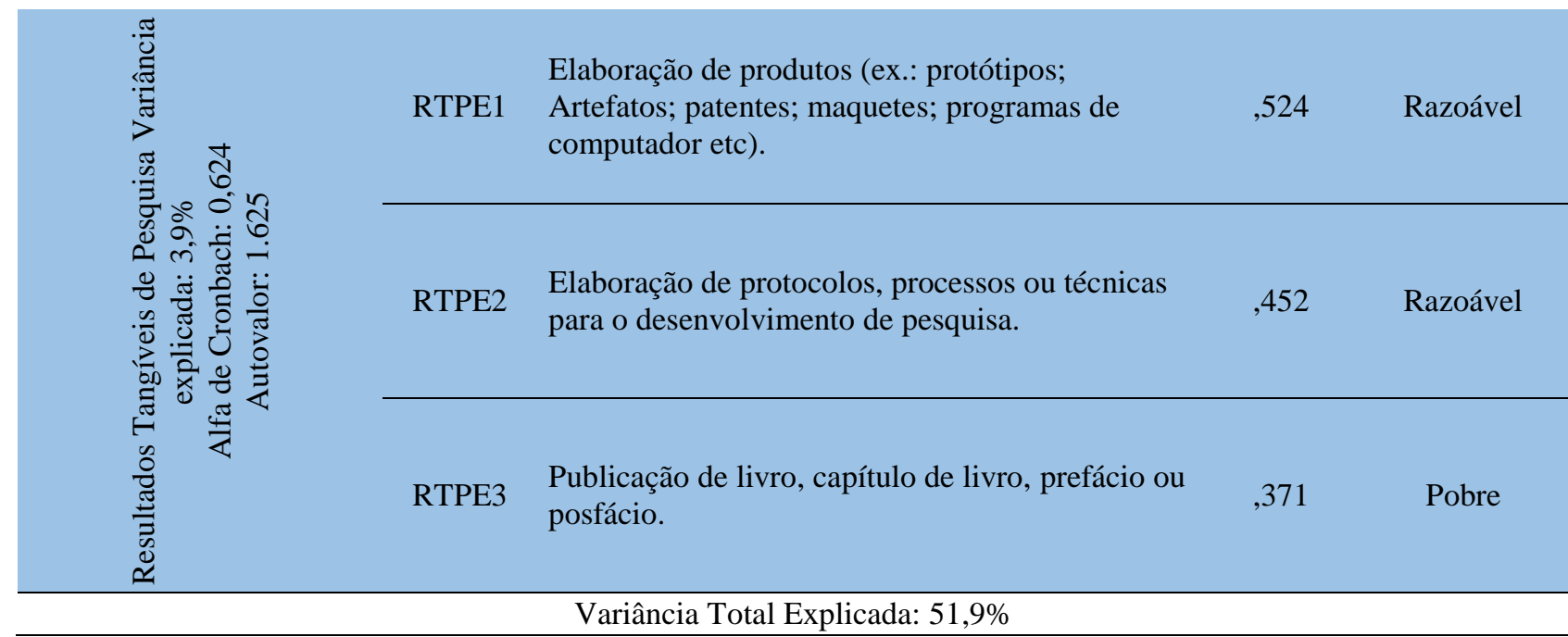

Fonte: Elaborada pelo autor com base em Dados da Pesquisa

Os nomes dos nomes dos fatores, com suas respectivas definições constam também da Tabela 22.

Tabela 22 - Definições adotadas para os fatores relativos a Resultados de Grupos de Pesquisa

\section{Fator relativo a Resultados de Grupos de Pesquisa}

\begin{tabular}{|c|c|}
\hline $\begin{array}{c}\text { Resultados Distais de Repercussão } \\
\text { Externa }\end{array}$ & $\begin{array}{l}\text { É o agrupamento de resultados indiretos das atividades e projetos de } \\
\text { pesquisa. Possuem caráter remoto e periférico, e complementam, } \\
\text { repercutem ou decorrem de resultados proximais e tangíveis } \\
\text { alcançados inicialmente pelo grupo. }\end{array}$ \\
\hline Resultados Proximais da Pesquisa & $\begin{array}{l}\text { É o agrupamento de resultados diretos de atividades e projetos de } \\
\text { pesquisa. Possuem ligação imediata com a produção de } \\
\text { conhecimento e contribuem para o alcance de futuros resultados } \\
\text { distais. }\end{array}$ \\
\hline Resultados Tangíveis da Pesquisa & $\begin{array}{l}\text { É o agrupamento de resultados concretos das atividades e projetos de } \\
\text { pesquisa. Possuem caráter corpóreo e material, e estão normalmente } \\
\text { relacionados com descobertas e inovações, científicas, novas } \\
\text { tecnologias ou novos métodos e contribuem para o alcance de futuros } \\
\text { resultados distais. }\end{array}$ \\
\hline
\end{tabular}

Fonte: Elaborada pelo autor com base em Dados da Pesquisa e na literatura

Sobre a nomenclatura dada aos fatores de resultados, vale mencionar que a denominação dos dois primeiros fatores se refere a termos comumente utilizados na literatura própria da avaliação de desempenho: resultados proximais (intimamente ligados ao negócio, no caso, à 
realização de pesquisa) e distais (mais remotos ou periféricos, que podem ser complementares e decorrentes dos resultados proximais (DYER; REEVES, 1995; WRIGHT; BOSWELL, 2002; LEVY; WILLIAMS, 2004; ODELIUS; SANTOS, 2008; SILVEIRA; DEL MAESTRO FILHO, 2013). Já para nomear o terceiro fator, recorreu-se a Mugnaini, Jannuzzi e Quoniam (2004), segundo os quais os resultados de pesquisa tangíveis são os que representam com concretude as pesquisas na comunidade científica, tais como livros, patentes, produtos, entre outros.

Quanto à literatura apresentada no referencial teórico, os Resultados Distais de Repercussão Externa abrangem aspectos como, por exemplo, reconhecimento e visibilidade dos participantes e do grupo de pesquisa (ODELIUS et al., 2011); prestação de serviços técnicos e de consultoria especializada (RESTREPO; VILLEGAS, 2007); e formação e mobilização de redes de pesquisa e parcerias interinstitucionais (ROBSON; SHOVE, 1999; HAYTHORNTHWAITE, 2006; ODELIUS et al., 2011; HARVEY; PETTIGREW; FERLIE, 2002; RAMOS-VIELBA; SÁNCHEZ-BARRIOLUENGO; WOOLLEY, 2015)

Já o segundo fator, Resultados Proximais de Pesquisa, reúne os aspectos apresentados na revisão da literatura, que são inerentes a existência de um grupo de pesquisa, são a sua razão de existir, tais como avanços nos conhecimentos e diagnósticos nos campos de pesquisa (ARAUJO et al., 2015); publicações em eventos científicos e em periódicos (VIOTTI, 2003; RESTREPO; VILLEGAS, 2007; MENDES; CALIARI; SANTOS, 2014; ARAUJO et al., 2015); desenvolvimento de competências sociais e técnicas (ODELIUS; SENA,2009; ODELIUS et al., 2010); e conclusão de monografias, dissertações, teses ou outros trabalhos acadêmicos com o apoio do grupo de pesquisa (ARAUJO et al., 2015; RESTREPO; VILLEGAS, 2007).

Sobre os dois fatores já discutidos, vale sublinhar que três itens teoricamente próximos acomodaram-se em fatores distintos: "Mobilização da rede de relacionamentos para executar atividades de pesquisa" e "Formação de redes profissionais", que constam do primeiro fator, e "Estabelecimento de parcerias com outros grupos ou pesquisadores", que se acomodou isoladamente no segundo. Uma decisão a ser tomada poderia ser a exclusão deste último item, sob a alegação de falta de aderência aos demais itens do fator. Contudo, optou-se pela manutenção do item, com a seguinte interpretação: o termo "rede", presente nos dois primeiros itens, pode ter conferido ao item um caráter mais distal, ou seja, um resultado mais amplo e, portanto, mais dependente de variáveis que fogem ao controle do grupo; já o termo "parceria", presente no terceiro item, pode estar mais associado a um resultado proximal e de menor 
proporção, sendo uma variável passível de controle pelo próprio grupo de pesquisa. Outra possibilidade de interpretação seria a de que o estabelecimento de parceria estaria associado ao desenvolvimento conjunto de atividades de pesquisa e à colaboração e coautoria, revelando-se um resultado mais direto da pesquisa, e, portanto, um resultado proximal.

Por fim, ao último fator, Resultados Tangíveis de Pesquisa, aderiram-se itens relativos a resultados concretos de pesquisa, tais como protocolos, processos e técnicas para o desenvolvimento de pesquisa; produtos (protótipos, artefatos, patentes, softwares, etc); e livros ou subpartes. Esses aspectos constam do rol de produções do CNPq e foram mencionados na revisão teórica, sobretudo, por Moura et al. (2008); Riquelme e Langer (2010); Restrepo e Villegas (2007); Vasquez-Rizo (2010); Mendes, Caliari e Santos (2014); e Araújo et al. (2015).

\subsection{Testes não-paramétricos U de Mann-Whitney e $H$ de Kruskall-Wallis}

Esta seção se destina a apresentar eventuais diferenças ou semelhanças entre grupos com relação a competências gerenciais ou resultados em grupos de pesquisa, a depender de dados sociodemográficos e funcionais (tipo de instituição, unidade da federação e grande área do conhecimento a que o grupo se vincula; sexo, faixa etária, tempo de experiência, recebimento de bolsa de produtividade do CNPq e titulação/escolaridade do líder; entre outros), assim como foi estabelecido no quinto objetivo específico.

$\mathrm{O}$ intento pretendido com os testes não-paramétricos $\mathrm{U}$ de Mann-Whitney e $\mathrm{H}$ de Kruskall-Wallis foi a comparação entre grupos. As variáveis originalmente dicotômicas e as que foram adaptadas para tal foram utilizadas como critério para separação da amostra em dois grupos distintos, por exemplo, homens e mulheres; vínculo com instituições públicas ou privadas. Para elas, aplicou-se o teste U de Mann-Whitney, específico para comparação entre dois grupos (2 amostras independentes), quando não há normalidade na distribuição dos dados (FIELD, 2009).

Já para variáveis que apresentavam múltiplas opções de resposta, como, por exemplo, unidade da federação ou grande área do conhecimento, recorreu-se ao teste H de KruskallWallis, já que é próprio para a comparação de múltiplos grupos da amostra (k amostras independentes) (FIELD, 2009).

Em ambos casos, quando os testes apresentaram diferenças estatisticamente significativas, procurou-se explicitar o grau que distinguia um grupo de outro a partir da 
diferença entre medianas, já que está é preferível à média (FIELD, 2009). Apenas se optou pela média como medida de dispersão, diante da igualdade entre medianas.

Por fim, é impor tante relatar que as próximas seções apresentarão apenas os casos em que houve diferença significativa intergrupos para algumas das variáveis. Assim, algumas variáveis sociodemográficas ou funcionais não estarão contempladas, como é o caso das Regiões geográficas do Brasil e das Unidades da Federação.

De qualquer forma, a inexistência de diferenças relevantes para essas duas variáveis, por si só, já é um achado interessante, pois vai de encontro a Backes et al., (2012), Bueno (2014); Canever et al. (2014); Vieira, Welter e Mello-Carpes (2014), Canever et al. (2014) e Ferraz e Dornelas (2015), que haviam encontrado indícios de que essas variáveis poderiam influenciar nos resultados de grupos, em função dos déficits infraestruturais experimentados por grupos de determinadas localizações com baixo número de docentes doutores e com menor Produto Interno Bruto (PIB). Provavelmente, pelo fato de 91,7\% da amostra ser composta por líderes de instituições públicas, que estão sujeitas a semelhantes políticas, regras e diretrizes de fomento, é possível que tenha havido um equilíbrio nos resultados dos grupos e competências gerenciais dos líderes pesquisados, fazendo com que não houvesse diferenças significativas nos respondentes das diversas Regiões e Unidades da Federação. Em suma, políticas de fomento a Regiões e Unidades da Federação mais carentes podem já ter resultado em minimização da falta de infraestrutura. Outra possível explicação seria o fato de $76,2 \%$ dos líderes pesquisados receberem bolsa produtividade, o que faz com que tenham recursos adicionais e melhores condições para pleitear recursos, mediante os editais de fomento. Além disso, os respondentes são, em sua maioria, pesquisadores experientes e podem ter, ao longo do tempo, conquistado as condições estruturais necessárias ao desenvolvimento de suas atividades. De qualquer forma, para que essas hipóteses se confirmem ou se afastem, são indispensáveis pesquisas futuras.

\subsubsection{Diferenças entre os graus de domínio de Competências Gerenciais}

A primeira comparação realizada foi a de verificar se o grupo de líderes que relatou maior grau de domínio de competências gerenciais apresenta resultados distintos daqueles alcançados pelo grupo de líderes que afirma possuir grau de domínio menor dessas competências.

Sempre que possível, os dados foram processados na sua categorização inicial de resposta. Mas, para processar essa análise, que exigiu variáveis dicotômicas, foram necessários ajustes na gradação das respostas. Destarte, os dados referentes ao grau de domínio de 
competências gerenciais foram reagrupados da seguinte maneira: respostas 1,2 e 3 passaram a significar "domínio insuficiente" e respostas 4 e 5, "domínio suficiente".

A comparação entre o grupo de domínio suficiente e insuficiente de competências gerenciais, em seus dois fatores, revelou que o grupo de líderes com domínio suficiente de competências gerenciais apresenta maior incidência de resultados, em seus três fatores, do que os líderes que possuem domínio insuficiente de competências gerenciais de Gestão de Pessoas e de Resultados de Pesquisa (Tabela 23) e Captação de Recursos e de Pessoas (Tabela 24).

Tabela 23 - Diferenças nos Resultados a depender da suficiência ou insuficiência no domínio de Competências para a Gestão de Pessoas e de Resultados de Pesquisa

\begin{tabular}{|c|c|c|c|}
\hline \multicolumn{2}{|c|}{ Competências Gerenciais para Gestão de Pessoas e de Resultados da Pesquisa } & \multirow{2}{*}{$\begin{array}{l}\mathbf{N} \\
82\end{array}$} & \multirow{2}{*}{$\begin{array}{r}\text { Mediana } \\
3,20\end{array}$} \\
\hline \multirow{3}{*}{ Resultados Distais de Repercussão Externa } & Domínio Insuficiente & & \\
\hline & Domínio Suficiente & 291 & 4,04 \\
\hline & Total & 373 & \\
\hline \multirow{3}{*}{ Resultados Proximais de Pesquisa } & Domínio Insuficiente & 82 & 4,20 \\
\hline & Domínio Suficiente & 291 & 4,52 \\
\hline & Total & 373 & \\
\hline \multirow{3}{*}{ Resultados Tangíveis de Pesquisa } & Domínio Insuficiente & 81 & 3,00 \\
\hline & Domínio Suficiente & 289 & 3,91 \\
\hline & Total & 370 & \\
\hline
\end{tabular}

Fonte: Elaborada pelo autor com base em Dados da Pesquisa e na literatura

Tabela 24 - Diferenças nos Resultados a depender da suficiência ou insuficiência no domínio de Competências para a Captação de Recursos e de Pessoas

\begin{tabular}{llrr}
\hline \multicolumn{2}{c}{ Competências Gerenciais para Captação de Recursos e de Pessoas } & N & Mediana \\
\hline \multirow{2}{*}{ Resultados Distais de Repercussão Externa } & Domínio Insuficiente & 128 & 3,36 \\
& Domínio Suficiente & 245 & 4,14 \\
\hline \multirow{2}{*}{ Resultados Proximais de Pesquisa } & Total & 373 & 4,16 \\
& Domínio Insuficiente & 128 & 4,57 \\
\hline \multirow{2}{*}{ Resultados Tangíveis de Pesquisa } & Domínio Suficiente & 245 & 373 \\
& Total & 127 & 3,25 \\
& Domínio Insuficiente & 243 & 4,03 \\
\hline
\end{tabular}

Fonte: Elaborada pelo autor com base em Dados da Pesquisa e na literatura 
No que tange aos Resultados Proximais de Pesquisa, a superioridade de resultados atrelada ao domínio de competências se mostra condizente com a literatura, na medida em que sugere que os resultados proximais e, portanto, mais centrais no contexto de pesquisa (tais como avanço científico, publicações, desenvolvimento de competências técnicas e sociais, formação de profissionais etc) parecem ser sensíveis ao domínio de competências gerenciais do líder; o que ratifica o achado de Erdmann et al. (2012), que indicam que o domínio de competências gerenciais potencializa o desenvolvimento de habilidades sociais, fortalece as linhas de pesquisa e eleva produção científica, resultados considerados proximais, de acordo com a escala desenvolvida nesta Dissertação.

Com relação aos Resultados Distais de Repercussão Externa, os achados apontam que esses resultados são sensíveis ao maior ou menor grau de domínio de competências gerenciais para a captação de recursos, da mesma forma que indicaram alguns autores citados no referencial teórico, segundo os quais o domínio de competências para a captação de recursos e de pessoas proporciona resultados como a obtenção financiamento para as pesquisas de agências externas de fomento - Morris e Goldstein (2007); o desenvolvimento de redes de pesquisa - Odelius e Sena (2009) e Odelius et al. (2011); e o reconhecimento do grupo - Araujo et al. (2015), todos considerados resultados distais de repercussão externa.

Sobre os Resultados Tangíveis de Pesquisa, o incremento nos resultados como decorrência do domínio suficiente de competências gerenciais vai ao encontro de estudos tratados no referencial teórico: enquanto Harvey, Pettigrew e Ferlie (2002) e Mendes, Caliari e Santos (2014) enfatizavam o domínio de competências ligadas ao provimento de recursos para os grupos de pesquisa (como o estabelecimento de parcerias com empresas do setor produtivo), Erdmann et al. (2012) destacaram a importância do domínio de competências atinentes à atração de pesquisadores para o grupo, como forma de proporcionar descobertas científicas e novas tecnologias, que dependem de experimentos, tão comuns para a consecução de resultados tangíveis, que são proveitosos não só para a academia, mas para a sociedade em geral.

\subsubsection{Diferenças entre a ocorrência ou não de resultados}

Outra comparação possível entre grupos é se o fato de o líder concordar ou discordar de que seu grupo tenha alcançado determinados resultados nos últimos 5 anos está relacionado ou não com o domínio das competências gerenciais em seus dois fatores. De forma semelhante à que foi apresentada na seção anterior, o nível de concordância com o alcance de resultados foi 
recodificado nos seguintes termos: 1, 2 e 3 passaram a representar "discordo" e 4 e 5, "concordo", de modo a tornar a variável categórica e dicotômica.

A comparação entre o grupo dos que concordam e o dos que discordam que o grupo tenha alcançado Resultados nos últimos cinco anos (nos três fatores) apresentou diferença significativa para as competências gerenciais, em seus dois fatores, conforme apresentado na Tabela 25. As medianas do domínio de competências é sempre maior para os líderes que atuam em grupos que têm alcançado mais resultados. Vale salientar que todas as medianas foram superiores a 4,0 .

Tabela 25 - Diferenças nas Competências Gerenciais a depender da concordância ou discordância quanto ao alcance de Resultados

\begin{tabular}{ccccccccc}
\hline Competência Gerencial & $\begin{array}{c}\text { Concordância } \\
\text { quanto ao } \\
\text { alcace de } \\
\text { Resultado }\end{array}$ & $\begin{array}{c}\text { Resultados Distais de } \\
\text { Repercussão Externa }\end{array}$ & $\begin{array}{c}\text { Resultados } \\
\text { Proximais de } \\
\text { Pesquisa }\end{array}$ & $\begin{array}{c}\text { Resultados } \\
\text { Tangíveis de } \\
\text { Pesquisa }\end{array}$ \\
\cline { 3 - 9 } & Discordo & 191 & 4,30 & 79 & 4,12 & 216 & 4,44 \\
\hline \multirow{2}{*}{$\begin{array}{c}\text { Gestão de Pessoas e de } \\
\text { Resultados de Pesquisa }\end{array}$} & Concordo & 181 & 4,80 & 293 & 4,63 & 156 & 4,74 \\
& Total & 372 & & 372 & & 372 & \\
\hline \multirow{2}{*}{ Captação de } & Discordo & 191 & 4,00 & 79 & 4,00 & 216 & 4,11 \\
Recursos e de Pessoas & Concordo & 182 & 4,75 & 294 & 4,56 & 157 & 4,67 \\
& Total & 373 & & 373 & & 373 & \\
\hline
\end{tabular}

Fonte: Elaborada pelo autor com base em Dados da Pesquisa

Esse achado é compatível com a literatura, a exemplo de Harvey, Pettigrew e Ferlie (2002), que consideram que o alcance de resultados mais expressivos é proveniente de aspectos como: capacidade de liderança, competências para atrair, motivar e reter talentos, e para estabelecer conexões em rede, que são competências constantes da escala desenvolvida nesta Dissertação.

\subsubsection{Diferenças entre os Tipos de Instituição de Pesquisa ou Ensino}

O Tipo de instituição a que o grupo está vinculado, pública ou privada, não se mostrou uma variável capaz de influenciar significativamente no domínio de competências gerenciais (em seus dois fatores), nem tampouco para a consecução de resultados distais de repercussão 
externa. Porém, o tipo de instituição revelou-se um aspecto diferenciador significativo entre os Resultados de pesquisa proximais e os tangíveis para grupos vinculados a Instituições públicas ou privadas.

Resultados proximais em Grupos de pesquisa vinculados a instituições públicas (Mediana=4,70) são significantemente superiores aos produzidos por grupos de instituições privadas (Mediana=4,40), $\mathrm{U}=3910, \mathrm{p}<0,05, r=-0,11$ ), conforme Figura 20.

Figura 20 - Resultados Proximais de Pesquisa versus Tipo de Instituição

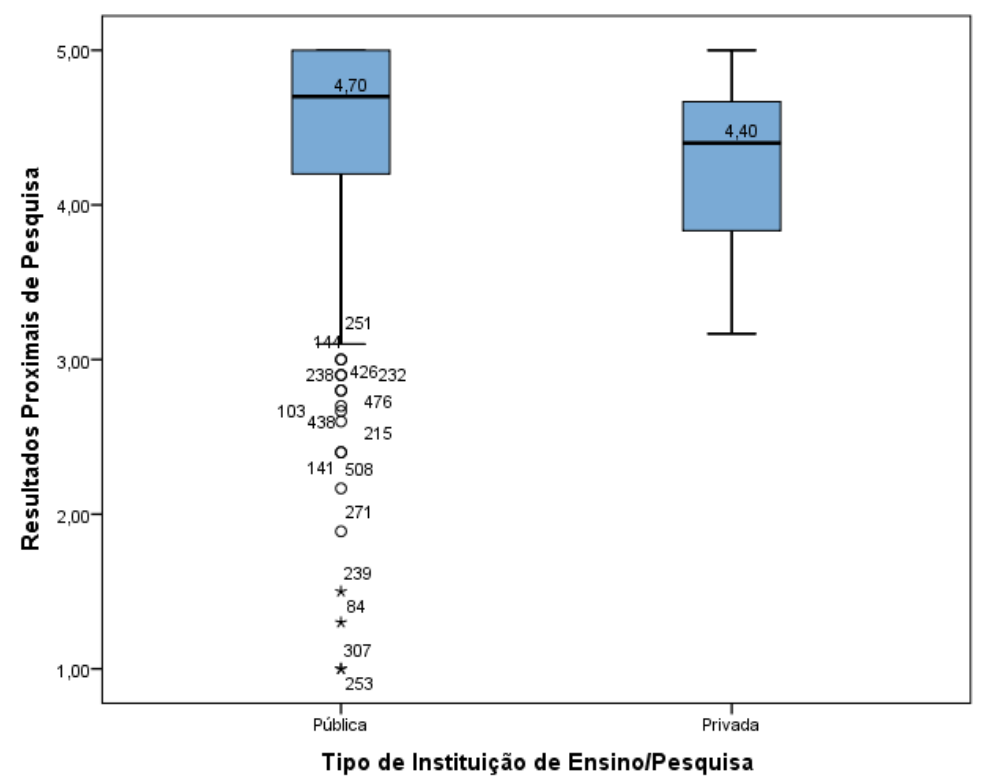

Fonte: Elaborada pelo autor com base em Dados da Pesquisa

Já os Resultados tangíveis em Grupos de pesquisa, embora tenham apresentado as mesmas medianas, revelaram médias significativamente diferentes. Grupo vinculados a instituições públicas (Média=3,80) possuem resultados tangíveis significantemente superiores aos produzidos por grupos de instituições privadas (Média=3,32) $(\mathrm{U}=4057, \mathrm{p}<0,05, \mathrm{r}=-$ 0,11), conforme Figura 21. 
Figura 21 - Resultados Tangíveis de Pesquisa versus Tipo de Instituição

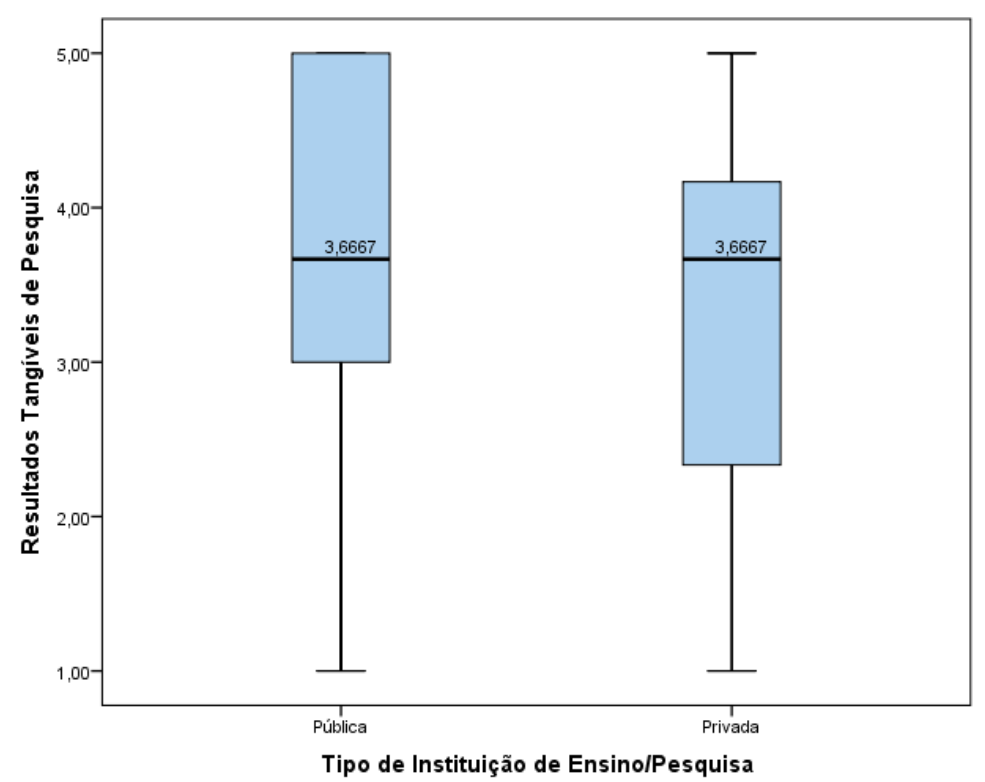

Fonte: Elaborada pelo autor com base em Dados da Pesquisa

Em que pese serem significativos os resultados apresentados, constatou-se que o número de líderes de instituições públicas pesquisado foi onze vezes maior que o de instituições privadas (343 versus 31), o que pode, de certa forma, acirrar as distinções entre os subgrupos. Por isso, foram selecionados, aleatoriamente, via SPSS, 31 respondentes de instituições públicas para que fossem comparados aos 31 líderes de instituições privadas existentes, quanto às medianas dos resultados proximais e tangíveis de pesquisa. De fato, mesmo quando a quantidade de respondentes é equiparada, os resultados Proximais e Tangíveis de Pesquisa possuem maior ocorrência em instituições públicas, conforme Figura 22 e Figura 23, respectivamente; e, com a amostra aleatória de 31 respondentes de instituições públicas, até mesmo a mediana dos resultados tangíveis revelou-se superior, não sendo necessária a comparação de médias. 
Figura 22 - Resultados Proximais versus Tipo de Instituição (Amostra aleatória)

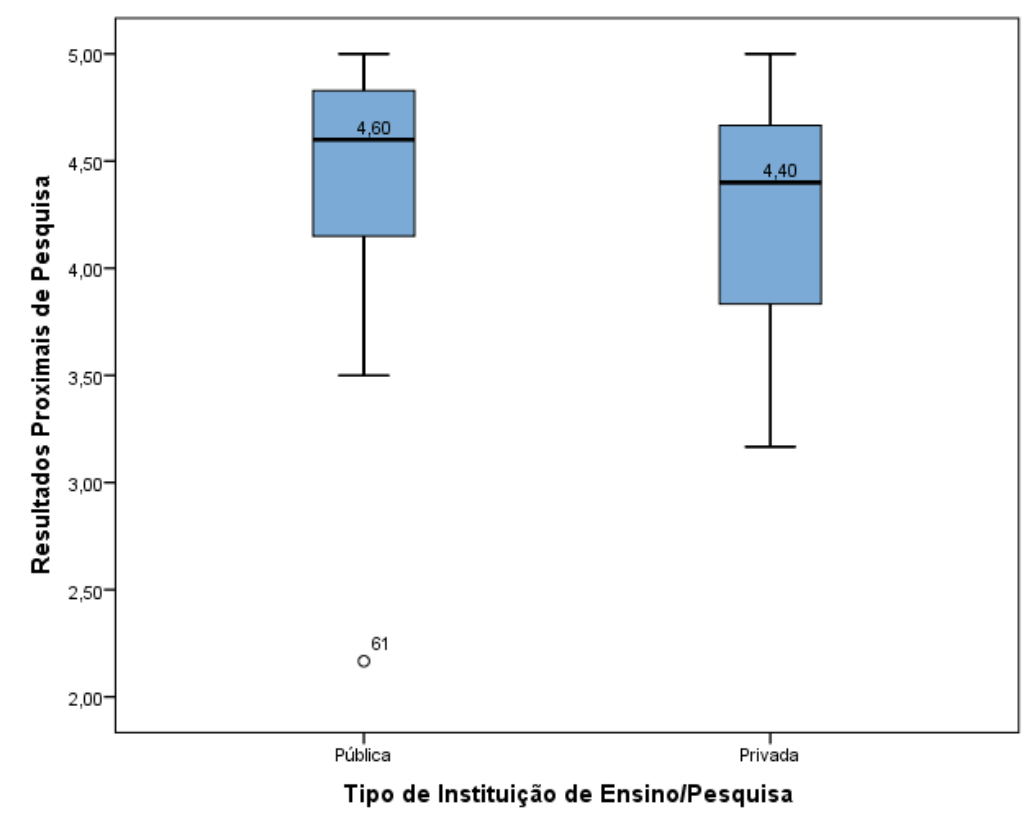

Fonte: Elaborada pelo autor com base em Dados da Pesquisa

Figura 23 - Resultados Tangíveis versus Tipo de Instituição (Amostra aleatória)

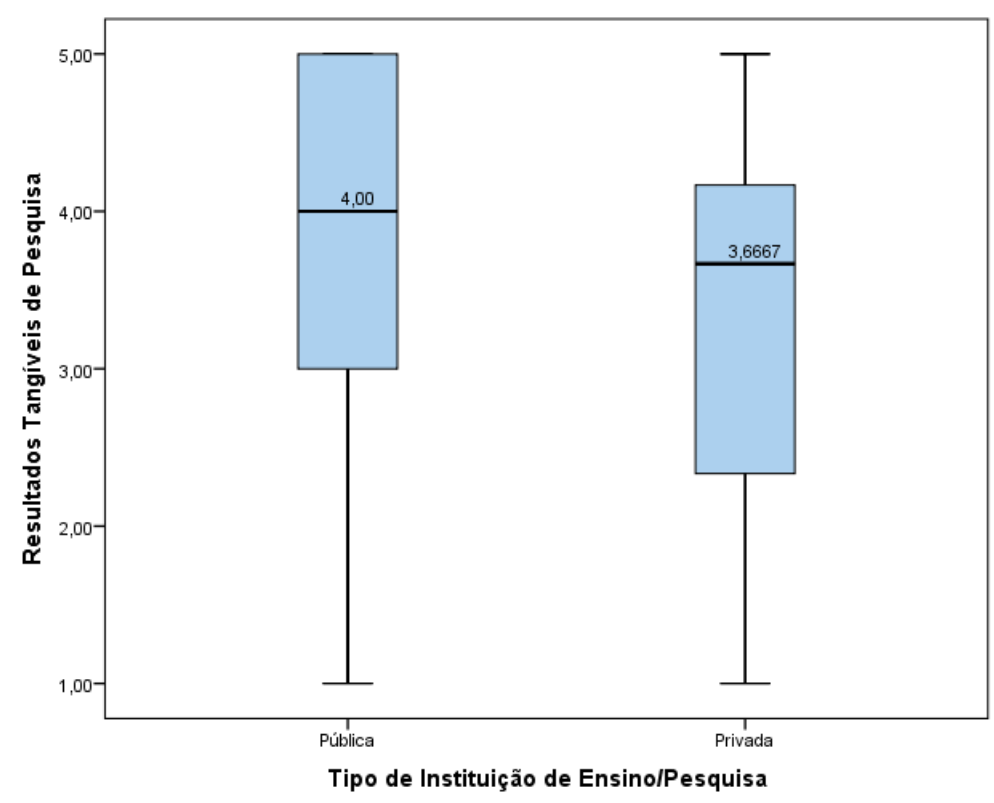

Fonte: Elaborada pelo autor com base em Dados da Pesquisa 


\subsubsection{Diferenças entre o Sexo dos Líderes de Grupo de Pesquisa}

O sexo dos líderes respondentes não se mostrou como uma variável Sociodemográfica capaz de influenciar significativamente em nenhum dos três fatores relativos a resultados de grupos de pesquisa. Também não apresentou diferença significativa no que tange a competências para captação de recursos e de pessoas.

Já com relação a competências relativas à gestão de pessoas e de resultados da pesquisa, as líderes mulheres apresentaram maior grau de domínio (Mediana=4,68) quando comparadas aos líderes homens (Mediana=4,51), $\mathrm{U}=13233,5, \mathrm{p}<0,05, \mathrm{r}=-0,14)$, conforme Figura 24.

Figura 24 - Gestão de Pessoas e de Resultados de Pesquisa versus Sexo do Líder

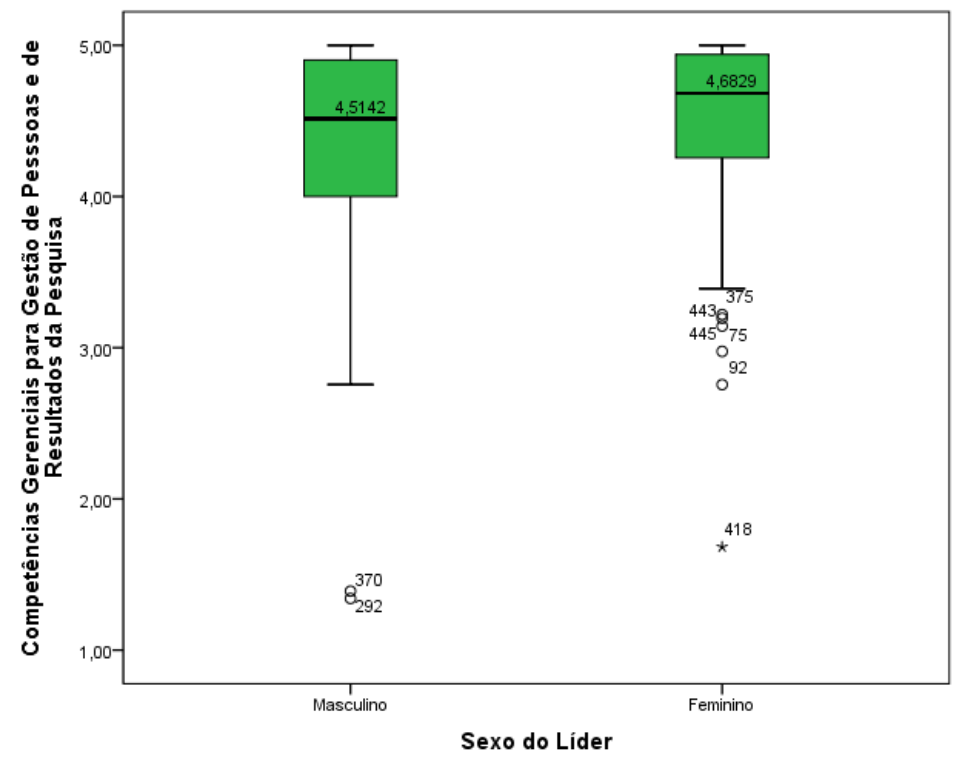

Fonte: Elaborada pelo autor com base em Dados da Pesquisa

De fato, Brito e Leone (2012), Cardoso (2014), Santos e Honório (2014) e Silva, Gil e Okabayashi (2014) já haviam publicado achados semelhantes relativos a diversos contextos de pesquisa, tal como mencionado no referencial teórico. Segundo esses autores, as gestoras, quando comparada aos homens, são ou se consideram mais competentes com relação a competências equivalentes às constantes do fator Gestão de Pessoas de Resultados de Pesquisa, tais como o interesse pelas pessoas, o planejamento, a organização, a flexibilidade, a disposição de trabalhar em equipe; a administração de conflitos, e a delegação.

Em suma, os achados dão conta de afirmar que as líderes de grupos de pesquisa consideraram dominar mais competências gerenciais de gestão de pessoas e resultados de 
pesquisa que os homens; e, quanto à captação de recursos e de pessoas, parecem possuir competências equivalentes às deles. Contudo, em que pese esse grau de domínio de competências excedente por parte das mulheres, os resultados produzidos por grupos liderados por homens ou mulheres são análogos e possuem medianas superiores a 4,0.

\subsubsection{Diferenças entre Líderes com ou sem pós-doutorado}

O pós-doutorado parece não estar relacionado diretamente com variações nos resultados alcançados pelo grupo, em quaisquer de seus três fatores. Contudo, a realização de atividade especializada ou de estágio de pesquisa posterior à conclusão do doutorado, embora não consista em uma titulação superior, se revelou como um diferencial para os dois fatores relativos ao domínio de competências gerenciais.

Líderes com pós-doutorado (Mediana $=4,63$ ) consideram dominar melhor competências gerenciais relativas à gestão de pessoas e de resultados de pesquisa, quando comparados aos líderes sem pós-doutorado (Mediana=4,53), $(\mathrm{U}=13793,5, \mathrm{p}<0,05, r=-0,11)$, conforme Figura 25.

Figura 25 - Gestão de Pessoas e de Resultados versus Pós-doutorado

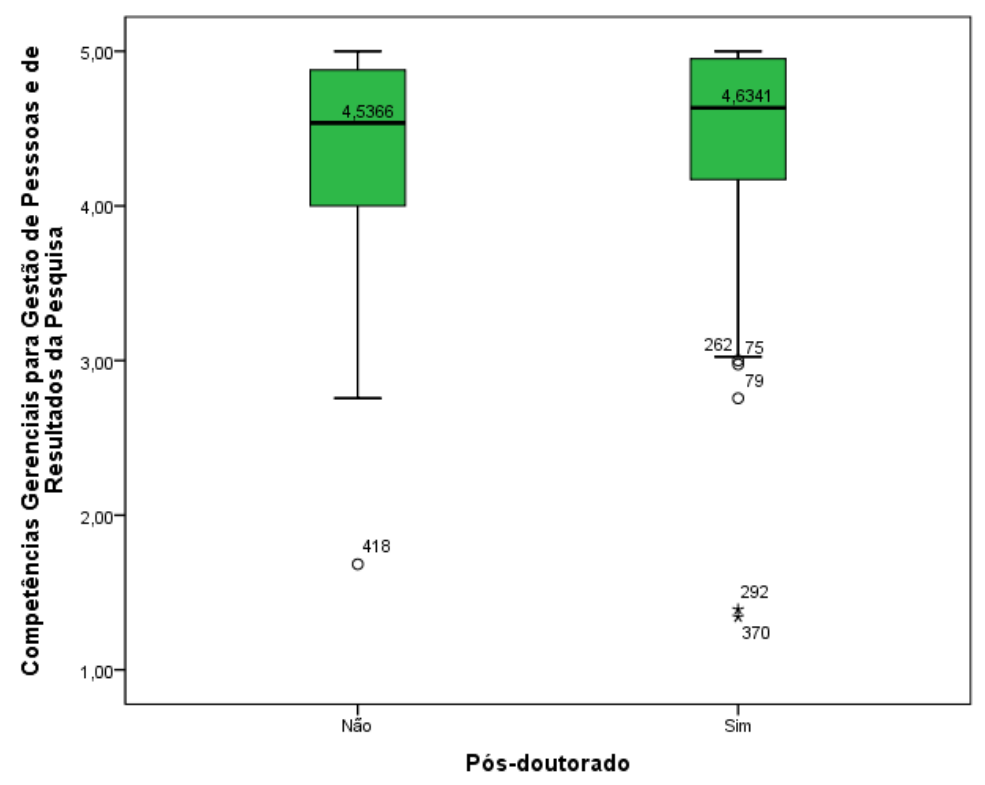

Fonte: Elaborada pelo autor com base em Dados da Pesquisa

Da mesma forma, os líderes com pós-doutorado (Mediana =4,56) consideram dominar em maior grau as competências relativas à captação de recursos e de pessoas, quando cotejados com os líderes sem pós-doutorado (Mediana =4,11), $(\mathrm{U}=13087, \mathrm{p}<0,05, r=-0,15)$, conforme Figura 26. 
Figura 26 - Captação de Recursos e de Pessoas versus Pós-doutorado

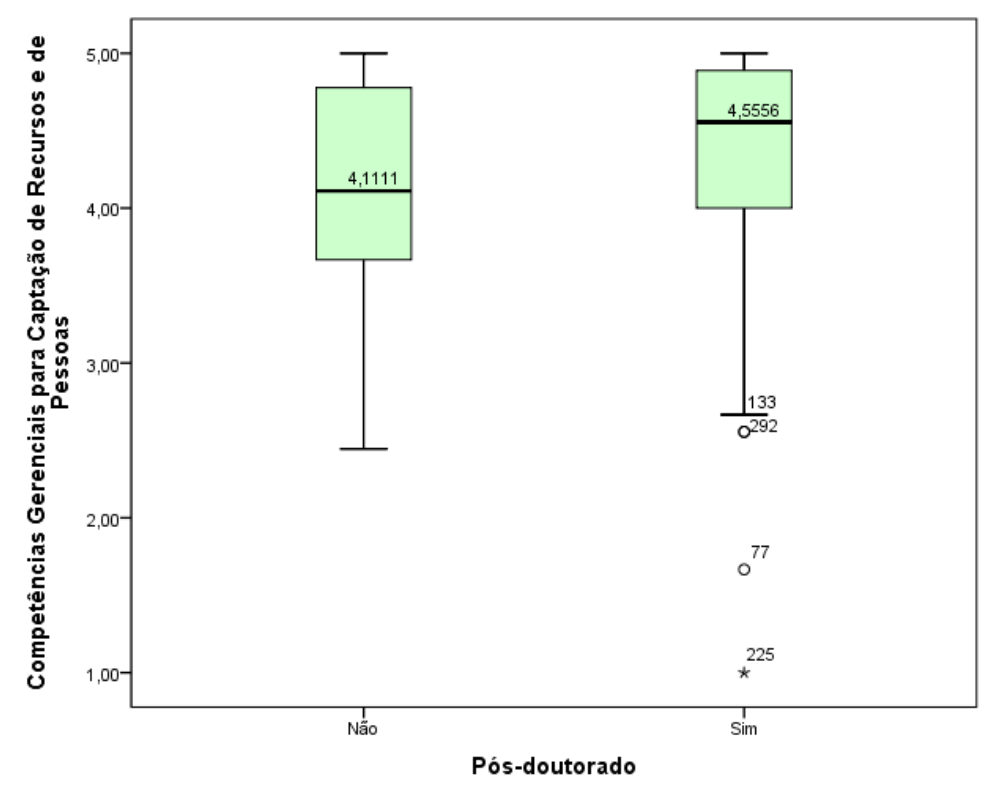

Fonte: Elaborada pelo autor com base em Dados da Pesquisa

Embora estatisticamente significativas, as diferenças não foram tão distintas, já que as medianas foram superiores a 4,0 com relação aos dois fatores.

Considerando que a literatura recorrida não apresenta achados comparáveis que sejam base para a discussão, retomam-se alguns estudos citados no referencial teórico que trataram do nível instrucional de modo geral, mas vale lembrar que o pós-doutorado não é considerado um nível instrucional mais elevado. No contexto de pesquisa, Valentim (2007) encontrou como resultado que o nível instrucional de participantes de grupos de pesquisa não se configura um aspecto diferenciador nos resultados do grupo, já que a atuação colaborativa daria conta de nivelar as contribuições dos integrantes. Embora não se refira ao contexto de grupos de pesquisa, Cardoso (2014) concluiu que, no que tange à percepção de domínio de competências gerenciais de (ex-)alunos de mestrado e doutorado em administração, o nível de escolaridade também não apresentou diferenças estatisticamente significantes. 


\subsubsection{Diferenças entre Líderes com ou sem bolsa de produtividade do CNPq}

O CNPq, visando a valorizar a produção científica, concede bolsas de produtividade para os pesquisadores que se destaquem entre seus pares, a partir de critérios normativos firmados pelo próprio Conselho e de outros critérios específicos, estabelecidos Comitês de Assessoramento do CNPq. Para poder fazer jus à bolsa, é necessário possuir o título de doutor ou perfil científico equivalente e se dedicar às atividades constantes de seu pedido de bolsa. Caso seja estrangeiro, o pesquisador precisa comprovar sua situação regularizada no Brasil. E, se aposentado, o pesquisador deverá manter suas atividades acadêmico-científicas oficialmente vinculadas a instituições de pesquisa e ensino.

O recebimento de bolsa não se mostrou relacionado diretamente com o domínio de competências gerenciais relativas à gestão de pessoas ou de resultados da pesquisa. Mas, como era de se esperar, os líderes que recebem bolsa de produtividade do CNPq (Mediana $=4,50$ ) informaram dominar melhor as competências gerenciais relativas à captação de recursos e de pessoas, quando comparados aos que não possuem bolsa do $\mathrm{CNPq}($ Mediana $=4,05)$, $(\mathrm{U}=$ 9713, $\mathrm{p}<0,05, \mathrm{r}=-0,17)$, conforme Figura 27.

\section{Figura 27 - Captação de Recursos e de Pessoas versus Bolsa de Produtividade CNPq}

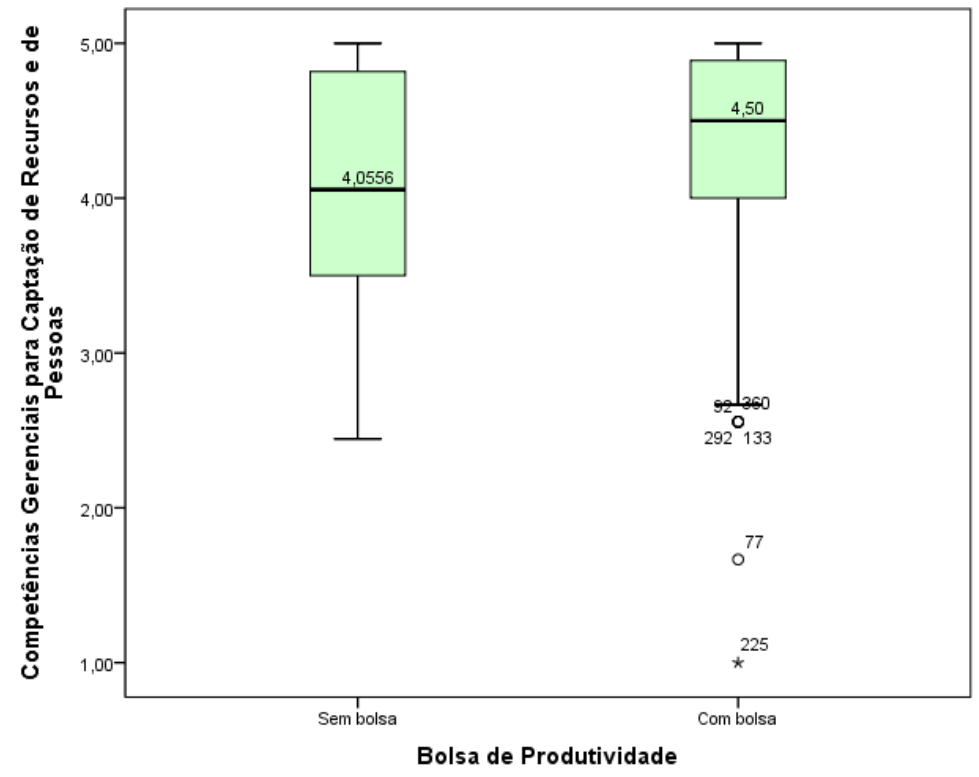

Fonte: Elaborada pelo autor com base em Dados da Pesquisa

No que tange aos resultados alcançados pelo grupo, o fato de o líder poder contar com bolsa de produtividade do CNPq interfere em todos os três fatores. Quanto aos resultados distais de repercussão externa, grupos em que os líderes possuem bolsa (Mediana =4,13) apresentam 
melhores resultados do que grupos dos quais os líderes não possuem (Mediana $=3,58$ ), $\mathrm{U}=$ 9873,5, $\mathrm{p}<0,05, \mathrm{r}=-0,16)$, conforme Figura 28.

Figura 28 - Resultados Distais de Repercussão Externa versus Bolsa Produtividade CNPq

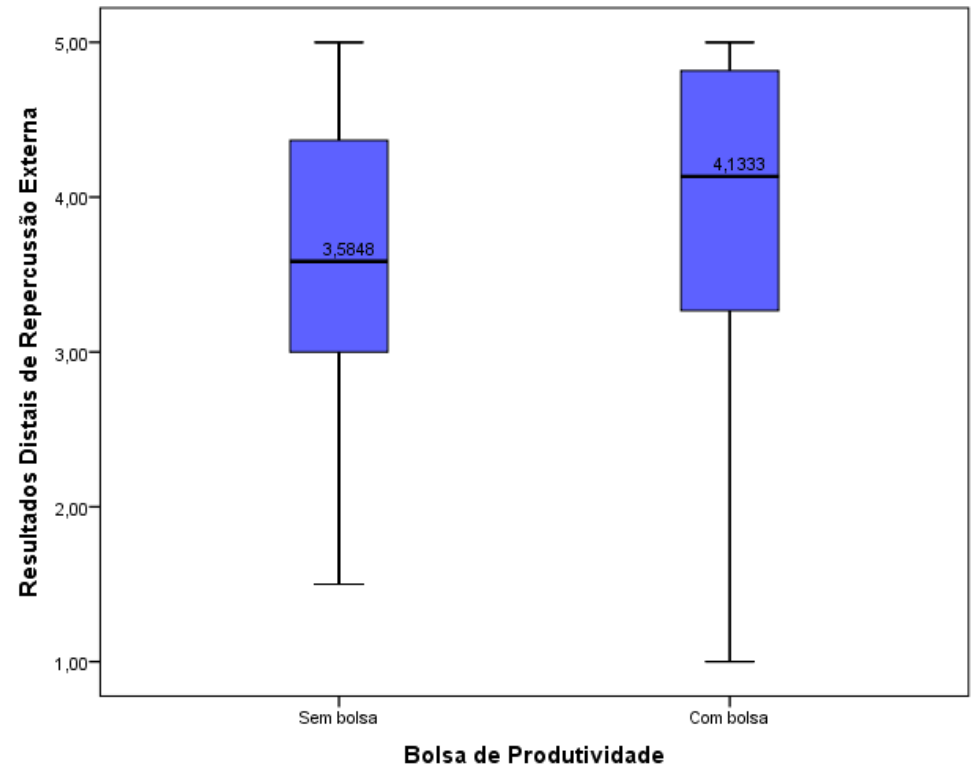

Fonte: Elaborada pelo autor com base em Dados da Pesquisa

Já quanto aos resultados proximais de pesquisa, grupos em que os líderes possuem bolsa (Mediana $=4,70$ ) obtiveram resultados mais expressivos do que grupos dos quais os líderes não possuem (Mediana = 4,55), $\mathrm{U}=10794, \mathrm{p}<0,05, \mathrm{r}=-0,10)$, conforme Figura 29.

Figura 29 -Resultados Proximais de Pesquisa versus Bolsa Produtividade CNPq

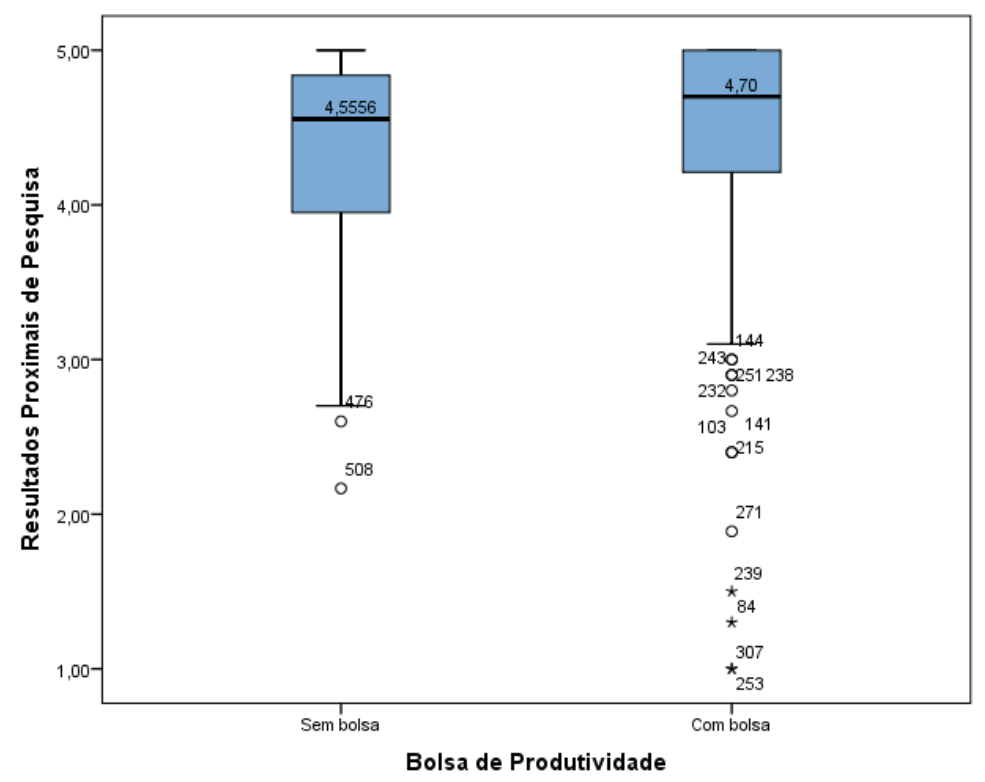

Fonte: Elaborada pelo autor com base em Dados da Pesquisa 
E, por fim, quanto aos resultados tangíveis de pesquisa, grupos em que os líderes possuem bolsa (Mediana $=4,00$ ) alcançaram resultados superiores aos dos grupos em que os líderes não a possuem (Mediana = 3,58), $\mathrm{U}=10088,5, \mathrm{p}<0,05, \mathrm{r}=-0,13$ ), conforme Figura 30.

Figura 30 - Resultados Tangíveis de Pesquisa versus Bolsa Produtividade CNPq

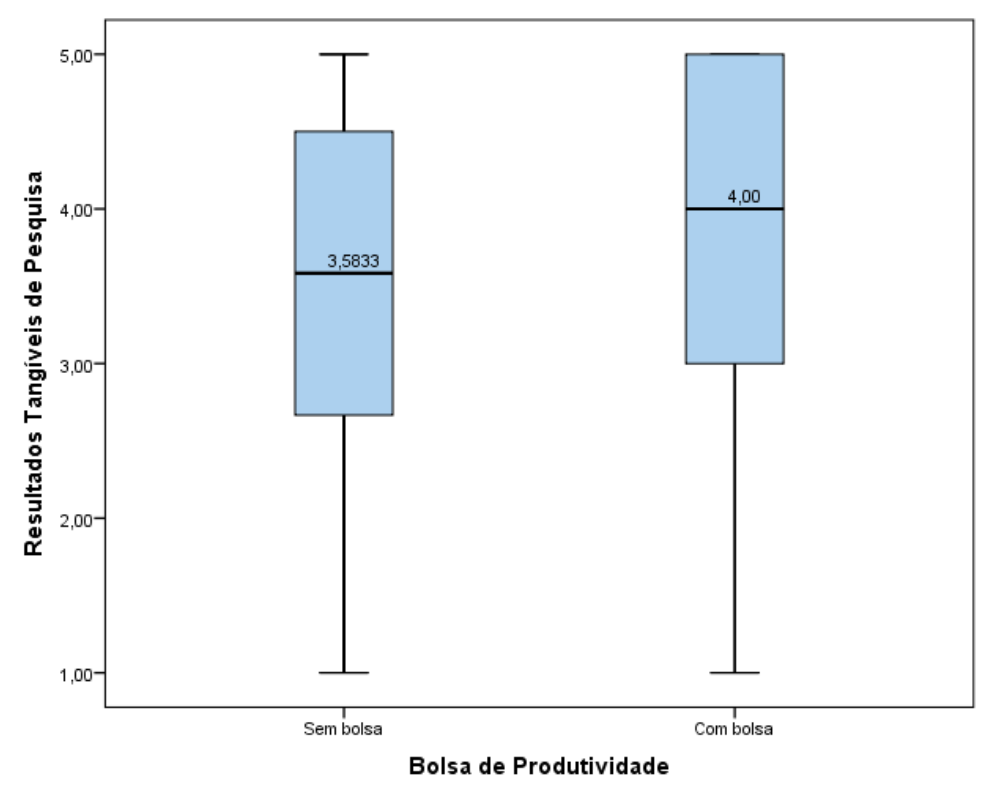

Fonte: Elaborada pelo autor com base em Dados da Pesquisa

\subsubsection{Diferenças quanto ao Tipo de bolsa de produtividade do CNPq recebida}

Existem cinco tipos diferentes de bolsas de produtividade seja em Pesquisa seja em Desenvolvimento Tecnológico e Extensão Inovadora: 1A, 1B, 1C, 1D e 2. Os respectivos valores podem ser acrescidos de 'Adicionais de bancada', que são valores opcionais para pesquisadores de nível 1 (A, B, C e D), que podem ser empregados em despesas como equipamentos, passagens e diárias, desde que relacionadas ao projeto de pesquisa ou dele decorrentes (CNPq, 2016). A Tabela 26 apresenta os valores atuais dos cinco tipos de bolsa e os respectivos adicionais de bancada. 
Tabela 26 - Valores das bolsas de produtividade CNPq e respectivos adicionais de bancada

\section{Produtividade em Pesquisa ou em Desenvolvimento Tecnológico e Extensão Inovadora}

\begin{tabular}{cccc}
\hline Tipo de Bolsa & Valor & Adicional de Bancada & Total \\
\hline 1A & $1.500,00$ & $1.300,00$ & $2.800,00$ \\
\hline 1B & $1.400,00$ & $1.100,00$ & $2.500,00$ \\
\hline 1C & $1.300,00$ & $1.100,00$ & $2.400,00$ \\
\hline 1D & $1.200,00$ & $1.000,00$ & $2.200,00$ \\
\hline 2 & $1.100,00$ & - & $1.100,00$ \\
\hline
\end{tabular}

Fonte: Elaborada pelo autor com base CNPq (2015)

Aqui vale esclarecer que o questionário aplicado, acrescentava indevidamente uma bolsa do Tipo 1 E, a qual inexiste. Para análise dos resultados, os 3 líderes que haviam assinalado essa alternativa, certamente por equívoco, foram considerados como missings.

Além de investigar se o recebimento ou não de bolsas do CNPq por parte do líder do grupo interfere no domínio de competências gerenciais ou no alcance de resultados pelo grupo, como relatado na seção anterior, quis-se verificar se os diferentes tipos de bolsa influenciavam nessas variáveis.

Inversamente ao ocorrido na comparação entre líderes com ou sem o recebimento de bolsa, o cotejamento entre os três fatores relativos a resultados alcançados pelo grupo não apresentou qualquer diferença significativa. Todavia, mediante o Teste $\mathrm{H}$ de Kruskall-Wallis, a comparação entre os tipos de bolsa com relação ao domínio de competências gerenciais apresentou diferença significativa, mesmo com todas as medianas superiores a 4 , seja para as competências gerenciais relacionadas à gestão de pessoas e de resultados da pesquisa $(\mathrm{H}(4)=$ 9,67, p < 0,05), seja para as concernentes à captação de recursos ou de pessoas $(H(4)=9,67, p$ $<0,05)$.

Neste caso, Field (2009) sugere que seja traçado o gráfico de caixa e bigodes, como forma de comparar as medianas entre os diferentes grupos estudados, quanto ao domínio de competências gerenciais relacionadas à gestão de pessoas e de resultados da pesquisa e à captação de recursos e de pessoas (Figura 31 e Figura 32, respectivamente). 
Figura 31 - Gestão de Pessoas e de Resultados de Pesquisa versus Tipo de bolsa CNPq

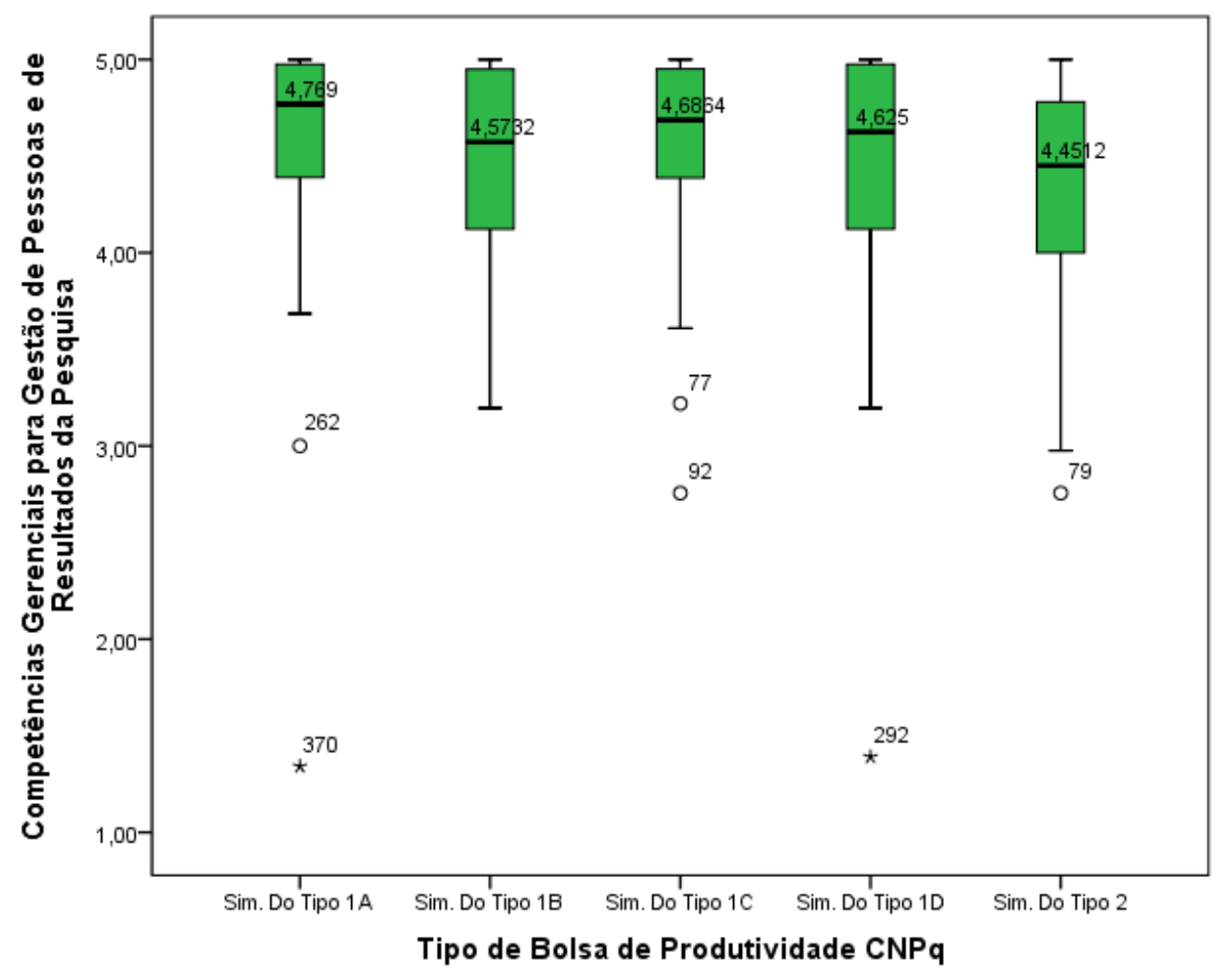

Fonte: Elaborada pelo autor com base em Dados da Pesquisa

Figura 32 - Captação de Recursos e de Pessoas versus Tipo de bolsa CNPq

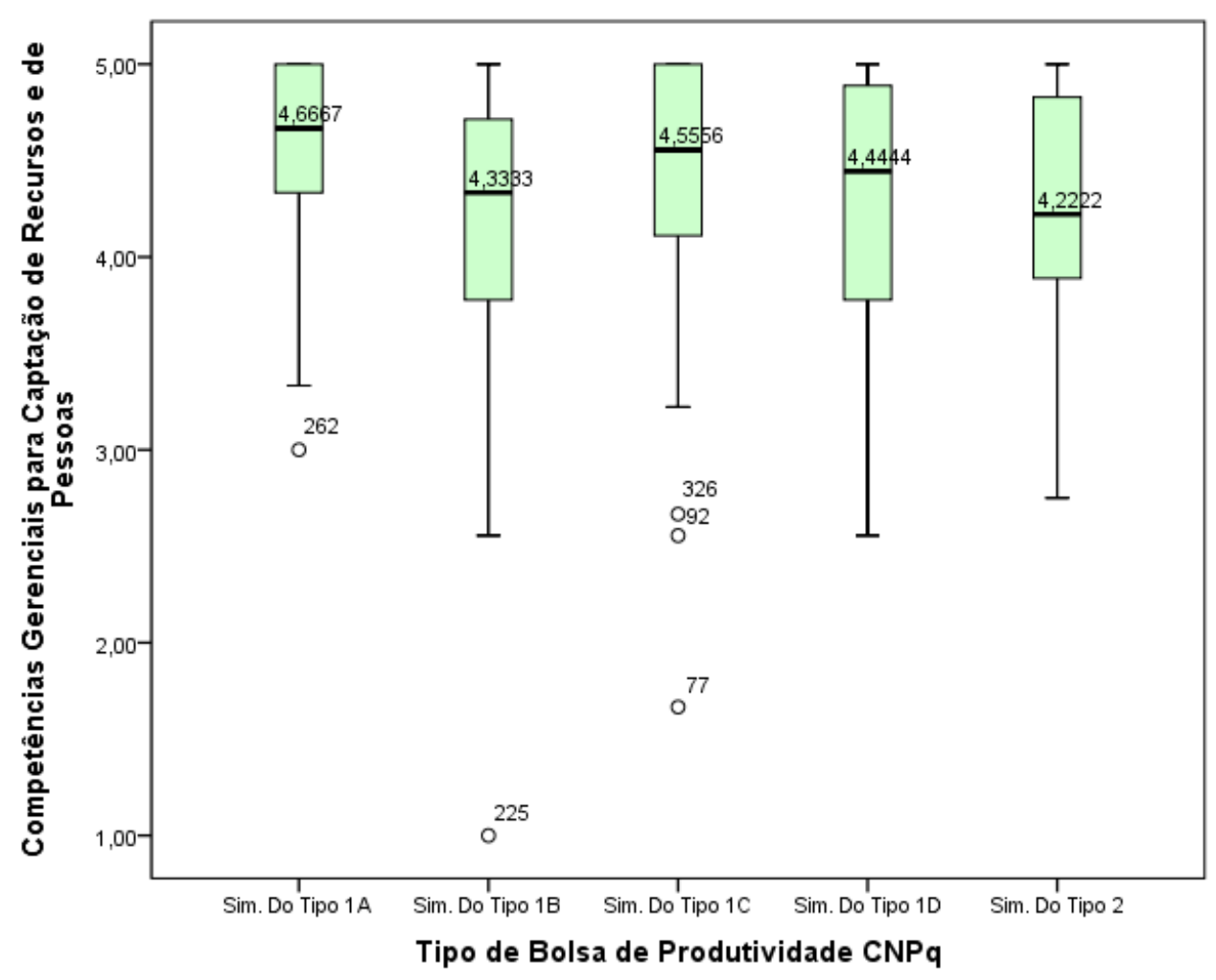

Fonte: Elaborada pelo autor com base em Dados da Pesquisa 
A inspeção visual dos gráficos permite a comparação entre as medianas do domínio de competências gerenciais relacionadas à gestão de pessoas e de resultados da pesquisa e à captação de recursos e de pessoas. Percebe-se que o grau de domínio reduz à medida que os valores das bolsas diminuem, exceto pela mediana referente ao recebimento de bolsa do tipo 1B, que está relacionada a líderes com domínio inferior inclusive aos que recebem apenas bolsa dos tipos 1C e 1D. De qualquer forma, as medianas foram superiores a 4,0 com relação a todos os tipos de bolsa.

Vale ainda sublinhar que cada círculo ou asterisco nos gráficos representa um sujeito que, embora receba algum tipo de bolsa, apresentou domínio de competência atípico ou extremamente inferior em relação aos demais.

Finalizada a exposição das relações provenientes do recebimento de bolsas de produtividade do $\mathrm{CNPq}$, questiona-se quais, de fato, são as variáveis dependentes e independentes constantes de um eventual framework com os elementos: competências gerenciais (em seus dois fatores); tipo de bolsa de produtividade recebida (em seus cinco tipos); e resultados alcançados pelo grupo (em seus três fatores). Sobre essa reflexão, uma hipótese seria que o domínio de competências gerenciais (variável independente) determinaria o recebimento de bolsa de produtividade (variável dependente). Outra hipótese seria o recebimento de bolsa produtividade (variável independente) ensejaria o domínio de mais competências gerenciais e mais resultados (variáveis dependentes). Estudos posteriores poderiam testar essas e outras hipóteses, analisando, inclusive, qual a ordem dessas influências e relações.

\subsubsection{Diferenças entre as Grandes áreas do conhecimento}

O Teste H de Kruskall-Wallis apontou que existe diferença significativa entre o domínio de competências dos líderes de grupos atuantes nas diferentes grandes áreas do conhecimento, tanto com relação às competências gerenciais relacionadas à gestão de pessoas e de resultados da pesquisa $(\mathrm{H}(7)=18,22, \mathrm{p}<0,05)$ quanto à captação de recursos e de pessoas $(\mathrm{H}(7)=17,13$, $\mathrm{p}<0,05)$ (Figura 33 e Figura 34, respectivamente). 
Figura 33 - Gestão de Pessoas e de Resultados de Pesquisa versus Grande Área do Conhecimento

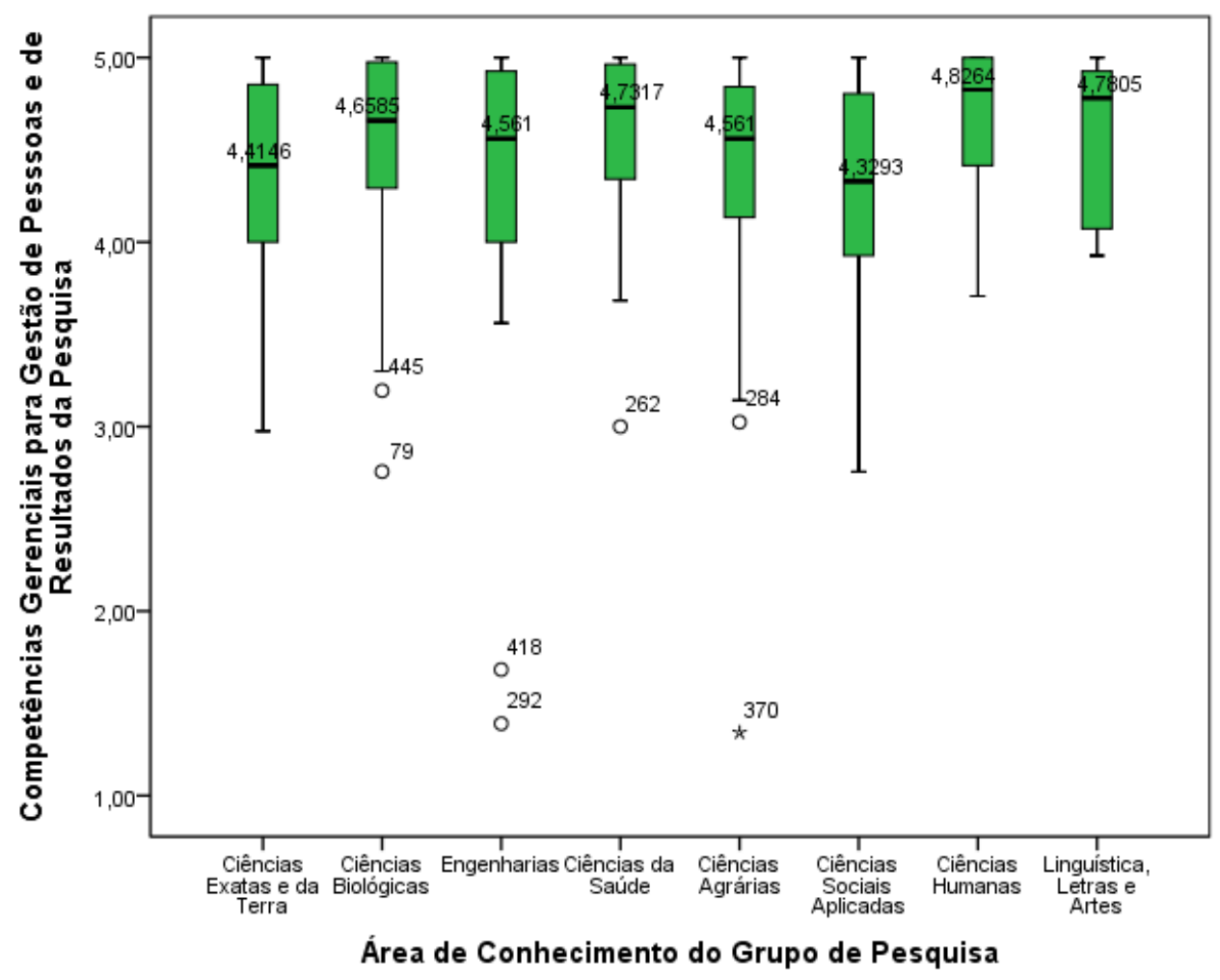

Fonte: Elaborada pelo autor com base em Dados da Pesquisa

A comparação entre as medianas aponta que, nas Ciências Humanas e na grande área que comporta estudos sobre Linguística, Letras e Artes, estão os líderes com maior domínio nas competências gerenciais de ligadas à gestão de pessoas e de resultados da pesquisa. Enquanto que os menores escores são relativos às Ciências Sociais Aplicadas e às Ciências Exatas e da Terra, valendo destacar que todas as medianas são maiores ou iguais a 4,0. 
Figura 34 - Captação de Recursos e de Pessoas versus Grande Área do Conhecimento

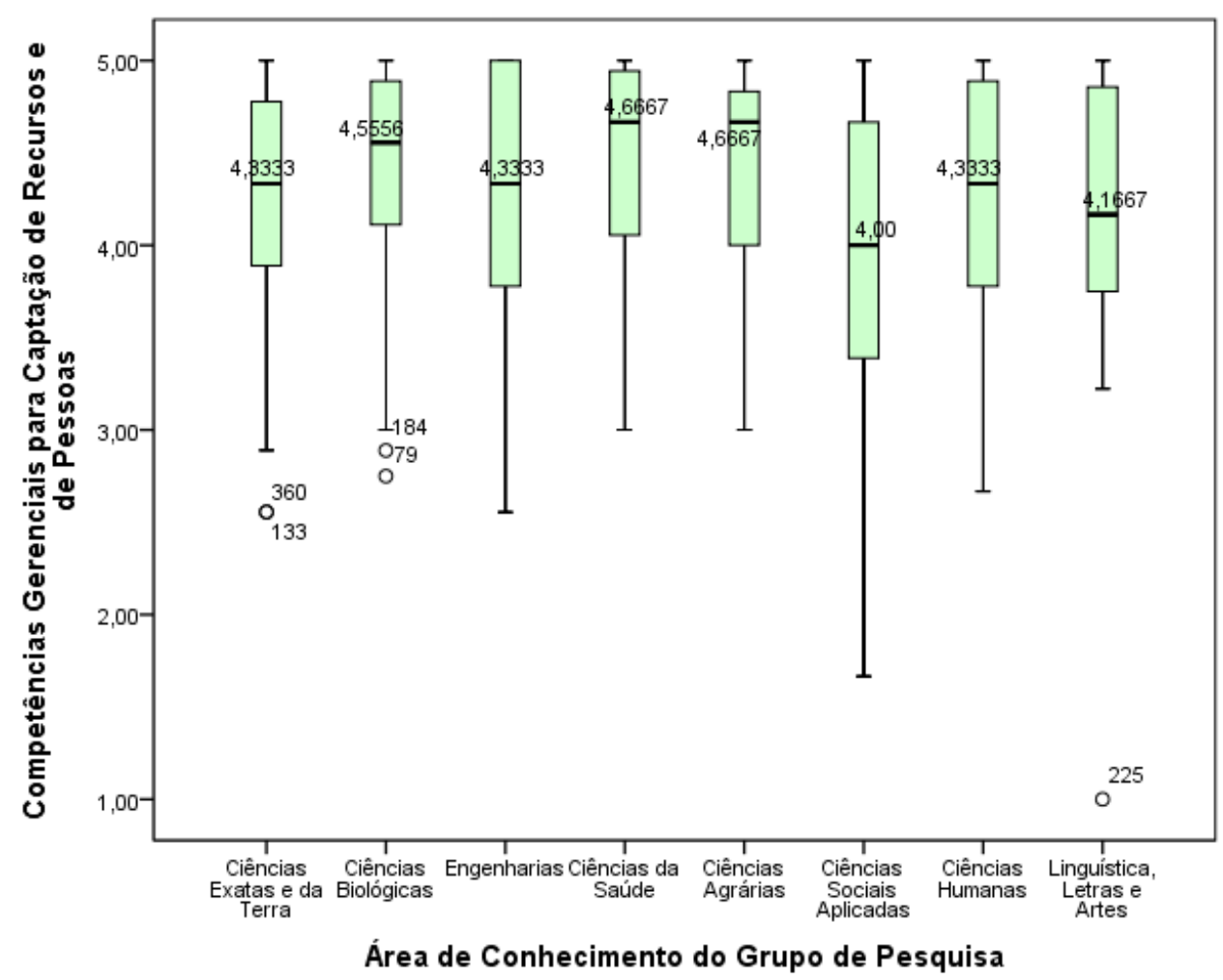

Fonte: Elaborada pelo autor com base em Dados da Pesquisa

Quanto à captação de recursos e de pessoas, os melhores graus de domínio são atribuídos aos líderes atuantes nas Ciências da Saúde e Ciências Agrárias, e as menores medianas ficaram a cargo das Ciências Sociais Aplicadas e da Linguística, Letras e Artes. Vale frisar que todas as medianas foram iguais ou maiores que 4,0 .

Com relação ao destaque para as Ciências Agrárias, este achado está compatível com o estudo de Garcia et al. (2015), que apontou essa Grande Área do Conhecimento como uma das que mais estabelece parcerias com o setor produtivo. Já com relação aos resultados do grupo, embora os proximais não demonstrem ser significativamente diferentes no que tange às grandes áreas do conhecimento, os dois outros fatores apresentaram distinções na comparação entre as áreas. Tanto os resultados distais de repercussão externa $(\mathrm{H}(7)=18, \backslash 16, \mathrm{p}<0,05)$ quanto os resultados tangíveis $(\mathrm{H}(7)=14,17, \mathrm{p}<0,05)$ se mostraram sensíveis a diferenças nas grandes áreas do conhecimento (Figura 35 e Figura 36, respectivamente). 
Figura 35 - Resultados Distais de Repercussão Externa versus Grande Área do Conhecimento

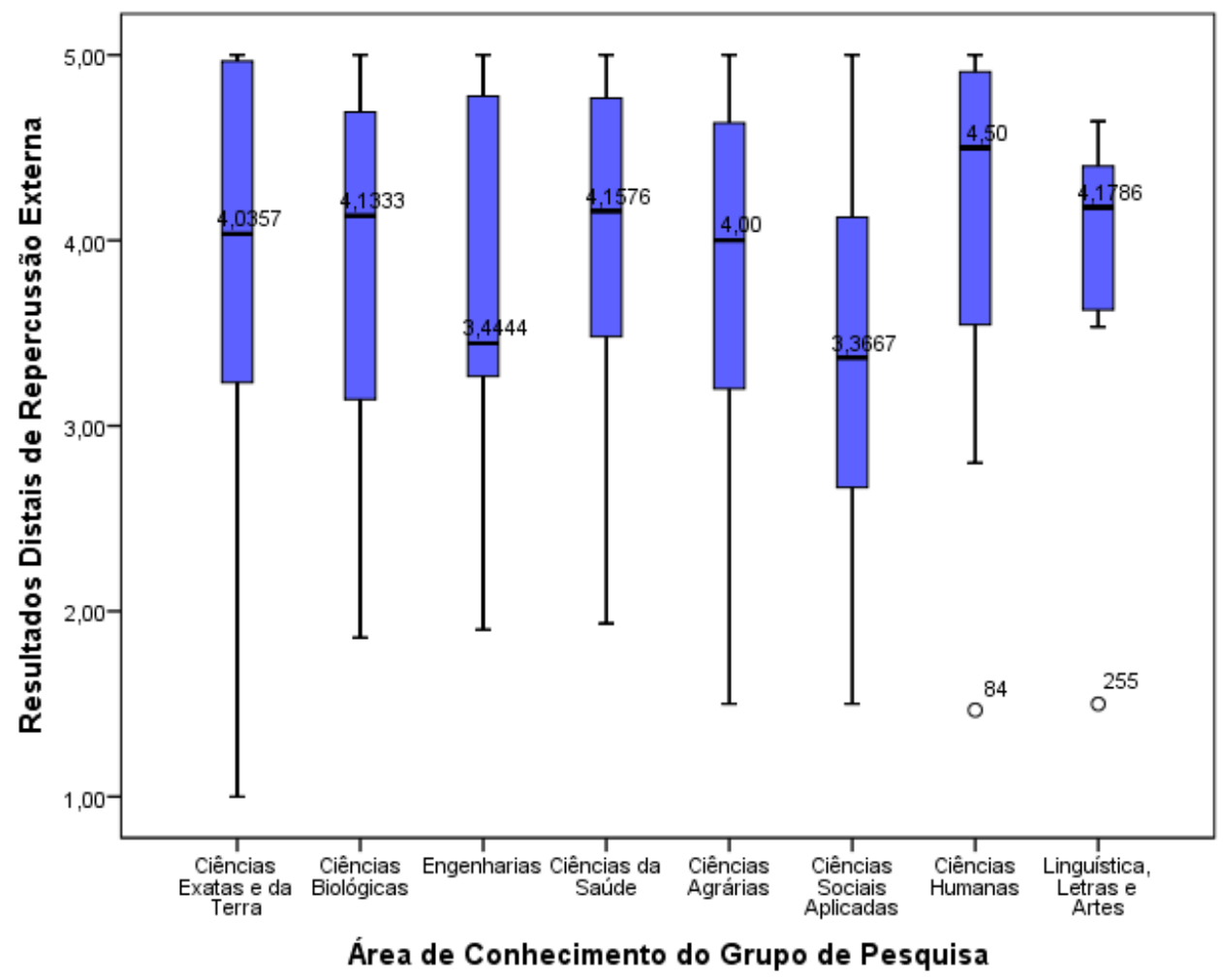

Fonte: Elaborada pelo autor com base em Dados da Pesquisa

No que tange aos resultados distais de repercussão externa, a comparação entre as medianas aponta que os melhores resultados são alcançados por grupos das Ciências Humanas e de Linguística, Letras e Artes, enquanto que os menos expressivos estão nas Ciências Sociais Aplicadas e nas Engenharias.

Com relação às Engenharias, esse achado diverge do estudo de Garcia et al. (2015) que apontaram que resultados distais de repercussão externa, como a prestação de assessoria ou consultoria técnica a empresas, é um resultado bastante alcançado por grupos da Grande área das Engenharias. 
Figura 36 - Resultados Tangíveis de Pesquisa versus Grande Área do Conhecimento

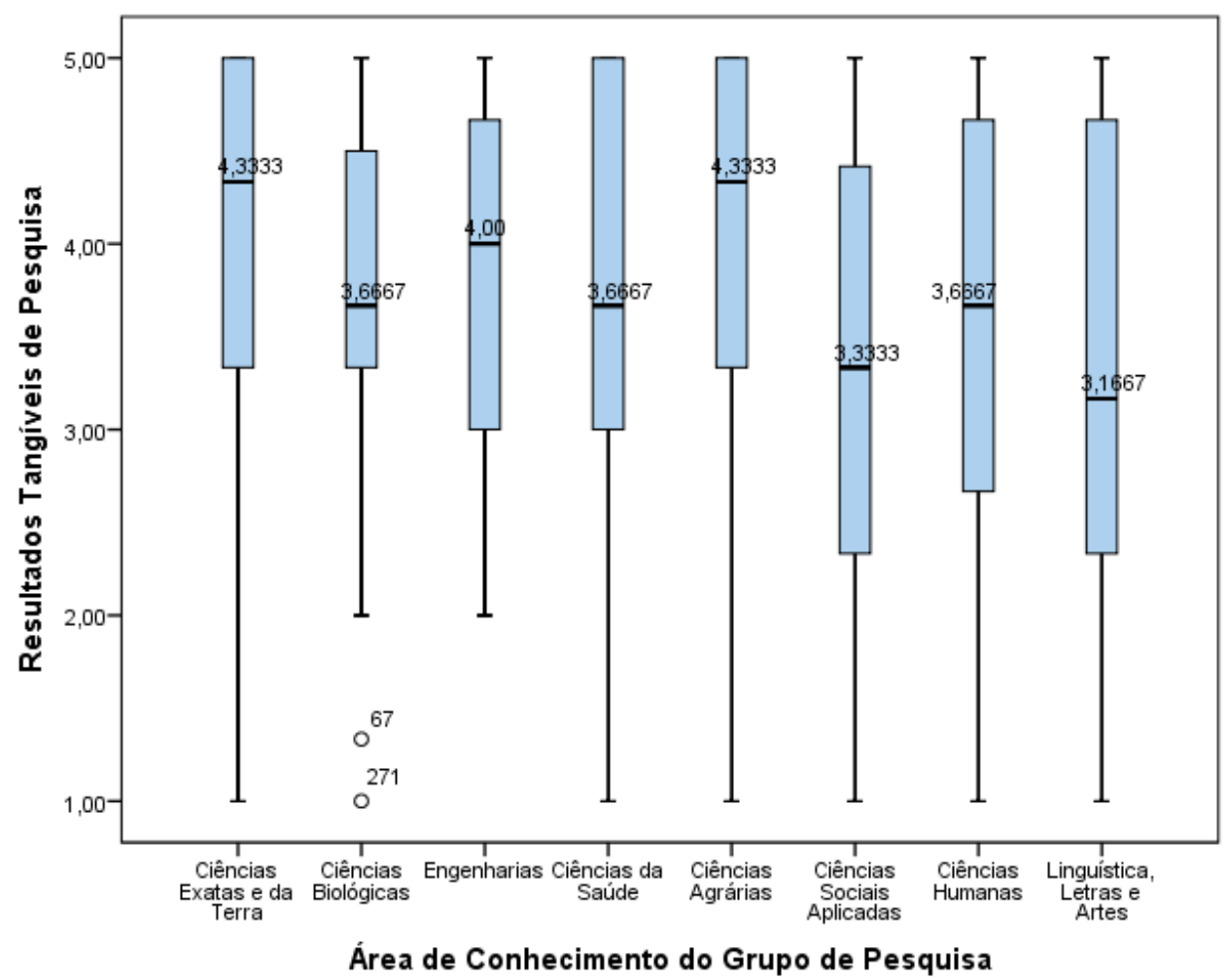

Fonte: Elaborada pelo autor com base em Dados da Pesquisa

Verifica-se ainda que, ao tratar de resultados tangíveis, há maior incidência entre grupos das Ciências Exatas e da Terra, bem como das Ciências Agrárias. Assim como para as competências gerenciais relativas à captação de recursos e de pessoas, as medianas menos expressivas se referem aos resultados tangíveis alcançados nas Ciências Sociais Aplicadas e da Linguística, Letras e Artes.

Por fim, sugere-se que estudos futuros confirmem e analisem os motivos que levam os resultados de grupos de pesquisa aparentarem maior variabilidade nos dados, quando comparados às competências gerenciais, no que tange às Grandes Áreas do Conhecimento. Essa variabilidade pode ser comparada por meio do tamanho das retas verticais (bigodes) que acompanham as caixas em todos os diagramas apresentados nesta seção: quanto maiores forem as retas verticais, maior será a variabilidade das respostas em determinada grande área do conhecimento. Uma hipótese a ser testada é que os resultados dependeriam de mais aspectos que as competências gerenciais, uma vez que estas são fenômenos de nível individual, enquanto aqueles são fenômenos de nível meso ou macro organizacional, e, portanto, se revelam mais complexos. 


\subsubsection{Diferenças quanto à Faixa Etária dos Líderes}

A idade dos respondentes foi coletada como uma variável discreta, em anos. Posteriormente, foi categorizada em faixas: até 25 anos; de 26 a 35 anos; de 36 a 45 anos; de 46 a 55 anos; de 56 a 65 anos; e 66 anos ou mais.

O Teste H de Kruskall-Wallis não apontou diferenças significativas, quanto à idade, para nenhuma das cinco variáveis, tal qual foi apontado por Cardoso (2014), que afirmaram que as diferentes faixas etárias não repercutiram em diferenças nas percepções de domínio de competências gerenciais de (ex-)alunos de mestrado e doutorado em administração.

Todavia, o teste simples de diferenças entre medianas apontou a existência de diferença significativa nos resultados distais de repercussão externa ( $\mathrm{gl}(7)$, Chi-Square $=17,7, \mathrm{p}<0,05)$ (Figura 37).

\section{Figura 37 - Resultados Distais de Repercussão Externa versus Idade do líder}

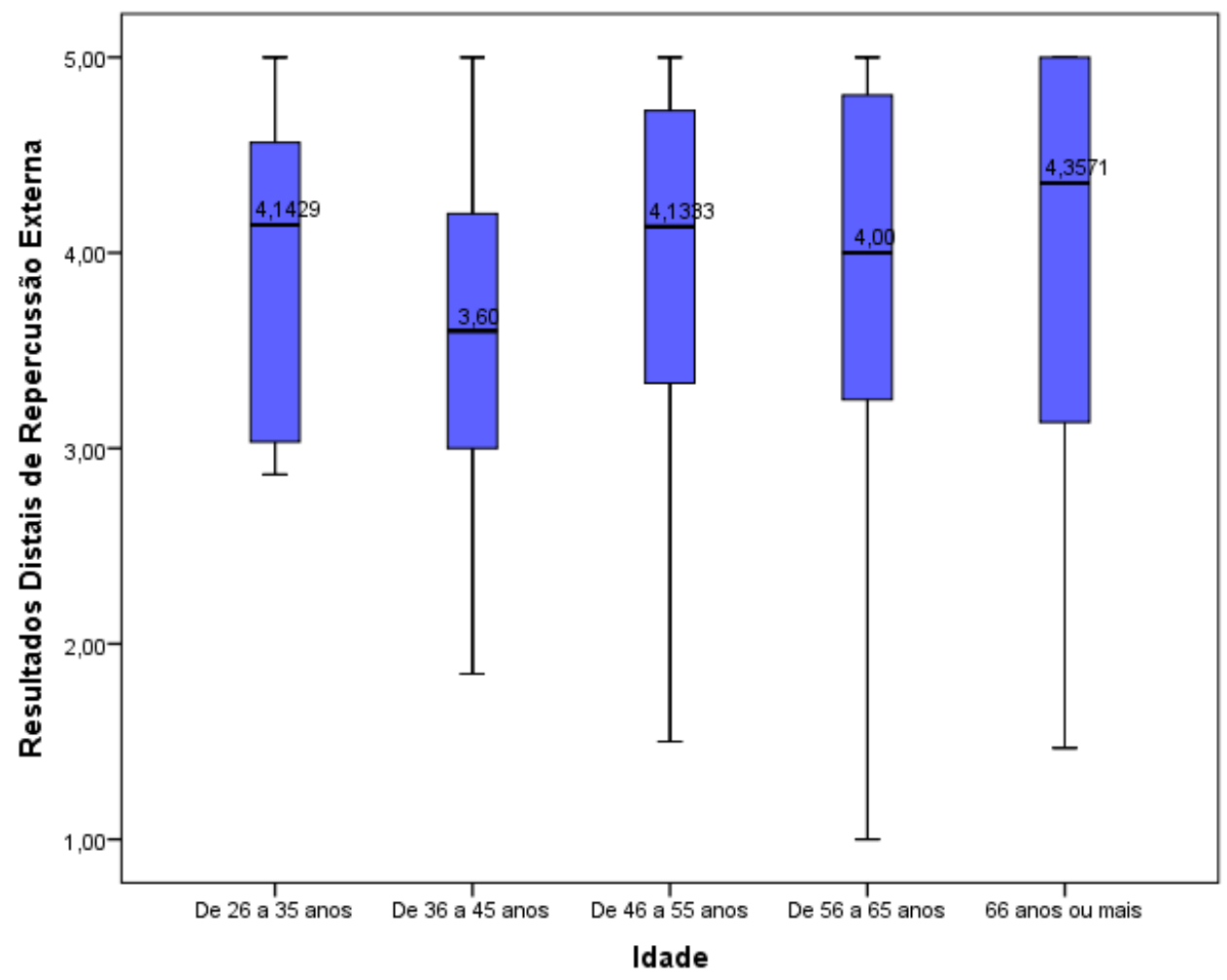

Fonte: Elaborada pelo autor com base em Dados da Pesquisa

O gráfico de caixas e bigodes revelou certa oscilação entre os resultados de repercussão externa em diferentes faixas etárias, por isso não se pode afirmar que a maturidade ou a juventude do pesquisador esteja ligada à consecução de resultados distais. Certamente, são recomendados estudos para confirmar e investigar os reais motivos que provocam essa 
oscilação. Nesse sentido, uma hipótese a ser testada é se pode ter havido leniência nas autoavaliações no que tange à consecução de resultados distais de repercussão externa, por parte de pesquisadores mais jovens (de 26 a 35 anos), os quais, provavelmente, estão em início de carreira e são menos experientes, o que pode ter acarretado as medianas maiores que as de líderes entre 36 e 45 anos de idade.

De qualquer forma, traçou-se a linha de ajuste total sobreposta ao o gráfico de dispersão (Figura 38), a qual - de maneira genérica - aponta que sujeitos com mais idade tendem a apresentar maior incidência de resultados de repercussão externa.

Figura 38 - Gráfico de Dispersão - Resultados Distais de Repercussão Externa versus Idade do líder

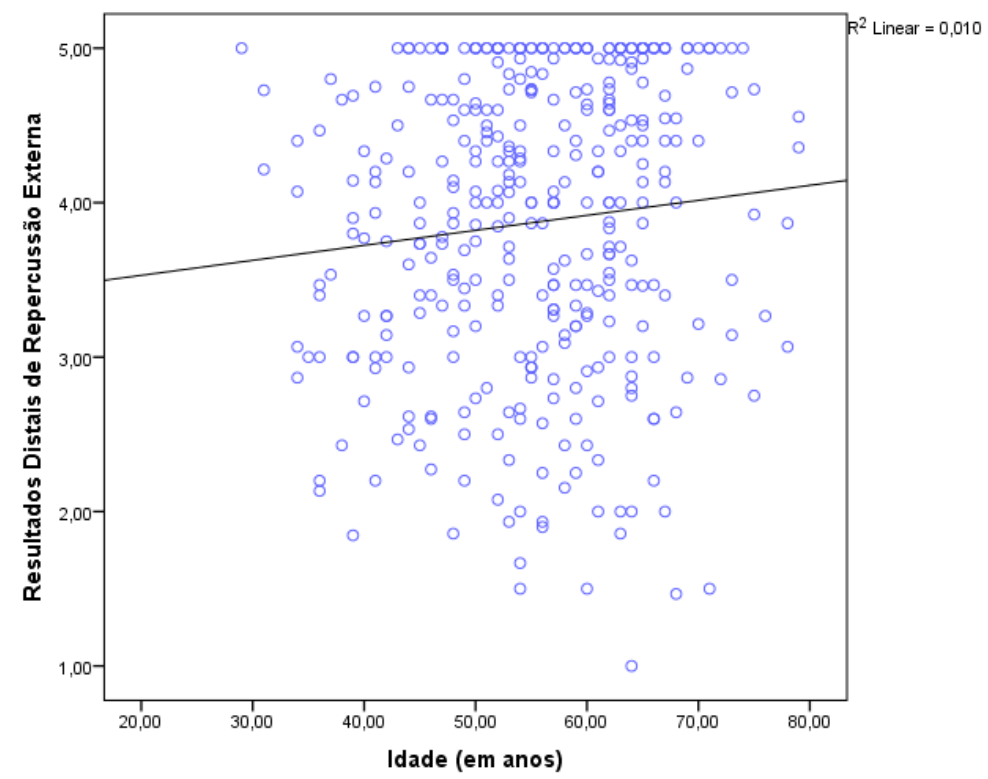

Fonte: Elaborada pelo autor com base em Dados da Pesquisa

\subsubsection{Diferenças quanto à Experiência dos Líderes com pesquisa acadêmica}

Quanto ao tempo de experiência com pesquisa acadêmica, o Teste H de Kruskall-Wallis revelou que existe diferença significativa nos dois fatores relativos ao domínio de competências gerenciais - gestão de pessoas e de resultados de pesquisa $(\mathrm{H}(4)=9,04, \mathrm{p}<0,05)$ e captação de recursos e de pessoas $(\mathrm{H}(4)=9,37, \mathrm{p}<0,05)$ - e também no fator de resultados proximais de pesquisa $(\mathrm{H}(4)=8,02, \mathrm{p}<0,05)$.

Antes de apresentar e discutir esses resultados, vale destacar que se esperava que quanto maior fosse a idade dos líderes, maior seria a probabilidade de que tivessem maior experiência com pesquisa e, portanto, seriam maiores os seus resultados distais de repercussão externa, por 
serem mais reconhecidos nas respectivas áreas de atuação. Contudo, embora a faixa etária dos líderes interfira significativamente nos resultados distais de repercussão externa - a experiência com pesquisa não revelou resultados distais significativamente diferentes.

Quanto às competências gerenciais relativas à gestão de pessoas e de resultados da pesquisa (Figura 39), o gráfico de caixas e bigodes revelou que os líderes com 5 a 9 e com 10 a 29 anos de experiência possuem semelhantes medianas para o grau de domínio. Porém, há que se notar a diferença entre o domínio apresentado entre os líderes com 1 a 4 anos de experiência e aquele apresentado pelos líderes com mais de 30 anos de experiência com pesquisa.

Figura 39 - Gestão de Pessoas e de Resultados de Pesquisa versus Tempo de Experiência com pesquisa

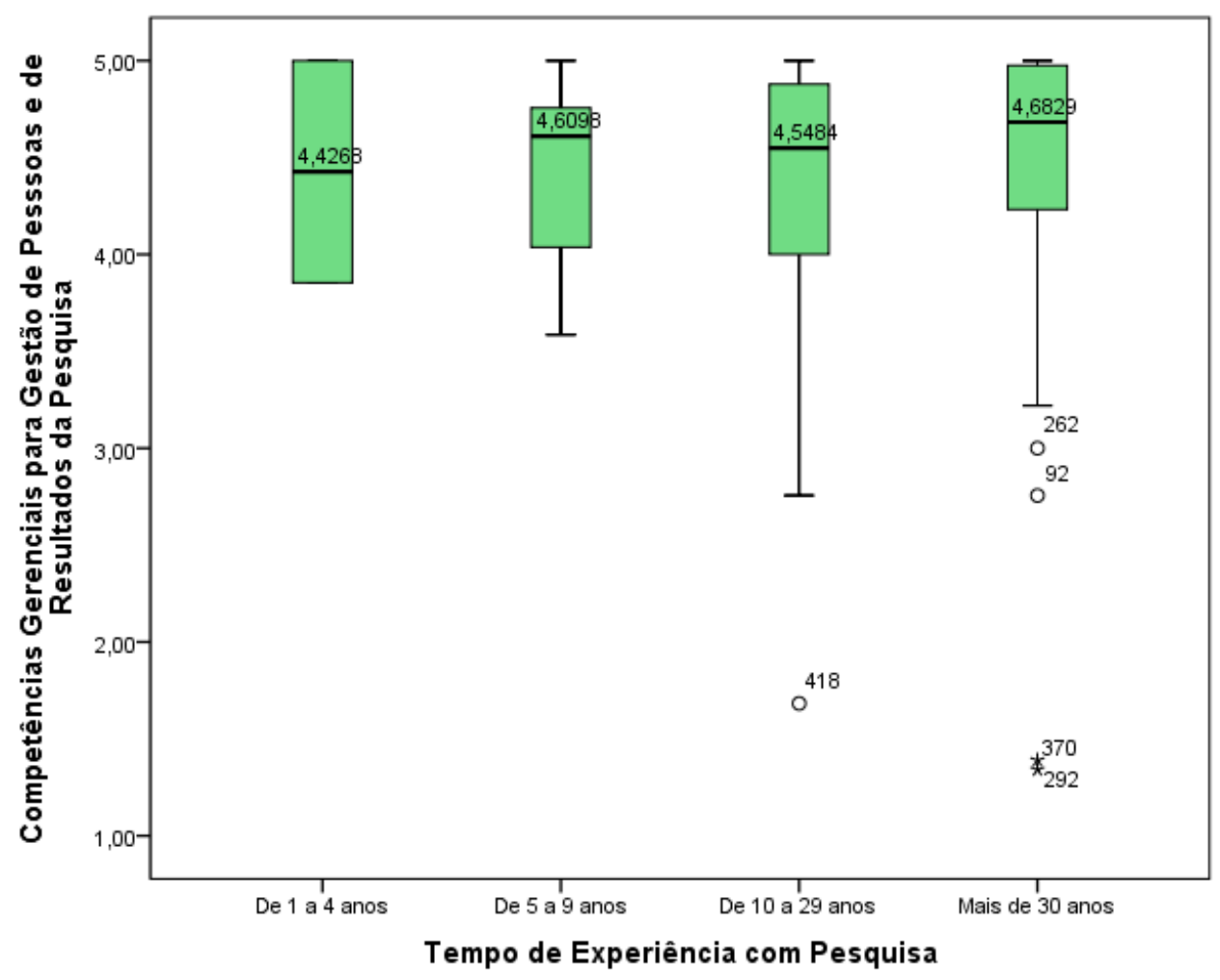

Fonte: Elaborada pelo autor com base em Dados da Pesquisa

Já para as competências gerencias relativas à captação de recursos e de pessoas (Figura 40) e para os resultados proximais do grupo (Figura 41), o gráfico de caixa e bigodes mostra que o domínio de competências e o alcance de resultados são superiores, quanto maior for a experiência do líder. 
Figura 40 - Captação de Recursos e de Pessoas versus Tempo de Experiência com pesquisa

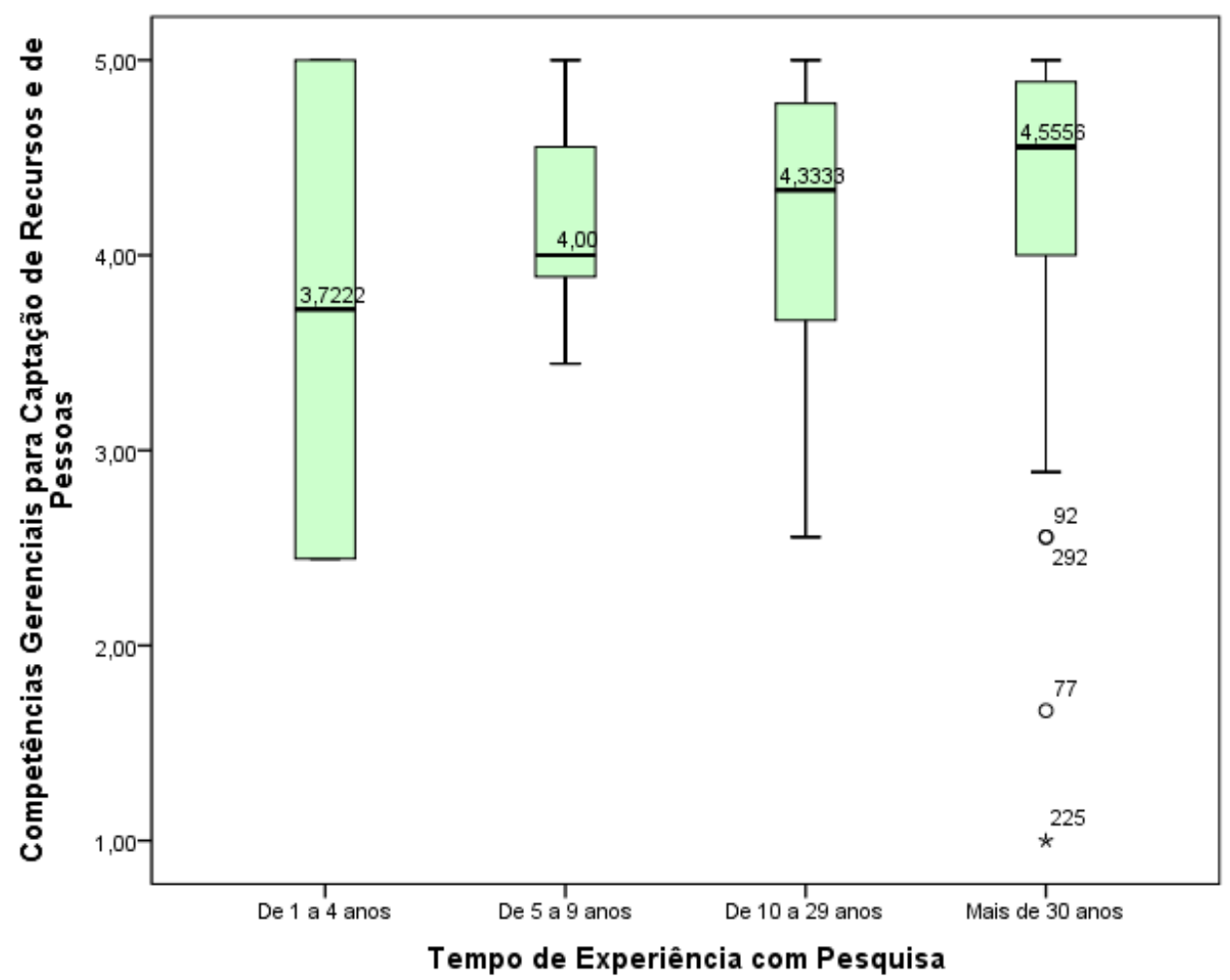

Fonte: Elaborada pelo autor com base em Dados da Pesquisa

Figura 41 - Resultados Proximais de Pesquisa versus Tempo de Experiência com pesquisa

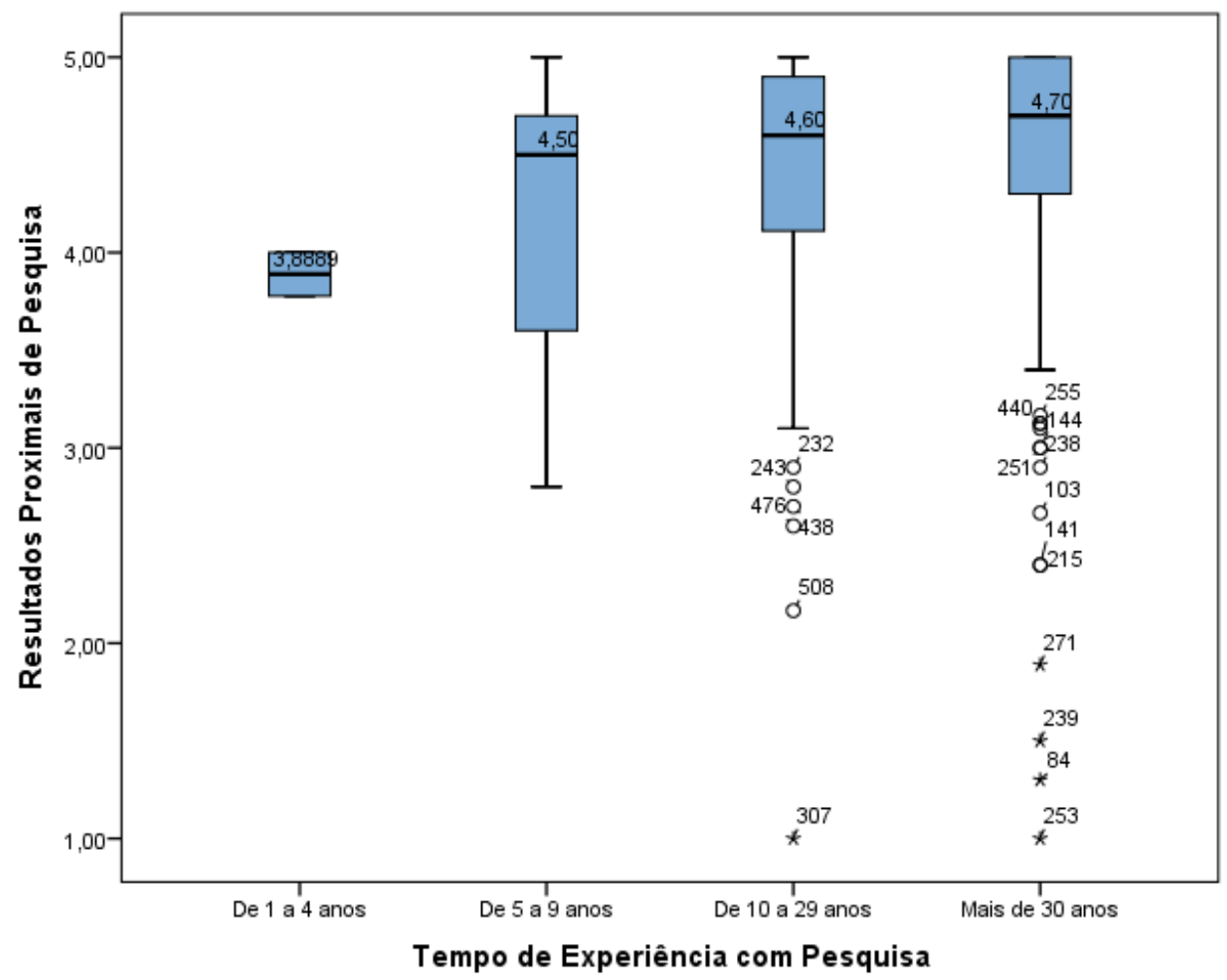

Fonte: Elaborada pelo autor com base em Dados da Pesquisa 
Por fim, destaca-se que o achado sobre a sensibilidade das competências gerenciais e de resultados proximais do grupo à variável sociodemográfica/funcional da experiência está compatível com as proposições de Odelius et al. (2010), segundo os quais o desempenho do grupo de pesquisa é afetado pela experiência técnica e científica do líder, já que esta interfere e rege as relações hierárquicas estabelecidas no grupo.

\subsubsection{Diferenças quanto ao Tempo de vínculo do Líder com o grupo atual}

O Teste $\mathrm{H}$ de Kruskall-Wallis apontou que líderes apresentaram diferentes graus de domínio de competências gerenciais para captação de recursos e de pessoas $(\mathrm{H}(4)=12,47$, p < $0,05)$ a depender do tempo de vínculo com o grupo de pesquisa atual.

Embora superiores a 4,0 independentemente do tempo de vínculo ao grupo, as diferenças entre as medianas estão ilustradas no diagrama de caixa e bigodes (Figura 42). Pela inspeção visual, a principal diferença parece estar entre o domínio de líderes com 1 a 4 anos de participação e com 5 a 9 anos de vínculo ao grupo. A partir dessa faixa de tempo, as medianas se mostram muito próximas, o que denota não haver considerável incremento no domínio com o passar do tempo de vínculo ao grupo. 
Figura 42 - Captação de Recursos e de Pessoas versus Tempo de participação no grupo atual

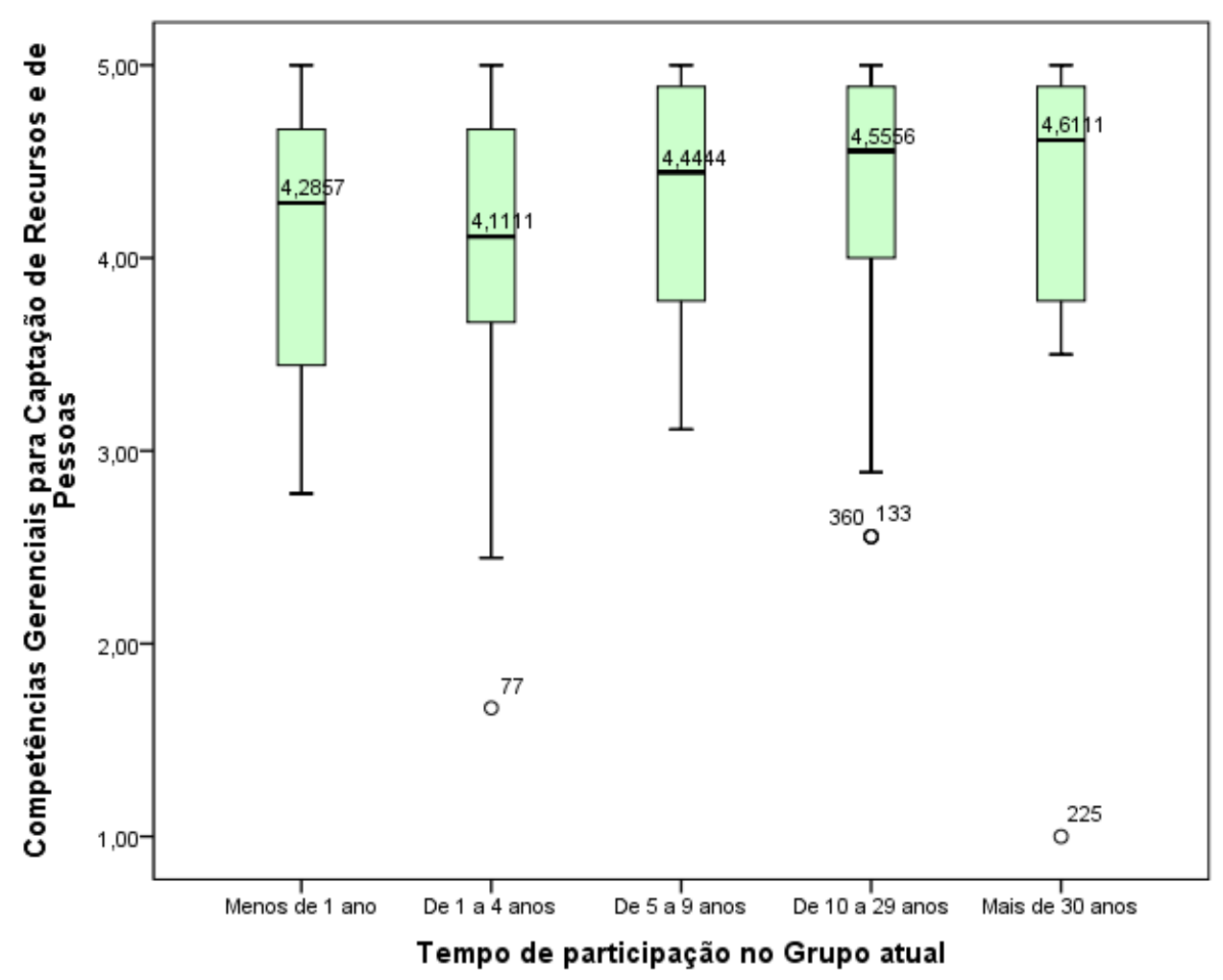

Fonte: Elaborada pelo autor com base em Dados da Pesquisa

Embora não se trate da mesma variável sociodemográfica/funcional, Mejía, Sánchez e Leza (2008) apontaram que, no contexto de uma agência de cooperação internacional de pesquisa, o tempo de existência do grupo influencia positivamente em seus resultados. Considerando que o grupo é formalizado com registro no $\mathrm{CNPq}$ e a respectiva investidura do líder e que casos de permuta ou sucessão de líderes são casos excepcionais, é possível inferir que o tempo de vínculo do líder ao grupo atual se assemelha ao tempo de existência do grupo, sendo possível afirmar que este achado de Mejía, Sánchez e Leza (2008) se assemelha ao exposto Dissertação.

Finalizada a exposição das diferenças entre grupos, a Tabela 27 resume os principais achados obtidos por meio dos Testes não-paramétricos U de Mann-Whitney e H de KruskallWallis. 
Tabela 27 - Resumo dos Achados nos Testes não-paramétricos

\begin{tabular}{|c|c|}
\hline Variável & Resumo dos Achados - Testes não-paramétricos \\
\hline $\begin{array}{l}\text { Grau de } \\
\text { domínio de } \\
\text { Competências } \\
\text { Gerenciais }\end{array}$ & $\begin{array}{l}\text { Os líderes que consideram dominar suficientemente as competências gerenciais afirmam } \\
\text { que seus grupos têm alcançado mais Resultados, quando comparados aos líderes que } \\
\text { afirmam possuir um domínio insuficiente dessas competências. }\end{array}$ \\
\hline $\begin{array}{l}\text { Nível de } \\
\text { concordância } \\
\text { com o alcance } \\
\text { de Resultados }\end{array}$ & $\begin{array}{l}\text { Os líderes que concordam que seus grupos têm alcançado Resultados afirmam possuir } \\
\text { maior grau de competências gerenciais, quando comparados aos líderes que discordam } \\
\text { de que seus grupos tenham alcançado Resultados. }\end{array}$ \\
\hline Sexo do Líder & $\begin{array}{l}\text { Mulheres consideram dominar mais a Gestão de Pessoas e de Resultados de Pesquisa, } \\
\text { quando comparadas aos homens. }\end{array}$ \\
\hline Pós-doutorado & $\begin{array}{l}\text { Líderes com pós-doutorado consideram dominar mais as competências gerenciais, tanto } \\
\text { de Gestão de Pessoas e de Resultados de Pesquisa quanto de Captação de Recursos e de } \\
\text { Pessoas }\end{array}$ \\
\hline $\begin{array}{l}\text { Recebimento de } \\
\text { bolsa de } \\
\text { Produtividade } \\
\text { CNPq }\end{array}$ & $\begin{array}{l}\text { Líderes que contam com bolsa de produtividade do CNPq consideram dominar mais a } \\
\text { Captação de Recursos e de Pessoas. Além disso, afirmam que seus grupos possuem } \\
\text { maior incidência de Resultados Distais de Repercussão Externa, Resultados Proximais } \\
\text { de Pesquisa, e Resultados Tangíveis de Pesquisa }\end{array}$ \\
\hline $\begin{array}{l}\text { Tipo de bolsa de } \\
\text { Produtividade } \\
\text { CNPq }\end{array}$ & $\begin{array}{l}\text { Os Líderes consideram dominar mais as competências gerenciais, tanto de Gestão de } \\
\text { Pessoas e de Resultados de Pesquisa quanto de Captação de Recursos e de Pessoas, à } \\
\text { medida que contam com bolsas de produtividade do CNPq de maior valor. Exceto para } \\
\text { líderes que recebem bolsa do Tipo } 1 \mathrm{~B} \text {, que indicaram possuir menor domínio que os } \\
\text { líderes que recebem bolsa do Tipo 1C. }\end{array}$ \\
\hline $\begin{array}{l}\text { Grandes áreas } \\
\text { do } \\
\text { Conhecimento }\end{array}$ & $\begin{array}{l}\text { O maior domínio da Gestão de Pessoas e de Resultados de Pesquisa foi indicado por } \\
\text { líderes das Ciências Humanas, e o menor, das Ciências Sociais Aplicadas. } \\
\text { O maior domínio da Captação de Recursos e de Pessoas foi indicado por líderes das } \\
\text { Ciências da Saúde e Ciências Agrárias, e o menor, das Ciências Sociais Aplicadas. } \\
\text { A maior incidência de Resultados Distais de Repercussão Externa foi apontada por } \\
\text { líderes das Ciências Humanas, e a menor, das Ciências Sociais Aplicadas. } \\
\text { A maior incidência de Resultados Tangíveis de Pesquisa foi apontada por líderes das } \\
\text { Ciências Agrárias e Ciências Exatas e da Terra, e a menor, da Linguística, Letras e Artes. }\end{array}$ \\
\hline Faixa etária & $\begin{array}{l}\text { Em geral, líderes com mais idade consideram que seus grupos obtêm mais Resultados } \\
\text { de Repercussão Externa }\end{array}$ \\
\hline $\begin{array}{l}\text { Experiência } \\
\text { com Pesquisa } \\
\text { Acadêmica }\end{array}$ & $\begin{array}{l}\text { Líderes com mais de } 30 \text { anos de experiência consideram dominar mais a Gestão de } \\
\text { Pessoas e de Resultados de Pesquisa do que os que possuem } 1 \text { a } 4 \text { anos de experiência. } \\
\text { Quanto maior a experiência do líder, maior é a autopercepção quanto ao domínio da } \\
\text { Captação de Recursos e de Pessoas e maior a incidência dos Resultados Proximais de } \\
\text { Pesquisa no grupo. }\end{array}$ \\
\hline $\begin{array}{l}\text { Tempo de } \\
\text { vínculo ao } \\
\text { grupo atual }\end{array}$ & $\begin{array}{l}\text { Líderes consideram dominar mais a Captação de Recursos e de Pessoas, à medida que } \\
\text { aumenta o seu tempo de vínculo ao grupo. Exceto para líderes que possuem } 1 \text { a } 4 \text { anos } \\
\text { de vínculo, os quais consideram possuir menor domínio que os líderes com menos de } 1 \\
\text { ano de vínculo. }\end{array}$ \\
\hline $\begin{array}{l}\text { Unidade da } \\
\text { Federação }\end{array}$ & Não apresentou diferenças estatisticamente significativas \\
\hline Região & Não apresentou diferenças estatisticamente significativas \\
\hline
\end{tabular}

Fonte: Elaborada pelo autor com base em dados da pesquisa

\subsection{Análise de Correlação de Kendall-Tau}

Esta seção se destina a identificar as relações existentes entre competências gerenciais e aspectos que evidenciam resultados de grupos de pesquisa brasileiros. Os coeficientes de correlação encontrados indicam o grau de associação entre as variáveis e, quando se eleva o 
coeficiente de correlação ao quadrado, tem-se como resultado o coeficiente de determinação $\left(\mathrm{R}^{2}\right)$, que representa o percentual do quanto a variância de uma variável é explicada por outra. Mas, vale o alerta: os coeficientes de correlação e de determinação não são suficientes para medir o quanto uma variável causa a outra, ou seja, não explicitam relações de causalidade (FIELD, 2009).

Como todas as variáveis eram desprovidas de normalidade, poderiam ser aplicados os coeficientes de correlação de Spearman ou de Kendall-Tau, ambos apropriados para distribuições não-paramétricas. Contudo, embora o coeficiente de Spearman seja mais popular e a amostra não seja inexpressiva, o coeficiente de correlação de Kendall-Tau é preferível, já que há grande quantidade de postos empatados (FIELD, 2009), pois as escalas usadas (Tipo Likert para competências gerenciais e Likert para resultados), embora teoricamente contínuas, estavam ancoradas em cinco pontos. Outrossim, Howell (2012) considera o coeficiente Kendall-Tau como mais representativo da população, podendo-se estabelecer generalizações mais precisas (FIELD, 2009).

As seções seguintes se dedicam a explicitar os coeficientes de correlação $(\tau)$ e de determinação $\left(\mathrm{R}^{2}\right)$, para assim ser possível o atingimento do sexto objetivo específico.

\subsubsection{Correlações entre Competências Gerenciais e Resultados}

A Tabela 28 resume os resultados da análise de correlação entre as cinco principais variáveis deste estudo: Competências Gerenciais para Gestão de Pessoas e de Resultados da Pesquisa; Competências Gerenciais para Captação de Recursos e de Pessoas; Resultados Distais de Repercussão Externa; Resultados Proximais de Pesquisa; e Resultados Tangíveis de Pesquisa. 


\begin{tabular}{|c|c|c|c|c|c|c|}
\hline & & 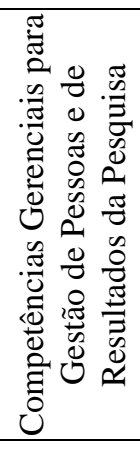 & 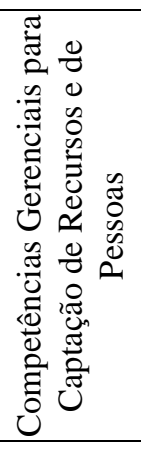 & 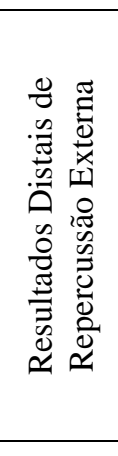 & 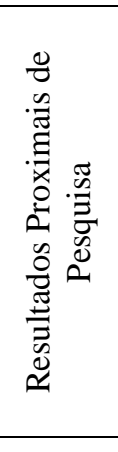 & 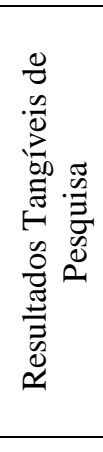 \\
\hline \multirow{2}{*}{$\begin{array}{l}\text { Competências Gerenciais para } \\
\text { Gestão de Pessoas e de Resultados } \\
\text { da Pesquisa }\end{array}$} & $\begin{array}{l}\text { Coeficiente de Correlação - } \\
\text { Kendall-Tau } \\
\text { Sig. (2-tailed) }\end{array}$ & 1,000 & & & & \\
\hline & $\mathrm{N}$ & 372 & & & & \\
\hline \multirow[t]{2}{*}{$\begin{array}{l}\text { Competências Gerenciais para } \\
\text { Captação de Recursos e de Pessoas }\end{array}$} & $\begin{array}{l}\text { Coeficiente de Correlação - } \\
\text { Kendall-Tau } \\
\text { Sig. (2-tailed) }\end{array}$ & $\begin{array}{l}, 661^{* *} \\
, 000\end{array}$ & 1,000 & & & \\
\hline & $\mathrm{N}$ & 372 & 373 & & & \\
\hline \multirow[t]{2}{*}{$\begin{array}{l}\text { Resultados Distais de Repercussão } \\
\text { Externa }\end{array}$} & $\begin{array}{l}\text { Coeficiente de Correlação - } \\
\text { Kendall-Tau } \\
\text { Sig. (2-tailed) }\end{array}$ &, $287^{* *}$ & $\begin{array}{l}, 369^{* *} \\
, 000\end{array}$ & 1,000 & & \\
\hline & $\mathrm{N}$ & 371 & 372 & 373 & & \\
\hline \multirow{3}{*}{ Resultados Proximais de Pesquisa } & $\begin{array}{l}\text { Coeficiente de Correlação - } \\
\text { Kendall-Tau }\end{array}$ &, $305^{* *}$ &, $332^{* *}$ &, $547^{* *}$ & 1,000 & \\
\hline & Sig. (2-tailed) &, 000 & ,000 &, 000 & & \\
\hline & $\mathrm{N}$ & 371 & 372 & 372 & 373 & \\
\hline \multirow{3}{*}{ Resultados Tangíveis de Pesquisa } & $\begin{array}{l}\text { Coeficiente de Correlação - } \\
\text { Kendall-Tau }\end{array}$ &, $241^{* *}$ &, $321^{* *}$ &, $501^{* *}$ &, $491^{* *}$ & 1,000 \\
\hline & Sig. (2-tailed) & ,000 &, 000 & ,000 &, 000 & \\
\hline & $\mathrm{N}$ & 368 & 369 & 370 & 369 & 370 \\
\hline
\end{tabular}

Fonte: Elaborada pelo autor com base em Dados da Pesquisa

Analisando a Tabela 28, verifica-se que as variáveis pertencentes à mesma escala possuem maiores coeficientes de correlação. O maior deles se dá entre as variáveis de competências: Gestão de Pessoas e de Resultados da Pesquisa e Captação de Recursos e de Pessoas e Competências Gerenciais. A associação entre elas é positiva $(\tau=0,661, p<0,01)$ e configura um coeficiente de determinação $\mathrm{R}^{2}=0,437$, que indica que 43,7\% de uma variável é explicada pela outra. Essa correlação é atestada também teoricamente, uma vez que HiguitaLópez, Molano-Velandia e Rodríguez-Merchán (2011) consideram que as atividades de gestão de pessoas e de resultados estão ligadas ao suprimento de recursos e equipamentos específicos para o trabalho.

O segundo maior coeficiente de correlação ocorre entre Resultados Proximais de Pesquisa e Resultados Distais de Repercussão Externa, que apresentam associação positiva ( $\tau$ 
$=0,547, \mathrm{p}<0,01)$ e configura um coeficiente de determinação $\mathrm{R}^{2}=0,299$, que indica que $29,9 \%$ de uma variável é explicada pela outra. A esse respeito, a própria inspiração para os nomes dos fatores já predispõe essa correlação. Em simples palavras, resultados distais de repercussão externa, tais como a formação e a mobilização de redes de relacionamentos (HARVEY; PETTIGREW; FERLIE, 2002) dependem do impacto provocado pelos resultados proximais, tais como o estabelecimento de parcerias com grupos e pesquisadores, ou o avanço nos conhecimentos relativos ao campo de pesquisa. De qualquer forma, estudos futuros poderiam testar se Resultados Proximais de pesquisa são, de fato, antecedentes dos Distais de Repercussão Externa.

O terceiro maior coeficiente de correlação ocorre entre Resultados Tangíveis de Pesquisa e Resultados Distais de Repercussão Externa, que apresentam associação positiva ( $\tau$ $=0,501, \mathrm{p}<0,01)$ e configura um coeficiente de determinação $\mathrm{R}^{2}=0,251$, que indica que $25,1 \%$ de uma variável é explicada pela outra. Logo em seguida aparece a correlação entre Resultados Tangíveis e Proximais de Pesquisa, que apresentam associação positiva $(\tau=0,491, \mathrm{p}<0,01)$ e configura um coeficiente de determinação $\mathrm{R}^{2}=0,241$, que indica que $24,1 \%$ de uma variável é explicada pela outra. Essa relação é esperada uma vez que a obtenção de resultados tangíveis somente é possível a partir do momento em que foi desenvolvido conhecimento a respeito do tema/fenômeno, ou seja, para fazer a aplicação prática de um conhecimento é necessário que o conhecimento tenha sido desenvolvido. Vale informar, porém, que há estudo anterior que não encontrou relação entre item que compõe os resultados proximais de pesquisa (publicação em periódico) e o desenvolvimento de novas tecnologias (Mendes, Caliari e Santos, 2014).

Com coeficientes menos expressivos, e ainda em ordem decrescente, a maior correlação entre fatores de diferentes escalas é a correlação positiva existente entre Competências Gerenciais para Captação de Recursos e de Pessoas e Resultados Distais de Repercussão Externa $(\tau=0,369, \mathrm{p}<0,01)$ e configura um coeficiente de determinação $\mathrm{R}^{2}=0,136$, que indica que $13,6 \%$ de uma variável é explicada pela outra.

Não poderia ser diferente. De fato, a correlação entre essas duas variáveis latentes é nítida e de fácil compreensão. Odelius e Sena (2009) e Odelius et al. (2011) evidenciam essa relação ao explicitarem o desafio experimentado por grupos de pesquisa quanto à manutenção de redes de pesquisas interinstitucionais e internacionais (que são resultados de repercussão externa) por conta do déficit de competências gerenciais equivalentes a "obter financiamento para as pesquisas de agências externas de fomento" ou "Estabelecer parcerias com outros pesquisadores ou grupos de pesquisa", que relativas à captação de recursos e de pessoas. 
Araujo et al. (2015) também atestam essa correlação ao afirmarem que competências equivalentes a "Estabelecer parcerias com empresas do setor produtivo" (que são competências de captação de recursos) proporcionam resultados como "Reconhecimento de membros do grupo como referências acadêmicas ou profissionais" (resultado distal de repercussão externa).

Relate-se ainda a correlação entre Competências Gerenciais para Captação de Recursos e de Pessoas e Resultados Proximais de Pesquisa $(\tau=0,332$, $p<0,01)$ configura um coeficiente de determinação $\mathrm{R}^{2}=0,110$, que indica que $11 \%$ de uma variável é explicada pela outra. Resultados proximais como a formação das pessoas e a conclusão de trabalhos acadêmicos são exemplos trazidos por Araujo et al. (2015) como aspectos decorrentes do estabelecimento de parcerias com empresas do setor produtivo, que é uma competência de captação de recursos.

Destaque-se também a correlação entre Competências Gerenciais para Captação de Recursos e de Pessoas e Resultados Tangíveis de Pesquisa $(\tau=0,321, \mathrm{p}<0,01)$, que enseja um coeficiente de determinação $\mathrm{R}^{2}=0,103$, que indica que $10,3 \%$ de uma variável é explicada pela outra. São exemplos dessa correlação os estudos de Garcia et al (2015), Mendes, Caliari e Santos (2014); Lach e Schankerman (2008) e também de Araujo et al. (2015). Para esses autores, as competências voltadas ao estabelecimento de parcerias com o setor produtivo, chamadas também de interações universidade-empresa, geram novas tecnologias, mantém ou incrementam o potencial inovativo e geram resultados softwares, produtos, artefatos, patentes, design, criação de novas empresas, processos e produtos industriais, que podem ser considerados resultados tangíveis de pesquisa.

E, por fim, as três corrrelações menos expressivas foram 1) entre Competências Gerenciais para Gestão de Pessoas e de Resultados da Pesquisa e Resultados Proximais de Pesquisa $(\tau=0,305, p<0,01)$, com um coeficiente de determinação $R^{2}=0,093$, que indica que 9,3\% de uma variável é explicada pela outra; 2) entre Competências Gerenciais para Gestão de Pessoas e de Resultados da Pesquisa e Resultados Distais de Repercussão Externa ( $\tau=0,287$, $p<0,01)$, com um coeficiente de determinação $R^{2}=0,082$, que indica que $8,2 \%$ de uma variável é explicada pela outra; e entre Competências Gerenciais para Gestão de Pessoas e de Resultados da Pesquisa e Resultados Tangíveis de Pesquisa ( $\tau=0,241$, p $<0,01$ ), com um coeficiente de determinação $\mathrm{R}^{2}=0,058$, que indica que apenas $5,8 \%$ de uma variável é explicada pela outra.

A Figura 43 ilustra essas correlações, enunciando a força das correlações, por meio da expessura das setas duplas que ligam as variáveis; e também por meio dos coeficientes de correlação $(\tau)$ e de determinação $(\mathrm{R} 2)$ respectivos. 
Figura 43 - Correlações entre as cinco variáveis de competências gerenciais e resultados

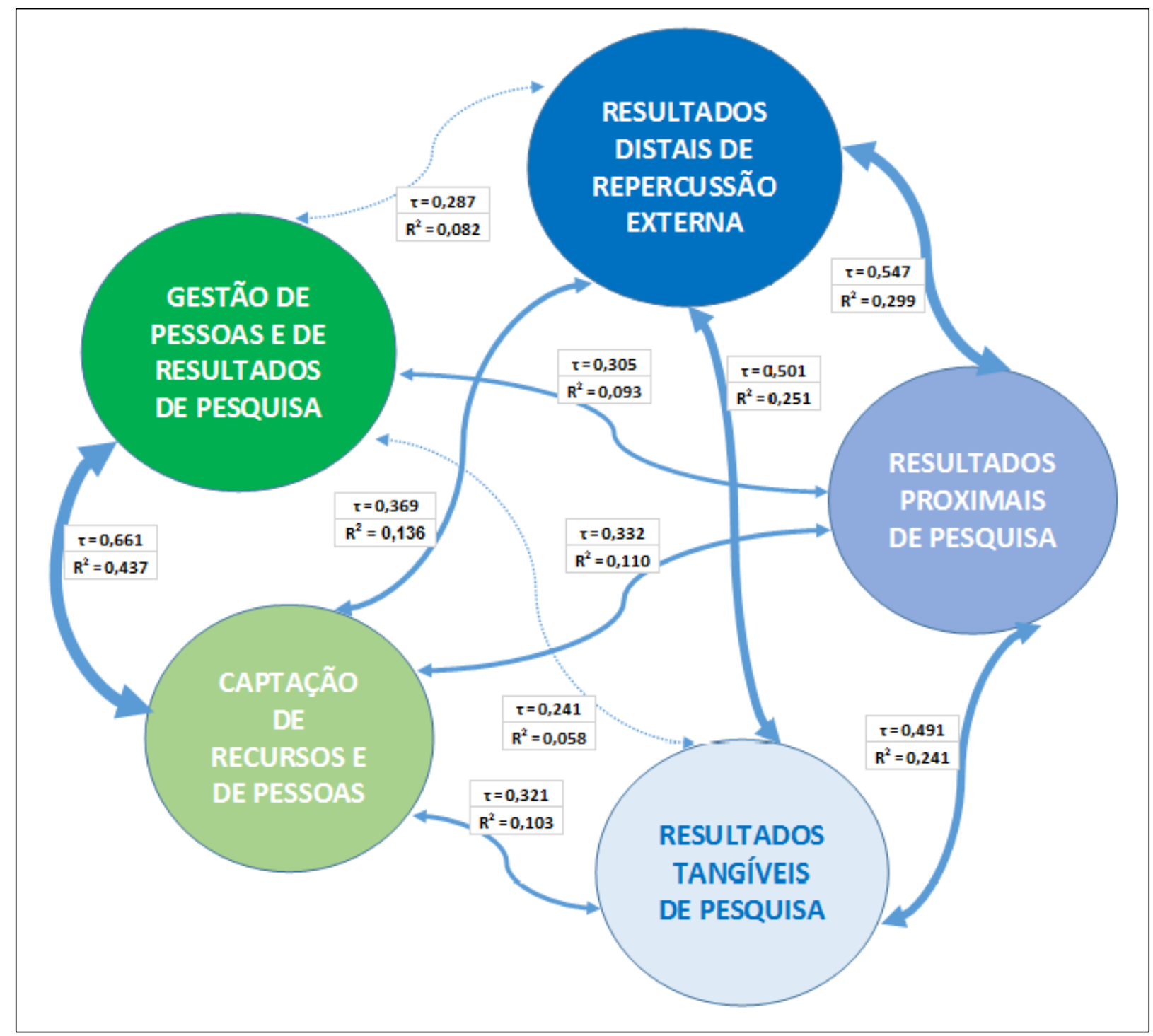

Fonte: Elaborada pelo autor com base em Dados da Pesquisa

\subsubsection{Correlações entre Competências Gerenciais e Variáveis sociodemográficas/funcionais}

Inicialmente, analisaram-se as variáveis sociodemográficas e funcionais correlacionadas com as Competências Gerenciais para Gestão de Pessoas e de Resultados da Pesquisa. A análise apontou que há correlação bivariada positiva dessa competência com a idade do líder ( $\tau=0,109, \mathrm{p}<0,05, \mathrm{R}^{2}=0,0061$ e $0,61 \%$ da variância explicada); com o sexo do líder ( $\tau=0,115, \mathrm{p}<0,05, \mathrm{R}^{2}=0,0133$ e 1,33\% da variância explicada); com o tempo de experiência do líder com pesquisa acadêmica $\left(\tau=0,078, \mathrm{p}<0,05, \mathrm{R}^{2}=0,0118\right.$ e $1,18 \%$ da variância explicada); com o tempo de vínculo do líder ao grupo atual e com a realização ou não 
de pós-doutorado, ambos com $\tau=0,101, \mathrm{p}<0,05, \mathrm{R}^{2}=0,0101$ e 1,01\% da variância explicada. As demais variáveis sociodemográficas/funcionais não apresentaram correlações estatisticamente significantes.

Por fim, verificaram-se as correlações significativas no que tange às Competências Gerenciais para Captação de Recursos e de Pessoas. As variáveis sociodemograficas e funcionais significativamente correlacionadas foram as mesmas, exceto o sexo do líder, porém, houve magnitudes diferentes. A análise apontou que há correlação bivariada positiva dessa competência com a idade do líder $\left(\tau=0,100, \mathrm{p}<0,05, \mathrm{R}^{2}=0,0101\right.$ e $1,01 \%$ da variância explicada); com o tempo de experiência do líder com pesquisa acadêmica $(\tau=0,119, p<0,05$, $\mathrm{R}^{2}=0,0143$ e $1,43 \%$ da variância explicada); com o tempo de vínculo do líder ao grupo atual ( $\tau=0,136, p<0,05, R^{2}=0,0186$ e 1,86\% da variância explicada); e com a realização ou não de pós-doutorado $\left(\tau=0,144, \mathrm{p}<0,05, \mathrm{R}^{2}=0,0206\right.$ e 2,06\% da variância explicada).

A Figura 44 resume as variáveis sociodemográficas/funcionais correlacionadas com as relativas às competências gerenciais. As variáveis em caixas na cor branca não apresentaram correlações significativas. 
Figura 44 - Resumo das correlações mais significativas entre Competências Gerenciais e Variáveis Sociodemográficas/funcionais

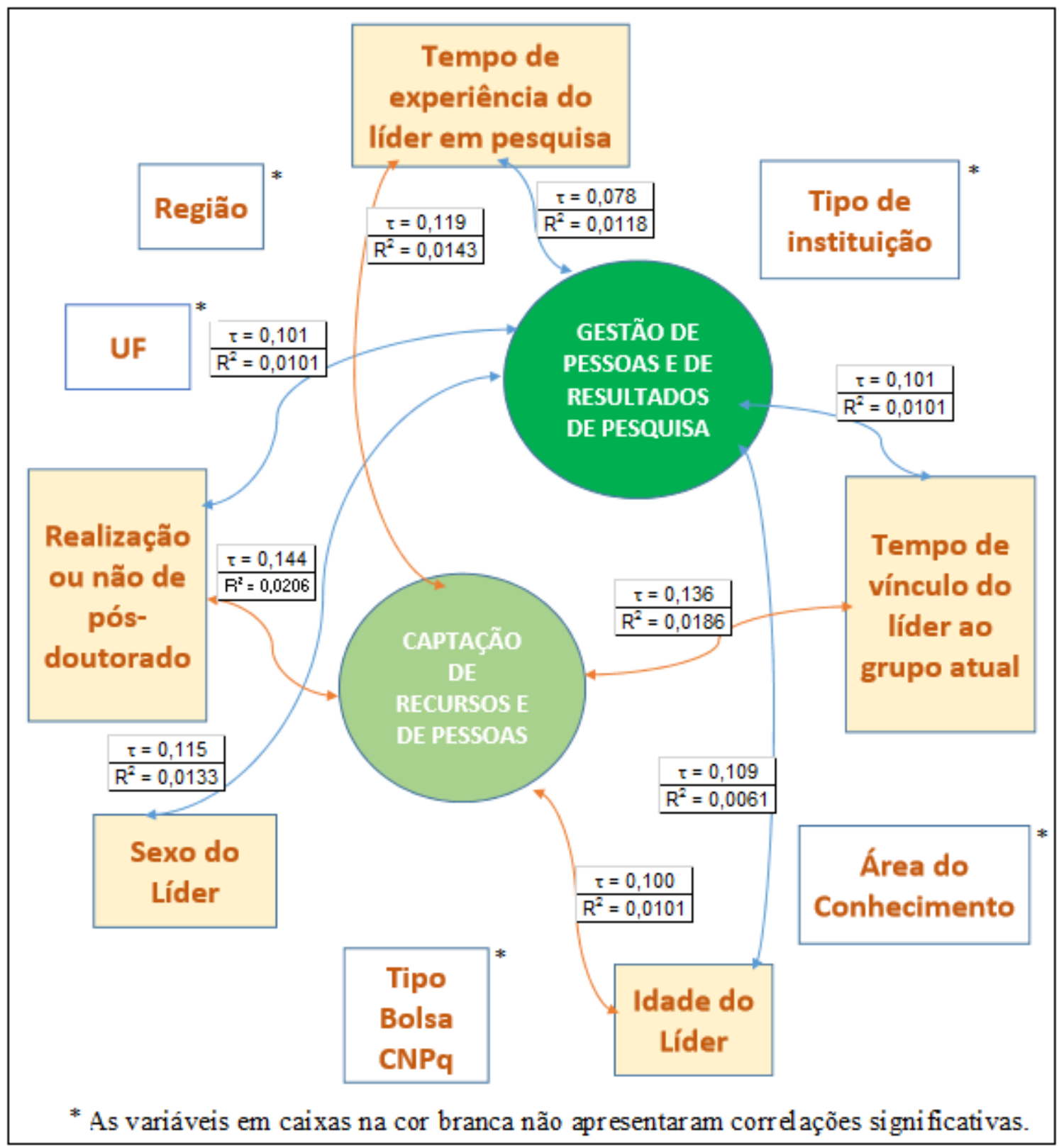

Fonte: Elaborada pelo autor com base em Dados da Pesquisa

\subsubsection{Correlações entre Resultados e Variáveis sociodemográficas e funcionais}

Inicialmente, verificaram-se as variáveis sociodemográficas e funcionais correlacionadas com os Resultados Distais de Repercussão Externa. A análise apontou que há correlação bivariada positiva desse fator com a idade do líder $\left(\tau=0,088, p<0,05, R^{2}=0,0078\right.$ e $0,78 \%$ da variância explicada); com o tempo de experiência do líder com pesquisa acadêmica ( $\tau=0,130, p<0,05, R^{2}=0,0168$ e $1,68 \%$ da variância explicada); com a realização ou não de 
pós-doutorado por parte do líder $\left(\tau=0,077, \mathrm{p}<0,05, \mathrm{R}^{2}=0,006\right.$ e $0,6 \%$ da variância explicada); e correlação negativa com o tipo de instituição a que o grupo está vinculado $(\tau=-0,081, \mathrm{p}<$ $0,05, \mathrm{R}^{2}=0,0066$ e $0,66 \%$ da variância explicada).

Já com relação aos Resultados Proximais de Pesquisa, as variáveis sociodemográficas/funcionais estatisticamente significantes foram: o sexo do líder $(\tau=0,076 \mathrm{p}$ $<0,05, \mathrm{R}^{2}=0,0058$ e $0,58 \%$ da variância explicada); o tempo de experiência do líder com pesquisa acadêmica $\left(\tau=0,084, \mathrm{p}<0,05, \mathrm{R}^{2}=0,0071\right.$ e $0,71 \%$ da variância explicada); a realização ou não de pós-doutorado $\left(\tau=0,083, \mathrm{p}<0,05, \mathrm{R}^{2}=0,0068\right.$ e $0,68 \%$ da variância explicada), todas positivas; e correlação negativa com o tipo de instituição a que o grupo está vinculado ( $\tau=-0,097, \mathrm{p}<0,05, \mathrm{R}^{2}=0,0094$ e 0,94\% da variância explicada).

Por fim, as correlações significativas, no que se refere aos Resultados Tangíveis de Pesquisa e as variáveis sociodemograficas/funcionais, foram o tempo de experiência do líder com pesquisa acadêmica ( $\tau=0,065, \mathrm{p}<0,05, \mathrm{R}^{2}=0,0043$ e $0,43 \%$ da variância explicada); a realização ou não de pós-doutorado $\left(\tau=0,086, \mathrm{p}<0,05, \mathrm{R}^{2}=0,0073\right.$ e $0,73 \%$ da variância explicada); o tipo de bolsa de produtividade do CNPq recebido ou o fato de não recebê-la $(\tau=$ $0,076 \mathrm{p}<0,05, \mathrm{R}^{2}=0,0058$ e 0,58\% da variância explicada), todas correlações positivas; e as negativas: tipo de instituição a que o grupo está vinculado $\left(\tau=-0,096, \mathrm{p}<0,05, \mathrm{R}^{2}=0,0092\right.$ e $0,92 \%$ da variância explicada) e a grande área do conhecimento a que pertence o grupo $(\tau=-$ $0,106, \mathrm{p}<0,05, \mathrm{R}^{2}=0,0113$ e $1,13 \%$ da variância explicada).

A Figura 45 ilustra as associações entre as variáveis sociodemográficas/funcionais e os resultados alcançados por grupos de pesquisa. Da mesma forma, as variáveis em caixas na cor branca não apresentaram correlações significativas. 
Figura 45 - Resumo das correlações mais significativas entre Resultados e Variáveis Sociodemográficas/funcionais

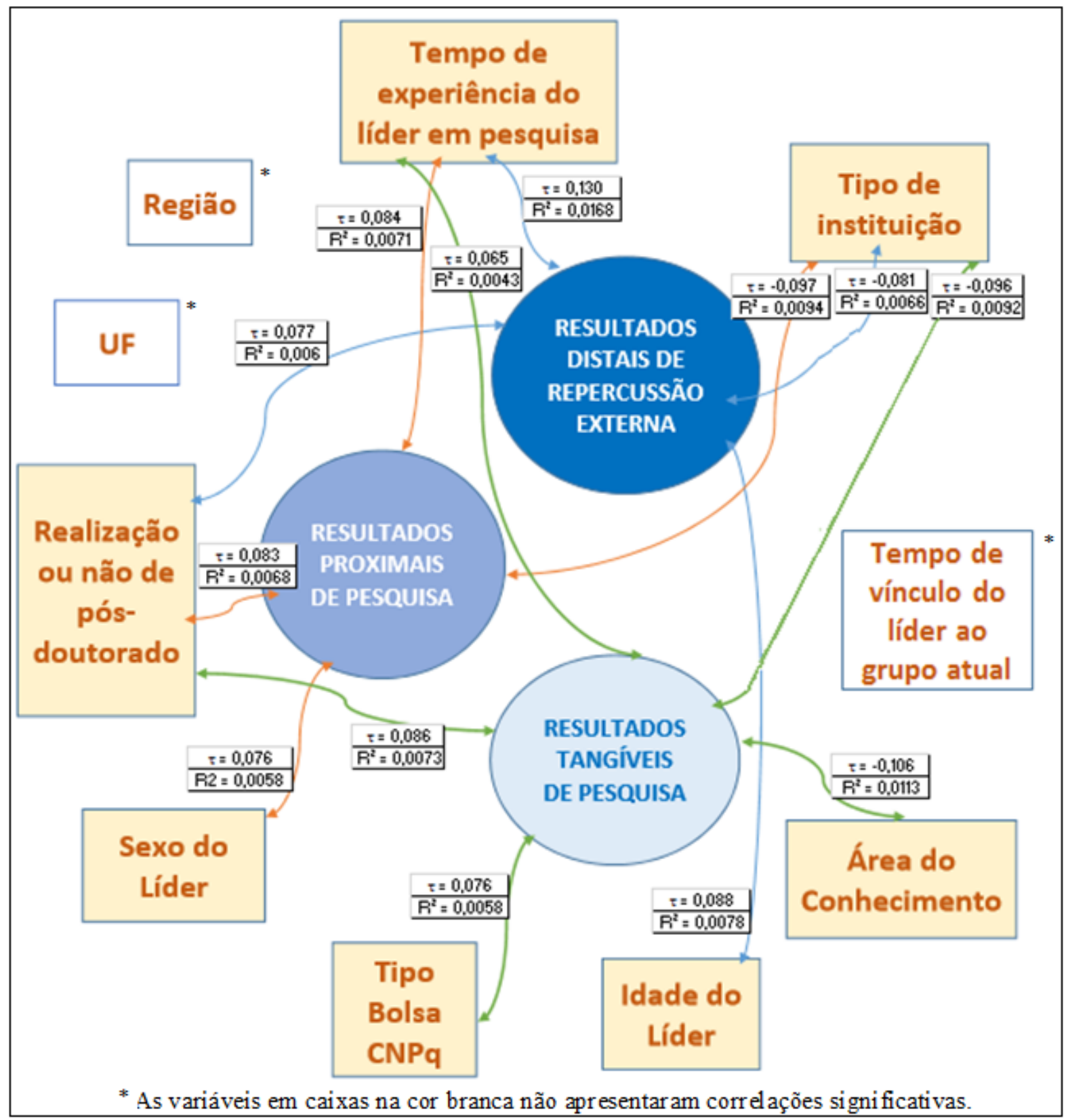

Fonte: Elaborada pelo autor com base em Dados da Pesquisa

As correlações entre variáveis ordinais ou contínuas variam de -1 a +1 . Quando negativas, interpreta-se que à medida que uma variável cresce a outra decresce. Contudo, os coeficientes negativos obtidos nas análises apresentadas nesta seção referiam-se a variáveis categóricas (Tipo de Instituição de Ensino ou Pesquisa a que o grupo está vinculado e Grande área do conhecimento). Neste caso, não faz sentido a sua interpretação, mas, deve-se considerar ao menos a magnitude da associação (FIELD, 2009). 
Vale tmbém destacar que as variáveis idade, experiência e tempo de vínculo ao grupo podem ser variáveis reciprocamente relacionadas, com interferências tanto para as competências gerenciais quanto para os resultados em grupos de pesquisa. Uma possibilidade sugerida seria que estudos futuros realizassem a análise de regressão, utilizando apenas uma dessas variáveis como proxy das demais, pois é possível que a idade influencie na experiência e no tempo de vínculo ao grupo. 


\section{CONCLUSÃO}

Além de fazer frente às justificativas acadêmicas, sociais e institucionais elencadas no capítulo introdutório, o desenvolvimento da presente pesquisa proporcionou a exploração das agendas de pesquisas apontadas por pesquisadores que estudam os fenômenos Competências Gerenciais e Resultados no contexto de Grupos de pesquisa como locus investigativo.

Por meio da revisão bibliográfica, que analisou estudos publicados entre 2005 a 2015, e da Pesquisa documental, que considerou relatórios publicados em sites da CAPES, do CNPq e da Plataforma Lattes, bem como relatórios e instrumentos para coleta de dados utilizados em pesquisas anteriores do Grupo de pesquisa ‘Inovação e Aprendizagem em Organizações’, foram identificados os comportamentos que demonstram o domínio de competências gerenciais em grupos de pesquisa e os aspectos que evidenciam resultados de grupos de pesquisa.

Mediante a Análise Fatorial exploratória, foram apresentados indícios de validade de duas escalas: uma de competências gerenciais $(51,1 \%$ de variância explicada) - que é constituída dos fatores Gestão de Pessoas e de Resultados de Pesquisa e Captação de Recursos e de Pessoas - e outra de aspectos que evidenciam resultados de grupos de pesquisa $(51,9 \%$ de variância explicada) - que inclui os fatores: Resultados Distais de Repercussão Externa, Resultados Proximais de Pesquisa e Resultados Tangíveis de Pesquisa. Considera-se, portanto, que ambos instrumentos constituem bons parâmetros estatísticos, uma vez que dão conta de explicar a maior parte da variância do construto. De toda sorte, as escalas podem ser aprimoradas em estudos posteriores, seja por meio da majoração das magnitudes das cargas fatoriais seja pela replicação ou adaptação dos itens em outros loci de pesquisa.

Com a aplicação de Testes não-paramétricos (U de Mann-Whitney e H de KruskallWallis), mostraram-se estatisticamente significativas, as diferenças encontradas nas competências gerenciais ou nos resultados em grupos de pesquisa, com relação às variáveis: sexo, idade, experiência com pesquisa, tempo de vínculo do líder ao grupo, bolsa de produtividade do $\mathrm{CNPq}$, realização de pós-doutorado pelo líder, grande área do conhecimento (dados sociodemográficos e funcionais); e também com relação ao grau de domínio de competências gerenciais e ao nível de concordância com o alcance de resultados pelo grupo (variáveis recodificadas como dicotômicas).

Por fim, a análise de Correlação de Kendall-Tau foi utilizada para identificar as associações havidas entre competências gerenciais e aspectos que evidenciam resultados de grupos de pesquisa brasileiros, bem como entre essas e as variáveis sociodemográficas e 
funcionais. A associação entre os fatores relativos a competências gerenciais indica que 43,7\% de uma variável é explicada pela outra e, entre os resultados, esses valores variam entre $24,1 \%$ e 29,9\%. Já a associação entre a competência de 'Captação de recursos e de pessoas' e resultados do grupo de pequisa, variou entre 10,3\% e 13,6\%. Para a associação entre competência de 'Gestão de Pessoas e de Resultados de Pesquisa' e resultados, os valores foram entre $5,8 \%$ e $9,3 \%$.

Já a relação entre competências e resultados do grupo com as variáveis sociodemográficas funcionais, as associações encontradas, apesar de significativas estatísticamente, foram bastante baixas, ficando entre $0,43 \%$ e $2,6 \%$.

Destarte, entende-se que foram cumpridos os seis objetivos específicos e, por consequência, chegou-se à consecução do objetivo geral traçado: identificar as relações entre competências gerenciais de líderes e resultados de grupos de pesquisa brasileiros. Com efeito, as discussões e a análise de dados realizada no âmbito desta Dissertação acrescentam ao debate científico, contribuindo para refinamento teórico e empírico do campo.

Além da apresentação e discussão dos resultados constantes do quarto capítulo, a experiência proporcionada por esta pesquisa permite que limitações do campo ou do método sejam explicitadas; e que algumas recomendações práticas sejam elencadas, de modo a se consolidar uma agenda para pesquisas futuras.

Quanto às limitações, destaca-se, inicialmente, a composição da amostra. Sabe-se que a coleta por acessibilidade combinada com a estratégia da "bola-de-neve", não é a melhor estratégia metodológica, quando se pretende generalizar os resultados para a população. Contudo, a limitação de tempo e financeira levaram o pesquisador a essa opção. Vale frisar que, mesmo com a disseminação do questionário eletrônico em larga escala, a coleta foi prorrogada por duas vezes para que se obtivesse o mínimo de respostas considerado representativo. No mais, como forma de atenuar os impactos, procedeu-se à comparação entre população e amostra, verificando-se que a amostra se aproximava da população quanto a dados sociodemográficos e funcionais.

Além disso, cite-se como limitação o fato de que - embora se tenha tentado - a pesquisa não incorporou indicadores duros, coletados normalmente mediante dados secundários. Essa limitação é relevante sobretudo no que tange aos resultados de grupos, assim como é relevante que o domínio de competências de determinado líder pudesse ter sido apurado também mediante heteroavaliação, por exemplo, por membros do grupo (subordinados) e por líderes de outros grupos (pares), evitando-se o viés da autoavaliação. Estudos futuros poderiam ir além da 
autopercepção, incluindo indicadores duros e avaliações na percepção de outrem, ainda que em caráter comparativo, seja no domínio de competências gerenciais seja na concordância quanto ao alcance de resultados.

Outra limitação, que acabou se tornando oportunidade, foi a inexistência de escalas já desenvolvidas para o contexto de grupos de pesquisa. Os instrumentos sobre competências gerenciais localizados não eram compatíveis com a atividade de líder de grupo de pesquisa. Os estudos empíricos sobre os resultados no contexto acadêmico não apresentaram uma escala construída, apenas relacionavam indicadores, os quais muitas vezes se referiam ao nível individual (desempenho do pesquisador), e, portanto, precisaram ser adaptados ao nível meso ou macro-organizacional (resultado do grupo de pesquisa).

Uma última limitação a ser destacada se refere à análise dos dados. Esperava-se explorar os dados mediante a correlação canônica, que é a análise estatística própria para identificar associações entre variáveis múltiplas, tanto independentes quanto dependentes (HAIR JR. et al., 2010). Contudo, mesmo com a tentativa de parametrização, a ausência de linearidade nos dados permaneceu, não se permitindo o emprego dessa técnica, por ser um pressuposto inegociável (HAIR JR. et al., 2010). Como solução, recorreu-se à análise de correlação bivariada de Kendall-tau, que é adequada para dados não-paramétricos (FIELD, 2009). Fica, portanto, a indicação de que novas coletas de dados sejam realizadas, em busca de dados lineares, viabilizando-se a análise de correlação canônica.

Quanto às recomendações, sugere-se o emprego do recorte longitudinal, sobretudo, no que se refere à escala de resultados em grupos de pesquisa. Como se apurou na literatura, os resultados dos grupos não podem se limitar à indicadores de produtividade científica. A escala de resultados ora apresentada é bem-sucedida ao conjugar indicadores objetivos, a exemplo das publicações de artigos, e indicadores subjetivos, como o desenvolvimento de competências sociais. A avaliação perene dos resultados dos grupos pode permitir a aferição da evolução científica dos grupos de pesquisa brasileiros, de modo a se promover o melhor direcionamento das políticas de ciência e tecnologia.

Outra recomendação seria a retomada dos itens excluídos durante a fase preparatória para a análise fatorial. Foram suprimidos a competência "Apoiar o grupo na busca por recursos necessários à realização de atividades"; e os resultados "Participação, como avaliador externo, de comissões examinadoras de dissertações ou teses"; "Atuação na revisão de periódicos científicos"; e "Atuação na revisão de projetos submetidos a agências de fomento". É possível 
que pequenos ajustes possam conferir adesão teórica e acomodação dos itens aos fatores já extraídos.

Além dessas recomendações, vale consolidar aqui, de forma sucinta, as sugestões de pesquisa mencionadas ao longo do quarto capítulo. Assim, compõem a agenda de pesquisa decorrente desta Dissertação:

a) Pesquisas capazes de testar se Resultados Proximais e Tangíveis de pesquisa são, de fato, antecedentes dos Distais de Repercussão Externa, e se há relação de cusalidade entre essas variáveis.

b) Estudos capazes de confirmar ou refutar a inexistência de diferenças significativas entre as competências gerenciais de líderes e entre os resultados de grupos atuantes em diferentes Unidades da Federação e em Regiões distintas.

c) Pesquisas capazes de diagnosticar se as políticas, regras e diretrizes de fomento; o recebimento de bolsa de produtividade do CNPq; a experiência dos pesquisadores; e outras variáveis podem estar tornando mais uniformes as competências gerenciais e os resultados em grupos de pesquisa atuantes em diferentes Regiões e Unidades da Federação.

d) Investigações quanto aos motivos capazes de justificar o fato de, mesmo com a baixa correlação no que tange aos dados sociodemográficos e funcionais, os grupos de pesquisa liderados por mulheres apresentarem resultados equivalentes aos coordenados por líderes homens, uma vez que seria esperado que os resultados das mulheres fossem mais expressivos, já que elas consideram dominar mais as competências gerenciais de gestão de pessoas e resultados de pesquisa.

e) Estudos relativos à relação entre competências gerenciais, Resultados de grupos e o tipo de bolsa de produtividade recebida do $\mathrm{CNPq}$, pois, ainda que esta última variável tenha apresentado correlação baixa com as demais, o Tipo de bolsa pode figurar como uma variável preditora, critério, mediadora ou moderadora na interação com as demais variáveis citadas.

f) Pesquisas que identifiquem o que levou os resultados dos grupos a apresentarem maior variabilidade nas respostas, quando comparados ao grau de domínio de competências gerenciais.

g) Verificação dos motivos que proporcionaram a oscilação no alcance de Resultados Distais de Repercussão na comparação quanto à idade dos líderes do grupo, uma vez que - embora houvesse diferenças significativas - para determinadas faixas etárias, 
sujeitos mais jovens afirmaram atingir mais resultados, enquanto que, para outras, eram os mais maduros que consideraram alcançar mais resultados. Vale, inclusive, considerar a hipótese de ter havido leniência por parte de respondentes de determinadas faixas etárias.

h) Estudos capazes de identificar com profundidade a associação entre as variáveis idade, experiência e tempo de vínculo do líder ao grupo, pois, embora essas variáveis tenham baixos percentuais de explicação da variância, podem estar reciprocamente relacionadas, sendo capazes de inflenciar tanto as competências gerenciais quanto os resultados em grupos de pesquisa. O método sugerido é a análise de regressão, utilizando apenas uma dessas variáveis como proxy das demais.

Destarte, além dessas agendas e recomendações, é preciso avançar nas análises das relações entre competências gerenciais e resultados em grupos de pesquisa, principalmente no que tange aos seguintes aspectos: 1) esta dissertação ateve-se a identificar a magnitude das associações entre as variáveis, mas estudos futuros podem apurar o grau de predição e as relações de causalidade entre elas; e 2) a variância explicada pelo modelo em ambas escalas foi de aproximadamente $51 \%$, ou seja, estudos futuros poderiam identificar outras variáveis que compõem os $49 \%$ restantes.

Em suma, espera-se que a presente pesquisa contribua, ainda que minimamente, para a compreensão científica e para a evolução do fenômeno das competências gerenciais; e que as escalas desenvolvidas gerem frutos aos grupos de pesquisa brasileiros seja no mapeamento das competências gerenciais dos líderes, seja no monitoramento dos resultados pretendidos. Em última instância, fica a pretensão de que este estudo contribua, ainda que discretamente, para as políticas e diretrizes de ciência e tecnologia, fazendo com que a produção do conhecimento no âmbito dos grupos de pesquisa traga frutos à sociedade brasileira, mesmo sendo singelos e de longo prazo. 


\section{REFERÊNCIAS}

ACEDO, F. J. et al. Co-Authorship in Management and Organizational Studies: An Empirical and Network Analysis*. Journal of Management Studies, v. 43, n. 5, p. 957-983, 2006.

ALDRICH, H. E.; PFEFFER, J. Environments of organizations. Annual review of sociology, p. 79-105, 1976.

ALMEIDA, J. E. O.; MUNIZ, J. Comportamentos gerenciais para implantação da norma de qualidade-uma análise para certificação Vda 6.3. IX Simpósio de excelência em gestão e tecnologia, 2014.

ALMEIDA, S.; MARÇAL, R. F. M.; KOVALESKI, J. L. Metodologias para avaliação de desempenho organizacional. XXIV Encontro Nac. De Eng. de Produção-Florianópolis, Brasil, 2004.

ALON, U. How to build a motivated research group. Molecular cell, v. 37, n. 2, p. 151-152, 2010. ALVAREZ, D.; VIDAL, M. C. A organização do trabalho na produção acadêmica: redes de pesquisa e estratégias de ação. Rio de Janeiro: mimeo, 2008.

ALVES-MAZZOTTI, A. J. Usos e abusos dos estudos de caso. Cadernos de pesquisa, v. 36, n. 129, p. 637-651, 2006.

ARAUJO, V. C. et al. A influência das percepções de benefícios, resultados e dificuldades dos grupos de pesquisa sobre as interações com empresas. Revista Brasileira de Inovação, v. 14, n. 1 jan/jun, p. 77-104, 2015.

ASTLEY, W. G.; VAN DE VEN, A. H. Central perspectives and debates in organization theory. Administrative science quarterly, p. 245-273, 1983.

BACKES, V. M. S. et al. Grupos de pesquisa de educação em enfermagem do Brasil. Revista da Escola de Enfermagem da USP, v. 46, n. 2, p. 436-442, 2012.

BAISCH, L.V. et al. Gestão estratégica e as competências gerenciais no departamento de marketing: estudo de uma indústria de bebidas. Revista de Administração da UFSM, v. 5, p. 729-748, 2012. BARÁTH, T. Effectiveness in public education: Models and aspects of leadership. 2009. Disponível em < http://ofi.hu/effectiveness-public-education-models-and-aspects-leadership > Acesso em 12 dez. 2015

BARRACHINA, L. A.; TORRENT, M. S.; SELLABONA, E. S. Una propuesta de renovación metodológica en el marco del Espacio Europeo de Enseñanza Superior: los pequeños grupos de investigación cooperativos. Revista electrónica interuniversitaria de formaleción del profesorado, v. 12, n. 3, p. 8, 2009. 
BARROS, C. M. P. et al. As competências gerenciais desenvolvidas pelos secretários executivos. Revista de Gestão e Secretariado, v. 4, n. 2, p. 25, 2013.

BENDASSOLli, P. E. Desempenho no trabalho: Revisão da literatura. Psicologia Argumento, v. 30, n. 68, p. 171-184, 2012.

BERCHE, B. et al. Academic research groups: evaluation of their quality and quality of their evaluation, 2015.

BERGENHENEGOUWEN, G. J.; HORN, H. F. K.; MOOIJMAN, E. A. M. Competence development - a challenge for human resource professionals: core competences of organizations as guidelines for the development of employees. Industrial and commercial training, v. 29, n. 2, p. 55-62, 1997.

BOAK, G.; COOLICAN, D. Competencies for retail leadership: accurate, acceptable, affordable. Leadership \& Organization Development Journal, v. 22, n. 5, p. 212-220, 2001.

BOOG, G. G. O desafio da competência. São Paulo: Best Seller, p. 16, 1991.

BOURNE, M. et al. Designing, implementing and updating performance measurement systems. International Journal of Operations \& Production Management, v. 20, n. 7, p. 754771,2000

BOWEN, N. K.; GUO, S. Structural equation modeling. Oxford University Press, 2011.

BOYATIZIS, R. The competent manager: a model of effective performance. New York: Wiley, 1982.

BRANDÃO, H. P. Competências no trabalho: uma análise da produção científica brasileira. Estudos de Psicologia, v. 12, n. 2, p. 149-158, 2007.

BRANDÃO, H. P. et al. Desenvolvimento e estrutura interna de uma escala de competências gerenciais. Psicologia: Teoria e Pesquisa, v. 26, n. 1, p. 171-182, 2010.

BRANDÃO, H. P., BORGES-ANDRADE, J. E., GUIMARÃES, T. A. Desempenho organizacional e suas relações com competências gerenciais, suporte organizacional e treinamento. R. Adm., São Paulo, v.47, n.4, p.523-539, out./nov./dez. 2012

BRANDÃO, H. P.; BAHRY, C. P.; FREITAS, I. A. Os impactos do suporte à transferência sobre a aplicação de competências no trabalho: a percepção dos mestres e doutores do Banco do Brasil. Revista de Administração, v. 43, n. 3, p. 224-237, 2008.

BRANDÃO, H. P.; BORGES-ANDRADE, J. E. Causas e efeitos da expressão de competências no trabalho: para entender melhor a noção de competência. Revista de Administração Mackenzie, v. 8, n. 3, 2008. 
BRITO, L. M. P.; LEONE, N. M. C. G. P. Competências gerenciais requeridas em empresas familiares: um olhar feminino. Revista de Ciências da Administração, v. 14, n. 32, p. 50, 2012. BRITO, L. M. P.; PAIVA, L. C. B.; LEONE, N. M. C. P. G. Perfil de competências gerenciais no Ensino Superior Tecnológico. Revista Ciências Administrativas, v. 18, n. 1, 2012.

BROWN, T. A. Confirmatory factor analysis for applied research. New York, NY: Guilford. Browne, MW, \& Cudeck, R.(1993). Alternative ways of assessing model t. KA Bollen \& JS Long, 2006.

BUCHELE, Robert B. How to evaluate a firm. California Management Review, v. 5, n. 5, p. 5$17,1962$.

BUENO, Wilson Costa. A investigação em comunicação organizacional no Brasil: uma leitura abrangente dos grupos de pesquisa cadastrados no CNPq. Comunicação \& Inovação, v. 15, n. 28, 2014.

BÜNDCHEN, E.; ROSSETTO, C. R.; SILVA, A. B.. Competências Gerenciais em Ação-O Caso do Banco do Brasil.Revista Eletrônica de Administração, v. 17, n. 2, p. 396-423, 2011.

BURRELL, G. Normal science, paradigms, metaphors, discourses and genealogies of analysis. In: CLEGG, S.; HARDY, C.; NORD, W. (Eds.). Handbook of Organization Studies. London: Sage, 1996.

CAMERON, K. S.; WHETTEN, D. A. (Ed.). Organizational effectiveness: A comparison of multiple models. Academic Press, 2013.

CANEVER, B. P. et al. Caracterização dos Grupos de Pesquisa em Educação em Enfermagem do Estado de São Paulo. Texto \& Contexto Enfermagem, v. 23, n. 1, p. 21-28, 2014.

CARBONE, P. P.; BRANDÃO, H. P.; LEITE, J. B. D. Gestão por competências e gestão do conhecimento. FGV, 2009.

CARDONA, N.; CALDERÓN, G. Confianza en las interacciones del trabajo investigativo. Un estudio en grupos de investigación en una universidad pública colombiana. Cuadernos de administración, v. 23, n. 40, 2010.

CARDOSO, A. L. J. Percepções de gestores sobre competências gerenciais em diferentes contextos: estabilidade e mudança organizacional. REBRAE. Revista Brasileira de Estratégia, Curitiba, v. 2, n. 2, p. 147-169, maio/ago, 2009

CARDOSO, A. L. J. Questão de Gênero: A Percepção de Alunos d Ex-Alunos de Pós-Graduação Stricto Sensu em Administração sobre Competências Gerenciais. Revista de Carreiras e Pessoas (ReCaPe). ISSN 2237-1427, v. 4, n. 1, 2014. 
CARVALHO, L. M. Educação Corporativa e Desempenho Estratégico. Revista de Administração FACES Journal, v. 13, n. 3, 2014.

CASSEPP-BORGES, V.; BALBINOTTI, M. A. A.; TEODORO, M. L. M. Tradução e validação de conteúdo: uma proposta para a adaptação de instrumentos. Instrumentação psicológica: fundamentos e prática, p. 506-520, 2010.

CASTRO, L. Modelo de medición de grupos de investigación, tecnológica o de innovación año 2008. Bogotá D. C.: Instituto Colombiano para el Desarrollo de la Ciencia y la Tecnología Francisco José de Caldas, Colciencias, sf, disponível em: < http://www.urosario.edu.co/Home/investigacion/Documentos/Documento-Modelo-MedicionGrupos-(1)/ > Acesso em: 9 jan. 2015

CHAKRAVARTHY, B. S. Measuring strategic performance. Strategic management journal, v. 7, n. 5, p. 437-458, 1986.

CHILD, J. Organizational structure, environment and performance: The role of strategic choice. Sociology, v. 6, n. 1, p. 1-22, 1972.

CLARK, L. A.; WATSON, David. Constructing validity: Basic issues in objective scale development. Psychological assessment, v. 7, n. 3, p. 309, 1995.

CNPq - Conselho Nacional de Desenvolvimento Científico e Tecnológico. Diretório de Grupos de Pesquisa. Disponível em: <http://www.cnpq.br>. Acesso em: 7 jan. 2015

COCHRAN, W. G. Sampling Techniques, New York: JohnWiley, 1977.

COCKERILL, T. The king of competence for rapid change. In: MABEY, C.; ILES, P. (Org.). Managing learning. London: Routledge, 1994. Cap.7, p.70-76.

COMBS, J. G.; CROOK, T. R.; SHOOK, C. L. The dimensionality of organizational performance and its implications for strategic management research. Research in Social Stratification and Mobility, v. 2, p. 259, 2005.

COMREY, A. L.; LEE, H. B. Interpretation and application of factor analytic results. Comrey AL, Lee HB. A first course in factor analysis, v. 2, 1992.

CRESWELL, J. W. Research design: Qualitative, quantitative, and mixed methods approaches. Sage publications, 2013.

CUNHA, J. A. C.; CORRÊA, H. L. Avaliação de desempenho organizacional: um estudo aplicado em hospitais filantrópicos. RAE-Revista de Administração de Empresas, v. 53, n. 5, p. 485-499, 2013.

DAMÁSIO, B. F. Uso da análise fatorial exploratória em psicologia. Avaliação psicológica, v. 11, n. 2, p. 213-228, 2012. 
DENISON, D. R.; HOOIJBERG, R.; QUINN, R. E. Paradox and performance: Toward a theory of behavioral complexity in managerial leadership. Organization Science, v. 6, n. 5, p. 524-540, 1995. DEMO, P. Pesquisa e construção do conhecimento. Metodologia científica no caminho de Habermas. 2 ed.. Rio de Janeiro: Tempo Brasileiro, 1996, 125 p.

DIAS, H. C. V. B.; PAIVA, K. C. M. Formação de competências gerenciais a partir de disciplinas de gestão no curso de enfermagem: percepções de alunos de uma universidade privada. Revista Mineira de Enfermagem, v. 13, n. 4, p. 474-484, 2009.

DIAS, H. C.; PAIVA, K. C. M. Competências do enfermeiro: estudo em um hospital privado. Rev. bras. enferm, v. 64, n. 3, p. 511-520, 2011.

DIMAGGIO, P.; POWELL, W. W. The iron cage revisited: Collective rationality and institutional isomorphism in organizational fields. American Sociological Review, v. 48, n. 2, p. 147-160, 1983. DRUCKER, P. F. The practice of management. NY: Harper \& Row, 1954

DRUCKER, P. Managing for the Future. Routledge, 1988.

DUTRA, J. S. Competências: conceitos e instrumentos para a gestão de pessoas na empresa moderna. Atlas, 2004.

DYER, L.; REEVES, T. Human resource strategies and firm performance: what do we know and where do we need to go?. International Journal of human resource management, v. 6, n. 3, p. 656-670, 1995.

ERDMANN, A. L. et al. Funcionalidade dos grupos de pesquisa de administração/gestão/gerência de enfermagem. Revista da Rede de Enfermagem do Nordeste-Rev Rene, v. 11, n. 2, 2012.

ERDMANN, A. L.; LANZONI, G. M. M. Características dos grupos de pesquisa da enfermagem brasileira certificados pelo CNPq de 2005 a 2007. Esc Anna Nery Rev Enferm, v. 12, n. 2, p. 316$22,2008$.

ERLEN, J. A. et al. Multiple authorship: issues and recommendations. Journal of Professional Nursing, v. 13, n. 4, p. 262-270, 1997.

ÉSTHER, A. B. As competências gerenciais dos reitores de universidades federais em Minas Gerais: a visão da alta administração. Cadernos EBAPE. BR. Rio de Janeiro, ed. Especial, v. 9, p. 648667, 2011.

FÉLIX, C. M. R. A prática de competências gerenciais no setor público. Revista de Administração Pública, v. 39, n. 2, p. 255 a 278, 2005.

FERIGOTTI, C.; FERNANDES, B. Competências Gerenciais E Capacidade Para Inovação: O Caso Da Electrolux Do Brasil S/A. RAI: revista de administração e inovação, v. 11, n. 1, p. 73-96, 2014. 
FERNANDEZ, F. F.; ODELIUS, C. C. Validação de uma escala de domínio de competências em grupos de pesquisa. Revista de Administração FACES Journal, v. 12, n. 2, 2013.

FERRAZ, I. N.; DORNELAS, J. S. Repertório Compartilhado de Recursos em Comunidades Virtuais de Prática: um estudo dos mecanismos de interação, organização e controle em grupos de pesquisa científica. Organizações \& Sociedade, v. 22, n. 72, p. 90-122, 2015.

FIELD, A. Descobrindo a estatistica usando o SPSS-2. Bookman Editora, 2009.

FLECK, C. F.; PEREIRA, B. A. D. Professores e Gestores: análise do perfil das Competências Gerenciais dos coordenadores de pós-graduação das Instituições Federais de Ensino Superior (IFES) do RS. Organizações \& Sociedade, v. 18, n. 57, 2011.

FLEURY, M. T. L.; FLEURY, A. Construindo o conceito de competência. Revista de administração contemporânea, v. 5, n. SPE, p. 183-196, 2001.

FLICK, U. An introduction to qualitative research. Sage, 2009.

FOWLER JR., F. J. Pesquisa de Levantamento. 4. ed. Penso Editora, 2011.

FREITAS JR., O. G. et al. Um modelo de sistema de gestão do conhecimento para grupos de pesquisa e desenvolvimento. Tese (Doutorado em Engenharia de Produção) - Universidade Federal de Santa Catarina, 2003.

GALVÃO, V. B. A.; SILVA, A. B.; SILVA, W. R. O desenvolvimento de competências gerenciais nas escolas públicas estaduais. Educação e Pesquisa, v. 38, n. 1, p. 131-147, 2012.

GARAVAN, T. N.; MCGUIRE, D. Competencies and workplace learning: some reflections on the rhetoric and the reality. Journal of Workplace learning, v. 13, n. 4, p. 144-164, 2001.

GARCIA, J. F. P. T\&D mobilizando a organização para a qualidade. Manual de Treinamento e Desenvolvimento, v. 3, p. 209-236, 1999.

GARCIA, R. et al. Interações universidade-empresa e a influência das características dos grupos de pesquisa acadêmicos. Revista de Economia Contemporânea, v. 18, n. 1, p. 125-146, 2014.

GAVIRIA VELÁSQUEZ, M. M.; MEJÍA CORREA, A. M.; HENAO HENAO, D. L. Gestión del conocimiento en los grupos de investigación de excelencia de la Universidad de Antioquia. Revista Interamericana de Bibliotecología, v. 30, n. 2, p. 137-163, 2007.

GLADNEY, A. P. et al. Consistency of findings produced by two multidisciplinary research teams. Sociology, v. 37, n. 2, p. 297-313, 2003.

GODOY, A. S. A pesquisa qualitativa e sua utilização em administração de empresas. Revista de Aministração de Empresas, v. 35, n. 4, p. 65-71, 1995. 
GODOY, A. S.; ANTONELLO, C. S. Competências individuais adquiridas durante os anos de graduação de alunos do Curso de Administração de Empresas. Revista de Ciências da Administração, v. 11, n. 23, p. 157-191, 2009.

GODOY, A. S.; D’AMELIO, M. Competências gerenciais desenvolvidas por profissionais de diferentes formações. Organizações \& Sociedade, v. 19, n. 63, 2012.

GODOY, A. S.; FORTE, D. Competências adquiridas durante os anos de graduação: um estudo de caso a partir das opiniões de alunos formandos de um curso de administração de empresas. Gestão \& Regionalidade, v. 23, n. 68, p. 56-69, 2007.

GONCZI, A. Competency-based learning: a dubious past-an assured future? In: BOUD, David; GARRICK, John (Ed.). Understanding learning at work. Psychology Press, p. 180-194, 1999. GONZÁLEZ-ALCAIDE, G.; ALEIXANDRE-BENAVENT, R.; DE GRANDA-ORIVE, J. I. Caracterización bibliométrica y temática de los grupos de investigación de Archivos de Bronconeumología (2003-2007). Archivos de Bronconeumología, v. 46, n. 2, p. 78-84, 2010.

GONZÁLEZ-ALCAIDE， G.; ALEIXANDRE-BENAVENT, R.; GRANDA-ORIVE， J. I. Caracterización bibliométrica y temática de los grupos de investigación de Archivos de Bronconeumología (2003-2007). Archivos de Bronconeumología, v. 46, n. 2, p. 78-84, 2010.

GORSUCH, R. L. Factor Analysis. Hillsdale, NJ: Lawrence Earlbaum Associates. 1983.

GRESSLER, L. A. Introdução à pesquisa: projetos e relatórios. 3.ed. São Paulo: Loyola, 2007. GRINYER, P. H.; MAYES, David G.; MCKIERNAN, Peter. Sharpbenders: The secrets of unleashing corporate potential. Basil Blackwell, 1988.

GUIMARAES, T. A. et al. Forecasting core competencies in an R\&D environment. R and D Management, v. 31, n. 3, p. 249-255, 2001.

GÜNTHER, H. Como elaborar um relato de pesquisa (Série: Planejamento de Pesquisa nas Ciências Sociais, No 02). Brasília, DF: UnB, Laboratório de Psicologia Ambiental, 2004. Disponível na URL<www.unb.br/ip/lpa/pdf/02Sugestoes.pdf $>$ Acesso em 20 jan. 2016.

HAIR JR., J. F. et al. Análise multivariada de dados. Trad. Adonai Schlup Sant'Anna e Anselmo Chaves Neto Bookman Editora, 2010.

HARVEY, J.; PETTIGREW, A.; FERLIE, E. The Determinants of Research Group Performance: Towards Mode 2? Journal of Management Studies, v. 39, n. 6, p. 747-774, 2002.

HAYTHORNTHWAITE, C. Learning and knowledge networks in interdisciplinary collaborations. Journal of the American Society for Information Science and Technology, v. 57, n. 8, p. 1079-1092, 2006. 
HENDERSON, M. E. et al. Collaborating to Improve Collaboration: Informationist Team Support for an Interdisciplinary Research Group. Disponível em < http://escholarship.umassmed.edu/escience_symposium/2015/posters/10/ > Acesso em $12 \mathrm{dez}$. 2015.

HENRI, J. Performance measurement and organizational effectiveness: Bridging the gap. Managerial Finance, v. 30, n. 6, p. 93-123, 2004.

HIGUITA-LÓPEZ, D.; MOLANO-VELANDIA, J.; RODRÍGUEZ-MERCHÁN, M. F. Necessary Skills Among Research Groups at the Universidad Nacional de Colombia that Work to Generate Technologically Based Developments. Innovar, v. 21, n. 41, p. 209-224, 2011.

HOLLIS, A. Co-authorship and the output of academic economists. Labour Economics, v. 8, n. 4, p. 503-530, 2001.

HOWELL, D. Statistical methods for psychology. Cengage Learning, 2012.

IRMÃO, M. N.; BARBALHO, C. R. S. Competências gerenciais dos gestores de bibliotecas universitárias de instituições de ensino público em Manaus. Biblionline, v. 10, n. 2, 2014.

ISRAEL, G. D. Determining sample size. University of Florida Cooperative Extension Service, Institute of Food and Agriculture Sciences, EDIS, 1992.

ITTNER, C. D.; LARCKER, D. F. Are nonfinancial measures leading indicators of financial performance? An analysis of customer satisfaction. Journal of accounting research, p. 1-35, 1998. IZQUIERDO-ALONSO, M.; MORENO-FERNÁNDEZ, L. M.; IZQUIERDO-ARROYO, J. M. Grupos de investigación en contextos organizacionales académicos: una reflexión sobre los procesos de cambio y los retos futuros. Investigación bibliotecológica, v. 22, n. 44, p. 103-141, 2008.

JANSEN, J. J. P.; VERA, D.; CROSSAN, M. Strategic leadership for exploration and exploitation: The moderating role of environmental dynamism. The Leadership Quarterly, v. 20, n. 1, p. 5-18, 2009.

JESUS, K. C. B. et al. Desenvolvimento de Competências Gerenciais de Gestores Públicos. Anais do Encontro Anual da Associação Nacional de Pós-Graduação e Pesquisa em Administração, 2014.

JEZERSKYTĖS, E.; ŽYDŽIŪNAITĖ, V. Comparing Teamwork Competencies of The School Administration and Educators: The Aspects of Groupthink (Avoidance) and Social Loafing. Social sciences, v. 3, n. 49, p. 87-95, 2005.

JOHNSON, H. T. J.; KAPLAN, R. S. Relevance lost: the rise and fall of management accounting. Harvard Business Press, 1991. 
JUNG, C. F. Metodologia Científica Ênfase em Pesquisa Tecnológica $3^{\mathrm{a}}$. Edição Revisada e Ampliada-2003/I Disponível em <http://www. mecanica. ufrgs. br/promec/alunos/download/metodolo. pdf>. Acessado em 11/02/2015, v. 26, 2011.

JURAN, J. M. Managerial breakthrough: A new concept of the manager's job. New York, NY: McGraw-Hill, 1964.

KAISER, H. F. An index of factorial simplicity. Psychometrika, v. 39, n. 1, p. 31-36, 1974.

KATZ, R. L. Skills of an effective administrator. Harvard Business, p. 33-42, 1955.

KENDALL, K. E.; KENDALL, J. E. Análisis y diseño de sistemas. Pearson educación, 2005.

KENNERLEY, M; NEELY, A. Measuring performance in a changing business environment. International Journal of Operations \& Production Management, v. 23, n. 2, p. 213-229, 2003.

KLINE, R. B. Principles and practice of structural equation modeling. Guilford publications, 2015.

KONRATH, M. L. P.; TAROUCO, L. M. R.; BEHAR, P. A. Competências: desafios para alunos, tutores e professores da EaD. RENOTE, v. 7, n. 1, 2009.

LACH, S.; SCHANKERMAN, M. Incentives and invention in universities. The RAND Journal of Economics, v. 39, n. 2, p. 403-433, 2008.

LADO, A. A.; WILSON, M. C. Human resource systems and sustained competitive advantage: A competency-based perspective.Academy of management review, v. 19, n. 4, p. 699-727, 1994.

LAROS, J. A. O uso da análise fatorial: algumas diretrizes para pesquisadores. In: L. Pasquali (Ed.). Análise fatorial para pesquisadores. 2012. p. 163-193.

LAROS, J. A.; PUENTE-PALACIOS, K. E. Validação cruzada de uma escala de clima organizacional. Estudos de Psicologia, v. 9, n. 1, p. 113-119, 2004.

LE BOTERF, G. Compétence et navigation professionnelle. Éditions d'organisation, 2000.

LEITE, M. T. S. Desenvolvimento de competências gerenciais e aprendizagem experiencial: um estudo entre os gerentes de agência do Banco do Brasil no Estado do Ceará. Anais do Encontro Anual da Associação Nacional de Pós-Graduação e Pesquisa em Administração, 2009.

LEVY, P. E.; WILLIAMS, J. R. The social context of performance appraisal: A review and framework for the future. Journal of management, v. 30, n. 6, p. 881-905, 2004.

LIMA, V. V. Competência: distintas abordagens e implicações na formação de profissionais de saúde. Interface Comun Saúde Educ, v. 9, n. 17, p. 369-79, 2005.

LITTO, F. M.; FORMIGA, M. Educação a Distância: Estado da Arte. São Paulo: Pearson Education do Brasil, 2009. 
LOHMAN, C.; FORTUIN, L.; WOUTERS, M. Designing a performance measurement system: A case study. European Journal of Operational Research, v. 156, n. 2, p. 267-286, 2004.

LOPES, M. C. et al. Análise da relação entre aptidões cerebrais e competências gerenciais: o caso de uma empresa têxtil. Gest. Prod., São Carlos, v. 17, n. 1, p. 123-136, 2010.

MACEDO, M. A. S.; SILVA, F. F. Análise de desempenho organizacional: propondo uma modelagem utilizando indicadores financeiros e não financeiros na avaliação de performance empresarial. Revista Alcance-UNIVALI, v. 12, n. 2, p. 211-231, 2005.

MARSICK, V. J.; WATKINS, K. E. Demonstrating the value of an organization's learning culture: the dimensions of the learning organization questionnaire. Advances in developing human resources, v. 5, n. 2, p. 132-151, 2003.

MARTIN, A. R. A pós-graduação no Brasil: dilemas do crescimento. Panorama da Geografia Brasileira, v. 2, 2006.

MATITZ, Q. R. S. Aspectos semânticos, formais e funcionais do conceito desempenho em estudos organizacionais e estratégia: um modelo analítico. 2009. Tese de Doutorado. Tese (Doutorado em Administração). Programa de Pós-Graduação em Administração da Universidade Federal do Paraná. Curitiba.

MATTAR, F. N. Pesquisa de marketing-Volume 1: Metodologia e planejamento. São Paulo: Atlas, 1996.

MAUTHNER, N. S.; DOUCET, A. Knowledge Once Divided Can Be Hard to Put Together Again'An Epistemological Critique of Collaborative and Team-Based Research Practices. Sociology, v. 42, n. 5, p. 971-985, 2008.

MCMULLAN, M. et al. Portfolios and assessment of competence: a review of the literature. Journal of advanced nursing, v. 41, n. 3, p. 283-294, 2003.

MCTI - Ministério de Ciência, Tecnologia e Inovação. Disponível em: < http://www.mcti.gov.br/> Acesso em: 12 out. 2015

MEJÍA CORREA, A. M. Estructura organizativa de los grupos de investigación de la Universidad de Antioquia como fuente de creación de conocimiento. Revista Interamericana de Bibliotecología, v. 30, n. 2, p. 89-112, 2007.

MEJÍA, A. C.; SÁNCHEZ, A. M.; LEZA, F. T. Determinantes de éxito en la participación de los grupos de investigación latinoamericanos en programas de cooperación científica internacional. Interciencia: Revista de ciencia y tecnología de América, v. 33, n. 11, p. 821-828, 2008. 
MELLO, S. P. T.; MELO, P. A. Mapeando competências gerenciais dos integrantes do Fórum de Gestão de Pessoas da Rede Federal de Educação profissional, científica e tecnológica. VII Congresso CONSAD de Gestão Pública, 2014.

MENDES, P. S.; CALIARI, T. S.; SANTOS, U. P. Geração de Tecnologia em Universidades/Institutos de Pesquisa e a Importância da Interação com Empresas: Constatações através da Base de Dados dos Grupos de Pesquisa do CNPQ. ANPEC-Associação Nacional dos Centros de Pós-graduação em Economia, 2014.

MEYER, J. W.; ROWAN, B. Institutionalized organizations: Formal structure as myth and ceremony. American journal of sociology, p. 340-363, 1977.

MITHAS, S.; RAMASUBBU, N.; SAMBAMURTHY, V. How Information Management Capability Influences Firm Performance. MIS quarterly, v. 35, n. 1, p. 237-256, 2011.

MOHRMAN, S. A.; WORLEY, C. G. Dealing with rough times: A capabilities development approach to surviving and thriving. Human Resource Management, v. 48, n. 3, p. 433-445, 2009. MONTANA, P. J.; CHARNOV, B. H. Administração. São Paulo: Saraiva, 1998.

MONTEZANO L.; SILVA, D. L. B.; COELHO JR. F. A. Competências Humanas no Trabalho: a Evolução das Publicações Nacionais no Novo Milênio. Anais do $3^{\circ}$ Encontro da Associação Nacional de Pós-Graduação e Pesquisa em Administração - EnANPAD, 2015.

MORAES, M. G.; CORRÊA, M. L. Competência Comunicativa dos Líderes e os Resultados da Equipe. Anais do $32^{\circ}$ Encontro da Associação Nacional de Pós-Graduação e Pesquisa em Administração - EnANPAD, 2008.

MORGAN, G.. Paradigmas, metáforas e resolução de quebra-cabeças na teoria das organizações. RAE-Revista de Administração de Empresas, v. 45, n. 1, p. 58-71, 2005.

MORRIS, S. A.; GOLDSTEIN, M. L. Manifestation of research teams in journal literature: A growth model of papers, authors, collaboration, coauthorship, weak ties, and Lotka's law. Journal of the American Society for Information Science and Technology, v. 58, n. 12, p. 1764-1782, 2007.

MOURA, G. R. et al. Prospects for group processes and intergroup relations research: A review of 70 years' progress. Group Processes \& Intergroup Relations, v. 11, n. 4, p. 575-596, 2008.

MOURA, M. C. C.; BITENCOURT, C. C. A articulação entre estratégia e o desenvolvimento de competências gerenciais. RAE-eletrônica, v. 5, n. 1, 2006.

MUGNAINI, R.; JANNUZZI, P. M.; QUONIAM, L. Indicadores bibliométricos da produção científica brasileira: uma análise a partir da base Pascal. Ciência da Informação, v. 33, n. 2, p. 123131, 2004. 
MUGNAINI, Rogério; JANNUZZI, Paulo de Martino; QUONIAM, Luc. Indicadores bibliométricos da produção científica brasileira: uma análise a partir da base Pascal. Ciência da Informação, v. 33, n. 2, p. 123-131, 2004.

NASCIMENTO NETO, R. V. Impacto da adoção da Internet em pesquisas empíricas: comparações entre metodologias de aplicação de questionários. ENCONTRO NACIONAL DOS PROGRAMAS DE PÓS-GRADUAÇÃO EM ADMINISTRAÇÃO, v. 28, p. 2004, 2004.

NASCIMENTO, M. D. L.; ALVES, M. B. Competências do administrador: um estudo comparativo entre a percepção da academia e do mercado. XII SEGET - Simpósio de Excelência de Gestão e Tecnologia, 2015.

NEIVA, E. R.; ABBAD, G. S.; TRÓCCOLI, B. T. Roteiro para Análise Fatorial de Dados. Brasília, 2011. Disponível em < http://aprender.ead.unb.br/pluginfile.php/107810/mod_folder/content/0/An\%C3\%A1lise\%20Fator ial/roteiro_analise_fatorial_Reformulado.doc?forcedownload=1> Acesso em: 20 jan. 2016.

NEIVA, Elaine Rabelo; FUSSI, Carolina Carvalho; CORRADI, Ariane Agnes. Relationship between academic productivity and social networks of Psychology researchers. Estudos de Psicologia (Campinas), v. 33, n. 1, p. 83-94, 2016.

NÓBREGA, A. B. N. et al. Competências Gerenciais do nutricionista gestor de unidades de alimentação terceirizada. RAUnP-ISSN 1984-4204, v. 4, n. 2, p. 49-60, 2012.

NORO, G. B.; ABBADE, E. B. Os tipos de projetos e as competências gerenciais nos projetos da AES sul distribuidora gaúcha de energia SA. Revista Gestão Organizacional, v. 3, n. 2, p. 141 $162,2010$.

NUNNALLY, J. C.; BERNSTEIN, I. H. Elements of statistical description and estimation. Psychometric Theory, 3 Edition (Edited by: Nunnally JC, Bernstein IH), 1994.

ODELIUS, C. C. et al. Grupos de Pesquisa: atividades, competências e processos de aprendizagem. ENCONTRO ANUAL DA ASSOCIAÇÃO NACIONAL DE PÓS-GRADUAÇÃO E PESQUISA EM ADMINISTRAÇÃO-ENANPAD, v. 34, p. 1-17, 2010.

ODELIUS, C. C. et al. Processos de aprendizagem, competências aprendidas, funcionamento, compartilhamento e armazenagem de conhecimentos em grupos de pesquisa. Cadernos EBAPE. BR, Rio de Janeiro, v. 9, n. 1, mar. 2011.

ODELIUS, C. C.; SANTOS, P. R. G. Avaliação de desempenho individual na administração pública federal: aspectos. Revista Economia \& Gestão, v. 7, n. 15, p. 10-30, 2008.

ODELIUS, C. C.; SENA, A. C. Atuação em grupos de pesquisa: competências e processos de aprendizagem. Revista de Administração FACES Journal, v. 8, n. 4, 2009. 
ODERICH, C. Gestão de competências gerenciais: noções e processos de desenvolvimento. Os novos horizontes da gestão: aprendizagem organizacional e competências. Porto Alegre: Bookman, p. 88-115, 2005.

OLIVEIRA, A. F.; TAMAYO, A. Inventário de perfis de valores organizacionais. Revista de Administração, v. 39, n. 2, p. 129-140, 2004.

ONO, R. N. Competências de trabalho em equipes de participantes de grupos de pesquisa: avaliando interáreas de conhecimento e características intragrupo. 2012. xii, 106 f., il. Dissertação (Mestrado em Administração em Estudos Organizacionais e Gestão de Pessoas) — Universidade de Brasília, Brasília, 2012.

OSBORNE, J. W. Improving your data transformations: Applying the Box-Cox transformation. Practical Assessment, Research \& Evaluation, v. 15, n. 12, p. 1-9, 2010.

PAIVA, K. C. M.; FERREIRA, L. S. Competências Gerenciais na área de Tecnologia de Informação: um estudo com gestores de empresas localizadas no Triângulo Mineiro. Revista Gestão \& Tecnologia, v. 13, n. 1, p. 205-229, 2013.

PAIVA, K.; SANTOS, A.; LACERDA, M. Competências gerenciais e sua gestão na hotelaria: um estudo com gestores brasileiros. Tourism \& Management Studies, v. 10, n. 2, p. 84-93, 2014.

PARRY, S. B. The Quest for Competencies. Training, v. 33, n. 7, p. 48, 1996.

PASQUALI, L. Instrumentação psicológica: Fundamentos e práticas. Porto Alegre. RS: Artmed, 2010.

PAULA, M. et al. Processo de trabalho e competências gerenciais do enfermeiro da estratégia saúde da família. Revista da Rede de Enfermagem do Nordeste-Rev Rene, v. 14, n. 5, 2013.

PEDHAZUR, E. J.; SCHMELKIN, L. P. Measurement, design, and analysis: An integrated approach. Hillsdale, Erlbaum, 1991.

PEIXOTO, A. L. A.; SOUZA, J. A. J. Longe dos olhos, longe do coração: desafios de gestão de uma universidade pública a partir da percepção dos seus gestores. Revista Gestão Universitária na América Latina-GUAL, v. 8, n. 3, p. 240-260, 2015.

PELHAM, A. M.; WILSON, D. T. A longitudinal study of the impact of market structure, firm structure, strategy, and market orientation culture on dimensions of small-firm performance. Journal of the Academy of Marketing Science, v. 24, n. 1, p. 27-43, 1996.

PELISSARI, A. S.; GONZALEZ, I. V. F. P.; VANALLE, R. M. Competências gerenciais: um estudo em pequenas empresas de confecções. Revista Eletrônica de Administração, v. 17, n. 1, p. 149-180, 2011 
PEREIRA, G. R. M.; ANDRADE, M. C. L. Aprendizagem científica: experiência com grupo de pesquisa. In: BIANCHETTI, L.; MEKSENAS, P. (Org.). A trama do conhecimento: teoria, método e escrita em ciência e pesquisa. São Paulo: Papirus, 2008. cap. 8. p. 153-168.

PETTIGREW, A.; WHIPP, R. Managing change for competitive success. Oxford, Blackwell, 1991.

PFEFFER, J.; SALANCIK, G. R. The external control of organizations: A resource dependence perspective. Stanford University Press, 2003.

PICCHIAI, D. Competências gerenciais: estudo de caso de um hospital público. Cadernos Gestão Pública e Cidadania, v. 13, n. 52, 2008.

PINTO, J. L. F. et al. Competências Gerenciais: Um Estudo Exploratório em uma Rede do Comércio Varejista. Global Manager, v. 14, n. 2, p. 23-40, 2014.

PINTO, J. S.; DORNELAS, J. S. Identificando Aspectos Colaborativos em Grupos de Pesquisa da UFPE. Disponível em < http://nepsi.adm.br/2013/wp-content/uploads/2014/10/GPADi-PosterJananda.pdf $>$ Acesso em 13 nov. 2015.

POLIT, D. F.; BECK, C. T.; HUNGLER, B. P. Pesquisa em enfermagem: métodos, avaliação e utilização. Porto Alegre (RS): Artmed, 2004.

PRAHALAD, C. K.; HAMEL, G. The core competence of the corporation. 1990.

QUINN, R. E. et al. Competências gerenciais princípios e aplicações. Rio de Janeiro: Editora Campus, 2003.

QUINN, R. E. Beyond rational management: Mastering the paradoxes and competing demands of high performance. Jossey-Bass, 1988.

RAMOS-VIELBA, I.; SÁNCHEZ-BARRIOLUENGO, M.; WOOLLEY, R. Scientific research groups' cooperation with firms and government agencies: motivations and barriers. The Journal of Technology Transfer, p. 1-28, 2015.

REGIO, M. L. S. et al. Gestão de competências profissionais na formação de administradores. Avaliação: Revista da Avaliação da Educação Superior, v. 19, n. 1, 2013.

RESTREPO, M. I.; VILLEGAS, J. G. Clasificación de grupos de investigación colombianos aplicando análisis envolvente de datos Ranking Colombian research groups applying Data Envelopment Analysis. 2007.

RICHARDSON, R. J. et al. Pesquisa social: métodos e técnicas. São Paulo: Atlas, 2010.

RIDGWAY, V. F. Dysfunctional consequences of performance measurements. Administrative Science Quarterly, p. 240-247, 1956. 
RIQUELME, G. C.; LANGER, A. Capacidades de los grupos de docencia e investigación en la circulación y producción del conocimiento: el caso de tres universidades argentinas. Revista de la educación superior, v. 39, n. 154, p. 19-49, 2010.

ROBSON, B.; SHOVE, E. (Ed) Interactions and influence: individuals and institutions A summary report of six pilot studies commissioned by the ESRC, 1999.

ROCHA NETO, I. Gestão estratégica de conhecimentos e competências: administrando incertezas e inovações. Brasília: ABIPTI, UCB/Universa, 2003.

ROWE, C. Clarifying the use of competence and competency models in recruitment, assessment and staff development. Industrial and Commercial training, v. 27, n. 11, p. 12-17, 1995.

ROZZETT, K.; DEMO, G. Development and Factor Validation of the Customer Relationship Scale" Revista de administração de empresas, v. 50, n. 4, p. 383, 2010.

RUAS, R. Desenvolvimento de competências gerenciais e contribuição da aprendizagem organizacional. Gestão estratégica do conhecimento: integrando aprendizagem, conhecimento e competências. São Paulo: Atlas, p. 242-269, 2001.

RUAS, R. L. Gestão por competências: uma contribuição à estratégia das organizações. In: RUAS, R. L.; ANTONELlO, C. S.; BOFF, L. H. (Orgs.). Os novos horizontes da gestão: aprendizagem organizacional e competências. Porto Alegre: Bookman, 2005.

SANTANA, G. A. et al. Indicadores dos grupos de pesquisa da área de Gestão da Informação na Região Nordeste: um enfoque para a colaboração em artigos de periódicos. Em Questão, v. 20, n. 3, p. 229-252, 2014.

SANTOS, A. R. Metodologia Científica: a construção do conhecimento. Rio de Janeiro: DP \& A, Editora, 2002.

SANTOS, E. P.; HONÓRIO, L. C. Competências Gerenciais em uma Rede Mineira de Farmácias. Revista Alcance, v. 21, n. 4, p. 650-673, 2014.

SANTOS, J. P., CAETANO, A., JESUÍNO, J. C. As competências funcionais dos líderes e a eficácia das equipas. Revista Portuguesa e Brasileira de Gestão. p. 22-33 Jul/Set 2008

SANTOS, W. R.; CARNEIRO, T. C. J. Inovação e desempenho organizacional: um estudo das publicações científicas da base Web of Knowledge. Revista Interdisciplinar Científica Aplicada, v. 7, n. 3, p. 75-96, 2013

SCHMITT, T. A.; SASS, D. A. Rotation criteria and hypothesis testing for exploratory factor analysis: Implications for factor pattern loadings and interfactor correlations. Educational and Psychological Measurement, p. 0013164410387348, 2011. 
SCHWARTZ, S. H.; BILSKY, W. Toward a theory of the universal content and structure of values: Extensions and cross-cultural replications. Journal of personality and social psychology, v. $58, \mathrm{n}$. 5, p. 878, 1990.

SCHWARTZMAN, S. CIÊNCIA, UNIVERSIDADE E IDEOLOGA: a política do conhecimento. SciELO - Centro Edelstein, 2008.

SCORNAVACCA JR., E.; BECKER, J. 1.; ANDRASCHKO, R. E-survey: concepção e implementação de um sistema de survey por Internet. Anais do XXV EnANPAD, 2001.

SCOTT, W. R. Rational, natural, and open systems. 1998.

SEABRA, A. L. C.; PAIVA, K. C. M.; LUZ, T. R. Managerial competences of coordinators of undergraduate nursing courses. Revista Brasileira de Enfermagem, v. 68, n. 5, p. 890-898, 2015. SIERRA-FLORES, M. m.; RUSSELL BARNARD, J. M. Los grupos de investigación más productivos de la Universidad Nacional Autónoma de México (UNAM) en el área de física: 1990 a 1999.Investigación bibliotecológica, v. 23, n. 48, p. 127-155, 2009.

SILVA, E. C.; GIL, A. C.; OKABAYASHI, S. C. S. Competências na gestão pública: uma avaliação dos servidores públicos do Grande ABC paulista. Gestão Pública: Práticas e Desafios, v. 5, n. 1, 2014.

SILVEIRA, V. N. S.; DEL MAESTRO FILHO, A. Gestão Estratégica de Pessoas E Desempenho Organizacional-Uma Análise Teórica. Revista Pretexto, v. 14, n. 1, p. 71-87, 2013.

SILVEIRA-MARTINS, E.; ROSSETTO, C. R.; AÑANA, E. S. Ambidestria, Exploração ou Explotação e seus Efeitos no Desempenho Organizacional de Vinícolas Brasileiras. Revista em Agronegócio e Meio Ambiente, v. 7, n. 3, 2014.

SMITH, G. T.; MCCARTHY, D. M. Methodological considerations in the refinement of clinical assessment instruments. Psychological Assessment, v. 7, n. 3, p. 300, 1995.

SONNENTAG, S.; FRESE, M. Performance concepts and performance theory. In: SONNENTAG, Sabine (Ed.). Psychological management of individual performance. John Wiley \& Sons p. 327,2002

SOUSA, A. F.; VALADÃO JR., V. M. Competências gerenciais no contexto internacional: possíveis contribuições de cursos superiores brasileiros de Administração. Organizações \& Sociedade, v. 20, n. 66, p. 383-402, 2013.

STAKE, R. E. Case Studies In: Denzin N. and Lincoln, Y.(Ed.). Handbook of qualitative research (pp. 435-455). 2000.

STAKE, R. E. The case study method in social inquiry. Educational researcher, v. 7, n. 2, p. 5-8, 1978. 
STEVENS, J. P. Applied multivariate statistics for the social sciences. Routledge, 2012.

STJ - Superior Tribunal de Justiça. Início - Conheça o STJ - Gestão Estratégica. Disponível em: <http://www.stj.jus.br/sites/STJ/default/pt_BR/Conhe\%C3\%A7a-o-STJ/Gest\%C3\%A3oestrat\%C3\%A9gica > Acesso em: 11 ago. 2015

STONER, J. A. F.; FREEMAN, R. E. Administração. 8 ed. Rio de Janeiro: Prentice Hall, 1999.

STUART, R.; LINDSAY, P. Beyond the frame of management competenc (i) es: towards a contextually embedded framework of managerial competence in organizations. Journal of European Industrial Training, v. 21, n. 1, p. 26-33, 1997.

SUTTON, M. H. Estructura de organización en la trayectoria de dos grupos de investigación científica de Ciencias Básicas de la Salud en la generación de conocimiento. Revista Mexicana de Investigación Educativa, v. 15, n. 46, p. 713-738, 2010.

TABACHNICK, B. G.; FIDELL, L. S. Using multivariate statistics, Pearson Prentice Hall, 2007. TAMAYO, A. Valores organizacionais e comprometimento afetivo.Revista de Administração Mackenzie, v. 6, n. 3, 2008.

TEECE, D.; PISANO, G. The dynamic capabilities of firms: an introduction. Industrial and corporate change, v. 3, n. 3, p. 537-556, 1994.

TEIXEIRA, L. A. A.; SILVA, J. T. M.; LIMA, H. S. Administração no sistema prisional - um estudo das competências gerenciais. Contextus-Revista Contemporânea de Economia e Gestão, v. 9, n. 2, p. p. 55-67, 2011.

THOMPSON, J. D. Organizations in action: Social science bases of administrative theory. Transaction publishers, 1967.

TOSTA, H. T.; DALMAU, M. B. L. Competências gerenciais requeridas aos gestores intermediários da Universidade Federal da Fronteira Sul. VII Congresso CONSAD de Gestão Pública, 2014.

TOURINHO, E. Z. Organização e representação da comunidade científica em análise do comportamento no Brasil. Revista Brasileira de Terapia Comportamental e Cognitiva, v. 8, n. 2, p. 232-236, 2006.

VALENTIM, M. Instrumentos integradores do ensino, pesquisa e extensão: o caso dos grupos de pesquisa. Revista teórica del Departamento de Ciencias de la Comunicación y de la Información Facultad de Humanidades, 2007.

VÁSQUEZ-RIZO, F. E. Modelo de gestión del conocimiento para medir la capacidad productiva en grupos de investigación. Ciencia, docencia y tecnología, n. 41, p. 101-125, 2010. 
VENKATRAMAN, N.; RAMANUJAM, V. Measurement of business performance in strategy research: A comparison of approaches. Academy of management review, v. 11, n. 4, p. 801-814, 1986.

VIEIRA, A. S.; WELTER, M. R. T.; MELLO-CARPES, P. B. Perfil dos Grupos de Pesquisa em Neurofisiologia do Brasil. Rev Neurocienc, p. 37-44, 2014.

VILKINAS, T. The gender factor in management: how significant others perceive effectiveness. Women in Management Review, v. 15, n. 5/6, p. 261-272, 2000.

VINCENT, Mary Anne. The Value of Research Group Meetings. Biological Research For Nursing, v. 11, n. 2, p. 117-118, 2009.

VIOTTI, E. B. Fundamentos e evolução dos indicadores de CT\&I. In: MACEDO; M. M. Indicadores de ciência, tecnologia e inovação no Brasil. Campinas: Editora da Unicamp, p. 4187, 2003.

VISWESVARAN, C.; ONES, D. S. Perspectives on models of job performance. International Journal of Selection and Assessment, v. 8, n. 4, p. 216-226, 2000.

WEIJDEN, I. V. D. et al. Implications of managerial control on performance of Dutch academic (bio) medical and health research groups. Research Policy, v. 37, n. 9, p. 1616-1629, 2008.

WRIGHT, P. M.; BOSWELL, W. R. Desegregating HRM: A review and synthesis of micro and macro human resource management research. Journal of management, v. 28, n. 3, p. 247-276, 2002.

YIN, R. K. Case Study Research: Design and Methods, London. 1994.

ZARIFIAN, P. Objectif compétence. Pour une nouvelle logique. 1999. 


\section{APÊNDICE A - Itens: Domínio de competências gerenciais em grupos de pesquisa.}

\begin{tabular}{|c|c|}
\hline Código & Item \\
\hline $\mathrm{C} 01$ & Acompanhar a implementação das mudanças no grupo. \\
\hline $\mathrm{C} 02$ & Acompanhar a realização de tarefas. \\
\hline $\mathrm{C} 03$ & Administrar o ritmo de desenvolvimento das atividades de pesquisa. \\
\hline $\mathrm{C} 04$ & Administrar recursos utilizados na pesquisa (materiais, equipamentos, dinheiro etc). \\
\hline $\mathrm{C} 05$ & Analisar informações para diagnósticos ou tomada de decisão. \\
\hline $\mathrm{E} 06$ & $\begin{array}{l}\text { Apoiar o grupo na busca por recursos necessários à realização de atividades.(Item excluído } \\
\text { da escala) }\end{array}$ \\
\hline $\mathrm{C} 07$ & $\begin{array}{l}\text { Assegurar fácil acesso às informações do grupo (relatórios, diretórios, bases de dados, } \\
\text { memória do grupo, etc). }\end{array}$ \\
\hline $\mathrm{C} 08$ & $\begin{array}{l}\text { Atrair novos integrantes para o grupo (alunos da graduação, mestrado, doutorado, } \\
\text { pesquisadores) por diferentes meios de recrutamento. }\end{array}$ \\
\hline $\mathrm{C} 09$ & Avaliar resultados de mudanças ocorridas no grupo. \\
\hline $\mathrm{C} 10$ & Buscar a solução de problemas em conjunto com os integrantes do grupo. \\
\hline $\mathrm{C} 11$ & $\begin{array}{l}\text { Buscar ajuda de pesquisadores e outros profissionais para atualização e aprofundamento de } \\
\text { temas de interesse do grupo. }\end{array}$ \\
\hline $\mathrm{C} 12$ & Capacitar membros do grupo em tarefas técnicas necessárias às pesquisas. \\
\hline $\mathrm{C} 13$ & Conciliar os horários de todo o grupo. \\
\hline $\mathrm{C} 14$ & Conduzir reuniões do grupo, coordenando apresentações, debates e processos decisórios. \\
\hline $\mathrm{C} 15$ & Conhecer o projeto de pesquisa como um todo, identificando a etapa em curso. \\
\hline $\mathrm{C} 16$ & Coordenar esforços da equipe para obtenção de resultados. \\
\hline $\mathrm{C} 17$ & Debater assuntos relativos à pesquisa com integrantes do grupo. \\
\hline $\mathrm{C} 18$ & Definir tarefas de acordo com a demanda de projeto. \\
\hline C19 & Distribuir atividades a realizar de forma equilibrada entre os membros do grupo. \\
\hline $\mathrm{C} 20$ & Distribuir atividades de pesquisa de acordo com as competências dos membros do grupo. \\
\hline $\mathrm{C} 21$ & Distribuir tarefas de acordo com sua complexidade. \\
\hline $\mathrm{C} 22$ & Estabelecer parcerias com empresas do setor produtivo. \\
\hline $\mathrm{C} 23$ & Estabelecer parcerias com outros pesquisadores ou grupos de pesquisa. \\
\hline $\mathrm{C} 24$ & Estimar prazos, estabelecendo cronograma de atividades de pesquisa. \\
\hline $\mathrm{C} 25$ & Estimular a flexibilidade do grupo no desenvolvimento de processos de trabalho. \\
\hline $\mathrm{C} 26$ & Estimular a troca de informações entre os integrantes do grupo. \\
\hline $\mathrm{C} 27$ & Estimular o interesse de integrantes do grupo na continuidade da pesquisa. \\
\hline $\mathrm{C} 28$ & Expor ideias e opiniões com clareza, concisão e coerência. \\
\hline $\mathrm{C} 29$ & Facilitar processos de comunicação entre os membros do grupo. \\
\hline $\mathrm{C} 30$ & Implementar ações estratégicas visando melhor desempenho das atividades de pesquisa. \\
\hline $\mathrm{C} 31$ & Implementar ações visando à permanência dos integrantes no grupo. \\
\hline $\mathrm{C} 32$ & Obter financiamento para as pesquisas de agências externas de fomento. \\
\hline $\mathrm{C} 33$ & Orientar membros da equipe quanto a atitudes eticamente corretas. \\
\hline $\mathrm{C} 34$ & Planejar atividades a serem realizadas. \\
\hline $\mathrm{C} 35$ & Prestar suporte frequente aos integrantes do grupo. \\
\hline $\mathrm{C} 36$ & Promover um ambiente produtivo no grupo. \\
\hline
\end{tabular}


C37 Propor ajustes em acordos estabelecidos nos momentos adequados.

C38 Realizar a gestão de pessoas do grupo considerando características individuais.

Reconhecer os elementos fundamentais para o desenvolvimento da pesquisa e a

C39 sustentabilidade do grupo de pesquisa: recursos humanos e materiais/financeiros.

C40 Reconhecer potenciais de aprendizagem dos membros do grupo.

C41 Reelaborar as próprias ideias e conceitos com base em críticas de membros do grupo.

C42 Resolver conflitos surgidos entre os membros do grupo de pesquisa.

C43 Respeitar a diversidade de opiniões.

C44 Respeitar o ritmo de trabalho de cada um.

C45 Selecionar novos integrantes para o grupo com base em critérios técnicos.

C46 Sensibilizar o grupo para as mudanças.

C47 Solucionar problemas imprevistos, buscando garantir a realização da pesquisa.

C48 Ter visão sistêmica das atividades executadas.

C49 Tomar decisões acerca do andamento da pesquisa com autonomia.

C50 Verificar se resultados pretendidos são alcançados.

C51 Zelar pelo cumprimento de prazos de realização de atividades. 


\section{APÊNDICE B - Itens: Resultados de grupos de pesquisa}

\begin{tabular}{|c|c|}
\hline Código & Item \\
\hline R01 & Atmação na revisão de periódicos científices.(Item excluído da escala) \\
\hline $\mathrm{R} 02$ & Atuação na revisão de projetos submetidos a agências de fomento.(Item excluído da escala) \\
\hline R03 & Avanço nos conhecimentos relativos aos estudos realizados. \\
\hline R04 & Conclusão de trabalhos acadêmicos (monografias, dissertações ou teses). \\
\hline R05 & Coordenação de grupos de trabalho em eventos científicos. \\
\hline R06 & Curso ministrado. \\
\hline R07 & $\begin{array}{l}\text { Desenvolvimento de competências sociais (ex. relacionamento interpessoal; trabalho em } \\
\text { equipe; respeito a diversidade e a diferentes valores etc). }\end{array}$ \\
\hline R08 & $\begin{array}{l}\text { Desenvolvimento de competências técnicas associadas à atuação do grupo (ex.: } \\
\text { conhecimentos relativos ao tema; realização de coleta e análise de dados; redação de } \\
\text { relatórios etc). }\end{array}$ \\
\hline R09 & Elaboração de diagnósticos relativos ao campo de estudo. \\
\hline R10 & Elaboração de material didático ou instrucional. \\
\hline R11 & $\begin{array}{l}\text { Elaboração de produtos (ex.: protótipos; Artefatos; Patentes; maquetes; programas de } \\
\text { computador etc). }\end{array}$ \\
\hline R12 & Elaboração de protocolos, processos ou técnicas para o desenvolvimento de pesquisa. \\
\hline R13 & Estabelecimento de parcerias com outros grupos ou pesquisadores. \\
\hline R14 & Formação de profissionais para atuarem em uma área de conhecimento. \\
\hline R15 & Formação de redes profissionais. \\
\hline R16 & Inserção de integrantes do grupo de pesquisa no mercado de trabalho. \\
\hline R17 & Mobilização da rede de relacionamentos para executar atividades de pesquisa. \\
\hline R18 & Organização de eventos científicos. \\
\hline R19 & Participação em comitês de agências de fomento. \\
\hline R20 & Participação em corpo editorial de periódicos. \\
\hline R21 & Participação em diretorias de sociedades científicas. \\
\hline $\mathrm{R} 22$ & Participação em entrevistas, mesas redondas, programas de rádio ou TV e similares. \\
\hline R23 & Participação em eventos para proferir conferência, coordenar mesa ou simpósio. \\
\hline $\mathrm{R} 24$ & $\begin{array}{l}\text { Participação, comø avaliador externo, de comissões examinadoras de dissertações ou teses. } \\
\text { (Item excluído da escala) }\end{array}$ \\
\hline $\mathrm{R} 25$ & Participação, como avaliador externo, de comissões julgadoras de concursos. \\
\hline R26 & Prestação de assessoria ou consultoria técnica para organizações públicas ou privadas. \\
\hline $\mathrm{R} 27$ & Publicação (ou aprovação para publicação) de artigos científicos em periódico. \\
\hline $\mathrm{R} 28$ & $\begin{array}{l}\text { Publicação de artigos "não-científicos" para a mídia em geral (ex: jornais, revistas, redes } \\
\text { sociais, websites ou blogs). }\end{array}$ \\
\hline R29 & Publicação de livro, capítulo de livro, prefácio ou posfácio. \\
\hline R30 & Publicação de trabalhos em anais de eventos científicos. \\
\hline R31 & Reconhecimento de membros do grupo como referências acadêmicas ou profissionais. \\
\hline
\end{tabular}




\section{APÊNDICE C - Questionário aplicado - versão completa}
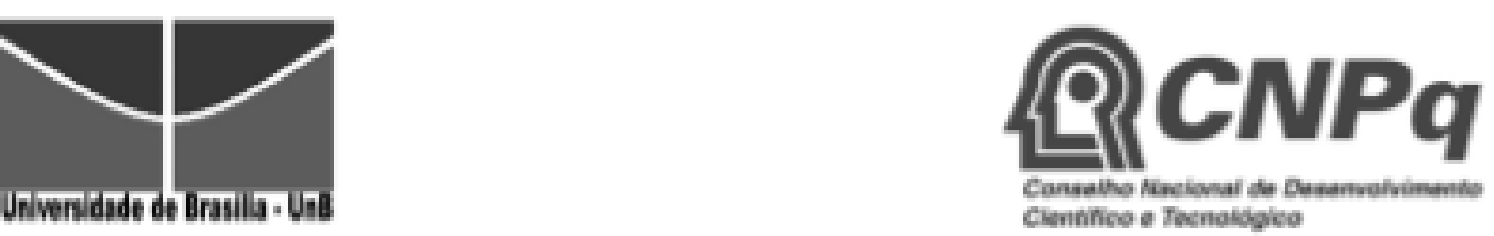

Apresentaçăo

Olál Meu nome é Pablo Fernando Pessos de Freitas e faço parte do Grupo de pesquisa

Inovaçäo e Aprendizagem em Organizaçóes' vinculado à Universidade de Brasilia - UnB e certificado junto ao Conselho Nacional de Desenvolvimento Cientifico e Tecnológico - CNPq.

Esta pesquisa é parte do meu Projeto de Dissertaçăo para obter o titulo de Mestre em Administraçăo e integra o projeto financiado pelo CNPq "Relaçōes entre Aprendizagem em Organizaçōes, Competências, Redes Sociais e Desempenho: uma análise em grupos de pesquisa", coordenado por minha orientadora, a Profa. Dra. Catarina Cecilia Odelius.

Este questionário tem o objetivo de 'identificar a relaçăo entre Competências Gerenciais e Resultados de Grupos de Pesquisa brasileiros'. Ao responder às questōes, tenha em mente que näo existem respostas certas ou erradas. $O$ importante é responder de forma consciente e coerente com sua percepçào. Os dados coletados teräo finalidade cientifica e acadêmica, portanto, só preencha o questionário se realmente participar de algum grupo de pesquisa brasileiro.

O questionário está dividido em 3 blocos:

1) Resultados alcançados pelo Grupo de Pesquisa(destinado exclusivamente para lider de grupo) - tempo de resposta: aproximadamente 7 minutos;

2) Dominio de Competências Gerenciais em Grupos de Pesquisa (destinado a todos os membros de grupos de pesquisa, quer sejam lideres de grupo, lideres de projeto ou demais membros) - tempo de resposta: aproximadamente 2 minutos; $e$

3) Informaçǒes do Grupo de Pesquisa e Dados sociodemográficos (destinado a todos os membros de grupos de pesquisa, quer sejam líderes de grupo, lideres de projoto ou demais membros) - tempo de resposta: aproximadamente 4 minutes OBS.: os dados sociodemográficos servem para caracterizar a amostra e seräo tratados de modo conjunto, sem a identificaçăo dos respondentes.

Caso tenha alguma dúvida, peço que envie um e-mail para: freitaspfparegmail.com ou me acione pelo celular/whatsapp (61) 8609-3008. Minha orientadora também estará à disposição por e-mail: codeliusieunb.br ou codeliusiefemail.com; ou pelos teletones (61) 3107-1430; 3107-0759; ou 99765367.

Suas respostas serảo tratadas de modo estritamente confidencial, serảo registradas numa base de dados e analisadas em termos globais. As questōes sinalizadas com * săo de preenchimento obrigatório, mas vocé pode desistir de participar a qualquer momento, caso considere que o deve 
fazer.

Sua participação é voluntária. Ao clicar em 'Próxima' e responder ao questionário, você manifesta concordancia com o presente Termo de Consentimento Livre e Esclarecido.

Desde já, agradecemos sua participaçăo

Entăo, vamos lá...
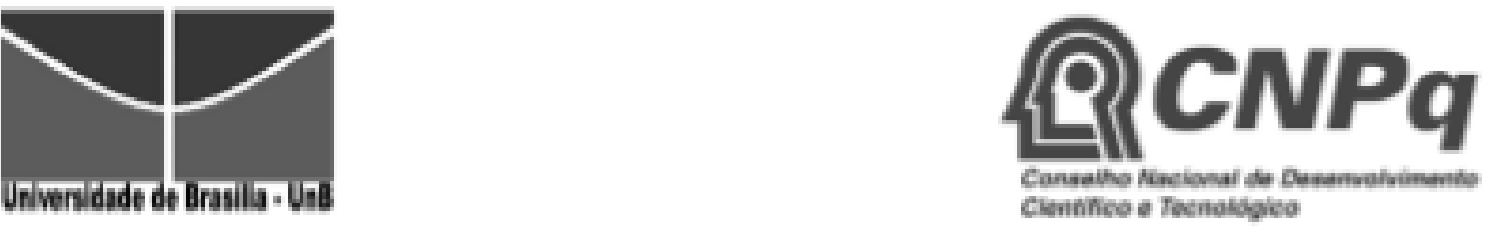

Atuaçăo no Grupo de Pesquisa

* Qual a sua atuaçăo no grupo de pesquisa?

Lider do gupo Lider de projeto ( Cemsis partiopartes ( Najo partaipo de gupos de pesquiss 


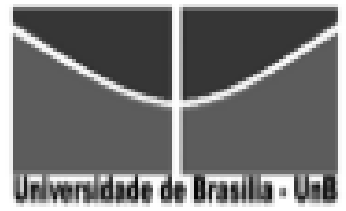

\section{Q는

\section{Resultados alcançados em Grupos de Pesquisa}

- É um resultado alcançado, nos úlitimos 5 anos, pelp gruno de cesquisa que lidero.

Consadero que asta nesukado

saja mou

(onquevio Nolar)

- NAO do

Disoondo

Concondo Grupo como um

folaimerite totaimerte fodo.

Atusça na revisso de pendidicos centhicos.

Atusça na revis5o de projolos submetdos a sgencias de somerto.

Avanç nce cortecimentes relafires ass estudes real zades.

Condusso de trabalhos academicos (monografiss.

dissertaphess ou teoves?

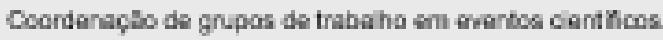

Cursoministrado.

Desonvolvimento de competincis sooals (ex.:

rejacionamerto intorpessosl; trabalho em equipe; respeito a

dvers dade e a d therentes valores etci.

Desonvolvimento de compelíncas teccricas assodadas a

susçân do grupo fex: conthecimertos relstvos ao tems:

resliescho de cuiets e andise de dados: redscalo de

retakries etci.

Elaboraçăa de dagndescosa relativos ac campo de estuda.

Elsboraça de msteris didatcos ou instruciansi.

Elsboraça de produtos fex: protót pos: ardofalos: patertes: maquetes, programas de computsdor etc)

Eloboraça de protocolos, processos ou técnicss para o desemvorimento de pesquisa.

Estabe'ecimento de parcerias com outros grupos ou posquisadores.

Formaçato de profissionais para atuarem em uma aros de corhedimento. 


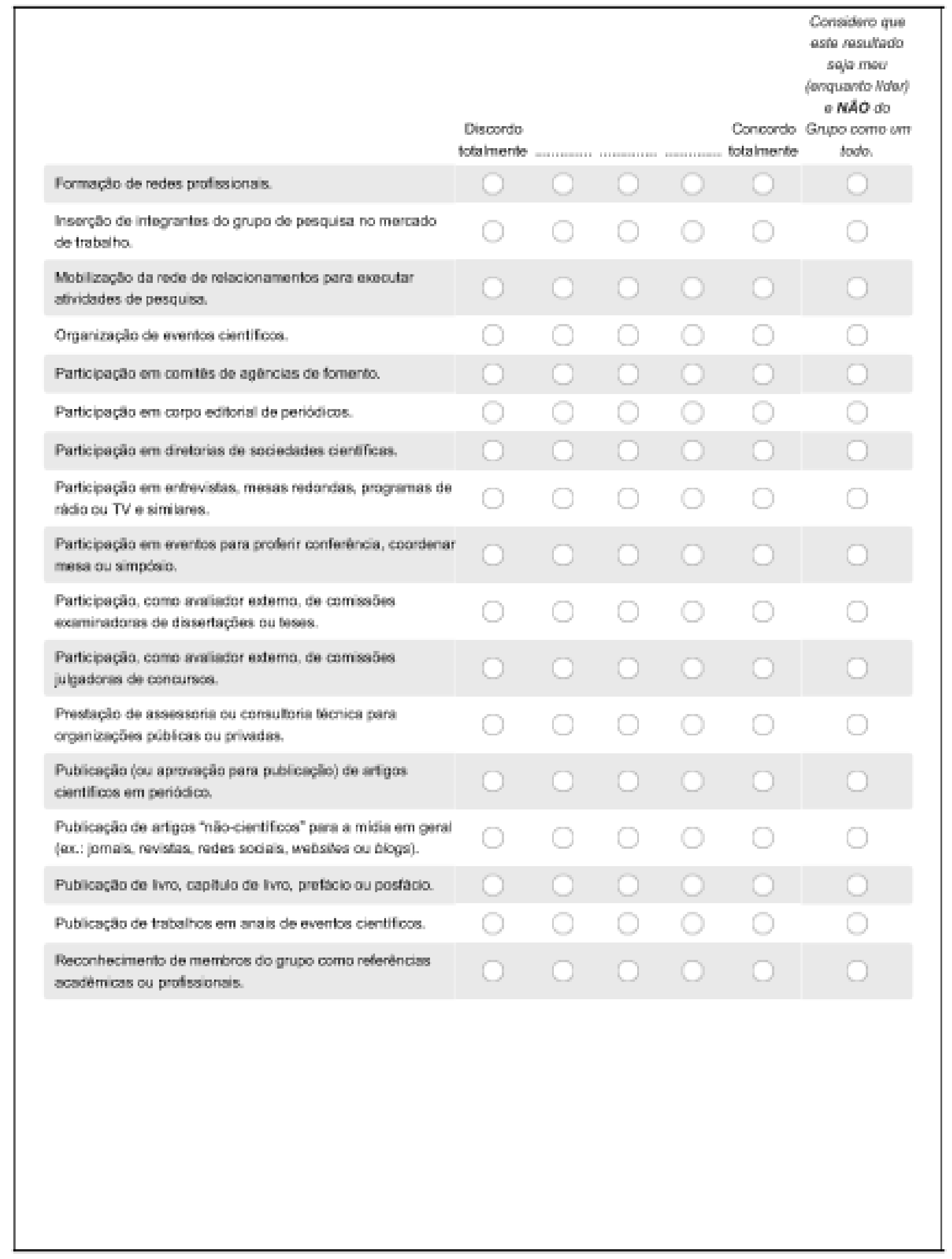




\section{Competências Gerenciais relativas a Grupos de Pesquisa}

* Indique o grau de domínio que wocé considera ter em releçăo a Competências Gerenciais necessárias à atuaçio em Grupos de Pesquisa:

Acompanhar a implementaçso das medanças no grupo.

Aoompanhar a roalzaçso do tarefas.

Administrar a filmo de cesenvelviments des afvidetes de pescubse

Adminstrar recursos utiliesdos na pesquisa (msterisis.

ecquipamentes, dintwire stek.

Anatsar infarmaptes para dagndetices ou vomada de cecisāa.

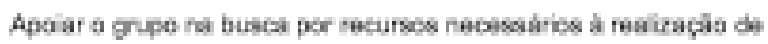
atividades.

Asaegunar facil acesco as infomaçles da grupa (relatárica. dretories, bases de dadoa, memoria do grupa, etc)

Atrair novea imbegrantea para o grupo laknos da graduapla, mestrado, douborado, pesequapdores] por dikenten meice de rocrutamenta.

Aval ar reoultsdos de mudancas coorridas no gupo.

Buscar a soluçso de problemas em conjunto com cs integrantes do orpo.

Buscar ajuda de pesquesdotes e cutros profissionais para stusitzaça e aprofundsarento de fermss de inkeresse do grupo.

Capacitar menbros to gupe en tarefic Hericas necasalias às censquases.

Concilar es horanios de todo o grupo. 


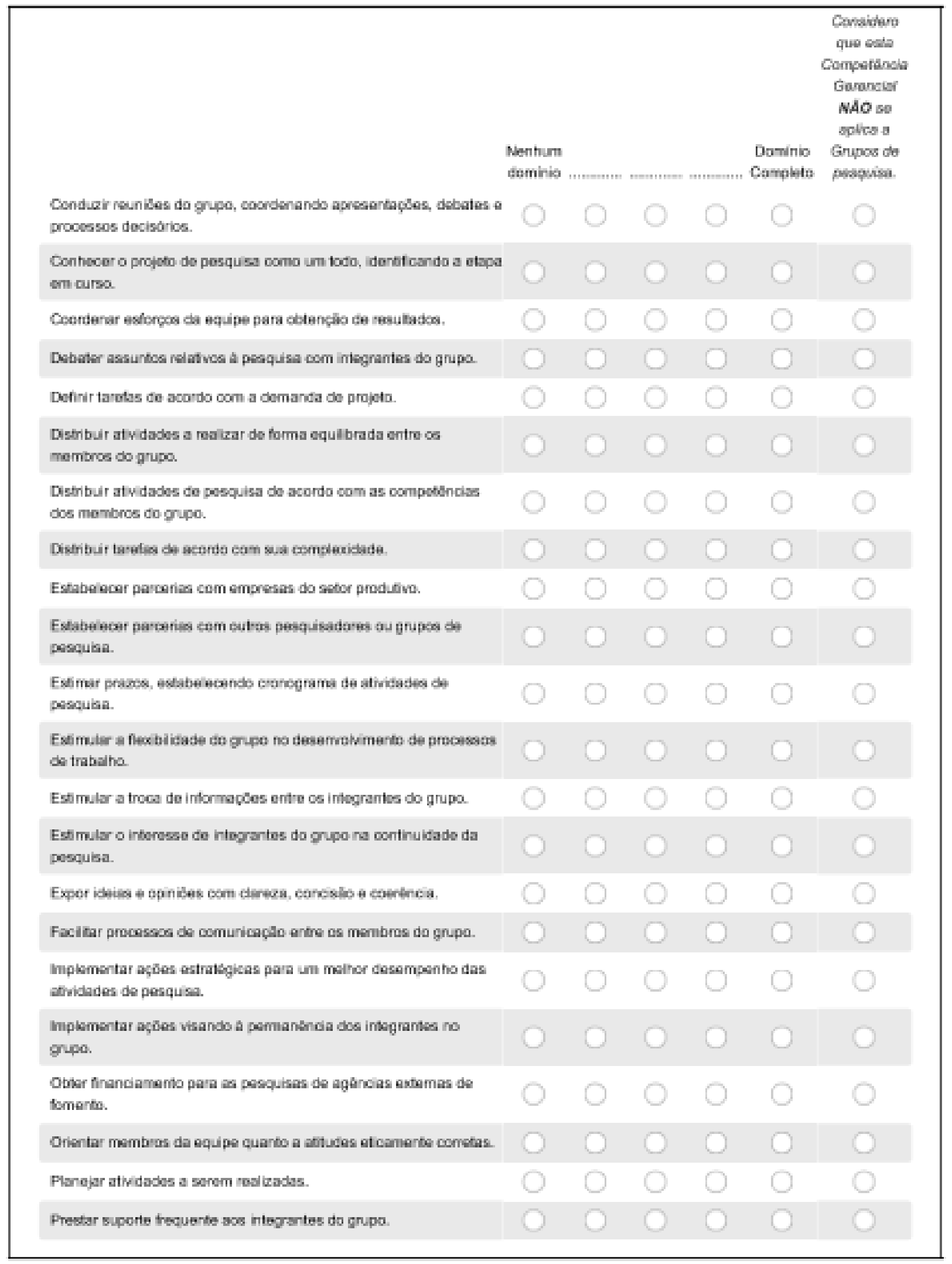


Promover um ambiente produtwo no gupo.

Propor ajustes en acordos estabelecidos nos momentos sdequados.

Pesalzar a pestlo de pesscas do grupo considerando carscteristicas ind vidusis.

Feconhecer as elementos fundamentss para o desemvolvmento da pesquiss e a sustentabilidade do grupo de pesquss recursos humines $\theta$ materiaisfranceirce.

Feoonhecer potenciais de aprendagaem dos membros do grupo.

Pueslaborar as pobprias ideias e conceiba com base am orifoas de membrea do grupa.

Fesolver confitos surgidos entre cos membros do grupo de pesquss.

Posspeitar a diversiclade ce cpiriťcs.

Fespeitar o ritmo de trabaha de cada um.

Seledanar noves integrankes para a grpo com base am ortérica Nericos.

\section{Sensibitizar o gupo para as mudancas.}

Soludonar problemss imprevisios, buscando garantir a realzaçlo da pesquisa.

Ter visale sisternica clas atiridadec eccecutedas.

Tomar đecisōes acerea do andamenbo da pesquiaล cam aubonamia.

Venficar se resulados pretendidos savo alcançados.

Zelar pela cumprimenb ce procts de real acalo de ativitadec. 


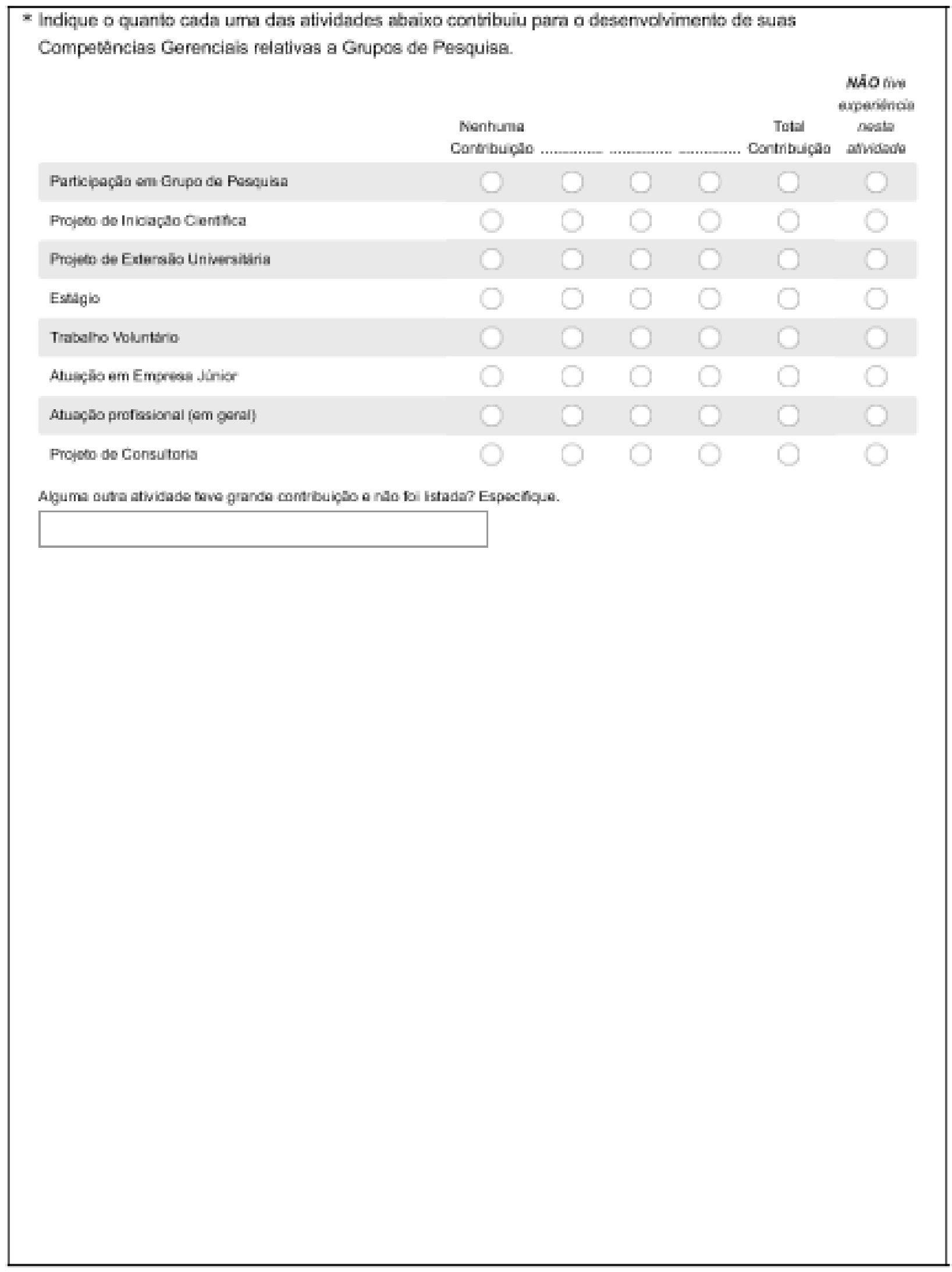


Informaçōes do Grupo e Dados Sociodemográficos

Sobre seu Grupo de Pesquisa...

Nome do Grupo de Pesquise

- Nome da Instituiçảo de EnsinoiPesquisa a que o grupo está vinculado

* Tipo de Instituição de Ensina/Pesquisa

Publica Privada

* Unidade da Federegáo onde as reunibes do gnupo ocorrem

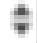

- Área de Conhecimento do Grupo de Pesquisa

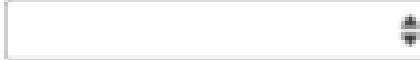



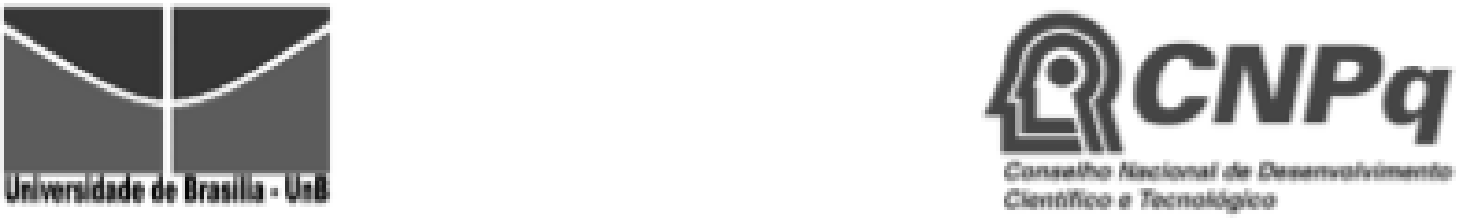

Informaçēes do Grupo e Dados Sociodemográficos

Sobre Você...

Seu sexo

Misculina Fetinina

Sua idade (em anos)

$*$

Indique o curso realizado ou em realizeçäo

Graduaça

Pós-Groduaçāo lofu sensu (Especiel bsę̧̄o)

Mestrado

Dounorsdo

Pós Dounorado

* Indique seu tempo de experiência em pesquisa acadẻmica. Lembre-se de mencions a unidade de tempo. (ex. 10 meses; 3 anos, 2 ance e 11 meses!).

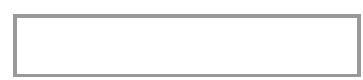

* Indique há quanto tempo vocé integra o seu atual Grupo de Pesquisa. Lembre-se de mencionar a unidade de tempo.

(ex.: 4 mesase 9 ands. 1 ino e 3 meseat.

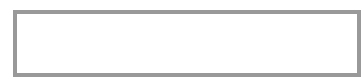


* Vocé possui bolsa de produfividade no CNPq?

\section{$*$}

Fique à wontade para realizar comentários adicionais e descrever outres Competências Gerenciais ou Resultados em grupos de pesquisa que nšo tenham sido abordados.

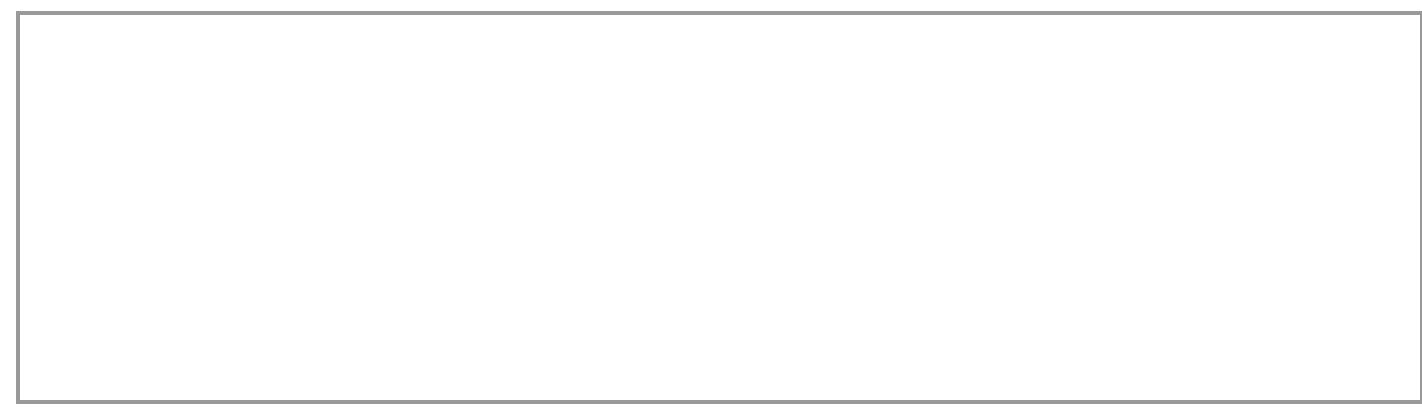

Caso queira receber o relatório final com os resultados encontrados, favor informar scu e-mail. 


\title{
ANEXO A - Instrumento preliminar: Competências relativas à Coordenação de
}

\author{
Atividades de Pesquisa
}

\section{Competências Relativas a Coordenação de Atividades de Pesquisa}

\begin{tabular}{|c|c|c|c|c|c|c|c|c|c|c|c|}
\hline $\begin{array}{l}\text { Leia as afirmações e indique o quanto a participação na coordenação das atividades do } \\
\text { grupo desenvolveu o domínio das competências relacionadas a seguir. Utilize } 0=\text { nenhum }\end{array}$ & & & & & & & & & & & \\
\hline $\begin{array}{l}\text { Recrutar novos integrantes para o grupo (alunos da graduação, mestrado, doutorado, } \\
\text { pesquisadores). }\end{array}$ & 0 & & 2 & 3 & 4 & 5 & 6 & 7 & 8 & 9 & 10 \\
\hline Treinar membros do grupo em diversa & 0 & 1 & 2 & 3 & 4 & 5 & 6 & 7 & 8 & 9 & 10 \\
\hline $\begin{array}{l}\text { Orientar pessoas quanto a comportamentos e atitudes necessários para atuação } \\
\text { profissional/acadêmica. }\end{array}$ & 0 & 1 & 2 & 3 & 4 & 5 & 6 & 7 & 8 & 9 & 10 \\
\hline Selecionar pessoas com o perfil adequado para o grupo. & 0 & 1 & 2 & 3 & 4 & 5 & 6 & 7 & 8 & 9 & 10 \\
\hline Acompanhar tarefas a serem realizadas. & 0 & 1 & 2 & 3 & 4 & 5 & 6 & 7 & 8 & 9 & 10 \\
\hline Executar ações necessárias para integrar novos membros na & 0 & 1 & 2 & 3 & 4 & 5 & 6 & 7 & 8 & 9 & 10 \\
\hline Planejar atividades a serem realizadas. & 0 & 1 & 2 & 3 & 4 & 5 & 6 & 7 & 8 & 9 & 10 \\
\hline Debater assuntos rela & 0 & 1 & 2 & 3 & 4 & 5 & 6 & 7 & 8 & 9 & 10 \\
\hline Obter informações s & 0 & 1 & 2 & 3 & 4 & 5 & 6 & 7 & 8 & 9 & 10 \\
\hline Solucionar probleme & 0 & 1 & 2 & 3 & 4 & 5 & 6 & 7 & 8 & 9 & 10 \\
\hline Apoiar a bi & 0 & 1 & 2 & 3 & 4 & 5 & 6 & 7 & 8 & 9 & 10 \\
\hline $\begin{array}{l}\text { Realizar atividades junto com outras pessoas, dividindo e sincronizando ações para obter } \\
\text { resultados. }\end{array}$ & 0 & 1 & 2 & 3 & 4 & 5 & 6 & 7 & 8 & 9 & 10 \\
\hline Administrar recursos utilizados na pesquisa (materiais, equipamentos, dinheiro, etc). & 0 & 1 & 2 & 3 & 4 & 5 & 6 & 7 & 8 & 9 & 10 \\
\hline Zelar pelo cumprimento de prazos de r & 0 & 1 & 2 & 3 & 4 & 5 & 6 & 7 & 8 & 9 & 10 \\
\hline $\begin{array}{l}\text { Distribuir atividades de pesquisa de acordo com as competências dos membros do } \\
\text { grupo. }\end{array}$ & 0 & 1 & 2 & 3 & 4 & 5 & 6 & 7 & 8 & 9 & 10 \\
\hline Engajar-se em discussões no grupo sem perder o foco no objetivo a ser alcançado. & 0 & 1 & 2 & 3 & 4 & 5 & 6 & 7 & 8 & 9 & 10 \\
\hline Estimar & 0 & 1 & 2 & 3 & 4 & 5 & 6 & 7 & 8 & 9 & 10 \\
\hline Admil & 0 & 1 & 2 & 3 & 4 & 5 & 6 & 7 & 8 & 9 & 10 \\
\hline Estimular o interesse de outros integrantes na continuidade da pesquisa. & 0 & 1 & 2 & 3 & 4 & 5 & 6 & 7 & 8 & 9 & 10 \\
\hline Estimular a troca de informações entre os integrantes do grupo. & 0 & 1 & 2 & 3 & 4 & 5 & 6 & 7 & 8 & 9 & 10 \\
\hline $\begin{array}{l}\text { Reconhecer os elementos fundamentais para o desenvolvimento da pesquisa e a } \\
\text { sustentabilidade do grupo de pesquisa: recursos humanos e materiais/financeiros. }\end{array}$ & 0 & 1 & 2 & 3 & 4 & 5 & 6 & 7 & 8 & 9 & 10 \\
\hline Reconhecer potenciais de aprendizagem dos $n$ & 0 & 1 & 2 & 3 & 4 & 5 & 6 & 7 & 8 & 9 & 10 \\
\hline Conhecer o projeto de pesquisa como um todo, identificando a etapa em curso. & 0 & 1 & 2 & 3 & 4 & 5 & 6 & 7 & 8 & 9 & 10 \\
\hline $\begin{array}{l}\text { Buscar ajuda de pesquisadores e outros profissionais para a atualização e } \\
\text { aprofundamento de conhecimentos de temas que sejam de interesse do grupo. }\end{array}$ & 0 & 1 & 2 & 3 & 4 & 5 & 6 & 7 & 8 & 9 & 10 \\
\hline Tomar decisões acerca do andamento da pesquisa com autonomia e senso crítico. & 0 & 1 & 2 & 3 & 4 & 5 & 6 & 7 & 8 & 9 & 10 \\
\hline Ter visão sistêmica das atividades executadas. & 0 & 1 & 2 & 3 & 4 & 5 & 6 & 7 & 8 & \begin{tabular}{|c|}
9 \\
\end{tabular} & 10 \\
\hline $\begin{array}{l}\text { Implementar ações estratégicas visando n } \\
\text { pesquisa. }\end{array}$ & 0 & & 2 & 3 & 4 & & & & & $y$ & 0 \\
\hline
\end{tabular}




\section{ANEXO B - Instrumento preliminar: Resultados alcançados por grupos de pesquisa}

\section{Resultados alcançados pelo grupo}

\begin{tabular}{|l|c|c|c|c|c|c|c|c|c|c|c|c|}
\hline $\begin{array}{l}\text { Assinale um número para indicar a importância do resultado alcançado pelo grupo. } \\
\text { Considere 0 = nenhuma importância e 10 = muito importante. Caso o resultado não tenha sido }\end{array}$ & \multicolumn{5}{|c|}{$(0)$ Nenhuma } \\
Importância
\end{tabular}




\section{ANEXO C - Instrumento preliminar: Inserção em Atividades do Meio Acadêmico}

\section{Inserção em atividades do meio acadêmico}

\begin{tabular}{|c|c|c|c|c|c|c|c|c|c|c|c|}
\hline $\begin{array}{l}\text { Assinale um número para indicar o grau de contribuição da atuação no grupo para a } \\
\text { inserção em atividades do meio acadêmico descritos a seguir. Considere } 0=\text { nenhuma }\end{array}$ & \multicolumn{6}{|c|}{$\begin{array}{l}\text { (0) Nenhuma } \\
\text { Contribuição }\end{array}$} & \multicolumn{5}{|c|}{$\begin{array}{c}\text { Total } \\
\text { Contribuição (10) }\end{array}$} \\
\hline Participar em diretorias de sociedades científicas. & 0 & 1 & 2 & 3 & 4 & 5 & & 7 & 8 & 9 & 10 \\
\hline Participar em comitês de agências de fomento. & 0 & 1 & 2 & 3 & 4 & 5 & 6 & & 8 & 9 & 10 \\
\hline Participar em corpo editorial de periódicos qualificados. & 0 & 1 & 2 & 3 & 4 & 5 & 6 & 7 & 8 & 9 & 10 \\
\hline Prestar assessoria para agências de fomento. & 0 & 1 & 2 & 3 & 4 & 5 & 6 & 7 & 8 & 9 & 10 \\
\hline Atuar como editor de periódicos científicos. & 0 & 1 & 2 & 3 & 4 & 5 & 6 & 7 & 8 & 9 & 10 \\
\hline Constituir parceria em equipes de pesquisa (nacionais e/ou internacionais). & 0 & 1 & 2 & 3 & 4 & 5 & 6 & 7 & 8 & 9 & 10 \\
\hline $\begin{array}{l}\text { Participar regularmente em eventos, nacionais e internacionais, como convidado para } \\
\text { proferir conferência, coordenar mesa ou simpósio. }\end{array}$ & 0 & 1 & 2 & 3 & 4 & 5 & 6 & 7 & 8 & 9 & 10 \\
\hline Organizar eventos científicos de relevância. & 0 & 1 & 2 & 3 & 4 & 5 & 6 & 7 & 8 & 9 & 10 \\
\hline Participar como membro externo em bancas de mestrado e doutorado. & 0 & 1 & $\underline{2}$ & 3 & 4 & & 6 & 7 & 8 & 9 & 10 \\
\hline Coordenar grupos de trabalho em congressos da área. & 0 & 1 & 2 & 3 & 4 & & 6 & 7 & 8 & 9 & 10 \\
\hline Formar profissionais para atuarem em uma área de con & 0 & 1 & 2 & 3 & 4 & 5 & 6 & 7 & 8 & 9 & \\
\hline
\end{tabular}

